\title{
A broken tandem
}

Citation for published version (APA):

de la Fuente Vilar, A. (2020). A broken tandem: Understanding Lack of Witness cooperation in the Interview Room. [Doctoral Thesis, Maastricht University, University of Gothenberg]. The House of Legal Psychology. https://doi.org/10.26481/dis.20201014afv

\section{Document status and date:}

Published: 01/01/2020

DOI:

10.26481/dis.20201014afv

Document Version:

Publisher's PDF, also known as Version of record

\section{Please check the document version of this publication:}

- A submitted manuscript is the version of the article upon submission and before peer-review. There can be important differences between the submitted version and the official published version of record.

People interested in the research are advised to contact the author for the final version of the publication, or visit the DOI to the publisher's website.

- The final author version and the galley proof are versions of the publication after peer review.

- The final published version features the final layout of the paper including the volume, issue and page numbers.

Link to publication

\footnotetext{
General rights rights.

- You may freely distribute the URL identifying the publication in the public portal. please follow below link for the End User Agreement:

www.umlib.nl/taverne-license

Take down policy

If you believe that this document breaches copyright please contact us at:

repository@maastrichtuniversity.nl

providing details and we will investigate your claim.
}

Copyright and moral rights for the publications made accessible in the public portal are retained by the authors and/or other copyright owners and it is a condition of accessing publications that users recognise and abide by the legal requirements associated with these

- Users may download and print one copy of any publication from the public portal for the purpose of private study or research.

- You may not further distribute the material or use it for any profit-making activity or commercial gain

If the publication is distributed under the terms of Article $25 \mathrm{fa}$ of the Dutch Copyright Act, indicated by the "Taverne" license above, 


\section{A Broken Tandem: \\ Understanding Lack of Witness Cooperation in the Interview Room}

Alejandra De La Fuente Vilar 
(C) Alejandra De La Fuente Vilar, 2020

All rights reserved. No part of this book may be reproduced or transmitted in any form or by any means without prior permission in writing by the author.

Cover design by Iwona Lisiecka

Printing: Gildeprint - the Netherlands

ISBN: 978-94-641-903-35

ISSN: 1101-718X Avhandling/Göteborgs universitet, Psykologiska inst. 
A Broken Tandem:

Understanding Lack of Witness Cooperation in the Interview Room

\section{Dissertation}

To obtain the degree of Doctor of Philosophy by the University of Gothenburg, on the authority of the Deputy Vice-Chancellor, Dr. Mette Sandoff in accordance with the decision of the Faculty Board of Social Sciences and the degree of Doctor by Maastricht University, on the authority of the Rector Magnificus, Prof. dr. Rianne M. Letschert in accordance with the decision of the Board of Deans, to be defended in public on

Wednesday October $14^{\text {th }} 2020$ at 16:00 hours in Maastricht

by

\section{Alejandra De La Fuente Vilar}

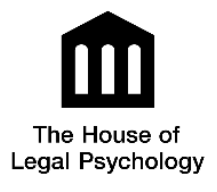




\section{Supervisors:}

Prof. dr. Peter J. van Koppen

Prof. dr. Leif A. Strömwall

\section{Co-Supervisors:}

Dr. Robert Horselenberg

Dr. Sara Landström

\section{Assessment Committee:}

Prof. dr. Marko Jelicic (Chair)

Prof. dr. Karl Ask

Prof. dr. Henry Otgaar

Prof. dr. Gavin Oxburgh

Prof. dr. Renate Volbert
Maastricht University, the Netherlands

VU University Amsterdam, the Netherlands

University of Gothenburg, Sweden

Maastricht University, the Netherlands

University of Gothenburg, Sweden
Maastricht University, the Netherlands

University of Gothenburg, Sweden

Maastricht University, the Netherlands

Catholic University of Leuven, Belgium

Northumbria University, United Kingdom

Psychologische Hochschule Berlin, Germany

Charité - Universitätsmedizin Berlin, Germany

The research presented in this dissertation was funded with a grant from the Erasmus Mundus Joint Doctorate Program - The House of Legal Psychology awarded to Alejandra De La Fuente Vilar (FPA 2013-0036 with SGA 2016-1339). 


\section{Contents}

Chapter 1 The Importance of Witness Cooperation in Investigative Interviews 7

Chapter $2 \quad$ Quality Evidence from the Interview Room: An Archival Study of 31 Adult Witness Interviews

Chapter $3 \quad$ Lack of Witness Cooperation in Investigative Interviews: An $\quad 59$ International Survey of Criminal Investigators

Chapter $4 \quad$ Unfulfilled Expectations of Cooperation in Witness Interviewing 89

Chapter 5 Effects of Cooperation on Information Disclosure in Mock-Witness 117 Interviews

Chapter 6 The Detrimental Effects of Lack of Witness Cooperation $\quad 141$

Chapter $7 \quad$ Cooperation in Investigative Interviewing: Psycho-legal 175

Contributions with Societal Impact

$\begin{array}{ll}\text { References } & 185\end{array}$

$\begin{array}{ll}\text { Summaries } & 211\end{array}$

Summary in English 213

Summary in Dutch (Samenvatting) 218

Summary in Swedish (Sammanfattning) 222

Summary in Spanish (Resumen) 226

$\begin{array}{ll}\text { Acknowledgements } & 230\end{array}$

$\begin{array}{ll}\text { Curriculum Vitae } & 232\end{array}$

Dissemination 233

$\begin{array}{ll}\text { Appendices } & 237\end{array}$ 

Chapter 1

The Importance of Witness Cooperation in Investigative Interviews

This chapter is an extended version of the following publications:

De La Fuente Vilar, A. (in press). Navigating New Waters: Lack of Cooperation in Witness Interviews. In R. Horselenberg, V. van Koppen, \& J. de Keijser (Eds.), Bakens in de Rechtspsychologie [Beacons in Legal Psychology]: Liber Amicorum Peter van Koppen (pp. 119). Boomuitgevers.

De La Fuente Vilar, A. (2020). The Role of Witness Cooperation in Investigative Interviews. Manuscript submitted for publication. 



\section{The Importance of Witness Cooperation in Investigative Interviews}

Considering that witnesses of a crime hold relevant knowledge regarding the offence that may otherwise be unavailable to the police (Fisher, 1995), witness reports are critical for successful investigations. The police interview witnesses to elicit detailed and accurate information about a crime in question. For that task of information elicitation, police heavily rely on witness cooperation, which is not always granted. In most democratic societies, civilians have a duty but not a legal obligation to report crime and come forward as a witness (Goldsmith, 2005; Sunshine \& Tyler, 2003). Therefore, cooperation from a witness is voluntary and necessary to obtain information that helps open, advance and solve criminal investigations, and can later be used as evidence in court for the prosecution of offenders. Ultimately, witnesses assist the police and their cooperation contributes to managing crime effectively and in the adjudication of justice (Tyler \& Fagan, 2008).

In May 2019, a father allegedly intervened in a children's quarrel in the neighbourhood of the Dutch city of Enschede. In reaction, a group of 15-20 neighbours visited his home. After an argument, they dragged him and his wife out of their home and beat them with sticks in front of their children, and a large crowd of witnessing bystanders (Rohmensen, 2019; Te Bogt \& Timmers, 2019). Reportedly, the assaulted family were Syrian refugees, and the alleged perpetrators were Dutch citizens. The police immediately investigated this incident and relocated the refugee family for safety reasons. A month later the police still did not have any major leads in the investigation. Despite having called witnesses to come forward using a 'sms-blast' (i.e., a simultaneous and automated mass text messaging based on information from mobile antennas) to a large number of citizens present, around the time when, and in the vicinity of where, the incident took place (Politie, 2019a), and despite having invested many resources in the investigation with the neighbourhood police (Timmers, 2019), the investigation stood still. The mayor of the city declared that the investigation had stalled as "too many people do not dare to speak up" (Lindeman, 2020; my translation). The public prosecution, on the other hand, stated that the media attention had hampered the investigation as "camera crews in the neighbourhood keep the doors closed everywhere" (Te Bogt \& Timmers, 2019; my translation). In the following month, an eighteen-year-old woman was arrested for public 
violence. She lived in the house next to the alleged victims' house, and was accused of facilitating the entrance of the 'mob' of neighbours into the Syrian family's home. The suspect was forced to leave her 7-month old son in the care of her parents while she was in custody. The media reported that the suspect's mother was advised to encourage the perpetrators to come forward for the release of her daughter (Timmers, 2019). As a result, three individuals turned themselves in and the suspect was released. The suspect later reported in her own social media having felt used as 'bait' by the police and expressed her distress from being separated from her infant (Timmers, 2019). The police officially reported to have six suspects in the investigation (Politie, 2019b), but when the case was closed only three people were convicted of the crime (Lindeman, 2020). This unique case illustrates how necessary public cooperation is for effectively policing crime. In particular, it highlights the need for cooperation from witnesses in the absence of other type of evidence. The case also demonstrates some of the factors that motivate citizens not to cooperate with the police, and the detrimental consequences that lack of witness cooperation can have for a police investigation. A better understanding of how to overcome lack of witness cooperation to gather witness evidence is therefore of societal importance.

A large body of research on eyewitness memory, investigative interviewing, social influence and communication has demonstrated that the way in which police investigators conduct witness interviews influence the quantity and the quality of witness accounts (for reviews see Fisher, 2010; Hope \& Gabbert, 2019). However, the stance of the witness regarding their willingness to cooperate and provide information and its effect on interview outcomes has received little empirical scrutiny. Nevertheless, research findings regarding interviewee's lack of cooperation in victim, suspect and human intelligence interviewing warn about its detrimental influence on information elicitation. Lack of cooperation decreases the amount and accuracy of information disclosed and influences the interviewing approach of police investigators determining interview outcomes (Alison et al., 2014; Cabell et al., 2020; Hershkowitz et al., 2006; Holmberg \& Christianson, 2002; Kim et al., 2020; Meissner et al., 2012; Pearse \& Gudjonsson, 1999; Vrij, et al., 2017).

Extensive research has demonstrated the influence of diverse reasons that reduce cooperation with the police, and that police behaviour can contribute to ameliorating and deteriorating civilian's willingness to cooperate with them (cf. Spencer \& Stern, 2001). 
Despite this evidence, the traditional standpoint that witnesses are individuals likely to be cooperative in criminal investigations has prevailed (Antaki \& Stoke, 2017; Fyfe \& Smith, 2007; Roberts, 2010). Academic endeavours in collaboration with practitioners have advanced the theoretical and practical understanding of the testimony from cooperative witnesses (Brewer et al., 2018; Fisher \& Geiselman, 1992; Fisher et al., 2011; Gabbert et al., 2009; Hope et al., 2013; Loftus, 2005; Memon et al., 2010), without similar research efforts concerning witnesses who do not cooperate in interviews with the police. To address this gap of knowledge, the current dissertation focuses on interviewing of uncooperative witnesses.

\section{The Current PhD Dissertation}

The overarching aim of the current dissertation was to provide an initial examination of witness cooperation in police interviews with crime witnesses. The main research question is how does cooperation and lack of cooperation affect interviewers, the interviewees, and the outcome of police witness interviews? In the current dissertation, I aimed to examine: 1 ) how police investigators gain witness cooperation in their current practice; 2 ) police experiences in interviewing uncooperative witnesses; and 3) the effects of cooperation and lack thereof on information elicitation.

\section{Scope}

Before developing the theoretical background of the topic of this PhD dissertation any further, it is necessary to explicitly demarcate the research scope and clarify that some relevant literature will not constitute objects of study in this doctoral programme of research. Effective interviewing of witnesses is critical in the criminal justice system as witness accounts form the basis to advance investigations and are later used as evidence in the process of guilt adjudication. In this dissertation, I focus on police interviews as it is the first stage to obtain a verbal account of a witnessed crime, thereby limiting the scope of this research to only the pre-trial investigative stage despite the participation of witnesses in further legal proceedings. Consequently, the presentation of witness testimony in court and evaluation of witness evidence by police, prosecutors, lawyers and judges falls outside the 
scope of this dissertation. In addition, the witness accounts of interest concern recalled information and details from past events, rather than identifications of people.

It should also be noted that while the term witnesses sometimes refers to victims of a crime as well (e.g., Davis, 1983; Fisher, 1995), in this dissertation, I only examine cooperation in interviews of witnesses, more specifically in interviews of adult witnesses albeit issues of non-cooperation are also common in adult and child victims (e.g., Orbach et al., 2013; Taylor \& Gassner, 2010). In essence, witnesses hold knowledge (i.e., they know what happened in the crime, thus can provide information), or are bystander eyewitnesses, of a criminal offence and unlike victims, they are not the target of, nor have they necessarily suffered harm caused by, the criminal act. As a consequence, the status of witnesses in the legal system is different and more neutral considering that victims often become partisan (e.g., complainant) against the defendant in court proceedings (Davis, 1983). Some issues related to lack of cooperation in investigative interviewing from (adult and child) victims (Fisher \& Geiselman, 2010; Hershkowitz et al., 2006; Holmberg \& Christianson, 2002) as well as from suspects and human intelligence sources have previously been studied (Alison et al., 2014; Meissner et al., 2012; Pearse \& Gudjonsson, 1999). Hence, these topics when relevant are examined in relation to the research included in this dissertation; however, they are also independent from this research, as police interviews vary to the same extent according to the legal status of the interviewee (e.g., Vrij et al., 2014; 2017). Because to date, the issue of lack of cooperation of witnesses during police interviews had not been put to direct empirical scrutiny, I focus the research included in this dissertation on the examination of cooperation in police interviews with adult crime witnesses.

The difference between adult witnesses who are not motivated to cooperate, referred to as 'uncooperative' in this dissertation, from witnesses who are vulnerable is warranted especially in light of the overlap between these two categories in some cases. Vulnerable witnesses unlike uncooperative witnesses may not have the ability to remember or report due physical and psychological factors that makes them vulnerable in investigative contexts (e.g., age, mental illness, intellectual disabilities; Gudjonsson, 2010; Lamb et al., 2011; Ridley et al., 2013). However, some vulnerable witnesses are also uncooperative. For example, witnesses in investigations of child sexual abuse. In such case, besides the limitations in the ability to report, there is an unwillingness to report (Shepherd, 1993-see 
below the 'Witness Cooperation and Information Disclosure' section). Given the concurrence of these complex factors, and in order to further demarcate the scope of this dissertation, the focus is only on the effects of unwillingness to report from adult witnesses.

Relatedly, it should be noted that in this dissertation the body of techniques analysed to promote witness cooperation focus on investigative interviewing in policing contexts. This decision explicitly precludes research in security contexts focused on the use of different information-gathering approaches to promote interviewee cooperation (see Alison et al., 2013; Oleszkiewicz et al., 2014), and in other policing contexts, such as crisis negotiations, in which eliciting cooperative behaviour is also crucial (e.g., Taylor, 2002). The first decision relates to the differences according to the legal status of the interviewee, similarly to the above mentioned need to differentiate witnesses cf. victims, suspects, sources. An additional difference between police interviews with witnesses in criminal investigations in contrast to human intelligence gathering interviews is that in the latter information elicitation does not necessarily concern a past event as it can include intentions and actions about the future rather than the past; Evans et al., 2010). The second decision is grounded on the differences of what cooperation means in other policing contexts in comparison to the specific context of witness interviewing. Cooperation in this dissertation, is examined in terms of the willingness of an interviewee to co-operate with the investigative goals of information elicitation during a police witness interview. Some research from police negotiations offers valuable insights regarding human communication relevant to information elicitation, such as error management, interpersonal sense-making and different cultural dimensions that affect alignment between interlocutors (e.g., Giebels et al., 2017; Oostinga et al., 2018; Taylor, 2002). However, in those contexts cooperation involves a wider range of actions given the high risk and threat context that exceed the narrower study of cooperation of this dissertation focused on eliciting information concerning a witnessed crime. Therefore, the relevant literature from these contexts is reviewed in relation to the study of uncooperative witnesses and is also discussed in the 'Future Directions' section in Chapter 6.

Before turning to the individual studies included in this dissertation, I will review relevant empirical research that influence the decision to cooperate with the police and report crime. I will also review critical notions from eyewitness memory research and other 
psychological factors that influence investigative interviewing and evidence gathering as these give insights into the role of cooperation and lack thereof in police interviews with crime witnesses.

\section{Witness Cooperation in Criminal Investigations}

Cooperating with the police encompasses a range of law-compliant behaviours by civilians that require different levels of engagement (Murphy \& Cherney, 2012). In particular, crime reporting is the first of two ways of civilian cooperation with policing, which is not necessarily followed by a second one, which is the decision to divulge information and act as a witness in different legal instances (Sunshine \& Tyler, 2003). The latter action requires a more active stance from the individual who cooperates with the police as opposed to the first action (i.e., reporting a crime anonymously via a police hotline vs. repeated interviews with the police and giving testimony in court). It seems, therefore, that civic participation in crime reporting is a gradual process in which the likelihood of cooperation decreases as the situational demands require increased levels of engagement from an individual citizen.

Although estimations vary across nations, about half of committed criminal acts go unreported (Van Dijk et al., 2007). For instance, in the Netherlands, only 32\% of all criminal acts were reported to the police in 2019 (Centraal Bureau voor de Statistiek, 2020). In general, an observed pattern indicates that of the individuals who witness a crime some cooperate, and only a portion of them are willing to provide a police statement and even a smaller part are willing to testify in court (Kebbell \& Milne, 1998; Spencer \& Stern, 2001). To become a witness has been conceptualised as a rational choice dominated by a calculus of the implicated costs and benefits of such action (Kidd, 1979; Skogan, 1984), as unlike victims and suspects, witnesses do not necessarily have a personal invested interest in the legal process (Davis, 1983). If only motivated civilians cooperate with the police, it becomes crucial to understand the factors influencing the decision-making process of individuals who decide to cooperate and of those who choose not to (Sunshine \& Tyler, 2003). Below, I outline relevant research on the factors that can compromise or motivate the decision to cooperate with the police of an individual who witnessed a crime. 
Besides the risks and benefits associated with the cooperating behaviour (Clayman \& Skinns, 2012), the individual's moral ideas about society are critical when deciding to cooperate with the police (Papp et al., 2017). Aspects related to the individual's perceptions of the police determine cooperation. For instance, three of the four most common reasons not to report crime by victims in England and Wales in 2018 were the beliefs that the police could not do anything (33\%), that the police was not interested (20\%), and the decision to deal with it privately without the police (19\%) (Office for National Statistics, 2019). Overall, cooperation with the police increases with perceived police legitimacy (Sunshine \& Tyler, 2003), and in particular by perceived trust in the police (Papp et al., 2017). Albeit there are mixed findings, perceptions regarding how just and effective the police are also seem to influence cooperation (Papp et al., 2017; Tyler and Fagan, 2008). People's perceptions of the police can be formed by personally experienced interactions with the police or indirectly through the experience of others (Rosenbaum et al., 2005). Thus, witness cooperation can be affected by cultural and language barriers as well as personal lifestyle, race and socioeconomic status. In sum, negative perceptions of the police and the criminal justice system can detrimentally affect witness cooperation during investigative interviews (Confrey, 2017; Shepherd \& Griffiths, 2013).

Regarding the instrumental benefits and risks involved in crime reporting, there are two main factors that reduce cooperation: the relationship between the witness and the offender (Nicksa, 2014), and fear of retaliation (Clayman \& Skinns, 2012; Papp et al., 2017). The negative effect is exacerbated when these factors occur in combination (Ministry of Justice, 2011; Spencer \& Stern, 2001). Conversely, witnesses who are familiar with the perpetrator may fail to cooperate with the police to protect the perpetrator (Spencer \& Stern, 2001). In a laboratory setting, Swanner, Beike, and Cole (2010) found that a witnessperpetrator relationship reduced the willingness to provide an incriminating statement about a forbidden act. In addition, past criminal history of the witness and the risk of selfincrimination reduce cooperation (Confrey, 2017).

The type and severity of a crime often regulate individual decisions to report a crime. For example, crimes causing substantial damage or serious harm, such as murder or assault, are more likely to be reported (Spencer \& Stern, 2001). However, violent offences can deter cooperation, as witnesses may fear retaliation from the suspect (Papp, et al., 2017). Violent 
offences may also increase the risk for intimidation (Maynard, 1994). Additionally, if witnesses view an offence as justifiable (e.g., fraud), they will be less likely to report it (Spencer \& Stern, 2001). The practical resources around reporting coupled with concerns regarding the legal proceedings (e.g., trial cross-examination, Ash, 1972; Spencer \& Stern, 2001) reduce the willingness of some individuals to fulfil their civil duty. Lack of information or understanding of the role as witnesses in the criminal justice system is also a disincentive (Cannavale \& Falcon, 1976). Lastly, being the sole vs. one of a number of witnesses in a case also affects the cost-benefit weight in both directions. The presence of multiple witnesses can lead to apathy or diffusion of responsibility (Spencer \& Stern, 2001), or it can encourage reporting by reinforcing intrinsic cooperative tendencies (Cannavale \& Falcon, 1976).

In sum, several factors affect civilian ${ }^{1}$ cooperation to assist the police in criminal investigations in general, and the decision to report crime in particular. The decision to become a witness is influenced by one or many of the characteristics and contexts of the crime, the perpetrator and the witnesses themselves (Fyfe \& Smith, 2007; Kidd, 1979; Spencer \& Stern, 2001). Remarkably, whether these factors also influence witnesses' cooperation during police interviews specifically has not received much empirical scrutiny before. However, beyond the myriad of causes of witness cooperation, in this dissertation, I focus on examining the effects of cooperation, and lack thereof in particular, as a determinant of interview outcomes by regulating information disclosure from the interviewee and the interviewing approach.

\section{Witness Cooperation and Information Disclosure}

Cooperating with the police in a criminal investigation in essence refers to the willingness to aid in the reconstruction of the witnessed crime (Milne \& Bull, 1999). Previously, it has been proposed that the motivation of civilians to cooperate with the police relates to the consequences and risks of the specific cooperative behaviour (Papp et al.,

\footnotetext{
${ }^{1}$ 'Civilian' is a term used in some of the reviewed research to refer to a citizen, a member of the general public, who interacts with the police. Other research on witnesses (particularly stemming from Psychology), on the other hand, commonly uses the term 'individual', or formerly 'subject', in reference to a person who has information about a crime. In this dissertation, these terms are used interchangeably to refer to a witness of a crime (see also the above section 'Scope').
} 
2017). The cooperative behaviour at stake in an investigative interview concerns information elicitation; there is a unilateral request of information from the police investigator and the choice to cooperate results is information disclosure. The decision of the interviewee to comply with this request is thus considered a prosocial behaviour. A vast corpus of research has demonstrated that rewards increase the likelihood of helping, whereas costs decrease it (for a review see Bierhoff, 2002). Homans (1958) posited that in human social interactions, we engage in a mutual exchange of material and non-material goods in which our behaviour is regulated by costs and rewards that result from benefits minus associated costs of an action. This behavioural economical approach has been refined, accepted widely, and empirically tested to explain human decision-making in different contexts (e.g., Camerer \& Loewenstein, 2003), and importantly for this research, to examine decisions to report crime information.

After witnessing a criminal offence, an individual will make the decision whether to report it or not to the authorities (Kidd, 1979) and whether to cooperate with the investigation. To make such decision, the individual who witnessed the crime engages in a cost-benefit analysis (Kidd, 1979; Skogan, 1984). In this model, therefore, a witness is a rational decision maker that processes information and weighs the material and psychological costs and benefits of reporting the crime. However, Kidd (1979) noted that emotion could override the cognitive evaluation, and that this model was limited by not accounting for the related cultural and societal aspects of cooperation with the police. In addition, Davis (1983) argued that focusing on merely reducing the hurdles of the criminal justice system (i.e., the material costs such as wage loss to appear in court) that witnesses bear was ineffective to increase cooperation, if other needs of the witnesses are not taken into consideration. For instance, addressing communication problems between the police and the witness including setting the expectations of serving as witness (Cannavale \& Falcon, 1976). More recently, slightly more sophisticated behavioural economics approaches involving cost-benefits analyses have been proposed to account for decisions to report crime by victims (Bowles et al., 2009; Goudriaan et al., 2004), as well as to explain information disclosure by suspects (Yang et al., 2017), and informants (Neequaye \& Luke, 2018). Such models extended Kidd's proposal (1979) of individuals engaging in a calculus to make the decision to report crime onto the interview room under the shared premise that 
the extent to which individuals disclose or withhold information is based on subjective perceptions of outcomes and their perceived utility (Yang, et al., 2017).

Building on the aforementioned research, I propose that witnesses evaluate their involvement in the criminal investigation in a similar way. Particularly, they engage in an analysis of costs and rewards when making their decision to participate in an investigative interview and disclose information. Witness disclosure will thus result from a positive appraisal of the associated rewards outweighing the costs. Conversely, a subjective evaluation of high costs with no perceived reward can lead to the decision to not cooperate with the police, which in turn, will negatively affect information disclosure. Consequently, lack of cooperation in an investigative interview jeopardises the provision of an accurate and detailed witness account. This tenet recognises the facilitating role of cooperation in information elicitation and is in line with previous investigative interviewing research findings indicating that fostering witness cooperation maximises interviewee information disclosure (Gabbert et al., 2020; Vrij et al., 2014).

In a witness investigative interview conducted following evidence based guidelines (e.g., Fisher et al., 2011), the interviewer requests the interviewee to report as much accurate information as they can remember about the witnessed crime. The resulting witness account represents both the witness's ability and willingness to remember and report. Regarding the latter, Shepherd (1993) noted the fluctuation of interviewee engagement in a continuum of willingness-unwillingness to talk with resistance at the end of it. More recently, researchers have investigated resistance and cooperation of suspects (Kelly et al., 2016), and of human intelligence sources (Alison et al., 2014), as two opposing ends on a spectrum rather than as distinct categories. Arguably, investigative interviews of witnesses share a similar dynamic nature in which the stance of the interviewee also oscillates in the continuum between cooperativeness and uncooperativeness. Therefore, the witness' unwillingness to cooperate will affect the witness' willingness to talk (i.e., report) during the investigative interview.

The motivation to engage with the interviewer and to actively participate in the effortful task of recall predicts how much information witnesses will report (McCauley \& Santee, 2019). In the case of uncooperative witnesses, therefore, poor memory reports will not result from an inability to remember driven by any intellectual or developmental aspect 
(see Ridley et al., 2013 for a review), but from an unwillingness to report instead (Shepherd, 1993). Consequently, in healthy adult witnesses, motivational factors rather than cognitive aspects of witness memory determine the accuracy and detail in witness accounts obtained following evidence-based interviewing guidelines (Westera \& Powell, 2015). Relatedly, Blank (2009) provides a useful distinction between memory beliefs and memory statements about remembered events (i.e., memory trace). The latter are the result of externally communicating a memory, a stage susceptible to normative influences (e.g., social costs and benefits), in which the individual selects what to communicate and may also modify what is communicated, relative to the memory belief (Blank, 2009). Simply put, there is a choice of not disclosing all what is remembered (cf. Stone et al., 2012).

In an investigative interview, the conversation between the witness and the police is marked by conversational norms based on informational demands from the interviewer requiring to report as much relevant, truthful and reliable information as possible from the witnessed crime (Antaki \& Stokoe, 2017; Grice, 1975). However, these conversational maxims are often violated, and the memory report eventually includes a compromise between them according to personal and situational goals (Koriat \& Goldsmith, 1994). Consequently, uncooperative interviewees can avoid disclosure by strategically controlling whether to report or omit pieces of information. For instance, intelligence sources use counter-interviewing strategies to omit new or critical information, often aiming to strike a balance of disclosing not too much nor too little to appear cooperative (Granhag et al., 2015). Instead of fulfilling the investigator's expectations that witnesses will communicate relevant information in an efficient manner (Antaki \& Stokoe, 2017; Fyfe \& Smith, 2007; Roberts, 2010), resistant interviewees in human intelligence interviews provided brief, fabricated, scripted, unrelated answers or do not answer at all (Alison et al., 2014).

Deception research has also shed light into verbal strategies used to act cooperatively while not providing complete truthful accounts, for example by omitting information or embedding lies in truthful statements (Strömwall et al., 2006; Verigin et al., 2019). From the research reviewed, the act of withholding information seems to be associated with lack of cooperation, which is not considered lying per se; however, such responses qualify as deceptive based on the intentional act of not volunteering all information and failing to be as informative as required (Antaki \& Stokoe, 2017; Dynel, 2018). 
Previously, academics and practitioners have made references concerning lack of witness cooperation under varied terminology and definitions, including the following categories and labels: uncooperative, non-cooperative, unwilling to be involved in a criminal investigation, reluctant to talk, resistant to engaging in the criminal justice system, hostile towards the police, and intimidated witnesses (Confrey, 2017; Maynard, 1994; Spencer \& Stern, 2001; Shepherd \& Griffiths, 2013). Linguistically those terms are not synonyms of one another and in some jurisdictions lead to differences in the legal systems with cascading consequences to how the witness interviews are conducted (e.g., the use of special measures such as anonymity). However, the behaviour of witnesses in such categories overlaps to the extent that it can be described as 'uncooperative' as it does not aid the police conducting a criminal investigation. Drawing on the research reviewed in this section, I conceptualised that the behaviour that characterises uncooperative witnesses during a police interview is the unwillingness to disclose accurate and detailed (remembered) information about a witnessed crime. Thus, uncooperative witnesses are witnesses whose behaviour is not cooperative the police's goal of advancing the investigation, and specifically, antagonistic to the investigative goal of (fully) eliciting information. The focus of my research is investigative interviewing of witnesses who are, at least initially, either overtly or covertly, uncooperative.

\section{Witness Investigative Interviewing}

The purpose of an 'investigative interview' with witnesses, victims and suspects is to obtain accurate accounts when investigating a crime. The term 'investigative interview is henceforth used in this dissertation in reference to police interviews conducted during pretrial investigations in the search for facts (i.e., fact-finding) concerning a criminal case. In particular, it is worth noting that in the context of interviewing crime witnesses ${ }^{2}$, investigative interviews are characterised by the investigator's efforts to elicit rather than confirm information (for overviews on investigative interviewing research and practice, see

${ }^{2}$ Notably, the difference between 'investigative interviewing' as an alternative to 'interrogation' influenced a turn towards more ethical, non-accusatory, and not guilt-presumptive information gathering approaches to interviewing persons accused of crimes (Meissner et al., 2012; Williamson, 2003). 
Milne \& Bull, 1999; National Police Improvement Agency, 2009; Schollum, 2005). Therefore, not all police interviews with a witness are in practice investigative interviews. In the past, research on real-world interviewing practices has found that a 'standard' police interview that is, before introducing formal training programmes and national interviewing models is often incompatible with the ethos of an information-gathering investigative interview (see Fisher \& Schreiber, 2007; Launay \& Py, 2015; Walsh et al., 2016) in which a witness is typically questioned about specific knowledge using closed, directive and leading questions (e.g., Clifford \& George, 1996; Memon et al., 1997b; 2010).

Two distinct interviewing approaches have been distinguished in the literature, namely an information-gathering approach and an accusatorial style (Kelly et al., 2013; Meissner et al., 2012). At a broad level, the approach in which an interview is conducted refers to an overarching framework that encompasses the tools investigators employ to achieve their interview goals. Interviewing techniques, at a more specific level, can be the used in the act of eliciting information (Kelly et al., 2013). In concrete, national interviewing models and interviewing protocols generally dictate the use of specific techniques to elicit an account, in doing so these prescriptions become the standard of best practice in a jurisdiction. Some interviewing guidelines recommend the use of either interviewing techniques or an interviewing protocol based on supporting scientific evidence (e.g., evidence-based interviewing).

An accusatorial interviewing approach in direct contrast to investigative interviewing following an information-gathering approach, is traditionally an interrogation approach (particularly for suspects). The accusatorial style is confrontational and guilt-presumptive in nature, and characterised by the use of closed-ended, confirmatory questions with the aim of eliciting admissions and confessions (Meissner et al., 2012). Research has demonstrated that an accusatorial interviewing style can increase interviewee resistance and is detrimental to memory recall overall reducing accurate information elicitation and increasing the risk of obtaining false confessions (Meissner et al., 2012; Vrij et al., 2017). On the contrary, an information-gathering approach is more successful in obtaining more comprehensive and accurate testimonies from witnesses and suspects (Fisher et al., 2011; Meissner et al., 2012; Vrij et al., 2014). This approach advocates for the use of open-ended and exploratory questions to elicit an account of the event from the interviewee, and 
promotes rapport building techniques, which fosters trust and cooperation that in turn promote disclosure and decrease reluctance (Collins et al., 2002; Duke et al., 2018; Gabbert et al., 2020; Vallano \& Schreiber Compo, 2015).

In the context of witness investigative interviews, the onus to promote, gain, maintain and recover witness cooperation to facilitate disclosure of information is on the interviewer (Gabbert et al., 2020). Below, I describe comprehensively, but not exhaustively, past research on interviewing of witnesses shown to be effective and ineffective in relation to information elicitation 3 .

\section{Effective Witness Interviewing}

In the last three decades, researchers in psychology and practitioners from different law enforcement agencies have advanced the field of applied memory research and investigative interviewing by providing empirical evidence that supports police interventions to improve witness statements (Fisher et al., 2011). The Cognitive Interview $(\mathrm{Cl})$, in its enhanced version, is the gold standard protocol to obtain best evidence from witnesses (Fisher \& Geiselman, 1992), which combines social dynamics and cognitive aspects of interviewing.

Research has proven that the $\mathrm{Cl}$ elicits significantly more correct details with a small increase in errors (Memon et al., 2010), and it is overall superior compared to the standard police interview (Fisher et al., 1989). The efficacy of the $\mathrm{Cl}$ has been attributed to the tandem effect of the relational and cognitive elements that enhance memory reports (Memon et al., 1997). However, the empirical research which has evaluated the $\mathrm{Cl}$ has focused on testing the four retrieval mnemonic techniques to enhance memory recall (e.g.,

\footnotetext{
3 In this dissertation, widely varying interviewing practices from different countries around the world are discussed (e.g., Launay \& Py, 2015; Walsh et al., 2016). In Chapter 2, research stemming from archival interviews of adult witnesses is reviewed, shedding light on interviewing practices in the United States, England and Wales, Canada and the Netherlands. In addition, in Chapter 3, we attempted to gather respondents from an international sample (succeeding at very different response rates), including those five countries as well as Norway and Australia. As the models of interviewing applied in each country are undoubtedly an important determinant of practice, thus further explanation is provided in the ensuing chapters when appropriate. For this dissertation, however, the main focus has been on examining the available research concerning techniques and protocols recommended for eliciting information from witnesses, and more specifically from uncooperative witnesses. In Chapter 6, I note some limitations of this approach.
} 
report everything, reinstate context, report in reverse order, report from different perspectives) rather than the techniques that facilitate communication and the establishment of a relationship between the interviewer and the interviewee (e.g., rapport building, transfer of control) (Gabbert et al., 2016). Therefore, while the $\mathrm{Cl}$ contemplates the importance of promoting cooperation, the efficacy and application of its cognitive components is highly dependent on the level of cooperation from the interviewee (McCauley \& Santee, 2019; Vrij et al., 2017). Hence, the use of the $\mathrm{Cl}$ while valuable to interview uncooperative witnesses is limited and deemed more suitable for cooperative witnesses.

\section{Interpersonal Approach and Rapport-building: Keys to Promote Cooperation}

Alison and colleagues (Alison, et al., 2013; 2014) have demonstrated the influence of adapting the interviewing approach to the interviewee's stance in order to effectively produce gradual movement towards cooperativeness, or to at least not exacerbate resistance. If the interviewer's success to maximise information disclosure is ultimately dependant on witness (un)cooperativeness, it logically follows that the interviewer needs to employ an approach with the goal of gathering information and using rapport-building techniques that foster cooperation and trust (Abbe \& Brandon, 2014). Therefore, rapport fulfils a utilitarian function as it enables a productive relationship with the interviewee and contributes to effective interview outcomes (Gabbert et al., 2020; Vallano \& Schreiber Compo, 2015).

At present, research on rapport demonstrates that in investigative interview contexts is considered a key element to elicit information (e.g., Abbe \& Brandon, 2013; 2014). Similarly, evidence from practitioners and researchers in witness interviews confirm this finding (Vallano \& Schreiber Compo, 2015; Vallano et al., 2015). However, there are many formulations of what rapport is, and consequently a diverse range of verbal and nonverbal behaviours are considered and claimed to be effective for rapport-building between an interviewer and an interviewee. Indeed a commonality in the rapport literature is that its definition is related to creating a bond, a connection, or forming a professional or working relationship between the interviewer and the interviewee (Abbe \& Brandon, 2013; 2014; 
Gabbert et al., 2020; Neequaye \& Mac Giolla, 2020; Vallano \& Schreiber Compo, 2015; Vanderhallen et al., 2011).

Effectively establishing rapport seems to be based on the use of specific techniques by the interviewer with positive effects for interview outcomes, in terms of the experience during the interview and information elicitation. The problem with this claim is that is verification and falsification has relied on different manipulations and measures (e.g., Duke et al., 2018; Vallano \& Schreiber Compo, 2011). Therefore, the lack of a clear and shared definition of rapport is not one without important consequences for research, as well as for practice. How practitioners are trained to build rapport and which rapport-building techniques are incorporated in their interviewing practice consequently lacks uniformity and derives in a wide spectrum, which makes practice evaluation and comparisons cumbersome (Abbe \& Brandon, 2014; Gabbert et al., 2020; Neequaye \& Mac Giolla, 2020; Vallano \& Schreiber Compo, 2015).

A recent unpublished review by Gabbert and colleagues (2020) reviewed the entire body of empirical evidence on the use of rapport in information-elicitation contexts, and found that previous research used smiling, making eye contact, manipulating body posture and head nodding as effective non-verbal manipulations of rapport. Verbal rapportbehaviours concerned interviewer's active listing skills, utterances showing a personal interest in the interviewee, and the use of empathy during an interview. Overall in witness interviews, establishing rapport has been found to facilitate communication and to elicit more detailed and accurate reports (Collins et al., 2002; Vallano \& Schreiber Compo, 2011). Consequently, recently information disclosure has been conceptualised as an intended behavioural effect of rapport that relates to the willingness to cooperate after a positive interviewing experience (Duke et al., 2018). However, the underlying mechanisms to explain the positive effect of rapport on increasing accurate reporting have not been disentangled.

The academic literature speculates about the direct effect on memory retrieval, and on the effects of rapport on the motivation of the interviewee to try harder to remember and to increase complete reporting (e.g., Fisher, 1995; Vallano \& Schreiber Compo, 2015; Vrij et al., 2014). More specifically, effective rapport-building makes interviewees feel more comfortable and safer, thus increasing compliance and cooperation (Geiselman et al., 
1984). Further, rapport facilitates disclosure, by motivating witnesses to try to recall information (Fisher, 1995).

Relevantly for the current research, lack of rapport-building increases reluctance, negative perceptions of the interaction and the interviewer (Duke et al., 2018; MacDonald et al., 2017a; Vanderhallen et al., 2011), and has the potential to turn a cooperative witness into an uncooperative one (Collins et al., 2002). Nevertheless, the extent to which rapportbuilding benefits interviewing of adult uncooperative witnesses has not been scrutinised; and it may be only one piece of the puzzle, as gaining and maintaining rapport is necessary, but it is insufficient for a successful interview (Abbe \& Brandon, 2014).

Depending on the witness' stance in the continuum of cooperativenessuncooperativeness, the investigator's goal will be to gain cooperation and overcome resistance. The interpersonal interaction between the interviewer and the interviewee pursuits the goal of information elicitation that constitutes an exchange relationship as conceptualised by Homans (1958), in which the interviewer has the faculty to promote prosocial behaviour. For this purpose, interviewers need to re-frame their information request (i.e., cooperative behaviour) in terms that favours the interest of the witness (Bierhoff, 2002; Tyler \& Fagan, 2008). An effective approach to interview uncooperative witnesses requires a double undertaking of promoting cooperation and overcoming resistance. Such double-pronged approach aligns with the previously described economical decision-making perspective (see section 'Witness Cooperation and Information Disclosure'). It is better to first persuade the interviewee into believing that the request of information is attractive by maximising the rewards, thereby moving the individual towards the cooperative behaviour. Subsequent efforts can then focus on reducing the perceived negative consequences of cooperating as individuals otherwise will tend to avoid fulfilling the initial request for information (Knowles \& Linn, 2004). While specific protocols to interview uncooperative witnesses shave not been developed nor implemented, the proposed model of cooperation and disclosure finds in the interviewer its counterpart, as the interviewing approach can modulate the witness' cost-benefit analysis. 


\section{Ineffective Witness Interviewing}

As previously stated, there are no specific interviewing protocols to use with adult uncooperative witnesses. However, a review of the literature indicates that there are two protocols that propose techniques to interview uncooperative witnesses, but with serious shortcomings that limit their effectiveness. These are namely the Conversation Management (CM; Shepherd \& Griffiths, 2013) and the Reid Technique (Inbau et al., 2013). The former has not been empirically validated and its use did not widespread (Clarke \& Milne, 2001; Schollum, 2005). Besides, in comparison to the $\mathrm{Cl}$, the $\mathrm{CM}$ was found to be inferior in the elicitation of information (Clifford \& George, 1996). The latter also lacks empirical support of its efficacy, and evidence demonstrates that its techniques risk decreasing the quality of witness evidence. In general, the Reid manual provides minimal prescriptions to interview witnesses. To break witness resistance, the use of accusations and confrontations, together with offers of empathy and sympathy as well as moral justifications that excuse lack of cooperation are recommended (Inbau et al., 2013). These accusatorial interviewing techniques increase resistance and deteriorate memory recall (Vrij et al., 2017), and have also been shown to increase false allegations against the innocent in laboratory experiments (Kaasa et al., 2013; Loney \& Cutler, 2016), legal cases (Moore et al., 2014), and can contribute to miscarriages of justice (Guerra-Thompson, 2012; Gross \& Gross, 2013; Moore et al., 2014; The National Registry of Exonerations, 2020).

In addition, reviews of witness interviewing practice in real criminal cases consistently reveal poor investigative interviewing skills despite training in specific best practice guidelines (Clarke \& Milne, 2001; Schreiber Compo et al., 2012). Across samples, archival data show that interviewers predominately ask closed and directive questions, pose some leading questions, often interrupt the interviewee, and rarely employ memory enhancing techniques (Clarke \& Milne, 2001; Mclean, 1995; Schreiber Compo et al., 2012; Snook \& Keating, 2011; Wright \& Alison, 2004). Such interviewing approach is directive and excessively controlling, which restricts the interviewee's account at best and, at worst, leads to incomplete accounts or potential confabulations when the interviewee feels intimidated (Griffiths et al., 2011; Oxburgh \& Dando, 2011). Based on these findings, it would seem that current witness interviewing practices are not conducive to securing cooperation, which in turn, negatively affects the quantity and quality of the information disclosed (Launay \& Py, 
2015; Vrij et al., 2014). Poor interviewing techniques can increase resistance and contaminate witness testimony. Considering that the value of witness evidence relies on how it is obtained (Wells et al., 2006), a closer examination into the role of cooperation during witness interviews is warranted to obtain best evidence from (uncooperative) witnesses.

\section{The Risk of False Testimony by Uncooperative Witnesses}

The information reported by a witness concerns their autobiographical memory. As such, a witness account is a memory report prone to be influenced by different social and psychological processes that can lead to common memory errors, such as forgetting, error, distortion, contamination, and omission (Wells et al., 2006). Considering that remembering is an act of reconstruction, not mere reproduction, of a past event (Bartlett, 1932; Loftus, 1975), memory traces rather than being permanent are malleable and susceptible to modification, change or supplementation (Bartlett, 1932). Particularly in the context of investigative interviews, in which police investigators can, advertently or inadvertently, introduce post-event misinformation, the memory reports of crime witnesses are not protected from contamination (Frenda et al., 2011; Loftus, 2005). The introduction of misinformation is facilitated by the use of closed, direct and leading questions (Sharman \& Powell, 2012), increasing inaccuracy in witness reports, and even risking false allegations from witnesses (Kaasa et al., 2013; Loftus \& Pickrell, 1995). Moreover, memory traces which are not reported due to lack of cooperation are vulnerable to forgetting considering normal decay and lack of rehearsal. However, memories of the witnessed event could also be conserved if covertly retrieved despite lack of overt reporting (Stone et al., 2012). One way or the other, empirical testing is warranted. Simply put, in light of the malleability of our memories in legal settings (Loftus, 1975, 2005), a closer examination of the way in which memory reports are obtained is key to evaluate witness evidence (Wells et al., 2006).

More than half of the recorded exonerations in the United States show that perjury or false witness testimony significantly contribute to miscarriages of justice, followed by police and prosecutorial misconduct (The National Registry of Exonerations, 2020). Gross and Gross (2013) have argued that false testimony later recanted in exoneration cases could be a product of pressure and threats from police or prosecutors during the investigation. 
Uncooperative witnesses have been identified at risk of being interviewed following coercive interrogation practices (Davis \& Leo, 2016), potentially given the interviewers' preference of these interviewing techniques to overcome resistance (Griffiths et al., 2011), or as a result of lack, ineffective and insufficient training (Clarke \& Milne, 2001; Dando et al., 2008; Fisher \& Schreiber, 2007; Snook et al., 2012).

Given that police officers report frequently encountering individuals who refuse to become involved in an investigation when they witness a crime (Wheeler et al., 2017), the perils of poor interviewing of uncooperative witnesses calls for more scrutiny. Findings and implications from this research will facilitate the police to be better equipped to adapt and overcome lack of cooperation from witnesses. Such contributions are crucial for real-life investigations like the described case in Enschede. Moreover, this overdue research programme will serve as a foundation to evaluate witness evidence obtained from uncooperative witnesses in criminal investigations.

\section{Overview of Chapters}

The aim of the current dissertation was to explore cooperation and lack thereof in police interviews with witnesses. The first specific aim was to examine how police investigators gain witness cooperation in their current practice, for which I conducted an archival study that analysed the type of questions and techniques used by the practitioners in murder case investigations in the Netherlands (Chapter 2). The second specific aim of this dissertation was to examine police experiences in interviewing uncooperative witnesses, for which I conducted a survey of police officers examining their beliefs, experience and perceptions regarding lack of witness cooperation (Chapter 3 ). Next, based on the knowledge of the first two studies, and in relation to the third specific aim of this dissertation, I investigated the effects of witness cooperation and lack thereof experimentally in the laboratory. The first laboratory study addressed how witness cooperation affects the interviewers' approach to eliciting information, and whether this approach was guided by expectancy effects (Chapter 4). The second laboratory study examined whether witness cooperation and lack thereof regulates witnesses' information disclosure (Chapter 5). The findings as well as the theoretical implications and practical 
contributions of this dissertation are outlined in Chapter 6. Finally, I make some concluding remarks including the limitations of my research and suggest future research avenues. 

Chapter 2

Quality Evidence from the Interview Room: An Archival Study of Adult Witness Interviews

An adapted version of this chapter has been submitted for publication as:

De La Fuente Vilar, A., Horselenberg, R., \& van Koppen P. J. (2020). Quality Evidence from the Interview Room: An Archival Study of Adult Witness Interviews. Manuscript submitted for publication. 



\begin{abstract}
Objective: Despite the importance of witness statements to advance criminal investigations and further legal proceedings, a small body of evidence has indicated that there is a gap in the application of evidence-based interviewing techniques for eliciting witness accounts. In this chapter, we review past evidence from police interviewing rooms across jurisdictions, and analyse interviewing practice of adult witnesses in the Netherlands.

Method: Based on archival interview transcripts, we examined how the Dutch police conducted 21 interviews with adult witnesses in closed murder investigations.

Results: Interviewers used few open-prompts (less than 1\%) and open-ended questions (6\%), and predominantly asking closed yes/no (49\%) and direct questions (36\%) to gather information. They also asked few closed option-posing questions ( $5 \%)$. In comparison with evidence from other countries, leading questions were asked infrequently $(4 \%)$, however suggestion was seldom introduced in opinion statements by interviewers.

Conclusions: The observed pattern of interviewer behaviour was in line with previous international findings indicating poor interviewing performance in police interviews of adult witnesses. A predominance of closed and directive questions that only seek to confirm specific information rather than attempting to gather as much information as possible risks reducing the amount, accuracy, and detail of the information elicited. The implications for interviewing training and the evaluation of witness evidence are discussed to improve current investigative interviewing practices.
\end{abstract}




\section{Quality Evidence from the Interview Room:}

\section{An Archival Study of Adult Witness Interviews}

On one hand, eyewitnesses are perceived by police officers as sources of critical leads to advance criminal investigations; on the other hand, officers believe that witnesses do not provide sufficient information (Kebbell \& Milne, 1998). Consequently, investigators have the task of facilitating the most complete and accurate witness accounts by promoting cooperation and facilitating memory recall (Fisher, 2010; Fisher \& Geiselman, 1992; Gabbert et al., 2020). Optimal interviewing henceforth increases both the interviewee's willingness to talk and ability to remember (Shepherd, 1993; for reviews see Hope \& Gabbert, 2019; Fisher et al., 2011). Using rapport-building, transfer of control, and open-ended questions and avoiding closed questions, leading questions, and interruptions are generally considered the cornerstone of interviewing to maximise the quantity and quality of information provided by witnesses (Fisher et al., 2011). However, there is a gap in the application of evidence-based interviewing techniques indicating current poor interviewing practice that reduces cooperation and hampers memory recall (see Launay \& Py, 2015 for a review). In this chapter, we review past evidence from police interviewing rooms across jurisdictions, and analyse interviewing practice of adult witnesses in the Netherlands.

Several factors that negatively affect the witness recollection of the crime are outside the control of the legal system. However, the way in which investigators conduct witness interviews is within the control of the police and determines the quantity and the quality of the information gathered (e.g., Fisher, 2010; Hope \& Gabbert, 2019; Wells et al., 2006). The evidence from police witness interviews reveals an overuse of closed, direct, and leading questions that exert control over the interviewee and makes fact checking rather than information gathering the focus of the interview (e.g., Wright \& Alison, 2004). Such interviewing practices restrict the opportunity to facilitate recall, testing memory recognition of the interviewer's knowledge instead of eliciting information from the witness memory recollection and thus leading to incomplete accounts (Clifford \& George, 1996; Fisher, 1995). In addition, there is evidence of an inappropriate use of leading questions, which have been shown to more readily implant post-event information from the investigative team's version of the events into the memory and account of a witnessed 
crime, contributing to potential confabulation or false statements and allegations (Kaasa et al., 2013; Loftus \& Pickrell, 1995; Sharman \& Powell, 2012). The largest repository of overturned wrongful convictions in the United States confirms that false testimony from witnesses (e.g., perjury) is the number one factor contributing to miscarriages of justice, being present in around $60 \%$ of the 2572 overturned convictions (The National Registry of Exonerations, 2020). Considering the weight of witness statements in advancing and solving criminal investigations, and later as evidence in criminal proceedings, it is imperative to strive to gather accurate and detailed information in investigative interviews.

Police interviewing practice with adult witnesses is reviewed in archival and field research, which includes the evidence from before and after interviewing training programmes. Overall, this body of research is rather limited, compared with research on interviewing child witnesses or of suspect interrogations. A database reviewing the empirical evidence on interviewing witnesses identified 58 peer-reviewed research articles on adult witnesses (Gabbert et al., 2016), of which only four are field studies. Those four articles are focused on testing the validity of protocols or specific techniques used by police investigators in field interviews. The 'standard police interview' was analysed in terms of its effectiveness on information yield rather than in terms of quality aspects of the interviewing approach. Only in one of those four publications reported on the use of interviewing techniques prior to training. Clifford and George (1996) observed that the standard police interviews were reduced to a questioning procedure, in which almost three quarters $(73 \%)$ of the questions were closed and used to confirm facts; moreover, open and leading questions were asked in almost an equal proportion (i.e., $20 \%$ vs. $17 \%$ ). The results of this interviewing approach were shorter witness accounts, compared with the post-training measure (Clifford \& George, 1996). The characteristics and efficacy of the standard police interview had been similarly described by Fisher et al., (1989), in the first field validation of police officers using the Cognitive Interview (Fisher et al., 1989). Further research reporting on the pre- and post-witness interviewing skills training of police investigators also demonstrates that the standard police practice before specialised training (i.e., intuitive interviewing) includes fewer effective interviewing practices (e.g., less use of open-ended questions) and greater use of specific and leading questions, hampering the quality of witness statements (e.g., Launay \& Pi, 2015; MacDonald et al., 2017a). Altogether, 
structured interviews, which require specialised interviewing skills, elicit more detailed and accurate accounts than do standard intuitive police interviews (Fisher et al., 1989; Memon et al., 1997). That finding has sparked different reforms in witness interviewing internationally (see Walsh et al., 2016 for a review).

Despite the efforts to implement best practice guidelines, poor interviewing practice in witness interviews seems to be pervasive across different countries. For instance, Schreiber Compo et al. (2012) and Clarke and Milne (2001) found limitations in the incorporation of the respective applicable national evidence-based guidelines for practice (Central Planning and Training Unit, 1992; National Institute of Justice, 1999). Although few published articles have examined the real-life practice of police interviewing of adult witnesses, the evidence consistently reveals similar sequences of ineffective questioning in interviewing practices in the United States (Fisher et al., 1987; Schreiber Compo et al., 2012), England and Wales (Clarke \& Milne, 2001; Clifford \& George, 1996; Mclean, 1995), and Canada (Snook \& Keating, 2011; Wright \& Alison, 2004), which we review in detail in the next section.

\section{International Witness Interviewing Practice}

Thirty years ago, Fisher and colleagues (1987) conducted the first field evaluation of police interviewing of witnesses and urged a review of interviewing practices. In the analysed interviews, there was little opportunity for presentation of a free and uninterrupted narrative of what happened by the witness, overuse of many direct shortanswer questions with little structure, and little or no assistance to enhance the witnesses' recollections (Fisher et al., 1987). In response to the identified problems in practice, the Cognitive Interview (Cl; Fisher \& Geiselman, 1992) was developed based on principles of memory, social dynamics and communication at play in forensic interviewing. The $\mathrm{Cl}$ is intended to maximise the interviewer's ability to guide multiple retrieval attempts of the mental representation of the crime event, in order to increase the witness' accurate recall (Fisher \& Geiselman, 1992). A meta-analysis including laboratory and field studies has confirmed the efficacy of the $\mathrm{Cl}$ to elicit significantly more correct information, at the cost of a small increase in the recall of incorrect information (Memon et al., 2010). Overall, the evidence is in favour of adopting the $\mathrm{Cl}$ for police investigative interviewing. Fisher (1995) 
estimated that the $\mathrm{Cl}$ elicits on average 30-35\% more information than a standard police interview. Official police interviewing guidelines in the United States (U.S. hereafter; National Institute of Justice, 1999) are based on the $\mathrm{Cl}$, and suggest the use of rapportbuilding, encouraging free witness narratives, not interrupting the witness, asking openended questions and avoiding leading questions or invitations to guess, as well as the use of memory-enhancing techniques such as reinstating the context of the original event to enhance witness memory recall (National Institute of Justice, 1999).

Schreiber Compo et al. (2012) examined the implementation of the U.S. interviewing guidelines into police investigative practice with real-world adult witnesses. Interviewers posed an open-ended narrative request in a minority of interviews (10.81\%). Most questions asked were yes/no questions (59.25\%), other closed questions (25.75\%), and multiple-choice questions (4.16\%). Schreiber Compo et al. (2012) also reported frequent interruptions, use of suggestive and multiple questions, and few rapport-building attempts. Over 20 years later, findings were still in line with those of Fisher et al. (1989), demonstrating the lack of implementation in practice of empirically based interviewing guidelines in the United States.

The first evaluation of the 'quality' of witnesses interviewing in England and Wales by Mclean (1995) reported an analysis of 16 random police interviews with witnesses. The findings revealed an ineffective questioning pattern: $46.9 \%$ of questions were counterproductive (i.e., leading), 34.2\% productive (including open questions, probing questions, and closed identification questions), and 18.9\% risky (i.e., questions that can only elicit confirmation with 'yes' and 'no' answers to stated facts, which may be wholly or partially inaccurate). Moreover, Mclean noted that a witness was in greater danger of being misled by the police than a suspect was, as witness interviews included twice as many counter-productive/leading questions as did suspect interviews (46.9\% vs. 25.3\%). Overall, the observed interviewing approach was described as assertive and directive, limiting the ability to build on the information elicited, as a full account was not sought from the witnesses and witnesses were not listened to. Instead, interviewers talked too much and quickly changed topics, without taking sufficient time to investigate deeper or probe further. Mclean (1995) further questioned the effectiveness of the investigative practice, as the written witness statements did not fully reflect the witness accounts. Relevant 
information was very frequently omitted, and in $25 \%$ of the interviews, information contrary to what the witness said was included, likely to bolster the plausibility of the police case theory, so Mclean recommended that every witness interview should be recorded. An important caveat concerning the research paper by Mclean (1995) is that while it refers to the new model of investigative interviewing, the paper does not clarify whether the analysed police interviews were conducted by interviewers trained in the new PEACE national model of interviewing which was officially rolled out in 1992 (Central Planning \& Training Unit, 1992).

The second and largest evaluation of adult witness interviews in England and Wales was conducted by Clarke and Milne (2001). They analysed 61 interviews with witnesses and victims conducted by PEACE-trained police officers, 17 from serious crime and 44 from volume crime. The mean duration of the interviews was 50 minutes (range 8-131 minutes), increasing to 93 minutes $(S D=39.25)$ in murder crime investigative interviews. Interviews lasted on average 14 minutes (range o-131 minutes), before taking the witness statement was taken. Therefore, their first conclusion was that only a quarter of the time is spent conducting the interview, whereas, three quarters of the time was spent taking the statement from the witness, and that in many interviews, interviewing as such was nonexistent, the exercise instead being one of statement taking. On average, a question was posed once every minute of the interview, and in $47 \%$ of interviews there were no appropriate pauses. The most frequently asked question types were: closed (42\%), openended (36\%), and leading (20\%). As a result, in $62 \%$ of the interviews, only a partial account was obtained, and almost half the interviewers were deemed to need further interviewing training. Moreover, the average interview did not include the proper techniques outlined in the guidelines. For instance, rapport-building was deemed to not have been established in $40 \%$ of the interviews. Overall, the interviewers also seemed to talk too much and interrupt the interviewees. Like Mclean (1995), Clarke and Milne (2001) noted poorer interviewing performance in the interviews with witnesses than in the interviews with suspects, given the larger number of closed questions and leading questions asked, simply because most interviewers did not allow the witnesses to tell their accounts. The interviews were mostly police led, unstructured, and not well-planned, similar to results from the United States (Fisher et al., 1987; Schreiber Compo et al., 2012). Importantly, Clarke and Milne's (2001) 
evaluation revealed problems in the implementation of the PEACE-CI components in practice, a finding that would later be replicated in investigators' self-reported concerns about embracing the new interviewing practices (Dando et al., 2008, 2009; Kebbell et al., 1999; Kebbell \& Milne, 1998).

In Canada, two archival studies point to similar deficiencies in interviewing practice for adult witnesses. First, Wright and Alison (2004) analysed patterns of questioning during 19 adult witness interviews at two Canadian law enforcement agencies. They concluded that the testimony obtained to reconstruct the witnessed crime resulted from a 'negotiation between the interviewer and the interviewee' (p. 138). The analysis of the sequence of questioning adopted (e.g., the style and order of questions) showed that in the first half of the interviews, information was gathered predominately using closed identification questions (e.g., who, where, when, and how questions), followed by a series of rapid fire yes/no questions used to confirm or deny statements by the interviewer. Wright and Alison (2004) cautioned that this pattern allows the interviewer's bias, beliefs, and case hypothesis to be transferred into the interviewee's narrative through the use of suggestion. Specifically, not asking open-ended questions, and asking very specific questions, which may be repeated to obtain confirmation, can compromise the accuracy of the witness testimony.

Snook and Keating (2011) observed similar poor interviewing behaviour in 90 'standard police officer' interviews with witnesses. In that sample, interviewers asked mostly close-ended (34.5\%), probing (32\%), and clarification questions (15.8\%), in combination with little use of open-ended questions (5.8\%). Other types of questions were used with less frequency: multiple (4.6\%), re-asked (3.2\%), forced-choice (2.3\%), and leading questions (1.5\%). Opinion statements were used very infrequently (0.20\%). Remarkably, a free narrative was requested in $73 \%$ of the interviews and, on average, $36 \%$ of the talking was attributed to the interviewer. Snook and Keating (2011) called for improved professional interviewing practice considering the cumulative evidence of similar fundamental mistakes in standard police witness interviews across country samples.

In conclusion, researchers have consistently found poor interviewing skills in witness interviews (Snook \& Keating, 2011; Wright \& Alison, 2004), despite the introduction of best practice guidelines (Clarke \& Milne, 2001; Fisher et al., 1987; Mclean, 1995; Schreiber 
Compo et al., 2012), which calls into question the quality of the witness statements used in later legal decisions.

\section{The Current Research}

Our review of the literature revealed that archival analyses of real-life investigative interviews of adult witness are limited in number. In a previous international review of professional adult witness interviewing practices, Launay and Py (2015) identified four archival studies from the United States, Canada, and England and Wales. We identified two additional research articles from England and Wales. The limited research on this topic may be because of a lack of video-recordings and of legislation enforcing recording, or because previous efforts focused on reforming suspect rather than witness interviewing (Clarke \& Milne, 2001). Likely for these reasons, and due to lack of transparency in scrutinising police practices, to our knowledge, there is no previous empirical evidence regarding adult witness interviewing practices in continental European countries, in the Netherlands in particular. However, recent reviews of Dutch interviewing of child victims (Otgaar et al., 2019) and vulnerable interviewees (Geijsen, 2018) have demonstrated the need to improve the application of evidence-based interviewing guidelines in interviewing practice. Therefore, the current archival analysis of adult witness interviews aims to examine how interviews are conducted in the Netherlands, constituting an initial contribution to identifying good practice, science-to-practice learning gaps, and interviewing training needs that can ultimately improve current investigative interviewing practice.

The corpus of police interviews analysed was originally collected for an internal evaluation within the Dutch Police Academy to evaluate the application of the current national models for witness interviewing. In the current study, we therefore focused on the types of questions and statements made by the interviewer. The complementary analysis assessing interviewing protocol adherence by the Academy will not be included in this chapter. The report from that analysis has so far not been made public and we are not privy to its findings.

The current research project is based on archival data from interviewing witnesses in murder case investigations. In murder investigations, information from witnesses can be crucial for clearance rates (Wellford et al., 1999), and for resolving cold cases (Davis et al., 
2014; Politie, n.d.). Considering the volume of unsolved murder and manslaughter cases in the Netherlands (Politie, 2018), the findings of this research are especially relevant to investigators working on current and cold case investigations of this type of crime. In addition, the increased prevalence of false testimony later recanted in murder cases exonerations in the United States (Gross \& Gross, 2013), as well as the evidence of the coercive interviewing of witnesses in a homicide investigation in Canada (R. v. Morgan, 2013), emphasises the significance of analysing how witness testimony is obtained in murder investigations for operators in the criminal justice system evaluating its probative value.

The relevance of this research to the case of the Netherlands also lies in the characteristics of its legal system. Specifically, in Dutch criminal cases, witness testimony constitutes powerful evidence for convictions (Van Koppen \& Malsch, 2008). To put this in context, in the Netherlands, as in other countries with Inquisitorial legal systems, the pretrial investigation is an inquiry led by the investigative judge whose role is fact-finding, for which both incriminatory and exculpatory evidence is collected, which is then included in the 'dossier' (i.e., case file). This characteristic marks the preference for the documentary presentation of evidence in Dutch courts. In contrast, in adversarial systems, the role of the judge and jury is to weight the evidence presented by the defence and prosecutor, emphasising the oral presentation of evidence (Van Koppen \& Penrod, 2003). Consequently, the witness statements taken by the police carry weight as witnesses are rarely heard in Dutch courts, highlighting the operational importance of securing the best evidence during investigative interviews (Dubelaar, 2014).

\section{Method}

\section{Sample}

A convenience sample of 22 witness interviews conducted by criminal investigators in one police unit in the Netherlands was analysed. One interview was conducted with a minor and excluded from analysis, given that the conventions for interviewing children are different from those for adults. Hence, our final sample consisted of 21 interviews. The interviews belonged to closed murder investigations and were conducted by different police officers. Six of the interviews were conducted by two interviewers whilst the rest were 
conducted by one interviewer. Information about the training, rank, and demographics of the police interviewers was not made available to the research team. Furthermore, to ensure anonymity and confidentiality, the transcripts were redacted and we did not have access to any identifying information regarding the interviewees or information on case outcome. The interviews took place between September 2011 and August 2013. We received transcripts of the interviews without any audio- or video- recordings of the interview process. The original interview transcripts were in Dutch and were translated in language and meaning into English for the analysis. The translations were reviewed by native speakers from different regions of the Netherlands to correct for vernacular expressions and nuances in language.

Interview duration was only noted in five of 21 interviews; the mean length of those interviews was 84 minutes ( $S D=24.18$, range 50-115 minutes). To estimate the mean duration of the whole corpus of interviews, we considered the relationship between the reported duration of those five interviews and the word count of every transcript based on the English translations. On average, 99.44 words corresponded to one minute of interview. The estimated mean length of all 21 translated transcripts was therefore 8472.19 words (SD $=5106.93$, range $2046-24657) ;$ this is equivalent to 85.20 minutes, similar to the reported average known duration, but with a much wider range of 20.58-247.96 minutes (over four hours).

\section{Coding}

The types of questions and statements uttered by the interviewers were coded. The responses of the interviewees were not taken into account, because ground truth was unavailable to us in order to evaluate them. Specifically, the numbers of open prompts, open-ended, direct, closed yes/no, closed option-posing, leading, personal, multiple, and repeated questions were coded. See Table 1 for the definition of each question type.

The interviewer statements that were not questions were coded according to their content into five categories: statements conveying case information not mentioned by the witness; information provided by the witness (e.g., echo statements, summarising witness answers); instructions to the witness about the interview or legal procedures ("The most important thing is what you saw and heard and that you don't invent things" or "The tape is 
Table 1

Definitions of Question Type

\begin{tabular}{|c|c|c|}
\hline Question Type & Definition for Coding Procedure & Examples \\
\hline 1. Open prompts & $\begin{array}{l}\text { Open prompts invite a full and broad answer } \\
\text { about what happened (i.e., a free recall) in } \\
\text { the witness's own words. }\end{array}$ & $\begin{array}{l}\text { "Can you say in your own words } \\
\text { what exactly you saw?" }\end{array}$ \\
\hline 2. Open-ended & $\begin{array}{l}\text { Open-ended questions specify recall about } \\
\text { one general topic, including tell, describe and } \\
\text { explain questions. }\end{array}$ & $\begin{array}{l}\text { "What do you mean by } x ? ", \text { "Tell } \\
\text { me more about } y ? ", \text { "What } \\
\text { happened next?" }\end{array}$ \\
\hline 3. Direct & $\begin{array}{l}\text { Direct questions invite a limited answer about } \\
\text { knowledge of specific aspects of one topic, } \\
\text { including what/why/how/when/where/who } \\
\text { questions used to clarify or probe the } \\
\text { account. }\end{array}$ & $\begin{array}{l}\text { "Who was with you?", "What did } \\
\text { he say?", "Where were you?", } \\
\text { "When did you leave the } \\
\text { house?" }\end{array}$ \\
\hline 4. Closed yes/no & $\begin{array}{l}\text { Closed yes/no questions aim to check one } \\
\text { fact, and invite "Yes", "No", "Maybe", and "I } \\
\text { do not know" responses. }\end{array}$ & "Was the car door open?" \\
\hline $\begin{array}{l}\text { 5. Closed option- } \\
\text { posing }\end{array}$ & $\begin{array}{l}\text { Closed option-posing questions elicit forced- } \\
\text { choice answers from a restricted number of } \\
\text { possible answers presented in the question. }\end{array}$ & $\begin{array}{l}\text { "Was the car door open or } \\
\text { closed?" }\end{array}$ \\
\hline 6. Leading & $\begin{array}{l}\text { Leading questions strongly suggest one } \\
\text { correct or acceptable answer in the content } \\
\text { of the question (i.e., the wording is not } \\
\text { neutral). }\end{array}$ & $\begin{array}{l}\text { "You were home alone weren't } \\
\text { you?" }\end{array}$ \\
\hline 7. Personal & $\begin{array}{l}\text { Personal questions do not directly relate to } \\
\text { the case and are asked for a different purpose } \\
\text { other than that of information elicitation. }\end{array}$ & "Do you want a cup of tea?" \\
\hline 8. Multiple & $\begin{array}{l}\text { Multiple questions pose more than one } \\
\text { question at a time, simultaneously posing } \\
\text { different sub-questions and limiting the } \\
\text { chance of answering each question. }\end{array}$ & $\begin{array}{l}\text { "Did you see him? Was he } \\
\text { standing or sitting? Was he } \\
\text { carrying an umbrella?" }\end{array}$ \\
\hline 9. Repeated & $\begin{array}{l}\text { Repeated questions are those questions posed } \\
\text { more than once during an interview. }\end{array}$ & \\
\hline
\end{tabular}

Note. Definitions and examples are derived from the content dictionaries of question type by Wright and Alison (2004) and Snook and Keating (2011).

running, everything you say is being recorded"); comments conveying personal information; and leading statements in which the interviewer expressed an opinion or fact, usually before asking a question (e.g., "Your husband also saw something from them. Has he told you about it?"), in which case the statement was coded as Leading and the question as a Closed yes/no. 


\section{Inter-rater Reliability}

The first author read all transcripts to determine the coding procedure and checked the first coder's adherence to it. The analyses were conducted based on the coding performed by the main coder. All the interviews were analysed by the main coder, and a random subset of four interviews ( $21 \%$ of the sample) was independently analysed by a second coder. Both coders received a two-hour training session in which the coding scheme was explained with practical examples. The main coder performed one coding practice exercise using the transcript excluded from the analysis and received feedback from the first author before beginning to code all the interviews. The second coder received a sampled coded interview different from the four she coded. Queries and disagreements were resolved by a third coder (i.e., the first author) prior to assessing reliability.

To establish inter-rater agreement, a two-way mixed-effects model measuring consistency was calculated for each of the 14 coding categories (McGraw \& Wong, 1996). We identified two intra-class correlations coefficients (ICCs) that did not indicate moderate to excellent agreement (> .75), which were subsequently eliminated. We further eliminated three categories of statements due to unacceptable variance, as indicated by the confidence intervals (Koo \& Li, 2016). The excluded categories of statements were: Case information, Information from the witness, and Personal information. For the remaining variables, the levels of inter-rater agreement were: Open prompts, ICC $=1.00,95 \% \mathrm{Cl}[1.00$, 1.00]; Open-ended, ICC $=.96,95 \% \mathrm{Cl}[.30,1.00]$; Direct, ICC $=.99,95 \% \mathrm{Cl}[.77, .99] ;$ Closed yes/no, ICC = .99, 95\% Cl [.88, 1.00]; Closed option-posing, ICC = .99, 95\% Cl $[.79,1.00]$; Leading, ICC =.99, 95\% Cl [.87, 1.00]; Personal, ICC = .98, 95\% Cl [.76, 1.00]; Multiple, ICC = $1.00,95 \% \mathrm{Cl}[.92,1.00] ;$ Repeated, ICC $=.96,95 \% \mathrm{Cl}[.31,1.00] ;$ Instructions, ICC $=.98,95 \%$ $\mathrm{Cl}[.70,1.00] ;$ and Leading statements, $I C C=1.00,95 \% \mathrm{Cl}[1.00,1.00]$.

\section{Results}

\section{Interruptions}

The interruptions noted in the transcripts were tallied. On average, interviewers interrupted the interviewee's account slightly more than 50 times $(M=50.48, S D=39.34$, range 12-142) in each interview. Considering the known average duration of the interviews, 
an interruption occurred 0.60 times a minute (i.e., one interruption every less than two minutes).

\section{Interviewer-Interviewee Talking Ratio}

The interviewer and interviewee talking time corresponds to the recorded number of words spoken by each of them in the interviews. The amount of words used by interviewers and interviewees, on average, was evenly distributed between the interlocutors spoke half of the time ( $51.50 \%$ for interviewers and $48.50 \%$ for interviewees of the time, respectively).

\section{Analysis by Question Type}

The mean number of questions asked in each interview was 158.71 questions ( $M=$ 126.6o, $S D=126.60$, range $36-613)$. This means that, on average, slightly fewer than two (1.89 specifically) questions were asked per minute (i.e., about one question every half minute). Across the 21 interviews, 3333 questions were asked to elicit witness information (see Table 2 for descriptive statistics and Table 3 for a country comparison). Almost half of the questions asked were Closed yes/no questions (48.50\%), followed by more than a third of the sample that were Direct questions (35.58\%) and a small minority that were open questions: Open prompts (0.50\%) and Open-ended questions (6.30\%). Closed option-posing questions (5\%) and Leading questions (4.14\%) were also asked infrequently. Some (5.82\%) of these questions were asked in groups of more than one at a time (i.e., multiple questions), and very few (0.93\%) were asked more than once (i.e., repeated questions). Interviewers also posed, on average, almost seven personal questions in each interview $(M=6.95, S D=$ 8.14 , range $0-31)$.

\section{Analysis of Interviewer's Statements}

On average, in each interview, the interviewer gave 38 instructions to the witness ( $M$ $=38.62, S D=25.42$, range 8-111), and uttered seven leading statements $(M=7.43, S D=$ 8.10 , range $1-38)$. 
Chapter 2

Table 2

Descriptive Statistics on the Use of Question Types

\begin{tabular}{lcccc}
\hline Question Type & $n$ & $\%$ & $M$ & $S D$ \\
\hline Open prompts & 15 & 0.50 & 0.71 & 0.78 \\
Open-ended & 210 & 6.30 & 4.38 & 7.18 \\
Direct & 1186 & 35.60 & 56.48 & 52.02 \\
Closed yes/no & 1618 & 48.50 & 77.05 & 66.21 \\
Closed option-posing & 166 & 5.00 & 7.90 & 5.96 \\
Leading & 138 & 4.10 & 6.57 & 6.03 \\
\hline Total & 3333 & $100 \%$ & & \\
\hline
\end{tabular}

Note. Percent values represent the proportions of the types of question used in all interviews whereas means and standard deviations indicate the average use. 


\section{Table 3}

Review of Interviewing Practice in Police Interviews with Adult Witnesses

\begin{tabular}{|c|c|c|c|c|c|c|c|}
\hline \multirow[b]{2}{*}{ Article } & \multirow[b]{2}{*}{ Country } & \multirow[b]{2}{*}{$N$} & \multirow[b]{2}{*}{ Interruptions, $M$} & \multirow[b]{2}{*}{$\begin{array}{l}\text { Interviewer } \\
\text { talking \% }\end{array}$} & \multicolumn{3}{|c|}{ Type of Questions } \\
\hline & & & & & Open-ended, \% & Specific, \% & Leading, \% \\
\hline Fisher et al., 1987 & United States & 11 & 11 & - & 10.00 & 90.00 & - \\
\hline Schreiber Compo et al., 2012 & United States & 26 & 5.67 & - & 10.81 & 89.16 & - \\
\hline Wright \& Alison, 2004 & Canada & 15 & 9.10 & 32.62 & 4.91 & $73 \cdot 37$ & 4.91 \\
\hline Snook \& Keating, 2011 & Canada & 90 & 4.10 & 36.00 & 5.80 & 66.50 & 1.50 \\
\hline Mclean, 1995* & England and Wales & 16 & - & - & 34.20 & 18.90 & 46.90 \\
\hline Clarke \& Milne, 2001* & England and Wales & 65 & - & - & 36.00 & 42.00 & 20.00 \\
\hline Current research* & the Netherlands & 21 & 50.48 & 51.50 & 6.80 & 89.10 & 4.10 \\
\hline
\end{tabular}

Note. This table is a revised version of Table 1 from Launay and Py (2015). This adapted version only includes archival studies of the investigative interviewing of adult witnesses from the original, and excludes publications that report pre-test data from training evaluations. New relevant studies are included and noted with an asterisk.

a The proportions of questions do not sum to 100\%, as several types of questions were identified in each article. Following the original coding by Launay and Py (2015):

Open-ended questions require an elaborate answer; Specific questions include closed questions that require a direct answer, yes/no answer or forced answer; and Leading questions focus the answer in one direction.

${ }^{\mathrm{b}}$ The percentage of the interviewer talking time is reported. This new variable was not included in Launay and Py's (2015) Table 1. The talking ratio suggested by Shepherd and Griffiths (2013) is 30\% interviewer - 70\% interviewee. Excessive talking by the interviewer is noted in other articles but not measured or reported (Clarke \& Milne, 2001; Fisher et al., 1987; Mclean, 1995).

'Mclean's (1995) category of Productive questions refers to open, probing, and closed identification questions. Although this category is not exactly equivalent to the reported open-ended question category in this table, the data were not disaggregated to report only the open-ended questions rate. Therefore, when interpreting this country comparison, it should be taken into account that probing and closed identification questions are inflating the Open-ended rate and underestimating the true rate for Specific questions. The Specific and Risky question types reported by Mclean (1995) correspond to the Specific and Leading types, respectively, in the table. 


\section{Discussion}

This is the first publicly available analysis of archival data on how witness interviews are conducted in real-life murder investigations by the police in the Netherlands. Our first key finding was that interviewers did not conduct effective witness interviewing (e.g., Fisher \& Geiselman, 1992; Fisher et al., 2011). The interviewers asked few open questions; they mainly gathered information using closed and direct questions, and to a lesser extent, relied on option-posing and leading questions. These findings are in line with all previous archival studies of police witness interviews in the United States (Fisher et al., 1987; Schreiber Compo et al., 2012), England and Wales (Clarke \& Milne, 2001; Mclean, 1995); and Canada (Snook \& Keating, 2011; Wright \& Alison, 2004) (see Table 3 for a country comparison overview).

Besides the overuse of ineffective types of questions (in relation to the elicitation of accurate information; Sharman \& Powell, 2012), we also found that interviewers interrupted the witness very frequently, asked questions often, and spoke slightly more than half the time during the interviews. In comparison with the Canadian sample, the Dutch performed worse at not interrupting the witness and failing to maintain the 30-70 talking ratio (cf. Snook \& Keating, 2011; Wright \& Alison, 2004). However, these practices were also noted as part of problematic interviewing performance across samples, albeit in smaller proportions (Clarke \& Milne, 2001; Fisher et al., 1987; Mclean, 1995). In combination, these interviewing practices (e.g., interrupting, over-talking, and poor questioning) restrict the opportunity for the interviewee to provide an elaborate and free narrative demonstrating and exemplify obstructive and controlling interviewing style (Clarke \& Milne, 2001; Fisher et al., 1987; Griffiths et al., 2011), in turn obstructing collaboration to achieve information goals (Shepherd \& Griffiths, 2013). This pattern of interviewing draws a closer parallel to an accusatorial interviewing approach, which when applied to witness interviews, denotes a confirmatory nature rather than information-gathering aims. The excessive influence of the interviewer impedes the witness's reconstruction of the events, instead lending itself to making it compatible with the police version (Mclean, 1995; Wright \& Alison, 2004), as unsolicited information cannot be freely generated by the witness (Snook \& Keating, 2011). 
The stakes are high in murder case investigations, and a systematic failure to obtain leas much information as is potentially available from the witness is unacceptable.

Distilling the interview process to nothing more than the act of taking a statement using closed and direct questions to confirm facts entails two more problems that further contribute to poor information elicitation. The pattern of quick questions and quick answers fails to effectively encourage active witness participation (Clarke \& Milne, 2001; Fisher et al., 1987), thereby obstructing the transfer of control to the witness, who is given the passive role of answering questions generated by the interviewer (Fisher, 1995). Consequently, the interviewer dictates the pace and takes on more cognitive demands. Moreover, this restricted practice of interviewing (i.e., just firing questions) also leaves little room to build meaningful rapport or facilitate recall using memory-enhancing techniques (Fisher \& Geiselman, 1992), thereby also decreasing the accuracy of witness statements (Collins et al., 2002). Considering that rapport is necessary to generate trust and cooperation, in turn increasing information elicitation (Gabbert et al., 2020), the preferred types of question asked by this Dutch sample of interviewers reduce both the quantity and quality of the information elicited (Fisher et al., 2011; Launay \& Py, 2015).

\section{A Limited Cross-country Comparison: A Problem of Question Type? Open Questions}

Although there is scientific consensus advocating the use of open questions in order to maximise information disclosure and accuracy in witness statements (e.g., Fisher et al., 2011), we found that the prevalence of open prompts and open-ended questions was low $(6.80 \%)$. In the country comparison, that percentage was more similar to the proportion of open questions in the samples from the United States and Canada, but markedly below the percentages in the British ${ }^{4}$ samples, $36 \%$ and $34.20 \%$ according to Clarke \& Milne (2001) and Mclean (1995), respectively. The significant difference in the use of open prompts between the Dutch and British samples is likely due to an overestimation of the percentage of open-ended questions in the latter sample, resulting from the existing competing ways to and Wales.

${ }^{4}$ Hereafter, we refer to the 'British' sample with reference to the sampled interviews from England 
code types of questions (Oxburgh et al., 2010). Like Snook and Keating (2011) and Wright and Alison (2004), we included the category of direct questions; this was different from Clarke and Milne (2001), who counted only open versus closed questions. Schreiber Compo et al., (2012) also distinguished closed questions that elicit short answers from the open question category (and from the closed yes/no category). Therefore, some of the questions coded as direct questions in our study could have been considered open-ended questions in Clarke and Milne's (2001) study. This discrepancy highlights that the way in which questions are analysed creates distinctions in research that are relevant to interviewing training and practice (Oxburgh et al., 2010). In addition, the proportions of question types and their sequential use better reveals their appropriateness for the investigative objectives (see Griffiths, 2008; Griffiths \& Milne, 2006; Mclean, 1995).

Direct and closed questions are necessary to clarify and probe a witness account. However, it is better to ask such questions only after exhausting an uninterrupted free recall using open prompts and open-ended questions (Boon et al., 2016; Fisher, 1995; Memon et al., 1997; Wright \& Alison, 2004). The neglect of free narrative invitations reduces the amount of information witnesses provide (Boon et al., 2016; Fisher et al., 1989; Fisher et al., 2011; Memon et al., 1997). Even given the recommended sequence, caution is warranted due to the drop in accuracy of the information newly elicited by follow-up questions in relation to initial recall (Kontogianni et al., 2020), therefore interviewers should seek external corroboration.

\section{Leading Questions and Statements}

Notably, we observed that interviewers asked very few leading questions, although suggestion from the interviewer was instead seldom introduced in statements. Nonetheless, the country comparison with England and Wales is drastic: $4.10 \%$ leading questions in the current Dutch sample versus $20 \%$ or $46.90 \%$ in England and Wales as reported by Clarke \& Milne (2001) and Mclean (1995), respectively. However, the low prevalence of the use of leading questions in the Netherlands is similar to that reported in one of the Canadian studies (Wright \& Alison, 2004) and higher than that reported in the other one (Snook \& Keating, 2011). Schreiber Compo et al. (2012) treated the average of leading questions as a negative interviewing technique rather than as a type of question, 
reporting that they occurred on average six times per interview $(M=5.87, S D=4.68)$. In our Dutch sample, the average number of leading questions was seven per interview $(M=6.57$, $S D=6.03$ ). In addition, Dutch interviewers almost never repeated an (unanswered) question to the interviewee (0.93\% of questions), unlike their counterparts in other countries (e.g., $3.2 \%$ Snook \& Keating, 2011), who might repeatedly ask questions until information consistent with their suspicions is conveyed, thereby reducing accuracy (Clarke \& Milne, 2001). Therefore, the minimal use of leading and repeated questions observed in the analysed Dutch interviews contributes to reducing, or rather does not further increase, the risk of false testimony resulting from acquiescence to the interviewer's version of the events, rather than memorial representations from the witness (Wright \& Alison, 2004). Remarkably, both British analyses caution that witnesses are at a higher risk of being asked many leading questions than are suspects (Clarke \& Milne, 2001; Mclean, 1995). Considering the high-stakes consequences associated with legal decision making based on witness evidence in murder investigations in the Netherlands (Van Koppen \& Penrod, 2003), the limited use of leading questions is a commendable interviewing practice in the Dutch sample. Nonetheless, there is room for improvement and further research should scrutinise the use of statements and instructions by Dutch interviewers.

Some of the instructions delivered to the witnesses were in accordance with evidence-based interviewing techniques (e.g., do not guess: "You do not have to have seen it. If you do not know, just say so", transferring control: "I go off from what you say because I was not there"), and were used to correctly inform interviewees of the procedural aspects of the interview (e.g., stating the purpose of the interview, informing interviewees that they were being recorded). However, in some cases, these instructions contradicted evidencebased guidelines (e.g., asking for approximations rather than memories: "If you had to guess...", interrupting a free recall: "Hold on, because I'm going to ask specific questions"). In addition, some statements were posed in an accusatorial tone (e.g., "Do not think - you have to know it", and "You're a pretty bad liar"). The interviewers also introduced suggestion via statements (e.g., "You must have gotten it from somewhere", "Just say that it was on <day>", "Just before <certain circumstance>, let's say"). As with leading questions, with accusations in the context of a police interviewing room, the risk is suggestibility and the incorporation of the leading material into the witness's account (Loftus, 2005). 
Based on our preliminary findings, the observed pattern of the sampled Dutch interviews seems to be more akin to the pattern of interviewing followed by the police in North America rather than in Europe. Traditionally, the interviewing models in these regions fall into the dichotomous categories of accusatorial and information gathering respectively (Miller et al., 2018). Considering that an information-gathering approach to interviewing witnesses is informed by scientific research and its effectiveness is supported by evidence (Fisher, 2010; Fisher et al., 2011; Hope \& Gabbert, 2019; Vrij et al., 2014), we adhere to the call for the adoption of an investigative interviewing approach as the standard in Dutch investigative practices (Boon et al., 2016).

\section{Interviewing or Statement-Taking?}

There are two more alternative explanations for why interviewers in this sample may have over-relied on closed and direct questions to obtain the witness accounts. In all the interview transcripts, it was noted that the conversation was "typed directly". The large majority $(70 \%)$ of the interviews was conducted by only one interviewer. In practice, this means that the interviewer had the simultaneous tasks of listening to the witness, transcribing the witness account into a statement format, and generating questions. A likely first consequence of this interviewing approach is an increase in the use of closed questions given that to draft the statement, even implicitly, the interviewer needs to request and receive confirmation from the witness. Inevitably, and exacerbated by poor training, there is an imbalance between listening, speaking and writing that negatively affects the fidelity and accuracy of the statement content as a true record of what the witness reported (Heaton-Armstrong \& Wolchever, 1992; Milne et al., 2011; Rock, 2001). The second potential consequence of this interviewing practice is that the interviewer's increased cognitive load limits the capacity to also understand and follow the witness account, whilst remembering case information to probe the account and, at the same time, self-monitoring so as to not contaminate the statement, all of which ultimately limits adherence to bestpractice interviewing behaviour (Hanway et al., in press; Kleider-Offutt et al., 2016). The resulting witness statements should, therefore, be evaluated in light of these factors that affect their quality as evidence (Malsch et al., 2018; Mclean, 1995). 


\section{Is Training an Issue for Witness Interviewing Practice in the Netherlands?}

Another factor that may have contributed to the reduced number of open questions and large number of closed and direct questions asked during the interviews is a scientificknowledge gap among the Dutch interviewers. Odinot et al. (2015) found that even a group of interviewing specialists was insufficiently knowledgeable about episodic memory and interviewing. In particular, about half of their sample regarded the human memory as operating like a video-recorder. That metaphor is obsolete, as an individual's memory is not a replica of what happened, and in the process of remembering an event in a police interview, the witness reconstructs their memory for the crime (Bartlett, 1932; Loftus \& Pickrell, 1995). It is fundamental that interviewers fully understand that, in the interviewing process, the human memory is susceptible to error and manipulation (e.g., Loftus, 2005), to understand their role as interviewers and their participation in the elicitation of memory statements (Blank, 2009). In addition, $34 \%$ of the police interviewers failed to recognise that the formulation of questions determines reporting and the resulting memory statements. The sampled interviewing specialists considered that answers to specific questions (i.e., direct questions) are more often correct than answers to open-ended questions (Odinot et al., 2015), which is against the scientific evidence. Information provided to open questions is more accurate as it is elicited from the witness's memory rather than as a recognition test of the interviewer's knowledge (Fisher, 1995; Memon et al., 1997; Sharman \& Powell, 2012). Both of these topics are correctly covered in the Dutch interviewing manual (Odinot et al., 2015). Therefore, the effectiveness of transferrable skills in the current interviewing training in the Netherlands could benefit from evaluation.

The overuse of closed and direct questions in the current sample of witness interviews could also reflect training needs in the Netherlands, as previous research has indicated that poor adherence to evidence-based interviewing is associated with a perceived lack of or insufficient training according to police officers self-reports (Dando et al., 2009; Fisher \& Schreiber, 2007; Snook et al., 2012). For the effective incorporation of new techniques or tools, interviewers must be able to understand how and why they work, i.e., learn about memory research (Odinot et al., 2015), and perceive them as useful (Hirn et al., 2015). Due to the difficulty of transferring interviewing skills, training programmes must offer role-playing and practice, as well as refresher trainings, regular supervision, and 
evaluation (MacDonald et al., 2017b; Powell, 2008). It is imperative that every police officer who interviews crime witnesses should receive interviewing skills training. Interviewing should emphasise: gaining, maintaining and recovering cooperation to increase witness willingness to disclose accurate information; using open-ended questions to exhaust witness free recall; using cognitive memory-enhancing techniques; and using direct questions last to probe the account if needed (e.g., Fisher, 2010; Fisher \& Geiselman, 1992; Gabbert et al., 2020).

\section{Limitations and Future Research}

The findings of our study should be considered in light of its limitations. First, our sample size was small, thus the generalisability of our findings may be limited. Moreover, as the interviews were conducted by officers from only one police service in the Netherlands, and notably some years ago. Therefore, they may not reflect the current state of witness interviewing by the Dutch police. However, the models of witness interviewing prescribed in the training manual remains the same 5 . Future research should better represent contemporary witness interviewing practice across the country; research could then allow future comparisons and identify continuing training and research needs. In addition, information regarding the interviewing officers, particularly their interviewing training level could better inform the variables affecting interviewing performance (Smith et al., 2009).

Second, we analysed transcripts of the interviews, and did not have access to the associated audio- or video-recordings. This also limits the drawn conclusions to the material received; and they may not apply to the interviews as actually conducted, as it cannot be guaranteed that there are no differences between the whole interview process and the transcripts received. Ideally, future research could confirm the integrity of transcripts against recordings. Given that the current guidelines from the Dutch Prosecution Services calls for mandatory recording of witness interviews in major crime investigations, future research could examine audio- and video-recordings of witness interviews. The burden to

\footnotetext{
${ }^{5}$ An analysis of interviewing training would be included if information concerning the national interviewing programme were publicly available. Extraordinarily, we found out that, currently, interrogation training [emphasis added] is only available to some of the police officers who advance to detective roles. Part of such training covers witness interviewing (K. Geijsen, personal communication). A mandatory basic interviewing training programme for every police officer is not in place.
} 
scrutinise evidence from interview rooms therefore falls within the police. This endeavour would allow for larger and random samples to be evaluated, for example, by examining all interviews conducted within a specific period of time and randomly choosing from different regional forces. This would undeniably be a demanding undertaking, which could benefit from collaborations with academics and policy makers with the common goal of improving interviewing practice.

Third, in future research, based on the whole interview together with the aid of supporting case information, could assess the effects of interviewer behaviour on interviewee behaviour (e.g., Alison et al., 2013; Hershkowitz et al., 2006), focusing on the effects of interviewing practices on engagement from witnesses and information disclosure. This could be key to begin developing specialised skills to gain cooperation in general, and in particular, to overcome resistance from witnesses who are at least initially uncooperative. In addition, analyses of interviewing practices could benefit from going beyond the analyses of types of questions and statements in order to perform comprehensive evaluations of the standards of interviewing. In particular, in light of our discussion concerning the confirmatory style of interviewing and the associated risk of introducing investigator bias, we suggest combining traditional analysis of overt interviewer behaviour with forensic linguistic analyses to also take into account the influence of the interviewer's covert speech on interviewee behaviour (e.g., Adams-Quackenbush et al., 2019).

\section{Conclusions}

There is ample room for improvement in the practice of interviewing adult witnesses. A predominance of closed and directive questions that only seek to confirm specific information rather than attempting to gather as much information as possible risks reducing the amount, accuracy, and detail of the information elicited. In the field, this interviewing pattern limits new investigative leads, reduces the understanding of complex events such as murder crimes, and ultimately negatively affects advancing and solving criminal investigations along with future legal proceedings. Moreover, a confirmatory approach to criminal investigations more easily lends itself to bias, which can result in wrongful convictions and acquittals. This would undermine the criminal justice system, and public trust in it, besides being detrimental to the management of crime in our societies. In 
particular, regarding the practice of interviewing witnesses in the Netherlands, the current research highlights the need to improve the interviewer's ability to conduct an interview using an approach that promotes cooperation, and to maximise the use of open and nonleading questions to facilitate accurate reporting, and secure the best witness evidence. 


Chapter 3

Lack of Witness Cooperation in Investigative Interviews: An International Survey of Criminal Investigators

An adapted version of this chapter has been submitted for publication as:

De La Fuente Vilar, A., Horselenberg, R., Landström, S., \& van Koppen P. J. (2020). Lack of Witness Cooperation in Investigative Interviews: An International Survey of Criminal Investigators. Manuscript submitted for publication. 



\begin{abstract}
Some witnesses who are able to recall a crime are not willing to cooperate in the investigation. In this international survey, we explored self-reported criminal investigators' interviewing experience with, and perception of, uncooperative witnesses. The police participants $(N=274)$ were from the Netherlands, Sweden, and England and Wales, and conduct witness investigative interviews. Overall, our results showed that police officers endorsed evidence-based interviewing techniques to gain cooperation (e.g., rapport building), but they also endorsed techniques to overcome witness reluctance that have not received empirical support (e.g., making a moral appeal). Our findings also revealed an expectation of witness cooperation and negative perceptions associated with lack of witness cooperation. A rapport-based and information-gathering interviewing style is recommended to motivate reporting before facilitating recall. We call for mandatory recordings to secure the best evidence and a collaborative research agenda to inform guidelines and training that improve the interviewing of uncooperative witnesses.
\end{abstract}




\section{Lack of Witness Cooperation in Investigative Interviews:}

An International Survey of Criminal Investigators

Individuals witnessing a crime are by definition privy to details that may not otherwise be available to the authorities. It is therefore of utmost importance to maximise the quantity and quality of information elicitation in investigative interviews of witnesses (Fisher, 2010). While the onus to obtain accurate and comprehensive accounts from witnesses lies on investigators, they rely heavily on witness cooperation for successful interview outcomes (Roberts, 2010). However, some witnesses are unwilling to get involved in the criminal investigation and may become uncooperative with the police. As such, lack of witness cooperation represents a significant obstacle to securing witness evidence in particular (Spencer \& Stern, 2001), and is detrimental to successful crime management in general (Tyler \& Fagan, 2008).

Official reports in Europe estimate that around half of crime goes unreported because victims and witnesses who decide to not report (Van Dijk et al., 2007). This report is based on data from 38 developed and developing countries covering ten types of crime (e.g., vehicle-related crimes, burglary, attempted burglary, property theft, and contact crimes including robbery, sexual offences, assault and threat). This is strong evidence suggesting that witnesses often do not want to come forward to report crime. Further, witnesses are even less inclined to testify in court (Maynard, 1994; Spencer \& Stern, 2001). Research has shown that, according to police officers, although witnesses frequently provide central leads in investigations, they rarely provide sufficient information (Kebbell \& Milne, 1998). Lack of information disclosure can result from an inability to recall or an unwillingness to report on the part of witnesses (Shepherd, 1993; for a review see Hope \& Gabbert, 2019). These phenomena are associated with either cognitive-impairing factors or lack of motivation correspondingly (Westera \& Powell, 2015). In this study, we focus on how police officers perceive and attempt to effectively elicit information from uncooperative witnesses - that is, witness who are able to recall but are unwilling to report information.

Citizen-police cooperation with the authorities can take many forms. In the context of an investigative interview, cooperation refers to providing information as requested by the interviewer (Fyfe \& Smith, 2007; Roberts, 2010). Cooperative witnesses are thus 
compliant with the interviewer's information requirements (Roberts, 2010). Interviewers expect witnesses to provide full, truthful and relevant information in an efficient manner (Antaki \& Stokoe, 2017). For those reasons, cooperation is considered a determinant of information disclosure (Vrij et al., 2014). However, it is not certain that a witness will cooperate in an interview or that cooperation will continue throughout the legal proceedings (Roberts, 2010; Spencer \& Stern, 2001).

Considering the dynamic nature of interviewing, cooperation in suspect and humanintelligence interrogations has been conceptualised as a continuum rather than a distinct category (Alison et al., 2014; Kelly et al., 2016). Similarly, we argue that witnesses oscillate between cooperativeness, at one end, and uncooperativeness at the other end of the continuum. In this context, and with the goal of maximising information disclosure, interviewers aim at gaining and maintaining cooperativeness throughout the interview using specific interviewing techniques. This means that cooperation is inextricably influenced by the interviewer's behaviour and vice versa (Roberts, 2010). In the current study, we sought to gain an initial understanding of the effects of lack of witness cooperation from the practitioner's perspective. Specifically, we examined police officers' experience of encountering uncooperative witnesses, and their attempts to overcome lack of witness cooperation in practice.

The group of witnesses of our interest comprises 'the witnesses who do not cooperate with the police'. We found that the scholarly literature and practitioners utilise nuanced variations in their definitions of uncooperative, including witnesses who are: unwilling to be involved in a criminal investigation, reluctant to talk, resistant to engage in the criminal justice system, hostile towards the police, and intimidated (Confrey, 2017; Maynard, 1994; Spencer \& Stern, 2001; Shepherd \& Griffiths, 2013). For our study, we use uncooperative witnesses as an umbrella term focused on a common aspect from the above terminology and refers to individuals who are unwilling to be involved in criminal investigations and refuse to provide valid information during police interviews, for example, witnesses who are reluctant to talk, resistant to disclosing information, as well as intimidated witnesses or those hostile towards the police. 


\section{Interviewing Cooperative and Uncooperative Witnesses}

The Cognitive Interview $(\mathrm{Cl})$ is a well-established protocol for interviewing cooperative witnesses that promotes the use of communication strategies and four retrieval mnemonic techniques to enhance memory recall (e.g., report everything, reinstate context, report in reverse order, and report from different perspectives; Fisher \& Geiselman, 1992). Specifically to gain cooperation, the interviewer must establish personal rapport with the witness. Researchers and practitioners agree that rapport-building is vital for a successful investigative interview (Abbe \& Brandon, 2013; Vallano et al., 2015), as it increases the quantity and quality of information elicited (Collins et al., 2002; Vallano \& Schreiber Compo, 2011) and generates trust and cooperation (Gabbert et al., 2020; Vallano \& Schreiber Compo, 2015). To facilitate active witness participation, it is also key to transfer control to the witness, to ask primarily open-ended questions, and not to interrupt the account (Fisher \& Geiselman, 1992). However, the $\mathrm{Cl}$ is deemed more suitable for use to interview cooperative witnesses as it requires the witness to engage in mental work and control the flow of communication as it is the witness who holds the critical information (Fisher, 2010). As such, its efficacy and application are deemed to be highly dependent on the level of cooperation from the interviewee (McCauley \& Santee, 2019; Vrij et al., 2017).

Even though witness cooperation is key to gain accurate and relevant information from a witness, the literature on how to gain witness cooperation and how to interview uncooperative witnesses is meagre. There are as of yet no empirically validated specialised protocol for interviewing uncooperative witnesses in a policing context and the two models that do prescribe guidelines for interviewing this subset of interviewees have serious limitations. First, the Conversation Management (CM, Shepherd \& Griffiths, 2013) approach is applicable to suspects and witnesses and equips interviewers with social and communication skills to manage the conversation. CM focuses on the initial facilitation of information resulting from the positive influence of the interviewer's interpersonal skills and their ability to negotiate the interviewee's engagement (Shepherd \& Griffiths, 2013). However, $\mathrm{CM}$ has not been empirically validated and, in comparison with the $\mathrm{Cl}$, has been found in field trials to be inferior in the elicitation of information (Clifford \& George, 1996). 
Second, in the Reid technique manual, interviewers are advised to use accusations and confrontations in order to break resistance in witnesses, in combination with offers of empathy and sympathy as well as moral justifications to excuse witness reluctance (Inbau et al., 2013). However, such accusatorial interviewing techniques may be counterproductive, as research has shown that they increase resistance and degrade memory recall (Vrij et al., 2017). Laboratory experiments have also demonstrated that the use of accusatorial techniques to interview witnesses increases the likelihood of false allegations (Kaasa et al., 2013; Loney \& Cutler, 2016).

Data on overturned wrongful convictions (The National Registry of Exonerations, 2020) indicates that false testimony/perjury and police and prosecutorial misconduct are the major factors contributing to miscarriages of justice. Hence, using coercive techniques with uncooperative witnesses may make the witness even more reluctant and research has shown that false testimony produced under threats from the police or prosecutors is later recanted in these exoneration cases (Gross \& Gross, 2013). There is an elevated risk of uncooperative witnesses being interviewed with coercive techniques (Davis \& Leo, 2016), which are associated with the risk of eliciting inaccurate witness testimony (GuerraThompson, 2012; Moore et al., 2014).

\section{The Current Study}

The aims of the current study were: a) to examine criminal investigators' perceptions and experience of interviewing uncooperative witness; b) to assess which interviewing techniques they perceive to be effective at gaining cooperation; and c) to examine how they self-reportedly overcome lack of witness cooperation in their practice.

A previous survey has shown that front-line police officers in England frequently encounter reluctant witnesses (5-49\% prevalence), according to their own reports. These surveyed officers reported using a rapport-based approach to interviewing these witnesses, exploring the explanations for witness reluctance and minimising risk for those unwilling to become involved in the investigative process (Wheeler et al., 2017).

To facilitate an international dialogue on shared lessons rather than to conduct an evaluation of a specific country, we distributed the survey internationally to capture different police interviewing traditions. Group comparisons however would not have been 
adequately conducted without representative samples from each country. Therefore, based on the data collected, we limited the scope of our research to four European countries: the Netherlands, Sweden, England and Wales. The interviewing models in each of these countries is outlined below.

In the Netherlands, three protocols for interviewing witnesses are described in a national interrogation manual taught at the Netherlands Police Academy (i.e., Handleiding verhoor; Van Amelsvoort et al., 2015). The general model of witness interviewing, a guided remembrance model, and a modified version of the cognitive interview. According to this manual, the application of the first two models requires witness cooperation. Therefore, uncooperative witnesses should be interviewed using their $\mathrm{Cl}$ version. The first step of the Dutch $\mathrm{Cl}$ refers to the precondition of eliminating emotional barriers before starting the interview (Van Amelsvoort et al., 2015); however, it does not provide explicit recommendations for achieving this precondition. In Sweden, there are as of yet no official national guidelines on investigative interviewing (Granhag et al., 2013; Jakobsen et al., 2016). According to the official guidance of England and Wales, investigators should adhere to the principles of investigative interviewing and conduct witness interviews following the PEACE model. PEACE is an acronym for the model's five stages: Preparation and Planning; Engage and explain; Account, clarification and challenge; Closure and Evaluation; Central Planning and Training Unit, 1992). The recommendation is to interview cooperative witnesses using the $\mathrm{Cl}$ and uncooperative witnesses using the $\mathrm{CM}$. In addition, the investigators are encouraged to build rapport and address concerns leading to reluctance prior to investigative interviews of reluctant witnesses, and not to exert pressure to convince witnesses to talk to the police. Instead, the function of the investigator is to focus on the provision of information so that the potential witness can make an informed choice to give evidence (Ministry of Justice, 2011).

\section{Method}

\section{Participants}

At first, the authors used their own professional contacts to recruit police officers who conduct adult witness interviews. When an initial police contact was identified in each country, we used a snowball sampling procedure, in which the police officers formally and 
informally distributed the online survey link to their colleagues. We also posted public calls seeking police research participants in professional online social platforms. A total of 417 officers showed interest in the survey (i.e., opened the link) and 311 gave consent for their voluntary participation. Twenty-three respondents were excluded as they did not fulfil our inclusion criterion of conducting investigative interviews with adult witnesses. Based on the small samples collected, we excluded 14 participants who were from other nations than those we sought to explore (Norway, $n=7$; the United States, $n=3$; Canada, $n=3$; and Australia, $n=1$ ). Please note that attrition throughout the survey and voluntarily unanswered questions led to fewer responses for some items.

The vast majority (84.3\%) of participants comprised officers working in diverse criminal investigation units and their experience varied greatly from nine months to 48 years $(M=17.91, S D=11.14)$. Their experience of interviewing witnesses also varied. According to their own estimates, $14.7 \%$ had conducted less than one interview, $46.8 \%$ one to two, $17 \%$ three, $14.7 \%$ four to five, and $5.3 \%$ six or more witness interviews on average per week. Most respondents (72.6\%) had received some investigative interviewing training; however, there was a significant difference in training experience across countries: in England and Wales 98.44\%, in the Netherlands 78.20\%, and in Sweden 61.54\% had received training, $\chi^{2}(2)=24.90, p<.001$, Cramer's $V=0.32$. Furthermore, only a small portion (7.4\%) of all respondents $(N=249)$ had received specialised training in interviewing uncooperative witnesses. The type of training offered in each country and received by the respondents could not be assessed due to the variance and degree of detail offered in the responses to the open question posed in the survey. Furthermore, the date of last training was not requested.

\section{Survey Development}

In our review of the literature, we noticed a lack of scrutiny from academics and practitioners of the topic, and did not find sufficient information to meaningfully construct items for our survey. Therefore, we first conducted nine semi-structured interviews with a convenience sample of experts in the subject matter (i.e., police investigators, and researchers and trainers from the Netherlands and England) to explore their perceptions and experience of interviewing uncooperative witnesses. The verbatim interview transcripts 
were analysed following a thematic analysis methodology (Braun \& Clarke, 2016). We identified three overarching themes: the framework of the interview, the influence of the interviewee, and the influence of the interviewer. We used the qualitative analysis of the subthemes for the development of the survey items in order to complement the analysis with a quantitative examination, to provide a more comprehensive review of the current police practice of interviewing uncooperative witnesses. The survey was revised and pilot tested by police officers in each country of participant recruitment. Based on their feedback, we adapted and translated the survey in content and meaning from English to Dutch and Swedish (see Appendices 1, 2, and 3 respectively). This study received ethical approval from the university's standing ethical committee.

\section{Materials and Procedure}

Police officers received an invitation with the survey link and a short explanation of the research (see Appendices 1, 2, and 3). Before taking part, the officers received comprehensive, detailed information about the survey and provided informed consent. First, they completed a section on their demographic information. Participants received a reminder of the definition of 'uncooperative witness', as described above, before the start of the next section. Then, they reported on their own experience of interviewing cooperative and uncooperative witnesses using Likert scales ranging from $1=$ never to $5=$ always. Next, the participating officers reported their level of agreement with 20 statements using Likert scales ranging from $1=$ strongly disagree to $5=$ strongly agree. The first four items examined the interviewer's perception of lack of witness cooperation in investigative interviews (see the statements listed in Table 1). The rest of the statements proposed techniques for interviewing an uncooperative witness (see the statements listed in Table 2). Lastly, the participating officers provided open responses reporting on the interviewing techniques they would use to effectively elicit information from an uncooperative witness. 


\section{Results}

\section{Current Interviewing of Uncooperative Witnesses}

Respondents frequently encounter uncooperative witnesses $(N=241 ; M=2.34, S D=$ 0.65). Descriptive statistics indicated that $67.6 \%$ of the officers encounter them sometimes and $22.4 \%$ in about half their cases. Despite the high prevalence of uncooperative witnesses in practice, most of the interviews (56\%) involving uncooperative witnesses are reportedly conducted by officers without specialised training in interviewing such witnesses $(N=241 ; M$ $=1.59, S D=0.84)$.

In addition, only some of the witness interviews are recorded $(N=264 ; M=2.77, S D=$ 1.29) with the frequency varying per country, $\chi^{2}(2)=37.09, p<.001$, Cramer's $V=0.27$. On average, witness interviews were reportedly most often recorded in the Netherlands $(M=$ 3.09, $S D=1.30)$, versus England and Wales $(M=2.72, S D=1.23)$ and versus Sweden $(M=$ 1.98, $S D=0.96)$. It emerged from spontaneous responses that the decision making on whether to record the interviews is arbitrary and guided by compliance with guidelines or case characteristics.

\section{Reasons for Lack of Witness Cooperation}

In Figure 1, we report the estimated frequencies of the reasons why witnesses are uncooperative, according to the respondents. In their opinion $(N=231)$, the most common reason why witnesses are uncooperative is fear of retaliation from the suspect/perpetrator, and in about half of the time, another reason is that the witness who knows the suspect. In the same vein, lack of witness cooperation is sometimes motivated by a relationship between the witness and the suspect. Other reasons why witnesses are sometimes uncooperative are, according to the respondents, the witness' motivation to avoid selfincrimination and the witness' own criminal history. 
Figure 1

Means of Frequency Ratings of Reasons for Lack of Witness Cooperation

Witness has to mantain professional secrecy Witness has a history of mental illness or a disabililty

Witness is from a different culture Witness does not want to spend time in legal proceedings

Witness has been a victim in the past Witness distrusts the police Witness is afraid of retaliation from the suspect/perpetrator

Witness has a criminal history Witness is avoiding self-incrimination Witness knows the suspect Witness is a relative of the suspect

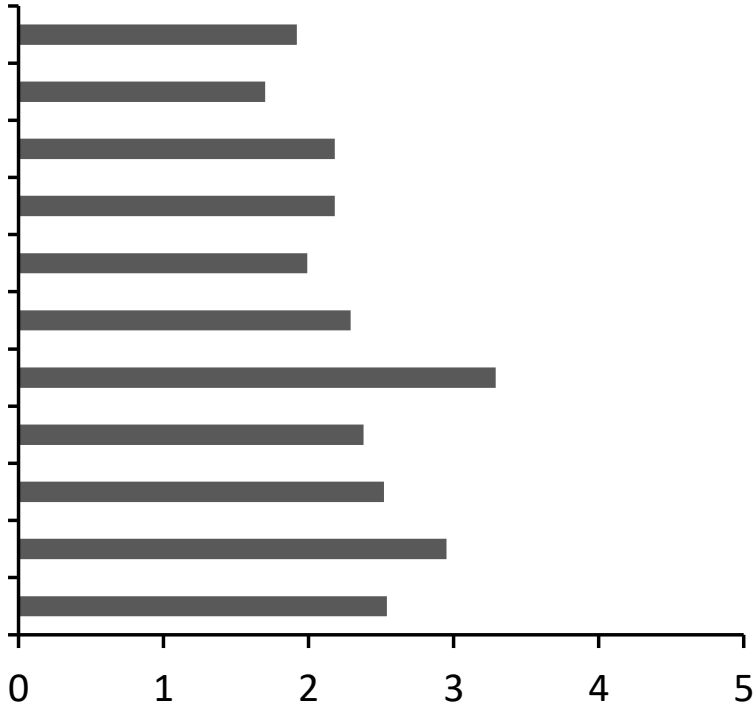

Note. Respondents rated the frequencies of the listed predefined reasons.

\section{Communication Strategies to Avoid Cooperation}

Respondents $(N=224)$ reported that when witnesses are uncooperative they sometimes provide incomplete information, say as little as possible, and balance disclosure of too little against too much information. In Figure 2, we report the estimated frequencies with which different communication strategies are used by uncooperative witnesses, according to the respondents, to report or withhold information in interviews. 
Figure 2

Means of Frequency Ratings of Communication Strategies Used by Uncooperative Witnesses

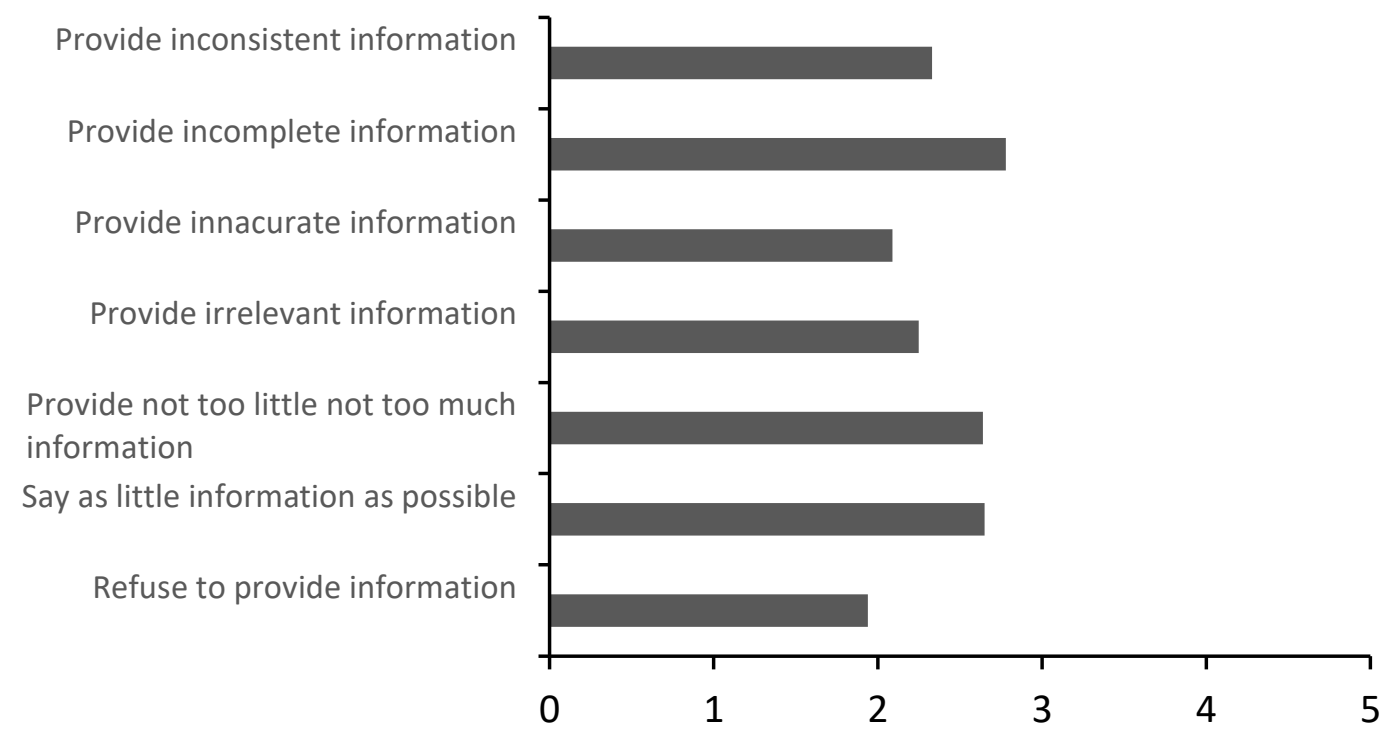

Note. Respondents rated the frequencies of the listed predefined communication strategies.

\section{Perceptions of Lack of Witness Cooperation}

See Table 1 for descriptive statistics on the four items regarding police perceptions of lack of witness cooperation. Most the respondents (53\%) (strongly) believed that individuals can refuse to talk to the police if they witness a crime $(M=2.63, S D=1.40)$. However, about a third of the respondents (32\%) considered cooperation an obligation. 
Table 1

Means and Standard Deviations of Agreement Ratings to Perceptions of Lack of Witness Cooperation with Country Comparisons and Inferential Statistics

\begin{tabular}{|c|c|c|c|c|c|c|c|c|c|c|c|c|}
\hline & \multicolumn{3}{|c|}{ Total } & \multicolumn{2}{|c|}{$\begin{array}{l}\text { the } \\
\text { Netherlands }\end{array}$} & \multicolumn{2}{|c|}{$\begin{array}{l}\text { England and } \\
\text { Wales }\end{array}$} & \multicolumn{2}{|l|}{ Sweden } & \multirow[t]{2}{*}{$\begin{array}{l}F \\
(2,208)\end{array}$} & \multirow[t]{2}{*}{$p$} & \multirow[t]{2}{*}{$\omega^{2}$} \\
\hline & $M$ & $S D$ & Mdn & $M$ & $S D$ & $M$ & $S D$ & $M$ & $S D$ & & & \\
\hline $\begin{array}{l}\text { Civilians cannot refuse to talk to the police } \\
\text { if they witness a crime. }\end{array}$ & 2.63 & 1.40 & 2 & $2.73 \mathrm{a}$ & 1.25 & $1.73 \mathrm{~b}$ & 1.11 & $3.46 c$ & 1.54 & 21.94 & $<.001 *$ & .166 \\
\hline $\begin{array}{l}\text { An uncooperative witness is hiding } \\
\text { something. }\end{array}$ & 2.62 & 0.94 & 3 & $2.51 \mathrm{a}$ & 0.89 & $2.50 \mathrm{a}$ & 0.78 & $3.07 b$ & 1.13 & 4.54 & $.013^{*}$ & .048 \\
\hline $\begin{array}{l}\text { If a witness continuously refuses to } \\
\text { cooperate, it feels like talking to a suspect. }\end{array}$ & 3.07 & 1.14 & 3 & 3.06 & 1.13 & 2.96 & 1.08 & 3.25 & 1.22 & 0.72 & .489 & .000 \\
\hline $\begin{array}{l}\text { Lack of cooperation prevents the police } \\
\text { from eliciting information that helps the } \\
\text { investigation. }\end{array}$ & 4.06 & 0.87 & 4 & 3.93 a & 0.91 & $4.27 b$ & 0.63 & $4.17 \mathrm{a}, \mathrm{b}$ & 0.97 & 3.95 & $.023^{*}$ & .020 \\
\hline
\end{tabular}

Note. Means sharing a common subscript are not statistically different at $p<.05$ according to post hoc comparisons. *Asterisks indicate significance at alpha level $p<.05$. 
There was a significant difference across countries, $F(2,208)=21.94, p<.001, \omega^{2}$ $=.166$. Follow-up post hoc comparisons with Bonferroni corrections showed that the expectation of witness cooperation was significantly lower for respondents in England and Wales than in the Netherlands, $t(208)=4.70, p<.001, d=-0.83,95 \% \mathrm{Cl}[0.49,1.16]$, or in Sweden, $t(208)=-6.49, p<.001, d=-1.32,95 \% \mathrm{Cl}[0.87,1.77]$. The expectation of witness cooperation was also lower for interviewers in the Netherlands than in Sweden, $t(208)=-3.1, p=0.005, d=-0.55,95 \% \mathrm{Cl}[0.19,0.91]$

Almost half of the respondents (47\%) (strongly) disagreed with the proposition that uncooperative witnesses are hiding something $(M=2.62, S D=0.94)$. Nonetheless, $45 \%$ of respondents reported that the experience of interviewing an uncooperative witness resembled a suspect interrogation $(M=3.07, S D=1.14)$. Overall, their opinion in these two statements was polarised and the average respondent neither agreed nor disagreed $(M d n=3)$.

Most respondents (strongly) agreed (84\%) that lack of witness cooperation is detrimental to criminal investigations, as it hinders effective information elicitation $(M=$ $4.06, S D=0.87)$. There was a small but significant difference across countries, Welch $F(2,208)=3.95, p=.023, \omega^{2}=.020$. Follow-up post hoc comparisons with Tukey corrections showed that respondents in England and Wales indicated greater agreement with the negative consequences of lack of witness cooperation than did respondents in the Netherlands, $t(208)=2.78, p=.017, d=-0.40,95 \% \mathrm{Cl}[-0.73,-0.07]$.

\section{Interviewing Techniques to Overcome Lack of Witness Cooperation}

For this portion of the survey, the sample was $N=211$. In Table 2, we report the agreement ratings of police officers for statements regarding the application of the listed interviewing techniques for interviewing uncooperative witnesses. For significant country comparisons, we report follow-up post hoc comparisons with Bonferroni corrections. 
Table 2

Means and Standard Deviations of Agreement Ratings for Interviewing Techniques for Uncooperative Witnesses with Country Comparisons and Inferential Statistics

\begin{tabular}{|c|c|c|c|c|c|c|c|c|c|c|c|c|}
\hline & \multicolumn{3}{|c|}{$\begin{array}{l}\text { Total } \\
N=211\end{array}$} & \multicolumn{2}{|c|}{$\begin{array}{l}\text { the } \\
\text { Netherlands }\end{array}$} & \multicolumn{2}{|c|}{$\begin{array}{l}\text { England and } \\
\text { Wales }\end{array}$} & \multicolumn{2}{|c|}{ Sweden } & \multirow[t]{2}{*}{$\begin{array}{l}F \\
(2,208)\end{array}$} & \multirow[t]{2}{*}{$p$} & \multirow[t]{2}{*}{$\omega^{2}$} \\
\hline & $M$ & $S D$ & $M d n$ & $M$ & $S D$ & $M$ & $S D$ & $M$ & $S D$ & & & \\
\hline $\begin{array}{l}\text { It is my job to convince the witness to provide } \\
\text { a statement. }\end{array}$ & 3.28 & 0.99 & 3 & 3.38 & 0.94 & 3.04 & 0.93 & 3.29 & 1.15 & 2.21 & .112 & .011 \\
\hline $\begin{array}{l}\text { It is my role as an interviewer to make sure } \\
\text { that witnesses are stress-free before starting } \\
\text { the interview. }\end{array}$ & 3.98 & 0.71 & 4 & $4.03 \mathrm{a}$ & 0.63 & $3.77 \mathrm{a}$ & 0.88 & $4.10 \mathrm{a}$ & 0.63 & 3.19 & $.043^{*}$ & .020 \\
\hline $\begin{array}{l}\text { You need to invest time in establishing a } \\
\text { relationship with uncooperative witnesses to } \\
\text { gain their trust and cooperation. }\end{array}$ & 4.16 & 0.71 & 4 & 4.10 & 0.74 & 4.15 & 0.64 & 4.32 & 0.69 & 1.41 & .247 & .004 \\
\hline $\begin{array}{l}\text { To overcome witness resistance, it is best to } \\
\text { ask the witness for the reasons for his/her } \\
\text { unwillingness to cooperate. }\end{array}$ & 3.98 & 0.81 & 4 & 4.04 & 0.73 & 4.08 & 0.74 & 3.66 & 1.04 & 2.65 & .076 & .028 \\
\hline $\begin{array}{l}\text { Providing information about the procedure at } \\
\text { the start of the interview increases witness } \\
\text { cooperation. }\end{array}$ & 3.73 & 0.94 & 4 & 3.63 & 0.97 & 3.78 & 0.89 & 3.95 & 0.89 & 1.96 & .143 & .009 \\
\hline $\begin{array}{l}\text { Open questions are not effective when } \\
\text { someone does not want to voluntarily } \\
\text { disclose information in the interview. }\end{array}$ & 2.72 & 1.12 & 3 & $2.53 \mathrm{a}$ & 1.08 & $2.81 \mathrm{a}, \mathrm{b}$ & 1.03 & $3.15 b$ & 1.24 & 5.07 & $.007^{*}$ & .037 \\
\hline $\begin{array}{l}\text { It is a good tactic to confront uncooperative } \\
\text { witnesses with what you already know about } \\
\text { the crime and only seek confirmation. }\end{array}$ & 2.32 & 0.93 & 2 & $2.24 \mathrm{a}$ & 0.88 & $2.15 \mathrm{a}$ & 0.89 & $2.76 \mathrm{~b}$ & 0.99 & 6.08 & $.003^{*}$ & .046 \\
\hline Witnesses should not avoid your question. & 2.45 & 1.05 & 2 & $2.03 a$ & 0.82 & $2.37 \mathrm{a}$ & 0.89 & $3.73 b$ & 0.78 & 64.58 & $<.001^{*}$ & .376 \\
\hline
\end{tabular}

You have to push and ask it again to get an answer. 


\begin{tabular}{|c|c|c|c|c|c|c|c|c|c|c|c|c|}
\hline & \multicolumn{3}{|c|}{$\begin{array}{l}\text { Total } \\
N=211\end{array}$} & \multicolumn{2}{|c|}{$\begin{array}{l}\text { the } \\
\text { Netherlands }\end{array}$} & \multicolumn{2}{|c|}{$\begin{array}{l}\text { England and } \\
\text { Wales }\end{array}$} & \multicolumn{2}{|l|}{ Sweden } & \multirow[t]{2}{*}{$\begin{array}{l}F \\
(2,208)\end{array}$} & \multirow[t]{2}{*}{$p$} & \multirow[t]{2}{*}{$\omega^{2}$} \\
\hline & $M$ & $S D$ & $M d n$ & $M$ & $S D$ & $M$ & $S D$ & M & $S D$ & & & \\
\hline $\begin{array}{l}\text { It is smart to use a leading question as bait to } \\
\text { get an uncooperative witness to start talking. }\end{array}$ & 2.10 & 0.98 & 2 & $1.94 \mathrm{a}$ & 0.94 & $1.94 \mathrm{a}$ & 0.83 & $2.76 b$ & 1.02 & 12.75 & $<.001^{*}$ & .100 \\
\hline $\begin{array}{l}\text { Making a moral appeal about the victim } \\
\text { persuades witnesses to cooperate. }\end{array}$ & 3.13 & 0.87 & 3 & $3.03 \mathrm{a}$ & 0.82 & $2.94 \mathrm{a}$ & 0.90 & $3.66 \mathrm{~b}$ & 0.79 & 10.39 & $<.001^{*}$ & .082 \\
\hline $\begin{array}{l}\text { You can convince witnesses to talk by } \\
\text { appealing to their sense of responsibility } \\
\text { when their statement is the only evidence in } \\
\text { the case. }\end{array}$ & 3.21 & 1.01 & 3 & $3.06 \mathrm{a}$ & 1.04 & $3.19 \mathrm{a}, \mathrm{b}$ & 0.95 & $3.66_{b}$ & 0.86 & 5.64 & $.004^{*}$ & .042 \\
\hline $\begin{array}{l}\text { To get uncooperative witnesses to give a } \\
\text { statement, you can offer some anonymity } \\
\text { (e.g., not writing their real address). }\end{array}$ & 2.72 & 1.12 & 3 & $2.53 \mathrm{a}$ & 1.08 & $2.81 \mathrm{a}, \mathrm{b}$ & 1.03 & $3.15 \mathrm{~b}$ & 1.24 & 64.88 & $<.001^{*}$ & .379 \\
\hline $\begin{array}{l}\text { With uncooperative witnesses it works better } \\
\text { to conduct the interview outside the police } \\
\text { station. }\end{array}$ & 3.21 & 0.82 & 3 & $3.09 \mathrm{a}$ & 0.75 & $3.60 \mathrm{~b}$ & 0.82 & $3.07 \mathrm{a}, \mathrm{b}$ & 0.85 & 8.15 & $<.001^{*}$ & .063 \\
\hline $\begin{array}{l}\text { Interviewers should remind witnesses who } \\
\text { are related to the suspect that their } \\
\text { statement is voluntary. }\end{array}$ & 3.62 & 0.91 & 4 & 3.64 & 0.89 & 3.64 & 0.82 & 3.54 & 1.08 & 0.22 & .804 & .000 \\
\hline $\begin{array}{l}\text { It is good practice to ask uncooperative } \\
\text { witnesses not to lie, and to warn them of the } \\
\text { risk of perjury. }\end{array}$ & 3.49 & 1.11 & 4 & $3.17 \mathrm{a}$ & 1.10 & $3.90 \mathrm{~b}$ & 0.98 & $3.90 \mathrm{a}, \mathrm{b}$ & 1.00 & 12.62 & $<.001^{*}$ & .099 \\
\hline $\begin{array}{l}\text { Uncooperative witnesses need to be } \\
\text { reminded of the legal consequences of } \\
\text { withholding information about a crime. }\end{array}$ & 3.43 & 0.99 & 4 & $3.53 \mathrm{a}$ & 0.98 & $3.00 \mathrm{~b}$ & 0.84 & $3.66 \mathrm{a}$ & 1.04 & 7.11 & $.001 *$ & .055 \\
\hline
\end{tabular}

Note. Means sharing a common subscript are not statistically different at $p<.05$ according to post hoc comparisons. *Asterisks indicate significance at alpha level $p<.05$. 


\section{Pre-Interview}

Almost half ( $48 \%)$ of the respondents considered it their job as interviewers to convince the witness to provide a statement $(M=3.28, S D=0.99)$. A large majority of the respondents $(83 \%)$ reported that their role was also to ensure that witnesses do not experience any stress before starting the interview $(M=3.98, S D=0.71)$. The interviewing techniques that respondents strongly endorsed for gaining witness cooperation before getting a witness account were: devoting time to relationship building to gain trust and cooperation $(M=4.16, S D=0.71)$; exploring the reasons for lack of cooperation $(M=3.98$, $S D=0.81) ;$ and providing information about the procedure $(M=3.73, S D=0.94)$.

\section{Open Questions}

Agreement was polarised regarding the effectiveness of using open questions when someone does not want to voluntarily disclose information, overall indicating neutrality towards the technique $(M=2.72, S D=1.12 ; M d n=3)$. There was a weak significant difference in agreement across countries, $F(2,208)=5.07, p=.007, \omega^{2}=.037$. Respondents in the Netherlands view the use of open questions more positively than do their counterparts in Sweden, $t(208)=-3.11, p=.006, d=-0.55,95 \% \mathrm{Cl}[0.19,0.91]$.

\section{Direct Questions}

Most (58\%) respondents did not consider only seeking confirmation of information by confronting uncooperative witnesses with known facts about the crime a good interviewing technique $(M=2.32, S D=0.93)$, but $31 \%$ neither agreed nor disagreed and $11 \%$ agreed with the technique. There was a weak significant difference in agreement across countries, $F(2,208)=6.08, p=.003, \omega^{2}=.046$. Respondents in Sweden gave higher ratings, indicating higher agreement with the statement, differing significantly from respondents in the Netherlands, $t(208)=-3.150, p=.006, d=-0.57,95 \% \mathrm{Cl}[0.19,0.91]$, and in England and Wales, $t(208)=-3.174, p=.005, d=-0.64,95 \% \mathrm{Cl}[0.21,0.93]$.

\section{Repeated Questions}

Most (59\%) respondents indicated disagreement with the technique of posing questions repeatedly and pushing the witness to get an answer $(M=2.45, S D=1.05)$; nonetheless, $21 \%$ were neutral towards, $18 \%$ agreed with, and $2 \%$ strongly agreed with this 
technique. There were strong differences in ratings across countries, $F(2,208)=64.58, p<$ $.001, \omega^{2}=.376$. Respondents in Sweden gave higher ratings indicating agreement, differing significantly from respondents in England and Wales, $t(208)=-7.92, p<.001, d=-1.63,95 \%$ $\mathrm{Cl}[-2.10,-1.16]$, and in the Netherlands, $t(208)=-11.34, p<.001, d=-2.11,95 \% \mathrm{Cl}[-2.53,-$ 1.69].

\section{Leading Questions}

While more than half (66\%) of respondents did not agree with posing leading questions to get uncooperative witnesses to talk $(M=2.10, S D=0.98)$, almost a quarter $(25 \%)$ indicated neutrality, and $9 \%$ (strongly) agreed with the statement. There were differences in agreement across countries, $F(2,208)=12.75, p<.001, \omega^{2}=.100$. Respondents in Sweden gave higher ratings indicating higher agreement, differing significantly from respondents in England and Wales, $t(208)=-4.20, p<.001, d=-.89,95 \%$ $\mathrm{Cl}[-1.32,-.46]$, and in the Netherlands, $t(208)=-4.85, p<.001, d=-.86,95 \% \mathrm{Cl}[-1.22,-$ $0.48]$.

\section{Moral Appeals}

Respondents opinions on making moral appeals to the witness to benefit the victim as a technique for increasing cooperation were on average neutral $(M=3.13, S D=0.87 ; M d n$ = 3), though divided: $21 \%$ (strongly) agreed, $43 \%$ neither agreed nor disagreed, and 36\% (strongly) disagreed. There were strong differences in ratings across countries, $F(2,208)=$ 10.39, $p<.001, \omega^{2}=.082$. Respondents in Sweden gave higher ratings indicating higher agreement, differing significantly from respondents in England and Wales, $t(208)=-4.12, p$ $<.001, d=-.84,95 \% \mathrm{Cl}[-1.27,-.42]$, and in the Netherlands, $t(208)=-4.14, p<.001, d=-.77$, $95 \% \mathrm{Cl}[-1.14,-0.41]$.

In addition, almost half ( $47 \%)$ of the participants agreed with making appeals to the witness's sense of responsibility to cooperate when their testimony is the sole evidence in the case $(M=3.04, S D=1.23)$; nonetheless, $28 \%$ indicated neutrality and $26 \%$ (strong) disagreement regarding this technique. There were differences in ratings across countries, $F(2,208)=5.64, p=.004, \omega^{2}=.042$. Respondents in Sweden gave higher ratings indicating higher agreement, differing significantly from respondents in the Netherlands, $t(208)=$ $3.36, p=.003, d=-.60,95 \% \mathrm{Cl}[-.96,-.24]$. 


\section{Anonymity Incentives}

Offering the witnesses to provide their statements anonymously evoked divided opinions: $46 \%$ (strongly) disagreed, 37\% (strongly) agreed, and 18\% neither agreed nor disagreed; however, the average respondent supported this technique $(M=3.04, S D=1.23$; $M d n=4)$. There were strong differences in ratings across countries, corrected Welch $F(2$, 208) $=64.88, p<.001, \omega^{2}=.379$. Follow-up post hoc comparisons with Games-Howell corrections showed that the respondents in the Netherlands gave higher ratings indicating higher agreement, differing significantly from respondents in England and Wales, $t(208)=-$ $9.97, p<.001, d=1.66,95 \% \mathrm{Cl}[1.29,2.03]$, and in Sweden, $t(208)=7.79, p<.001, d=1.58$, $95 \% \mathrm{Cl}[1.18,1.97]$.

\section{Interview Location}

On average $(M=3.21, \mathrm{SD}=.82)$, respondents $(48 \%)$ neither agreed nor disagreed with the benefit of conducting interviews outside the police station when interviewing uncooperative witnesses. On one hand, 36\% (strongly) agreed, and on the other hand $16 \%$ (strongly) disagreed regarding this technique. There were differences in ratings across countries, $F(2,208)=8.15, p<.001, \omega^{2}=.063$. Respondents in England and Wales gave higher ratings indicating higher agreement, differing significantly from respondents in the Netherlands, $t(208)=3.83, p<.001, d=.65,95 \% \mathrm{Cl}[-.98,-.32]$.

\section{Voluntariness of Statements}

Most (62\%) respondents (strongly) agreed that witnesses should be reminded that their statement is voluntary when the suspect is their relative $(M=3.62, S D=0.91)$; in contrast, $26 \%$ expressed neutrality and $12 \%$ (strongly) disagreed.

\section{Perjury Caution}

Most (55\%) respondents (strongly) agreed that uncooperative witnesses should be reminded to be truthful and should be warned of the risk of perjury $(M=3.49, S D=1.11)$; still, $26 \%$ expressed neutrality and 19\% (strongly) disagreed regarding this technique. There were differences in ratings across countries, $F(2,208)=12.62, p<.001, \omega^{2}=.099$. 
Respondents in Sweden gave higher ratings indicating higher agreement, differing significantly from respondents in England and Wales, $t(208)=4.19, p<.001, d=.69,95 \% \mathrm{Cl}$ $[.36,1.02]$, and in the Netherlands, $t(208)=-3.84, p<.001, d=-.68,95 \% \mathrm{Cl}[.32,1.04]$.

\section{Legal Warnings for Withholding Information}

Most respondents (51\%) (strongly) agreed that uncooperative witnesses need to be reminded of the legal consequences of withholding crime information $(M=3.43, S D=0.99)$. Nonetheless, 31\% expressed their neutrality and 17\% (strongly) disagreed regarding this technique. There were differences in ratings across countries, $F(2,208)=7.11, p=.001, \omega^{2}=$ .055. Respondents in England and Wales gave lower ratings indicating lower agreement, differing significantly from respondents in the Netherlands, $t(208)=-3.35, p=.003, d=-.57$, $95 \% \mathrm{Cl}[0.24, .90]$, and in Sweden, $t(208)=-3.29, p=.003, d=-.71,95 \% \mathrm{Cl}[.29,1.13]$.

\section{Self-Reported Interviewing Practice}

Respondents $(N=178)$ reported 696 techniques that they would use to elicit information from an uncooperative witness. We classified the open responses following the six domains in the Taxonomy of Interrogation introduced by Kelly et al. (2013). The most preferred techniques pertained to the 'Collaboration' domain (50\%); these techniques appeal to the sense of cooperation of the interviewee, in order to establish a working relationship that in turn facilitates information gain. In addition, $20 \%$ of the reported techniques aimed at 'Rapport and a Relationship building' to increase cooperation, and 15\% were so-called 'Emotion Provocation' psychological techniques that target emotions to gain compliance (see Table 3 for descriptive statistics and listed techniques). 


\section{Table 3}

Open Responses Regarding Techniques Employed to Interview Uncooperative Witnesses

\begin{tabular}{|c|c|c|}
\hline Domains & $\%$ & Interviewing Techniques \\
\hline $\begin{array}{l}\text { Rapport and } \\
\text { Relationship } \\
\text { Building }\end{array}$ & 19.68 & $\begin{array}{l}\text { 1. Find common ground or shared experiences }(n=7) \\
\text { 2. Show kindness and respect }(n=5) \\
\text { 3. Identify and meet basic needs }(n=2) \\
\text { 4. Be patient }(n=18) \\
\text { 5. Build a bond }(n=43) \\
\text { 6. Show concern for source and his/her situation }(n=9) \\
\text { 7. Employ active listening skills }(n=1) \\
\text { 8. Build trust* }(n=34) \\
\text { 9. Have an unrelated social conversation before the interview* }(n=18)\end{array}$ \\
\hline $\begin{array}{l}\text { Context } \\
\text { Manipulation }\end{array}$ & 1.29 & $\begin{array}{l}\text { 1. Move the interrogation from a formal room to a more neutral setting }(n=7) \\
\text { 2. Move the interrogation from a neutral setting to a more formal room }(n=1) \\
\text { 3. Consider the environment* }(n=1)\end{array}$ \\
\hline $\begin{array}{l}\text { Emotion } \\
\text { Provocation }\end{array}$ & 14.94 & $\begin{array}{l}\text { 1. Appeal to self-interest }(n=5) \\
\text { 2. Appeal to conscience }(n=39) \\
\text { 3. } \text { Reduce fears }(n=26) \\
\text { 4. } \text { Flatter source }(n=5) \\
\text { 5. Encourage source to take responsibility for the outcome }(n=20) \\
\text { 6. Try to play on their feelings* }(n=1) \\
\text { 7. Use social pressure* }(n=2) \\
\text { 8. Use persuasion* }(n=2) \\
\text { 9. Discuss previous experience with police* }(n=4)\end{array}$ \\
\hline $\begin{array}{l}\text { Confrontation } \\
\text { and Competition }\end{array}$ & 12.64 & $\begin{array}{l}\text { 1. Threaten source with consequences for non-cooperation }(n=8) \\
\text { 2. Do not speak to source, only stare at source }(n=1) \\
\text { 3. Confront source without insulting }(n=11) \\
\text { 4. Ask unexpected/alternative questions }(n=1) \\
\text { 5. Put firm pressure on witness* }(n=2) \\
\text { 6. Pose questions despite silence* }(n=11) \\
\text { 7. Escalate request to oblige witness to give testimony* } \\
\text { 8. Tell witnesses to tell the truth/not to lie* }(n=9) \\
\text { 9. Explain consequences of non-cooperation* }(n=40)\end{array}$ \\
\hline Collaboration & 50.14 & $\begin{array}{l}\text { 1. Make bargains with source }(n=1) \\
\text { 2. Appeal to sense of cooperation }(n=69) \\
\text { 3. Present scenario so source may regain or assert control }(n=70) \\
\text { 4. Ask witness about reasons for not cooperating* }(n=71) \\
\text { 5. Explore potential solutions to reduce reluctance* } \\
\quad(n=37) \\
\text { 6. Arrange special measures to give testimony* }(n=53) \\
\text { 7. Respect when the witness does not cooperate* }(n=36) \\
\text { 8. Use open questions to elicit a free account* }(n=10) \\
\text { 9. Use context reinstatement* }(n=2)\end{array}$ \\
\hline $\begin{array}{l}\text { Presentation of } \\
\text { evidence }\end{array}$ & 1.29 & $\begin{array}{l}\text { 1. Identify contradictions with source's story }(n=1) \\
\text { 2. Reveal true information* }(n=6) \\
\text { 3. Tell the witness they are not the only witness* }(n=2)\end{array}$ \\
\hline
\end{tabular}

Note. $N=696$. The interviewing techniques were categorised following the Taxonomy of Interrogations by Kelly et al. (2013). *Asterisks indicate additional techniques included from participants' responses. 


\section{Discussion}

In this survey we captured the police experience and self-reported practice of a large sample of experienced criminal investigators. It constitutes a significant contribution to the very limited empirical evidence concerning the interviewing of uncooperative witnesses. As such, this survey provides information on the inherently challenging situation of obtaining information and evidence from witnesses who would rather not cooperate with the police in a witness interview, shedding new insights concerning the dynamics between the interviewer and the interviewee resulting from lack of cooperation.

This survey reveals criminal investigators' self-reported perceptions and experience regarding their current practice of interviewing uncooperative witnesses. First, officers from all four countries reported encountering uncooperative witnesses increasingly frequently (in about half of their cases). Similarly, Wheeler et al. (2017) reported a 5-49\% prevalence of reluctant witnesses according to first-response police officers in England and Wales. A large majority of officers (83.90\%) in our survey also confirmed that lack of cooperation is a roadblock to eliciting information in criminal investigations. The challenges of lack of witness cooperation experienced by the police are well founded, considering its detrimental effects on witness disclosure of crime information (De La Fuente Vilar et al., 2020). These findings indicate that lack of witness cooperation is not a trivial problem for the criminal justice system; rather it is a societal concern given that it reflects low citizen engagement in the police's task of fighting crime and maintaining public order in the community (Spencer \& Stern, 2001; Tyler \& Fagan, 2008). A better grasp of the magnitude of the problem also substantiates the need for further empirical research to support law enforcement and inform policy reforms tackling this societal issue.

Our survey also shows that despite the importance of interviewing witnesses, $20 \%$ of the surveyed police officers currently conduct witness interviews without having undergone any formal training on general investigative interviewing (particularly in Sweden but also in the Netherlands). Moreover, specialised training in the investigative interviewing of uncooperative witnesses is negligible (less than 10\%) across our sample. The perils of intuitive rather than evidence-based interviewing practice is turning interviewing into a statement-taking exercises via the use of targeted, and closed questions (Fisher et al., 2011; 
Schreiber Compo et al., 2012). Untrained interviewers' overuse of closed and direct questions instead of posing open-ended questions results in incomplete statements (Clifford \& George, 1996). The non-existent or unsatisfactory levels of training that contributes to poor witness interviewing practice (Snook et al., 2012) also calls into question the quality and integrity of witness statements obtained by the police. Considering that witness statements serve as a legal basis in the adjudication of justice (Wells et al., 2006), compromising the accuracy of witness testimony comes with the risk of contributing to miscarriages of justice (Gross \& Gross, 2013; The National Registry of Exonerations, 2020). In particular, we caution that training deficiencies could make interviewers feel ill equipped for the task of overcoming witness reluctance (Soukara et al., 2000). Furthermore, intuitive interviewing practice potentially increases the use of accusatorial-style techniques in the interviewing of uncooperative witnesses (Davis \& Leo, 2016).

A significant proportion of the surveyed criminal investigators indicated that they expect individuals to talk to the police if they witnessed a crime, and that interviewing an uncooperative witness feels like talking to a suspect (32\% and $45 \%$ respectively). A priori expectations of witness cooperation are unfounded given the above-mentioned investigators' estimates of uncooperative witness prevalence. Moreover, lack of witness cooperation fuels the perception of police that they are interviewing suspects rather than witnesses, raising concerns about potentially ineffective and biased interviews. The police seem to expect that witnesses will spontaneously report all available information about the crime upon request (see also Antaki \& Stokoe, 2017; Fyfe \& Smith, 2007; Roberts, 2010). A previous survey of police officers already indicated that witnesses, on one hand, were perceived as crucial to gathering investigative leads and, on the other, were critiqued for not providing sufficient information (Kebbell \& Milne, 1998). While consistent with previous research findings, the default expectation of witness cooperation from the interviewer's perspective is at odds with the law and psychological theory. First, in most democratic societies, it is a duty and not an obligation to cooperate with the police (Tyler \& Fagan, 2008), as was the case in the jurisdictions of the surveyed police. Second, individuals engage in meta-cognitive monitoring processes that consider the accuracy of memory in their decision to report (Koriat \& Goldsmith, 1994); moreover, there seems to be an especially stringent threshold to report only accurate and potentially relevant information in 
investigative contexts (Brewer et al., 2018). Therefore, lack of witness cooperation should not be negatively perceived given that even cooperative witnesses do not volunteer all remembered information.

These findings should alert practitioners to remember that the onus of information elicitation is on the police. In that light, we argue that to obtain the best evidence from uncooperative witnesses, the police need to be fully equipped to facilitate information disclosure not only in the traditional sense of using evidence-based witness interviewing guidelines that improve recall (e.g., the $\mathrm{Cl}$ ). As a complement, interviewers need to be competent at managing the motivational and relational aspects of the interviewerinterviewee dynamic to increase willingness to report (Alison et al., 2014; Westera \& Powell, 2015). An information-gathering interviewing style and reliance on rapport-building to gain and maintain cooperation - not taking it for granted - could encourage reporting from initially uncooperative witnesses (Collins et al., 2002; Vallano \& Schreiber Compo, 2015) and maximise accurate recall (Gabbert et al., 2020). Our findings reveal that the three top-rated strategies for overcoming initial uncooperativeness were: building a relationship to gain witness trust and cooperation; exploring the witness's reasons for their unwillingness to cooperate; and providing information about the procedure at the start of the interview. Similarly, the interviewing techniques reported to be mostly used in practice to elicit information from uncooperative witnesses aim at establishing a collaborative relationship and building rapport. These results are in line with the suggestion to first increase witness willingness to report, and are also similar to those reported by Wheeler et al. (2017), overall demonstrating support for the functional role of rapport in gaining cooperation (Abbe \& Brandon, 2013). We therefore call for empirical testing of these methods on uncooperative witnesses, as they could potentially better equip officers to adjust their interviewing techniques in the face of unmet expectations of witness cooperation.

The police agreement with the application of specific types of questions in interviews of uncooperative witnesses is somewhat evidence based. Open questions are known to elicit more accurate and complete answers (Fisher, 2010); however, over two thirds of the criminal investigators questioned their effectiveness when the witness does not want to volunteer information. In addition, most officers disagreed with the use of direct, confirmatory, repeated, and leading questions, in line with evidence-based effective 
interviewing (Fisher, 2010; Sharman \& Powell, 2012). This pattern of findings, together with what is known about witness interviewing from archival studies (Clarke \& Milne, 2001; Mclean, 1995; Schreiber Compo et al., 2012; Snook \& Keating, 2011; Wright \& Alison, 2004), suggests that, in practice, officers may resort to the use of closed questions. Therefore, only field research will provide an evaluation of how uncooperative witnesses are interviewed in practice. However, according to the estimations of our respondents, the reality is that only half of the interviews are recorded, making the necessary objective evaluations difficult to realise.

There were other techniques endorsed by the respondents that do not have empirical standing. Officers considered it good practice to ask uncooperative witnesses not to lie, to warn them of the risk and consequences of perjury, and to remind them of the legal consequences of withholding information. Arguably, such measures are needed to guarantee the accuracy of testimony and to secure its admissibility as evidence $(R$. v. $B$. (K. G.), 1993). However, pre-interview instructions can lead to anxiety about the interviewing process and may foster interviewee passivity (Fisher \& Geiselman, 1992; Snook \& Keating, 2011). Lack of engagement due to anxiety given the situational demands can only be exacerbated by the complexity of legal warnings and lack of comprehension of the consequences (Luther et al., 2015), which, taken together, can reduce information disclosure (MacDonald et al., 2017a; Snook \& Keating, 2011). The possibility that administering legal warnings to witnesses can incur the cost of reduced information disclosure warrants further empirical testing; until then, based on current empirical findings, we caution practitioners on the perils of their application.

Our findings also indicate overall support for the use of anonymity incentives. Despite the lack of empirical evidence, many police agencies have introduced the possibility of making anonymous statements with the aim of reducing crime underreporting. The underlying rationale is that a promise of anonymity decreases fear of reprisal for reporting (Dreissen et al., 2012). However, research has not supported the positive effect of anonymity on the intention to report crimes (Aiello, 2019; Tolsma et al., 2012), except in certain social and political contexts (McCarthy et al., 2020). Therefore, future research is warranted to determine the benefits, if any, of anonymity incentives in interviews with uncooperative witnesses. 
A technique that has not yet received sufficient empirical scrutiny is the use of moral appeals to persuade uncooperative witnesses to talk; nonetheless, their application received some support from police. Applied memory research findings have amply demonstrated the frailties of human memory (e.g., Loftus, 2005). In this light, it could be argued that an unwanted consequence of persuasive moral appeals could be speculation beyond recall. However, in mock witness interviews, the administration of an appeal to civic duty as the only crime witness did not increase cooperation; in fact, it decreased overall disclosure but without compromising accuracy (De La Fuente Vilar et al., 2020). This means that moral appeals could inadvertently increase the threshold for reporting only accurate information. Nevertheless, whether moral appeals facilitate disclosure of uncooperative witnesses remains to be empirically tested.

Conducting the interview outside the police station was also partially endorsed as a technique for interviewing uncooperative witnesses. A different sample of practitioners indicated a greater perceived utility of this technique for interviewing suspects, but with limited frequency of use, suggesting that it helps put the suspect at ease and facilitates disclosure (Hoogesteyn et al., 2020b). However, preliminary evidence from a laboratory study did not demonstrate any superior effect of conducting interviews at mock witnesses' homes (Hoogesteyn et al., 2020a). At this time, then, the overall neutrality expressed by our respondents is reasonably aligned with the current evidence until further research is conducted.

\section{Limitations and Future Research}

Although this survey is a comprehensive initial assessment of the state of affairs in interviewing uncooperative witnesses, several of its limitations should be considered. First, it is based on self-reporting, which is subject to social desirability responding that may have led respondents to guess which interviewing practices were the correct ones rather than reflecting their own true perceptions. This is particularly relevant considering that some respondents were recruited in the context of their workplaces. However, we reassured participants that their responses would not be shared with their workplaces but would remain anonymous and confidential, which potentially reduced this concern. Second, this survey is based on self-reporting of police experience and practice, but it is not an 
evaluation of actual interviewing behaviour. Given the relevance of this topic, future research examining field data is warranted to examine the extent to which the surveyed practitioners' perceptions and experiences influence which interviewing techniques the police applies and in which sequence when interviewing uncooperative witnesses, and how these techniques affect witness behaviour in real criminal case investigations. Third, sampling bias should be considered. We collected responses from voluntary participants, recruited through professional contacts, who arguably might be more familiar with evidence-based interviewing guidelines than would regular police officers. Replication initiatives within police forces could represent a step towards counteracting this bias in future research, a step we highly encourage.

\section{Collaborative Research Agenda and Policy Implications}

Interviewers' perceptions regarding witness cooperation (and the lack thereof) are likely to affect how interviewers elicit information during a police (investigative) interview. Consequently, this survey serves as a basis for evaluating practice, tailoring interviewing training, and developing lines of research that examine the effects of specific interviewing strategies on witness accounts, considering their importance in advancing criminal investigations and as evidence in court. This research agenda demands an interdisciplinary approach, representing an opportunity for collaboration between researchers, practitioners, and law and policy makers.

We showed that police officers perceive lack of witness cooperation in the investigative interview as a challenge to their goal of information elicitation, one for which many are ill equipped as a result of poor or non-existent training. To start remedying the potentially negative outcomes of poor practices of interviewing crime witnesses, evidencebased training in transferable interviewing skills (general and specialised) is needed. The principles underlying the effectiveness of the techniques need to be explained (Fisher, 2010; Fisher \& Schreiber, 2007) to increase their perceived efficacy, in turn making police interviewers more likely to incorporate them into their practice (Hirn Mueller et al., 2015). To overcome some of the limitations of previous training programmes, practice in transferable skills, regular refresher trainings, and evaluation mechanisms should be in 
place to enhance adherence to best-practice interviewing guidelines (MacDonald et al., 2017b; Powell, 2008).

We strongly recommend the adoption of mandatory audio-visual recordings of every police interview with witnesses as the best tool to facilitate such evaluation. While we note that in some jurisdictions guidelines already recommend recording based on case characteristics (e.g., vulnerable witnesses in the Netherlands and in England and Wales), our contention is that every interview should be recorded. The benefits of video-recording extend to improving interviewing practice by inhibiting the use of coercive interrogation practices (Kassin et al., 2014), without affecting the disclosure of incriminating information (Kassin et al., 2019). In addition, the alternative to audio-visual recordings is written records that are demonstrably of limited quality as they preclude representation of the whole interviewing process and are subjected to bias, leading to decreased accuracy and completeness, which can affect judicial decision making (De Keijser et al., 2012; Mclean, 1995; Malsch et al., 2018). In sum, digital recordings would not only guarantee the integrity of the witness statement and facilitate its reproduction, but also to inform on how it was obtained, thereby enriching its evidential value (Horselenberg \& Van Koppen, 2011; Milne \& Shaw, 1999). Importantly, admitting a video-recorded police interview as evidence is crucial in criminal cases in which uncooperative witnesses are unwilling to provide their testimony in court.

\section{Conclusions}

Police officers frequently encounter crime witnesses who do not wish to get involved in the investigation and are uncooperative with requests for information. To elicit information from these uncooperative witnesses, increasing their willingness to report would seem to be a prerequisite before asking the witnesses to engage in recall efforts within an information-gathering and rapport-based interviewing approach. Further research is needed to develop evidence-based specific strategies for interviewing uncooperative witnesses. Police interviewing training and the mandatory recording of every witness interview are also recommended in order to better preserve witness evidence. Particularly, in light of current findings indicating the risk of using inadequate and ineffective interviewing techniques when challenged with lack of cooperation. 

Chapter 4 Unfulfilled Expectations of Cooperation in Witness Interviewing An adapted version of this chapter has been submitted for publication as:

De La Fuente Vilar, A., Horselenberg, R., Hope, L., Strömwall, L. A., \& van Koppen, P. J. (2020). Unfulfilled Expectations of Cooperation in Witness Interviews. Manuscript submitted for publication. 



\begin{abstract}
Witness cooperation and willingness to report recalled information has received little scientific scrutiny despite their influence on information elicitation. In an experiment, we examined expectancy effects of witness Cooperation and No Cooperation (cf. no expectations) on interviewing approach. After randomly receiving information about expected levels of witness cooperation, student and community participants $(N=109)$ planned and conducted mock police interviews with an individual who was a confederate in the experiment and exhibited uncooperative behaviour. We found no differences in the preferred interviewing approach between the conditions during either the interview planning phase or the actual interview. Additionally, we examined how participants managed uncooperative behaviour from the witness. We observed a shift from a planned information-gathering approach to an accusatorial approach when the witness refused to cooperate in the interview. This preliminary finding indicates an effect of lack of witness cooperation on interviewing behaviour with implications for interviewing practice.
\end{abstract}




\section{Unfulfilled Expectations of Cooperation in Witness Interviewing}

Research has contributed to improving the effectiveness of investigative interviewing by focusing on the interviewer's ability to maximise information disclosure (Fisher, 2010; Vrij et al., 2014). However, effective information elicitation is highly dependent on the interviewees' willingness to cooperate and their intention to disclose information (Alison et al., 2013). Despite the importance of witness cooperation for interview outcomes, the witness's willingness to engage with the interviewer and report crime-relevant information has received little scientific scrutiny. In particular, the extent to which witness cooperation affects the interviewing approach of an investigator has not been examined. Insights from investigative interviewing research and practitioner experience, however, suggest that the effectiveness of interviewing techniques and specific types of questions are likely determined by the interviewee's cooperation, or lack thereof (Vrij et al., 2017). The aim of the current study was to examine the effects of cooperation on the interviewing approach in witness interviews. Specifically, we experimentally tested how participants planned and conducted a mock police interview of a witness who was unwilling to cooperate and disclose crime-relevant information.

\section{Witness Cooperation in Investigative Interviews}

There is a dearth of research on the effects of witness cooperativeness (i.e., the interviewee's willingness to cooperate, hereafter referred to as cooperation) on information disclosure compared with the wealth of research regarding cooperation in the interrogation of suspects in criminal and security contexts. Whilst it is generally assumed that suspects will be less forthcoming with information to avoid incrimination (Strömwall et al., 2006), witnesses are often believed to be impartial individuals likely to cooperate with the police investigation (Fyfe \& Smith, 2007; Roberts, 2010). However, for a variety of reasons, witnesses may not be motivated to cooperate and may withhold crime information as a result (Spencer \& Stern, 2001), for instance, due to anticipated negative consequences from their involvement in the investigation (e.g., fear of intimidation; Papp et al., 2017). In addition to any internal motivations of the witness that reduce cooperation, the manner in which investigative interviews are conducted can also affect cooperation and, in turn, information disclosure and accuracy (Collins et al., 2002; Memon et al., 2010). 
Psychological theory and research have focused on developing evidence-based techniques that facilitate memory retrieval to increase accurate recall from witnesses (e.g., the Cognitive Interview, $\mathrm{Cl}$; Fisher \& Geiselman, 1992). Different police interviewing guidelines recommend the use of the $\mathrm{Cl}$ to obtain witness accounts (e.g., the PEACE model; Central Planning and Training Unit, 1992). However, while the $\mathrm{Cl}$ provides techniques to facilitate additional cooperation (e.g., rapport-building and transfer of control), for the application of its core, cognitive, memory-enhancing techniques, the interviewee is required to engage in the mental effort of remembering (Fisher, 2010). The $\mathrm{Cl}$ is therefore more suitable for use with cooperative witnesses given that its efficacy is dependent on high levels of interviewee cooperation (McCauley \& Santee, 2019; Vrij et al., 2017). Therefore, research-driven guidance, currently limited, on how to effectively obtain accounts from uncooperative witnesses in police criminal investigations is greatly needed.

Two distinct interviewing approaches have been distinguished in the literature, namely, an information-gathering approach and an accusatorial style (e.g., Meissner et al., 2012). The latter is an interrogation approach used mainly with suspects that is confrontational and guilt-presumptive in nature, in which closed-ended, and confirmatory questions are asked with the aim of eliciting admissions and confessions (Meissner et al., 2012). The standard police interview with crime witnesses has been found in archival research to follow a direct approach in which the interviewee is typically questioned about specific knowledge using closed, directive and leading questions (Clarke \& Milne, 2001; Mclean, 1995; Schreiber Compo et al., 2012; Snook \& Keating, 2011; Wright \& Alison, 2004). This type of interviewing approach is akin to the accusatorial approach, as it is rather confirmatory in nature, detrimental to memory recall, and has the potential to lead to biased versions of the events (Launay \& Py, 2015; Wright \& Alison, 2004). In contrast, research indicates that an information-gathering approach is more effective for obtaining comprehensive and accurate testimonies from witnesses (Fisher, 2010; Vrij et al., 2014). This approach advocates the use of open-ended and exploratory questions to elicit an account of the event from the interviewee, and promotes rapport-building techniques that foster trust and cooperation and, in turn, promote disclosure and decrease reluctance (Collins et al., 2002; Gabbert et al., 2020; Vallano \& Schreiber Compo, 2015). 
Despite evidence-based interviewing guidelines, poor interviewing skills can lead to poor interviewing practice, particularly in the face of unanticipated challenges (Baldwin, 1993). Insufficient and inadequate training in witness interviewing significantly influences the application of effective interviewing techniques (Dando et al., 2008; MacDonald et al., 2017b; Snook et al., 2012). In addition, resistance and lack of cooperation augment the complexity of an interview. To reduce the experience overload, even experienced interviewers self-report resorting to poor interviewing practices (Griffiths et al., 2011). In other investigative contexts, for instance, when suspects invoke their right to silence and when victims are reluctant to talk, uncooperative behaviour by the interviewee increases inappropriate and ineffective interviewing techniques that characterise a direct and accusatorial interviewing approach (Hershkowitz et al., 2006; Moston \& Engelberg, 1993). Taken together, the evidence indicates that lack of cooperation represents a challenge to the interviewer's goal of information elicitation and that an observed common response to this challenge is to adopt a more accusatorial interviewing approach.

The interviewer's expectations of witnesses and their role determine in part how the interview is conducted (Roberts, 2010). Typically, interviewers expect interviewees to provide full disclosure of truthful and relevant information (Antaki \& Stokoe, 2017). In practice, however, the police frequently encounter witnesses who are unwilling to become involved in the investigation and who, if interviewed, do not cooperate or readily disclose information (see Chapter 3; Wheeler et al., 2017). To date, it is not clear how interviewers respond when witnesses do not fulfil the interviewer's expectations of cooperation in an interview. Specifically, it is not clear how uncooperative witnesses are interviewed: how do interviewers overcome silence, refusals to engage, omission of critical information and provision of succinct, fabricated or irrelevant answers?

Davis and Leo (2016) noted that witnesses who are less willing to cooperate with the police are more likely to be targets of an accusatorial interviewing approach (e.g., the Reid Technique, Inbau et al., 2013; Meissner et al., 2012). This accusatorial approach has also been suggested for use with reluctant witnesses who are withholding information concerning another's guilt on the grounds that they are protecting the offender or are, in fact, offenders attempting to evade detection by posing as witnesses (Inbau et al., 2013). However, the accusatorial interviewing approach has been shown to increase false 
accusations in witness interviews (Loney \& Cutler, 2016). For example, in the Canadian case of R. v. Morgan (2013), false incriminating testimony was elicited through coercion from two eyewitnesses. The police used overt threats of incrimination and negative consequences for non-cooperation, and used conscience appeals downplaying the severity of the crime (see Loney \& Cutler, 2016; Moore et al., 2014). Moreover, false witness testimony is the leading factor contributing to more than half of the cases of overturned wrongful convictions in the United States (The National Registry of Exonerations, 2020). An analysis of recantation cases conducted by Gross and Gross (2013) suggests that the incidence of perjury (i.e., false testimony) results from coercion, undue pressure, and threats to witnesses from the police.

\section{Expectancy Effects in Suspect Interrogations and Witness Interviews}

Previous research on suspect interrogations shows that police interviewers adopt a confirmatory hypothesis-testing strategy if they hold certain beliefs or expectations about a suspect (Kassin et al., 2003). In particular, the belief that a suspect is indeed guilty is associated with an increased frequency of guilt-presumptive and suggestive questions during an interrogation (Hill et al., 2008; Kassin et al., 2003). A guilt bias also increases the likelihood of interviewers using more persuasive and accusatorial techniques, leading to an overall pressure-filled interrogation aimed at exerting pressure to obtain a confession (Narchet et al., 2011). The use of accusatorial techniques is associated with false confessions by innocent interviewees (Narchet et al., 2011), providing behavioural confirmation for the interviewer's initial expectations of guilt (e.g., nervous, defensive, and deceptive behaviour) (Hill et al., 2008; Kassin et al., 2003). Interviewee behaviour is affected by the accusatorial interviewing and questioning style to the extent that there is a self-fulfilling prophecy effect, resulting in the interviewee exhibiting behaviour congruent with the investigator's expectations (Darley \& Fazio, 1980; Hill et al., 2008).

Most research on investigator's expectancy effects and confirmation bias has stemmed from interrogations with suspects, yet expectancy effects can be equally problematic in witness interviews. Using a non-police sample, Rivard et al. (2016) examined whether pre-interview information would lead to confirmatory hypothesis testing that affected participants' interviewer behaviour. Limited pre-interview case information led to interviewers more frequently using an open question to start the interview; however, the 
rest of the interviewing behaviour was primarily filled with closed-ended yes/no questions (Rivard et al., 2016). Limiting pre-interview case information to reduce biased interviewer behaviour was not supported by the findings; however, interviewers who held correct prior information elicited less information (Rivard et al., 2016).

In the current research, the aims were twofold, given that police frequently encounter witnesses who are uncooperative in the investigative process and that lack of witness cooperation risks leading an interviewer to adopt an accusatory interviewing approach (Davis \& Leo, 2016; Loney \& Cutler, 2016). First, we examined how expectations of witness cooperation affected the planned and used interviewing approach. Second, we explored the effects of actual uncooperative behaviour of the witness on the types of questions used by the interviewer.

In light of the evidence for expectancy effects in investigative interviewing (Hill et al., 2008; Kassin et al., 2003; Narchet et al., 2011), we predicted that expectations of Cooperation or No Cooperation [cf. no expectations i.e., Control condition] would affect the formulation of the interviewing plan in terms of which types of questions (hypothesis 1a) and interviewing techniques (hypothesis 16 ) the participants would select during the planning phase. Specifically, we predicted that participants in the Cooperation condition would follow an information-gathering approach when formulating the interview plan, whereas we predicted that participants in the No Cooperation condition would follow an accusatorial approach in their interviewing plan. The Control condition was included to examine interviewing approach without manipulated expectations during the conducting of the mock police interview. We also predicted that the biased expectations of witness cooperation would influence interviewing behaviour during the interview phase. Specifically, we predicted that participants in the No Cooperation condition would pose more Direct, Closed, Leading, Multiple, and Repeated questions than would participants in the Control condition (hypothesis 2a). Conversely, we predicted that participants in the Cooperation condition would pose more Open-ended questions than would participants in the Control condition (hypothesis 26 ). 


\section{Method}

\section{Participants}

One hundred and ten individuals participated in the study. One participant withdrew before conducting the simulated police interview and was therefore excluded from the sample. The final sample $(N=109,76 \%$ female; $18-70$ years of age; $M=25.22$ years, $S D=$ 11.08) was recruited from the university research participation pool and local community ( $89 \%$ were students, of whom $65 \%$ were Psychology students). Participants were offered either one research point or a $£ 5$ gift card as compensation for their participation, and were eligible for a draw of $£ 50$ as an extra incentive.

The true effect size of the effect of investigator's bias on interviewing behaviour in witness interviews is unknown. We based our a priori statistical power analysis on the effects of guilt bias on guilt-presumptive questions reported by Kassin et al. (2003; Phase I). A sample of 78 participants was calculated to be required to detect a $d=0.72$ effect with a 0.80 statistical power. However, a sample size of $N=158$ could detect with the same power a more conservative medium-sized effect of $d=.50$ (Cohen, 1988); prior to the start of data collection, we decided to extend data collection until a maximum of $N=158$ or until the end of a specified period in which the research could be practically conducted.

\section{Design}

Using a between-subjects design, participants were randomly assigned to one of three experimental conditions manipulating expectations of different levels of witness cooperation: Cooperation $(n=35)$, No Cooperation $(n=37)$, or no expectations in the Control condition $(n=37)$. The interviewing approach was measured twice in each experimental session; first, in the interview planning phase, the dependent variables were the numbers of selected accusatorial and information-gathering interviewing techniques and questions; second, in the interview phase, the dependent variable was the type of question asked. 


\section{Materials}

\section{Case File}

Each participant received a two-page file on a mock murder case created for this experiment and formatted as a police file (see Appendix 4). The narrative was developed from anecdotal reports of assassinations involving organised crime gangs and was edited by an experienced retired police detective to increase realism and adapt the case to the local context.

\section{Witness Interview Reports}

The case file included one of three reports manipulating expectations of witness cooperation (see Appendix 5). Participants received a report from the officer who visited the witness to invite him to the police station for an interview. The perceptions of the officer regarding the witness cooperation during that encounter differed. In the Cooperation condition, the witness was described as collaborative, genuinely trying to remember the event in question, and willing to provide critical information. In contrast, in the No Cooperation condition the witness was perceived as reluctant, with a negative attitude towards the police, and avoidant in his responses to critical questions. In the Control condition, the report did not include information concerning perceived witness cooperation.

\section{Lists of Interviewing Techniques and Questions}

To plan their interview with the witness, participants received two lists (see items in Table 2 and 3). The first list contained a set of 20 questions concerning details of the crime. The list included items from materials used by Kassin et al. (2003) adapted to the context of interviewing uncooperative witnesses and the case file. The second list contained a set of 20 interviewing techniques. The listed interviewing techniques were self-reported by criminal investigators as part of the repertoire of current interviewing practice for interviewing uncooperative witnesses (see Chapter 3 ) and were drawn from research on witness investigative interviewing (Fisher, 2010). Both lists included an equal distribution of information-gathering and accusatorial question types and interviewing techniques. For each list, the items were presented to the participants in random order (see Appendix 6). 


\section{Procedure}

Participants, tested individually, provided consent to participate in the experiment and were asked to act as mock detectives in an ongoing murder investigation. The experimenter explained that their task was to interview a potential key witness in the case in order to obtain five new pieces of target information to advance the investigation: the number of perpetrators, person descriptions, description of the vehicle involved and weapon used in the crime, and potential motives. To start, participants received the case file and one of the three witness interview reports. Participants did not receive interviewing training. They independently prepared the witness interview: first, they were given pen and paper to self-generate questions to ask the key witness; then, they were given the lists of interviewing techniques and questions one at a time. Participants were notified that each list contained several interviewing techniques and questions used by professional police interviewers. They were also told that not all the listed techniques and questions were suitable for the case at hand. Hence, their task was to choose any questions or techniques perceived as effective for them to employ in their interview. Participants indicated their preferences from the lists by highlighting each technique or question selected. There was no limit on the number of items they were permitted to highlight. Lastly, they were explicitly told that they could deviate from the interview plan during the interview, i.e., they could use any question, including those that they had not selected.

Before conducting the interview, participants provided demographic information and completed a manipulation check concerning cooperation expectations. Next, participants conducted an interview with the 'witness'. Participants were asked to notify the experimenter once they had concluded their interviews, or they were interrupted after 15 minutes if the interview was ongoing. This time restriction was not communicated to participants beforehand to avoid confounding time pressure. Participants completed a post-interview questionnaire assessing perceived witness cooperation and credibility. Lastly, participants were debriefed and compensated for their participation.

Unbeknownst to the participants, the 'witness' was a confederate. The same person was the confederate throughout all interviews, and he was blind to the experimental conditions. The confederate was trained to regulate information disclosure depending on the interviewing approach. At the start of the interview, the confederate was instructed to 
be quiet, and to provide only short answers - that is, the baseline behaviour of the confederate was uncooperative. When interviewed following an accusatorial interviewing approach (e.g., no rapport-building and over use of closed and direct questions), the confederate was instructed to become more defensive and inhibited and to provide less information. Conversely, when interviewed following an information-gathering approach (e.g., using free recall prompts and not interrupting), the confederate was instructed to gradually provide more information and move towards cooperativeness. These response patterns have been observed in real interviews with uncooperative interviewees (Alison et al., 2013).The confederate was a graduate student with subject knowledge of investigative interviewing. He developed a character story and scripted his performance as an uncooperative witness over two months before data collection (e.g., he practised the same verbal and non-verbal answers to a list of potential questions). The confederate's performance was recorded for evaluation for 10 pilot test sessions. These test interviews were transcribed, and the questions were coded by the first author, to analyse and correct when needed, the corresponding extent of the uncooperative behaviour. Feedback from the pilot study participants included expressions of frustration at being unable to elicit the requested information, confirming that the confederate was perceived as antagonistic to the goal of eliciting information, and providing constructive criticism to make his behaviour come across as, at least initially, less cooperative.

\section{Coding}

The interviews were recorded and transcribed. From the verbatim transcripts, the numbers of type of open-ended, direct, closed yes/no, closed option-posing, leading, personal, multiple and repeated questions were coded. See Table 1 for the definition of each question type. Additionally, we coded the statements in which the participants provided Instructions to the witness (e.g., explanations about the procedure, such as "This conversation is video-recorded", or encouragement of disclosure, such as "It's important for the family and the victim" and "Try hard to remember"). 
Table 1

Definitions of Question Type

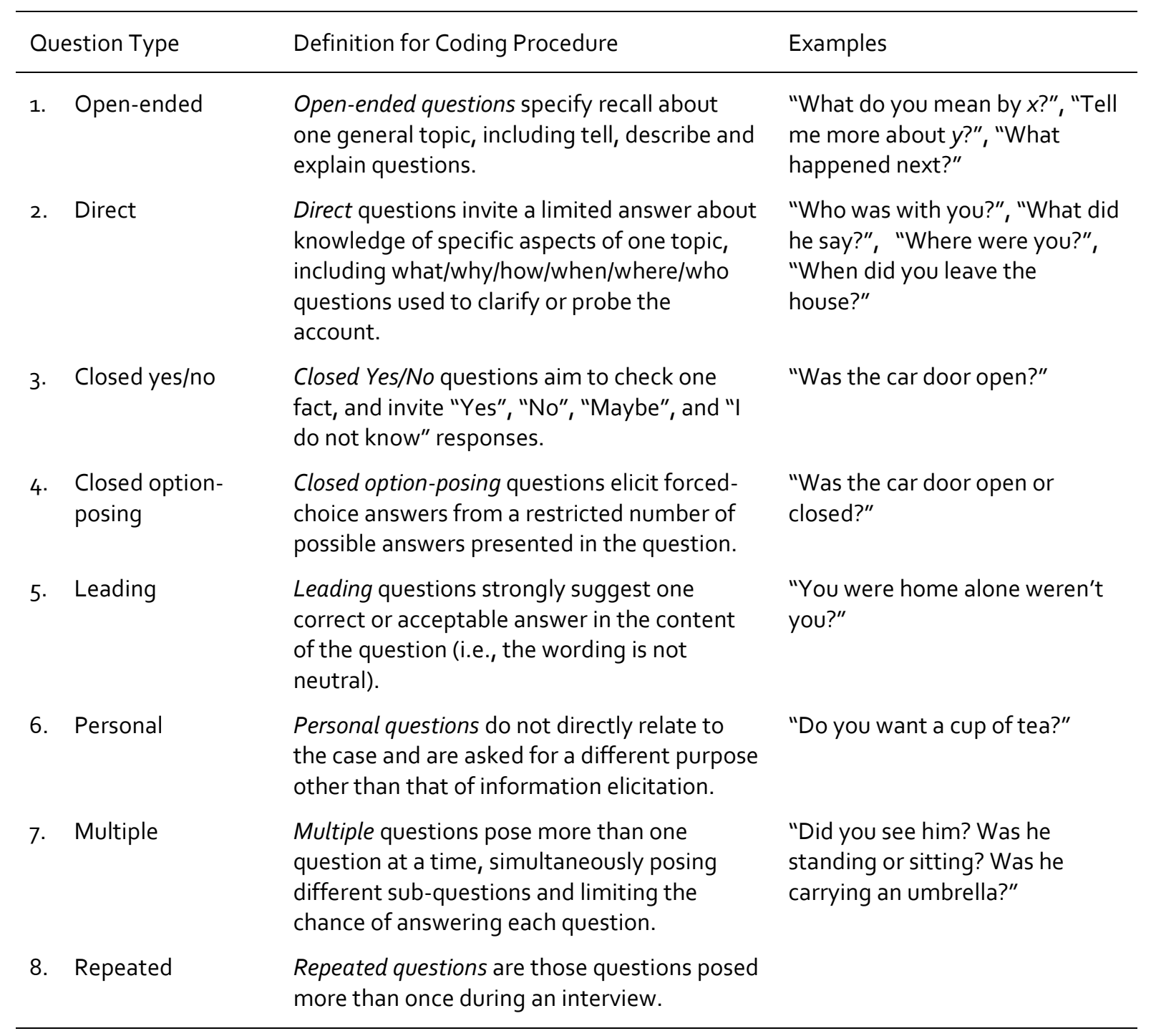

Note. Definitions and examples derived from the content dictionaries for question type by Wright and Alison (2004) and Snook and Keating (2011).

\section{Results}

\section{Preliminary Analyses}

\section{Inter-rater Reliability}

All the interviews were analysed by a main coder, and 22 interviews ( $20 \%$ of the sample) were randomly selected for independent analysis by a second coder (the first author) who was blind to the experimental condition of each transcript. The main coder was a graduate student with subject knowledge in memory research and investigative interviewing; this student received a one-hour training session in which the coding scheme 
was explained with practical examples from the pilot session interviews. Before beginning to code all the interviews, the main coder performed practice exercises using three transcripts and received feedback. To establish inter-rater agreement, a two-way mixedeffects model measuring consistency was calculated for each of the nine coding categories referring to the used types of questions and instructions used (McGraw \& Wong, 1996). We identified two intra-class correlations coefficients (ICCS) that did not indicate moderate to excellent agreement (Koo \& Li, 2016), and these variables, i.e., multiple and repeated questions, were excluded from subsequent analyses. For the remaining variables, the levels of inter-rater agreement were: Open-ended questions, ICC $=.93,95 \% \mathrm{CI}[.83, .97]$; Direct questions, ICC =.92, 95\% Cl [.81, .97]; Closed Yes/No questions, ICC = .88, 95\% Cl [.71, .95]; Closed option-posing questions, ICC $=.94,95 \% \mathrm{Cl}[.85, .98]$; Leading questions, ICC $=.92$, $95 \% \mathrm{Cl}[.80, .97] ;$ Personal questions, ICC $=1.00,95 \% \mathrm{Cl}[1.00,1.00 ;$ and for Instructions, ICC $=.96,95 \% \mathrm{Cl}[.91, .98]$.

\section{Manipulation Check}

Participants reported their agreement with the following item: '/ expect the witness to be willing to collaborate with me throughout the interview', on a seven-point scale, with values ranging from 'Completely Disagree' to 'Completely Agree'. This rating was used as a manipulation check. Rated expectations of witness cooperation were significantly different across the conditions, $F(2,108)=15.02, p<.001, \eta_{p}^{2}=.221$. Bonferroni-corrected post-hoc tests revealed significantly higher reported expectations for the Cooperation condition $(M=$ $5.34, S D=1.00)$ than the Control $(M=4.57, S D=1.28), t(108)=2.68, p=.026, d=0.67,95 \%$ $\mathrm{Cl}[0.19,1.14]$, or the No Cooperation condition $(M=3.76, S D=1.36), t(132)=5.48, p<.001$, $d=-1.32,95 \% \mathrm{Cl}[-1.83,-0.81]$. Ratings for the latter were also significantly lower than those for the Control condition, $t(132)=2.84, p=.016, d=0.61,95 \% \mathrm{Cl}[0.15,1.08]$. After the interview, participants reported perceived witness cooperation by responding to the following item, 'The witness cooperated with me during the interview', using the same agreement scale. There were no significant differences across conditions, $F(2,108)=0.26, p$ $=.772, \eta_{\mathrm{p}}^{2}=.005$; Control $M=3.43, S D=1.66$ versus Cooperation $M=3.43, S D=1.90$ versus No Cooperation $M=3.68, S D=1.47$. On average, participants partially disagreed with the statement $(M=3.51, S D=1.67 ; M d n=3)$. Together, these findings indicate that while the 
expectations of cooperation were different before the interview, in line with the experimental conditions, the behaviour of the confederate was uniformly rated somewhat uncooperative, as planned.

\section{Hypotheses-testing Analyses}

\section{Hypothesis 1a: Expectations of Witness Cooperation Affect Question Selection in the}

\section{Planning Phase}

Contrary to our predictions, there were no statistically significant differences by expectancy condition in the number of information-gathering questions selected, Welch $F(2,106)=1.48, p=.235, \eta_{p}^{2}=.022$, or in the number of accusatorial style questions selected, $F(2,106)=0.30, p=.745, \eta_{p}^{2}=.006$, in the planning phase (see Table 2 for descriptive and inferential statistics). This means that the expectations of witness cooperation did not guide the participants' preference for questions from either of the interviewing approaches before conducting the interview disconfirming our hypothesis 1 a. Participants, on average, selected 11 questions in total $(M=10.67, S D=3.07)$ when planning the witness interview. The number of selected questions was not affected by the experimental conditions, $F(2,106)=0.23, p=.796, \eta_{p}^{2}=.004$. The selection frequencies of all questions are reported in Table 3. 
Chapter 4

Table 2

Means and Standard Deviations for Questions and Techniques Selected in the Interview Plan per Condition

\begin{tabular}{|c|c|c|c|c|c|c|c|c|c|}
\hline & \multirow{2}{*}{\multicolumn{2}{|c|}{$\begin{array}{l}\text { Control } \\
(n=37)\end{array}$}} & \multirow{2}{*}{\multicolumn{2}{|c|}{$\begin{array}{l}\text { Cooperation } \\
\qquad(n=35)\end{array}$}} & \multirow{2}{*}{\multicolumn{2}{|c|}{$\begin{array}{l}\text { No Cooperation } \\
\qquad(n=37)\end{array}$}} & \multirow[t]{3}{*}{$F(2,106)$} & \multirow[t]{3}{*}{$p$} & \multirow[t]{3}{*}{$\eta_{p^{2}}$} \\
\hline & & & & & & & & & \\
\hline & $M$ & $S D$ & $M$ & $S D$ & $M$ & $S D$ & & & \\
\hline \multicolumn{10}{|l|}{ Selected Questions } \\
\hline Information-gathering & $7 \cdot 38$ & 1.64 & 6.89 & 2.48 & 6.65 & 2.48 & 1.48 & .235 & .022 \\
\hline Direct/Accusatorial & 3.60 & 2.15 & 3.63 & 2.00 & 3.95 & 2.31 & 0.30 & .745 & .006 \\
\hline Total & 10.97 & 2.76 & 10.51 & 3.27 & 10.59 & 3.23 & 0.23 & .796 & .004 \\
\hline \multicolumn{10}{|l|}{ Selected Interviewing Techniques } \\
\hline Information-gathering & 6.30 & 1.84 & $5 \cdot 77$ & 1.77 & 5.65 & 2.21 & 1.15 & .322 & .021 \\
\hline Direct/Accusatorial & 3.49 & 1.91 & $3 \cdot 51$ & 2.23 & 3.57 & 2.39 & 0.01 & .987 & .000 \\
\hline Total & 9.78 & 2.19 & 9.29 & 2.60 & 9.22 & 2.73 & 0.56 & .574 & .010 \\
\hline
\end{tabular}




\section{Hypothesis 1b: Expectations of Witness Cooperation Affect Interviewing Technique}

\section{Selection in the Planning Phase}

Similarly to our previous finding, there were no statistically significant differences by expectancy condition in the number of information-gathering techniques selected, $F(2,106)=1.15, p=.322, \eta_{p}{ }^{2}=.021$, or in the number of accusatorial-style techniques selected, $F(2,106)=0.01, p=.987, \eta_{p}{ }^{2}=.000$, in the planning phase (see Table 2 for descriptive and inferential statistics). This means that the expectations of witness cooperation did not guide the participants' preference for techniques from either of the interviewing approaches, which does not provide support for our hypothesis 1 b. On average, participants selected nine interviewing techniques in total $(M=9.42, S D=2.50)$ when planning the witness interview. The number of selected techniques was not affected by the experimental conditions, $F(2,106)=0.56, p=.574$, $\eta_{\mathrm{p}}{ }^{2}=.010$. The selection frequencies of all interviewing techniques are reported in Table 3.

\section{Hypotheses 2a and 2b: Expectations of Witness Cooperation Affect Question Type in the Interview Phase}

There were no statistically significant differences by expectancy condition in the types of question asked during the interview as a result of the manipulated expectancy (all ps > .05; see Table 4 for descriptive and inferential statistics); thus, hypotheses $2 a$ and $2 b$ were not supported. This means that the introduced bias with respect to expectations of witness cooperation did not affect the number of times each question type was used during the interview.

In addition, there were no statistically significant differences by expectancy condition in the total number of questions asked, $F(2,106)=1.50, p=.227, \eta_{p}^{2}=.028$, nor in the length of the interviews, $F(2,105)=1.71, p=.185, \eta_{\mathrm{p}}^{2}=.032$. On average, participants asked approximately 40 questions $(M=39.92, S D=18.80)$ in each interview with each interview lasting almost 10 minutes $(M=9.96$ minutes, $S D=4.29$; range 2.0717.01 minutes). 


\section{Table 3}

Frequencies of Selected Questions in the Interview Plan per Interviewing Approach

Frequency, \%

Information-gathering Approach

Please report everything even if it seems irrelevant to you, it may be important

87.2

Did you see anyone in the area where the shooting took place?

85.3

Describe everything you saw when you were walking home on early Saturday

84.4

morning

You mentioned " $\mathrm{x}$ " - can you tell me more about it?

72.5

Could you please tell me everything that you remember from early Saturday

morning?

Could you please report what happened in as much as detail as possible?

66.1

Please tell me what happened after/before " $x$ "?

66.1

You mentioned " $x$ " - what did you mean by that?

63.3

Did you see how the shooting took place?

56.9

Try hard to remember - do you remember anything else?

Direct/Accusatorial Approach

Why were you seen on Victoria North Road at the time of the crime?

Where were you and what were you doing on Saturday at 6:00?

You were seen near the crime scene minutes before the shooting - what do you

know about it?

You were near the crime scene on Saturday. Did you see who committed this crime?

Are you involved in gang activities?

It's not your fault if you saw something. Just tell me what happened.

Just admit you accidentally saw something. Are you protecting yourself or someone

involved in this crime?

You must know in which vehicle did the suspect(s) flee the crime scene?

Why don't you know anything else about the shooting if you were there?

You cannot deny you saw something. What happened and why are you not telling me?

Note. The items in the list of questions were presented to participants in a random order. 


\section{Table 4}

Frequencies of Selected Techniques in the Interview Plan per Interviewing Approach

Percentage \%

Information-gathering Approach

Encourage the witness to tell you in their own words and in details what they

87.2

witnessed.

Offer to make the statement anonymous if they are afraid of the suspect(s).

If the witness is unwilling to talk to you, ask why. Find out their reasons for being

uncooperative.

Make the witness feel valued for their knowledge about the event.

Do not interrupt the witness.

Offer support if the witness seems distressed by the situation. 63.3

Be friendly and try to establish rapport with the witness. $\quad 57.8$

Before starting the interview, clearly explain the interview situation and everything 57.8

that is going to happen.

Get the witness talking about another topic to start the conversation. 33.0

Make sure the witness understands that they are not obliged to talk to the police $\quad 13.8$

\section{Direct/Accusatorial Approach}

Emphasise the seriousness of the offense and the consequences of protecting those involved in the crime.

Point out to inconsistencies and contradictions.

Warn the witness that it is illegal to lie to the police.

Trust your instinct and keep pushing for information when the witness avoids a

question or gives short answers.

Use closed and short questions about specific details.

Appeal to the moral character of the witness and remind them that they are needed to get justice (for the victim and their family).

Convince the witness that cooperating is in their best interest, otherwise they can be summoned by the judge.

Repeat the same question until the witness gives you an answer.

Confront the witness when he claims "I don't remember" or "I don't know".

Tell the witness that you suspect they are hiding something.

Note. The items in the list of interviewing techniques were presented to participants in a random order. 


\section{Exploratory Analyses}

\section{Prevalence of Question Type in the Interview Phase}

To take a closer look at the interviewing approach used in the interview, we explored the complete pool of questions asked ( $N=4351$; see Table 5 for descriptive statistics). Across all interviews, there was a predominant preference for direct or probing questions (46.40\%) directed at a specific topic, followed by closed questions that only elicit "yes" or "no" responses (29.51\%), or a forced-choice response between options (6.53\%). Open questions that elicit detailed and complete responses were asked infrequently (9.97\%). Leading questions were seldom asked (5.91\%). Very few of the questions (1.68\%) asked did not relate to the case, and most of them were used to get to know the witness at the beginning of the interview (e.g., rapport-building).

\section{Procedural Statements in the Interview Phase}

The number of statements providing instructions to the witness $(M=6.77, S D=3.97)$ did not differ by experimental condition, $F(2,106)=2.20, p=.116, \eta_{p}^{2}=.040$.

\section{Shift in Interview Approach from the Planning Phase to the Interview Phase}

We explored whether the observed pattern of interviewing, using types of questions more characteristic of a direct and accusatorial interviewing approach, could be attributed to the interviewee's uncooperative behaviour given that the initial interview plans, on average, included more information-gathering questions. To compare the interviewing behaviour against the interview plans, we collapsed the six categories of types of questions employed during the actual interviews into the two interviewing approaches by which the interview plan was measured. Open and personal questions constituted the new 'information-gathering' variable, whereas direct, closed yes/no, and option-posing, as well as leading questions constituted the new 'direct/accusatorial' variable. Then, the proportion of information-gathering questions was calculated by dividing the number of selected information-gathering questions by the total number of selected questions (i.e., information-gathering plus accusatorial questions). 


\section{Table 5}

Means and Standard Deviations for Types of Questions Employed by Condition

\begin{tabular}{|c|c|c|c|c|c|c|c|c|c|c|}
\hline \multirow[t]{3}{*}{ Type of Question } & \multirow[t]{3}{*}{ Frequency, \% } & \multirow{2}{*}{\multicolumn{2}{|c|}{$\begin{array}{l}\text { Control } \\
(n=37)\end{array}$}} & \multirow{2}{*}{\multicolumn{2}{|c|}{$\begin{array}{l}\text { Cooperation } \\
\qquad(n=35)\end{array}$}} & \multirow{2}{*}{\multicolumn{2}{|c|}{$\begin{array}{l}\text { No Cooperation } \\
\qquad(n=37)\end{array}$}} & \multirow[t]{3}{*}{$F(2,106)$} & \multirow[t]{3}{*}{$p$} & \multirow[t]{3}{*}{$\eta_{p}^{2}$} \\
\hline & & & & & & & & & & \\
\hline & & $M$ & $S D$ & $M$ & $S D$ & $M$ & $S D$ & & & \\
\hline Open-ended & 9.97 & 4.65 & 3.14 & 3.14 & 2.33 & 4.11 & 2.85 & 2.66 & .075 & .048 \\
\hline Direct & 46.40 & 20.54 & 8.74 & 17.31 & 8.17 & 17.65 & 9.01 & 1.54 & .220 & .028 \\
\hline Closed yes/no & 29.51 & 12.30 & 6.17 & 10.31 & $5 \cdot 47$ & 12.65 & $9 \cdot 34$ & 1.08 & .342 & .020 \\
\hline Closed option-posing & 6.53 & 3.05 & 3.37 & 2,26 & 2.17 & 2.49 & 3.03 & 0.72 & .489 & .013 \\
\hline Leading & 5.91 & 2.03 & 2.17 & 2.17 & 1.87 & 2.87 & $3 \cdot 50$ & 1.08 & .345 & .020 \\
\hline Personal & 1.68 & 0.68 & 1.40 & 0.49 & 0.70 & 0.84 & 1.09 & 0.91 & .405 & .017 \\
\hline
\end{tabular}

Note. $N=4351$ questions. Percent values represent the proportion of each type of question used in all interviews whereas means and standard deviations indicate the average use across interviews. 
The average proportion of planned information-gathering questions decreased from the interview plan to the interview ( $67 \%$ vs. $12 \%$ ). We conducted a $3 \times 2$ mixed ANOVA that revealed a significant interaction effect of witness cooperation expectations and interviewing phase on the proportion of information-gathering questions, $F(2,106)=5.39, p$ $=.006, \eta_{\mathrm{p}}^{2}=.092$. The main effect of interviewing phase was significant, $F(1,106)=1273.93$, $p<.001, \eta_{p}^{2}=.923$, whereas the main effect of expectations of witness cooperation was not significant, $F(2,106)=1.89, p=.156, \eta_{p}^{2}=.034$. Follow-up simple-effects analysis indicates that the decline in the proportion of information-gathering questions between interview phases was significant in each condition (see Table 6 for average proportions of information-gathering questions and for inferential statistics). On average, participants asked a significantly smaller proportion of information-gathering questions during the interview, in contrast to the proportion of selected information-gathering questions in the planning phase.

\section{Table 6}

Means and Standard Deviations of the Proportion of Information-Gathering Questions across Experimental Phases by Condition

\begin{tabular}{|c|c|c|c|c|c|c|c|c|}
\hline & \multirow[t]{2}{*}{$n$} & \multicolumn{2}{|c|}{ Plan } & \multicolumn{2}{|c|}{ Interview } & \multirow[t]{2}{*}{$F(1,106)$} & \multirow[t]{2}{*}{$p$} & \multirow[t]{2}{*}{$\eta_{p}^{2}$} \\
\hline & & $M$ & $S D$ & $M$ & $S D$ & & & \\
\hline Control & 37 & 0.69 & 0.13 & 0.12 & 0.08 & 516.4 & $<.001 * *$ & .830 \\
\hline Cooperation & 35 & 0.70 & 0.15 & 0.10 & 0.06 & 599.2 & $<.001 * *$ & .850 \\
\hline No Cooperation & 37 & 0.61 & 0.17 & 0.13 & 0.07 & 258.6 & $<.001 * *$ & .709 \\
\hline
\end{tabular}

Note. Double asterisks indicate significance at alpha level $p<.001$.

\section{Post-interview Witness Performance Judgements}

After the interview, participants rated the quality of the witness's account (e.g., 'The witness provided accurate / detailed / comprehensive / consistent / trustworthy information'), on a seven-point Likert scale with values ranging from 'Completely Disagree' to 'Completely Agree'. The Cronbach's alpha coefficient indicated good item reliability, $\alpha=$ 0.85 . Hence, we conducted a MANOVA showing that witness cooperation expectations did not significantly affect witness performance judgements, Wilk's Lambda $\Lambda=0.93, F(2,106)$ $=0.64, p=.809, \eta_{p}^{2}=.036$. 


\section{Discussion}

The findings indicate that our expectancy manipulation did not affect the interviewing approach in the interview planning phase and nor did it affect the interviewing behaviour in the interview phase. Our findings instead indicated a marked difference in the interviewing approach used from the interviewing approach outlined in the planning phase. Contrary to our first set of hypotheses, we found that interview plans indicated a generalised preference for an information-gathering approach to interviewing in which most of the planned questions and techniques selected were in line with effective witness interviewing guidelines, primarily aimed at building rapport and facilitating cooperation and disclosure (Fisher, 2010; Vrij et al., 2014).

Contrary to our second set of predictions, we found that interviewing behaviour (i.e., questions asked in the interview) was not affected by the different expectations of witness cooperation. The interviewing approach used in most of the interviews over-relied on direct and closed questions that restrict the amount of information reported (Oxburgh et al., 2010; Sharman \& Powell, 2012). In contrast, open-ended questions shown to encourage more accuracy and details in witness accounts were used less often (Fisher, 2010). Leading questions were posed, albeit at a low rate.

The interviewing behaviour displayed by participants was not in line with evidencebased approaches to gain cooperation and elicit accurate information. Previous research has found similar patterns of intuitive interviewing among untrained police officers (Clifford \& George, 1996). Despite the different characteristics of this sample from those of police practitioners, the participants' interviewing behaviour was in line with the interviewing practices of police practitioners in some jurisdictions where witness interviews are conducted using mainly a direct approach that fails to promote cooperation and facilitate disclosure (Clarke \& Milne, 2001; Griffiths et al., 2011; Schreiber Compo et al., 2012; Snook \& Keating, 2011; Wright \& Alison, 2014).

We found that interviewing plans did not correspond to interviewing behaviour, which, based on our exploratory analysis, could be a result of the uncooperative witness's behaviour. The difference between the planning phase of the interview and the actual interviewing behaviour reflected a shift from an information-gathering approach to an 
accusatorial approach to interviewing. This shift could be explained by the increased difficulty introduced by the manipulated uncooperative behaviour of the witness, in the already complex task of investigative interviewing (Baldwin, 1993; Griffiths et al., 2011). This finding aligns with previous research showing the detrimental effects of lack of interviewee cooperation from on interviewer behaviour (e.g., Hershkowitz et al., 2006), a finding previously confirmed in questionable investigative practice (Davis \& Leo, 2016; Gross \& Gross, 2013; Moore et al., 2014). Relevant to the police interviewing of uncooperative witnesses, failing to secure cooperation from the onset can shift cooperative witnesses towards uncooperativeness (Collins et al., 2002) or exacerbate initial reluctance (Fisher \& Geiselman, 2010).

Findings from this experiment provide preliminary evidence that lack of witness cooperation, in combination with the low skill levels of untrained interviewers and a mismatch between expectations of and actual cooperation would seem to result in a deterioration of interviewing performance. Previous research has shown that the interviewer's expectations and training are important determinants of interviewing behaviour (Dando et al., 2008; Roberts, 2010; Smith et al., 2009; Soukara et al., 2002). Therefore, this finding highlights the need for interviewing training for everyone conducting police witness interviews (Oxburgh \& Dando, 2011; Snook et al., 2012). In particular, effective interviewing of uncooperative witnesses would seem to require specialised interviewing skills to adapt to the needs and demands of the interviewee (Alison et al., 2013). In practice, interviewers may need to be flexible (Bull \& Cherryman, 1996; Cherryman \& Bull, 2001), and competent at utilising different techniques to gain, maintain, and recover cooperation in order to facilitate witness disclosure (for a review, see Gabbert et al., 2020) and avoid decreased information elicitation driven by lack of cooperation (De La Fuente Vilar et al., 2020). In addition, the discrepancies observed between how interviews were planned and conducted also emphasise the importance of evaluating actual interviewing to identify any gaps between knowledge and practice.

\section{Methodological Considerations and Future Directions}

In mock police interviews, we empirically examined the effects of expectations of witness cooperation on interviewing. For this, we adapted the experimental paradigm used 
in previous studies of confirmation bias in suspects (Kassin et al., 2003; Narchet et al., 2011). Unlike in Kassin and colleagues (2003; Phase I) our participants conducted an interview face to face rather than over the phone overcoming one of the limitations of previous research. In addition, in our experimental design, the expectancy bias was introduced in the case information, which averted the risk of experimenter's effects contaminating the introduction of the bias. Furthermore, biased information is more likely to naturally be introduced in this manner in real-life criminal investigations. Biased evidence - such as police reports - can contaminate the subsequent interpretation of other pieces of the evidence (Kassin et al., 2013), including assessments of witness testimony (Ask \& Granhag, 2007). In addition, our experimental design enabled control of the interviewee behaviour by introducing a confederate as the witness thereby isolating the effects of the bias on the interviewer, which would not have been possible if following the participation in pairs, as in Kassin et al.'s (2003) and Narchet et al.'s (2011) experiments. This decision was essential to ensure that the witness would be uncooperative and, crucially, antagonistic to the goal of information elicitation so that we could examine how this challenge was addressed by participants. Based on the manipulation checks, we successfully introduced the bias before the interview and irrespective of it, and the participants equally perceived the confederate playing the role of the witness to be uncooperative. To our knowledge, few experimental manipulations have been tested recently to examine interview dynamics in the face of interviewee resistance (see Brimbal et al., 2019; Dando \& Ormerod, 2019; De La Fuente Vilar et al., 2020; Duke et al., 2018). In that context, our study's design contributes to the emergent body of research that experimentally examines the role of cooperation and the lack thereof in information elicitation, focusing on the context of witness interviews. With appropriate modifications, this methodology may also be useful for training purposes. However, our findings should also be considered in light of certain limitations (see also 'Methodological Considerations' in Chapter 6).

We did not find support for our hypothesised effect of biased expectations of witness cooperation on how interviews were planned and conducted. While the manipulation check indicated that we effectively introduced the bias, it is possible that we failed to induce a sufficiently strong belief in participants regarding witness cooperation. Instead, it is possible that we superficially modified how the witness was perceived, which 
did not activate a confirmatory bias with respect to how participants interviewed the mock witness. This could have been the case given our sample of untrained novice civilians who had no expertise in terms of police investigations or requisite training in conducting investigative interviews. While participants appreciated the differences in witness cooperation delivered in our experimental manipulation, they may not have comprehended the implications for this factor on their information elicitation goals given their limited interviewing experience. Even if they did, it is likely they were not equipped to adapt and tailor their interviewing approach in light of the witness cooperation. The use of a convenience sample rather than police practitioners underscores a limitation of ecological validity, and in light of this we strongly encourage replication of this study with a police sample. In a police sample holding requisite knowledge of witness interviewing, participants can be asked to generate their own questions and techniques rather than choosing from a given list, thereby removing one other aspect that reduced validity in our experimental design.

Our non-significant findings should also be interpreted in light of our sample size. While we concur with the argument about the low informative value of post hoc analyses, particularly for non-significant results (Lakens, 2014), in the interest of transparency, we report that the achieved power was 0.63 . Conventionally, a value below 0.80 indicates low power to detect a true effect size. However, a sensitivity analysis revealed that the current sample size could detect an effect size of $d=0.60$. This indicates that the experiment was sufficiently powered to detect the effect size used for the a priori calculation $(d=0.72)$. We acknowledge that the true effect could be smaller than the one used in our a priori power analysis, and if that is the case, the current study was not sufficiently powered to detect it. Alternatively, it is also possible that there is indeed no effect as we have reported (i.e., a true null-finding). In both cases, replication of our findings is necessary and we would suggest using a sequential analyses to reach an appropriate sample size (Lakens \& Evers, 2014).

Controlling the interviewee behaviour was a trade-off between experimental control and ecological validity in the current study. Deliberately, we used a single confederate, which in practice reduced the potential confounding noise of several different interviewees behaving in different ways; however, it further limits generalisability. Future research could 
include participants assigned to cooperative and uncooperative conditions to test the effects of cooperation and the lack thereof in the naturally occurring dynamic interaction between mock interviewers and interviewees. Analysing recorded police witness interviews would also allow for an examination of such a dynamic in the context in which it occurs in order to examine the effects of interviewing techniques on the interviewee's engagement and willingness to disclose information and the effects of witness cooperation on the interviewing approach. For this necessary advance in witness interviewing research, however, recorded police interviews conducted with cooperative and uncooperative witnesses need to be made available to researchers. As field and archival research in the witness interviewing domain is scarce (Launay \& Py, 2015; see also Chapter 2), in future experimental research, dyads might take part in interviews in which the interviewee is not motivated to cooperate, in order to examine which interviewing techniques are effective at gaining cooperation and overcoming witness resistance. In such a design, comparisons between cooperative and uncooperative witness behaviour could also be introduced to advance our understanding of the role of cooperation in the interviewing approach.

\section{Conclusions}

We provide initial empirical evidence for the effects of lack of witness cooperation on the interviewing approach used to elicit information. Specifically, our findings show that the planned interviewing behaviour shifted from an information-gathering approach to a direct approach to interviewing in the face of uncooperative witness behaviour. Although participants planned an information-gathering approach that could have promoted cooperation and facilitated disclosure, during the interview, participants posed very few open questions and over-relied on asking direct and closed questions. Contrary to our predictions, no expectancy effects concerning witness cooperation affected how the interview was planned and conducted. Instead, lack of witness cooperation represented an extra challenge in the already complex task of effective interviewing, one for which specialised interviewing training and techniques are required. We call for further research to examine interviewing techniques that effectively promote cooperation and reduce resistance from witnesses who are, at least initially, uncooperative. 

Chapter 5

Effects of Cooperation on Information Disclosure in Mock-Witness Interviews

This chapter in its present form has been published as:

De La Fuente Vilar, A., Horselenberg, R., Strömwall, L. A., Landström, S., Hope, L., \& van Koppen P. J. (2020). Effects of Cooperation on Information Disclosure in Mock-Witness Interviews. Legal and Criminological Psychology, 25(2), 133-149.

https://doi.org/10.1111/lcrp.12167 



\begin{abstract}
Purpose: Forensic interviewers often face witnesses who are unwilling to cooperate with the investigation. In this experimental study, we examined the extent to which cooperativeness instructions affect information disclosure in a witness investigative interview.

Methods: One-hundred and thirty-six participants watched a recorded mock-crime, and were interviewed twice as mock-witnesses. They were randomly assigned to one of four conditions instructing different levels of cooperativeness: Control (no instructions), Cooperation, No Cooperation, and No Cooperation plus Cooperation. The cooperativeness instructions aimed to influence how participants' perceived the costs and benefits of cooperation. We predicted that Cooperation and No Cooperation instructions would increase and decrease information disclosure and accuracy respectively.

Results: We found decreased information disclosure and, to a lesser extent, accuracy in the No Cooperation and No Cooperation plus Cooperation conditions. In a second interview, the shift of instructions from No Cooperation to Cooperation led to a limited increase of information disclosure at no cost of accuracy. Cooperativeness instructions partially influenced the communication strategies participants used to disclose or withhold information.

Conclusions: Our results demonstrate the detrimental effects of uncooperativeness on information disclosure and, to a lesser extent, the accuracy of witness statements. We discuss the implications of a lack of witness cooperation and the importance of gaining witness cooperation to facilitate information disclosure in investigative interviews.
\end{abstract}




\section{Effects of Cooperation on Information Disclosure in Mock-Witness Interviews}

Witnesses can provide crucial information in a criminal investigation, which later can serve as evidence in court (Fisher et al., 2011). In an investigative interview, witnesses hold first-hand knowledge not available to the police, thus by definition, witnesses are in control of the information and the onus to elicit accurate, detailed and complete witness accounts is on the interviewer (Fisher, 1995; Vrij et al., 2014). Interviewers consequently rely heavily on witnesses' cooperation and their willingness to disclose information. However, some witnesses do not want to get involved in criminal investigations and are unwilling to divulge information to the police (Spencer \& Stern, 2001), which can be detrimental to effective crime management (Tyler \& Fagan, 2008). Despite its relevance, the effects of lack of witness cooperation on information disclosure within investigative interviews has received little scientific scrutiny. In this experimental study, we examined the extent to which cooperativeness instructions affected information disclosure and accuracy of witness statements.

\section{Uncooperative Witnesses in Investigative Interviews}

Police officers report frequently encountering witnesses who are unwilling to become involved in the investigative process (Confrey, 2017; De La Fuente Vilar et al., 2018; Wheeler et al., 2017). Some witnesses are reluctant to talk, resistant to engage in the investigation, and can be hostile towards the police (Shepherd \& Griffiths, 2013). Witnesses who have been intimidated are also averse to cooperate with the police (Maynard, 1994). Beyond these labels and legal categories, witnesses' lack of motivation to cooperate with police is what characterises uncooperative witnesses. Their cooperativeness (or lack thereof) is reflected in their behaviour as witnesses, which in the context of an investigative interview, is their willingness to disclose detailed and accurate information.

Lack of witness cooperation can be motivated by fear of retribution from the suspect, a relationship with the suspect, a criminal history or risk of self-incrimination, distrust of the police or the criminal justice system, type and severity of the crime, cultural differences, language barriers, witness apathy or the inconvenience of legal proceedings 
(Confrey, 2017; Papp et al., 2017; Shepherd \& Griffiths, 2013; Spencer \& Stern, 2001; Westera \& Powell, 2015).

\section{Witness Cooperation and Information Disclosure in Investigative Interviews}

Individuals regulate their behaviour based on a subjective evaluation of benefits and costs (Homans, 1958). As in other social interactions and interpersonal relationships, civilian cooperation with the police is regulated by moral ideas about society and by any associated consequences and risks (Papp et al., 2017). A behavioural economics approach involving cost-benefits analysis has been proposed to account for decisions to report crime by witnesses (Kidd, 1979) and victims (Bowles et al., 2009; Goudriaan, 2006); as well as to explain information disclosure in interrogations by suspects (Yang et al., 2017) and informants (Neequaye \& Luke, 2018).

We propose to extend the cost-benefit analysis model for reporting crime by witnesses (Kidd, 1979), to the analysis of witnesses' decision to disclose information in investigative interviews. We argue that interview outcomes depend on the internal motivation of the witness to engage and cooperate with the interviewer, which ultimately determine the quality of witness statements. Consequently, the decision of a witness to disclose information is motivated by the perceived high benefits (and the low costs) associated with cooperating with the interviewer. Conversely, a subjective evaluation of high costs with no perceived benefits can lead to the decision of a witness to not cooperate with the interviewer, thus negatively affecting information disclosure.

A commonly held expectation is that an individual who becomes a witness to a crime will cooperate with the police (Fyfe \& Smith, 2007; Roberts, 2010). Given the demands of an investigative interview, interviewers expect disclosure of truthful and relevant information as is required and delivered in an efficient manner (Antaki \& Stokoe, 2017). Nonetheless, police officers report that witnesses rarely provide sufficient information during investigative interviews (Kebbell \& Milne, 1998). Lack of disclosure of information is often associated with memory limitations. However, due to social and motivational rather than cognitive factors, some interviewees who can remember are unwilling to report what they recall (Granhag et al., 2015; Shepherd, 1993; Westera \& Powell, 2015). 
Individuals strategically control whether to report or omit pieces of information based on personal and situational goals (Koriat \& Goldsmith, 1994). This monitoring process determines the quantity, accuracy and level of detail of the information disclosed. As a result, in the context of reporting to aid a criminal investigation, there are indications that individuals focus on maximising accurate and forensically relevant information (Brewer et al., 2018). Findings from eyewitness research indicate that cooperative witnesses in general are highly accurate and provide detailed albeit incomplete statements (e.g., Hope et al., 2013; Smeets et al., 2004).

The extent to which lack of witness cooperation regulates information disclosure has not previously been examined. However, similar research in human intelligence gathering demonstrated that uncooperative sources resist cooperating and avoid disclosing information by strategically omitting new or critical information and engage in providing succinct, fabricated, scripted, unrelated or no answers when being interviewed (Alison et al., 2014). Moreover, in order to appear cooperative, some interviewees aim to strike a balance of disclosing not too much nor too little information (Granhag et al., 2015).

Based on previous research, regulating information disclosure in the context of a witness interview is likely to affect the memory for the event. Researchers have shown that whether withholding information is accompanied, or not, by remembering determines memory preservation or forgetting (Stone et al., 2012). On one hand, unreported information may be forgotten due to lack of rehearsal. On the other hand, mental rehearsal facilitates remembering, even when information is not disclosed in conversation (Smith et al., 2013) and suppression efforts can be unsuccessful when purposefully trying to not remember an event (Anderson \& Green, 2011). Memory, therefore, is not necessarily impaired as a result of lack of disclosure (Stone et al., 2012). However, findings from experimental research examining the consequences of feigning crime amnesia showed that withholding information produces a memory-undermining effect and genuinely reporting it later comes at a cost for accuracy (Christianson \& Bylin, 1999; Van Oorsouw \& Merckelbach, 2004, 2006). More recent research on this topic suggests that the undermining memory effects of withholding information are not long lasting and might be an artefact of testing (Mangiulli et al., 2018; Sun et al., 2009). Another likely explanation for these positive effects in memory is the lack of purposeful avoidance and suppression efforts when withholding 
information (Otgaar \& Baker, 2018). While the mnemonic effects of witnesses withholding crime information have not been examined previously, it could mean that if uncooperative witnesses were not motivated to forget the event their memory of it might be preserved despite lack of disclosure. This expected memory preservation effect could be due to the self-rehearsal practice involved in remembering the event even in the absence of reporting which enhances memory recollection (Mangiulli et al., 2019).

\section{The Present Research}

The effects of lack of witness cooperation on the elicited information in an investigative interview have not been empirically tested. To address that shortcoming, we examined the extent to which the witnesses' cooperativeness affects information disclosure and accuracy of witness statements in investigative interviews. Participants were interviewed after watching a recorded mock-crime. We expected a cost-benefit analysis to guide the witness' decision to cooperate (Kidd, 1979), and subsequently disclose information. We manipulated the perception of benefits and costs associated with cooperating with the interviewer. Specifically, we increased the perceived cost of cooperation by placing participants at risk of self-incrimination; inversely, we increased the perceived benefits of cooperating by emphasizing civil duty of serving as a key witness in the investigation (Spencer \& Stern, 2001). In addition, participants received instructions designed to encourage cooperativeness or lack of cooperativeness, but independently decided on the extent of their disclosure thus allowing us to examine whether cooperativeness regulates information disclosure.

We hypothesised that cooperativeness instructions would affect information disclosure (measured in number of details) and accuracy. Specifically:

Hypothesis 1: We expected the instructions to cooperate to increase both information disclosure (hypothesis 1a) and accuracy (hypothesis 1b) in the Cooperation condition, and the instructions to not cooperate to decrease them in the No Cooperation and No Cooperation plus Cooperation condition in contrast with the Control condition, in the first interview.

Hypothesis 2: We predicted that the instructions to cooperate would increase both information disclosure (hypothesis $2 a$ ) and accuracy (hypothesis $2 b$ ) in the Cooperation 
condition, and the instructions to not cooperate to decrease them in the No Cooperation condition in contrast with the Control condition, in the second interview. Moreover, for the No Cooperation plus Cooperation condition we expected that a new instruction to cooperate, after initial instructions to not cooperate in the first interview, would effectively reframe the costs and benefits associated with cooperating consequently increasing information disclosure in the second interview.

Hypothesis 3: We hypothesised that the new instruction to cooperate would increase disclosure for the No Cooperation plus Cooperation condition in the second interview versus the first interview. Considering the different findings regarding the mnemonic effects of withholding information (cf. Stone et al., 2012), we did not provide directional hypotheses for the effects of delayed disclosure on the accuracy of previously withheld information.

Hypothesis 4: We also hypothesised that participants would regulate and strategically control information disclosure to avoid cooperating with the interviewer's requests of information. Therefore, we predicted that participants would use different communication strategies to disclose or withhold information according to the instructions to cooperate and not cooperate in the simulated interviews.

\section{Method}

\section{Participants and Design}

One-hundred-and-forty university students initially participated in the study. They earned either one research credit or a €10 gift card as compensation for their participation. Four cases were excluded (one participant did not attend the second interview while the remaining three participants were excluded due to technological problems during the interviews). Participants ( $N=136,78.7 \%$ female; $18-57$ years of age; $M=23.17$ years, $S D=$ 6.96) were randomly assigned to four experimental conditions instructing their cooperativeness: Control (no instructions), Cooperation, No Cooperation, and No Cooperation plus Cooperation (with 34 participants in each group), in a between-subjects design with cooperativeness instructions as independent variable and information disclosure (total amount of details) and accuracy as the main dependent variables. This research received approval by the university's ethical committee. 


\section{Materials}

\section{Stimulus Event}

Participants watched a recorded mock-crime (Takarangi et al., 2006). The recording lasts six minutes and 30 seconds, and depicts a home burglary. A man enters a house and performs different electrical work whilst stealing some objects from the household.

\section{Post-interview Questionnaires}

Participants self-reported whether they complied with the experimental instructions and how much complete information they estimated they disclosed in the interview. Participants provided ratings on a 5-point scale, with values ranging from 'Not at all' to 'Extremely', where higher scores indicated higher compliance and higher information disclosure respectively. Lastly, participants reported the communication strategies they used to disclose information. They provided ratings on a 5 point scale with values ranging from 'Never' to 'Always', where higher scores indicated higher frequency of use (see Table 3 for the listed strategies and descriptive statistics).

\section{Procedure}

\section{Interview 1}

Prior to watching the stimulus video, participants were asked to pay attention to the footage of a burglary, as they would be asked to provide a statement as an eyewitness to the crime later. During a 10-minute delay interval participants completed a demographics questionnaire, and performed an unrelated distraction task. Then, participants were asked to imagine being at a police station for an investigative interview about what they had seen. They received the cooperativeness instructions according to their experimental condition (see Appendix 7). As an incentive, participants were warned that failure to follow the instructions would disqualify them from receiving their compensation for participation.

Participants who were in the Cooperation condition were asked to act as the key and only witness in the investigation and instructed to cooperate with the police. They were reminded of the importance of their testimony to advance the investigation. In the No Cooperation and No Cooperation plus Cooperation (Interview 1) conditions, participants received instructions to not cooperate, and were explicitly told they were innocent of any crime but that the police was considering their involvement in the burglary. Participants 
were instructed to not cooperate with the police, but were not directed on how not to cooperate. As incentive to comply with the instructions to not cooperate, participants received a warning that their statement might incriminate them as they were present at the time of the crime and knew the suspect. In the Control condition, participants were instructed that they were independent witnesses who did not know the victim or the suspect, and they did not receive any instructions regarding cooperation.

All participants provided a verbal free recall account of the event, after which they were prompted once to provide any extra information. All interviews followed the same interviewing script that included evidence-based interviewing guidelines for witness interviews (e.g., rapport-building, mental context reinstatement, instructions to report everything in detail and to avoid guessing; Fisher et al., 2011).

\section{Interview 2}

All participants returned to the laboratory a week later, they all received the same instructions for the second interview, except for the participants in the No Cooperation plus Cooperation condition. Participants in that condition were informed that the police no longer had the suspicion they had committed the crime and therefore they were not at risk of being incriminated. They were instructed to act as independent witnesses and to cooperate in this second interview, and they were reminded of the importance of their new statement to advance the investigation. However, they were not asked to act as the key witness in the investigation, which was the role prescribed for participants in the Cooperation condition in both interviews.

\section{Coding}

Participants gave consent to be audio-recorded in both interviews and verbatim transcripts were used for coding. We coded details as correct if they were reported as presented in the recorded mock-crime, or as incorrect if they were in error or not present in the recording. The total amount of details was tallied for each interview as a measure of information disclosure. An index of accuracy was calculated for each interview by dividing the number of correctly recalled details by the total number of details (e.g., the sum of the number of correctly reported details plus the number of incorrect details). 


\section{Inter-rater Reliability}

A random sample of $25 \%$ interviews were coded by a research assistant blind to the experimental conditions. The level of inter-rater agreement was high, ICC $=.96,95 \% \mathrm{Cl}[.87$, $.99]$, and $I C C=.95,95 \% \mathrm{Cl}[.85, .98]$ for correct and incorrect details respectively.

\section{Results}

\section{Preliminary Analyses}

Participants reported themselves to be compliant with the experimental instructions $(M=4.64, S D=0.50)$. A one-way between-subjects analysis of variance (ANOVA) showed that participants' self-reported compliance with the experimental instructions to regulate their cooperativeness did not vary between the experimental conditions, $F(3,132)=1.20, p=$ $.311, \omega^{2}=.005$. This means participants reported to have followed the instructions to cooperate and to not cooperate. Participants also reported how much complete information they believed they disclosed in the interviews, $F(3,132)=3.03, p=.032, \omega^{2}=$ .043 ; Control $M=3.82, S D=0.94$ versus Cooperation $M=4.09, S D=0.71$ versus No Cooperation $M=3.53, S D=0.79$ versus No Cooperation plus Cooperation $M=3.82, S D=.58$. Post hoc comparisons with Bonferroni corrections revealed that the participants that received No Cooperation instructions indicated disclosing less information compared to those that received Cooperation instructions, $t(132)=3.02, p=.018, d=-.74,95 \% \mathrm{Cl}[-1.24$, 0.26]. All other pairwise comparisons were not statistically different (all $p s>.05$ ). These findings show that participants to some extent disclosed information according to the instructions to cooperate and not cooperate.

\section{Hypotheses Testing}

\section{Interview 1. Does Cooperativeness Affect Information Disclosure?}

We conducted a one-way between-subjects ANOVA that revealed a significant effect of cooperativeness instructions on information disclosure in the first interview, $F(3$, 132 ) $=13.43, p<.001, \omega^{2}=.215$ (see Table 1 for descriptive statistics and outcomes of condition comparisons). Follow up post hoc comparisons with Bonferroni corrections showed that information disclosure in the Control condition was significantly higher than in the No Cooperation condition, $t(132)=4.70, p<.001, d=-1.06,95 \% \mathrm{Cl}[-1.58,-0.56] ;$ and the 
No Cooperation plus Cooperation condition, $t(132)=5.53, p<.001, d=-1.33,95 \% \mathrm{Cl}[-1.85$, 0.80]. Similarly, information disclosure was significantly higher in the Cooperation condition compared to the No Cooperation condition, $t(132)=3.07, p=.016, d=-.75,95 \% \mathrm{Cl}[-1.24,-$ $0.26]$; and the No Cooperation plus Cooperation condition, $t(132)=3.89, p<.001, d=-1.02$, $95 \% \mathrm{Cl}[-1.53,-0.52]$. The difference between the Control and the Cooperation conditions was not significant, $t(132)=1.64, p=.627, d=-.37,95 \% \mathrm{Cl}[-0.84,0.11]$, and neither was the comparison between the two No Cooperation conditions, $t(132)=0.82, p=1.00, d=.22,95 \%$ $\mathrm{Cl}[-0.70,0.26]$. These results provide partial support to hypothesis $1 \mathrm{a}$, indicating that during the first interview, participants from the No Cooperation and No Cooperation plus Cooperation conditions disclosed significantly less information than those in the Control condition. However, participants in the Cooperation condition did not disclose significantly more information than those in the Control condition. Information disclosure by participants in the Control condition was higher than in the Cooperative condition, but not statistically different.

Table 1

Means and Standard Deviations for Information Disclosure and Accuracy in Interview 1 by Condition.

\begin{tabular}{|c|c|c|c|c|}
\hline & \multicolumn{2}{|c|}{ Information Disclosure } & \multicolumn{2}{|c|}{ Accuracy Rate } \\
\hline & $M$ & $S D$ & $M$ & $S D$ \\
\hline Control & $112.15 \mathrm{a}$ & 46.51 & $0.85 a$ & 0.08 \\
\hline Cooperation & $96.26 a$ & 40.34 & $0.82 \mathrm{a}, \mathrm{b}$ & 1.00 \\
\hline No Cooperation & $66.44 b$ & 39.07 & $0.79 a, b$ & 0.19 \\
\hline No Cooperation plus Cooperation & 58.47 b & 33.19 & $0.76 b$ & 0.19 \\
\hline
\end{tabular}

Note. Means sharing a common subscript are not statistically different at $p<.05$ according to post hoc comparisons.

\section{Does Cooperativeness Affect Accuracy in Interview 1?}

We conducted a one-way between-subjects ANOVA of cooperativeness instructions on accuracy of the information disclosed during the first interview. The Levene's test indicated inequality of variance $(p<.001)$, therefore we report the Welch $F$-ratio. There was a significant effect of cooperativeness instructions on the overall accuracy of the information disclosed, $F(3,131)=3.93, p=.012, \omega^{2}=.05$. Follow up Games-Howell post hoc 
comparisons showed that accuracy means were high and similar across the conditions (see Table 1 for descriptive statistics and outcomes of condition comparisons), except for significantly higher accuracy rates in the Control condition compared to the No Cooperation plus Cooperation condition, $t(131)=2.71, p=.046, d=-.62,95 \% \mathrm{Cl}[-1.11,-0.13]$. Overall accuracy rates were high across conditions. However, participants in the No Cooperation plus Cooperation condition disclosed less accurate information (76\%) than those in the Control condition (85\%). Providing partial support for hypothesis $1 \mathrm{~b}$, we found that cooperativeness instructions regulated to a small extent the proportion of accurate information disclosed during the first interview. Specifically, participants in the No Cooperation plus Cooperation disclosed significantly less accurate information, but participants in the Cooperation condition did not provide more accurate information.

Figure 1

Mean Number of Disclosed Details by Condition in Interview 1 and 2

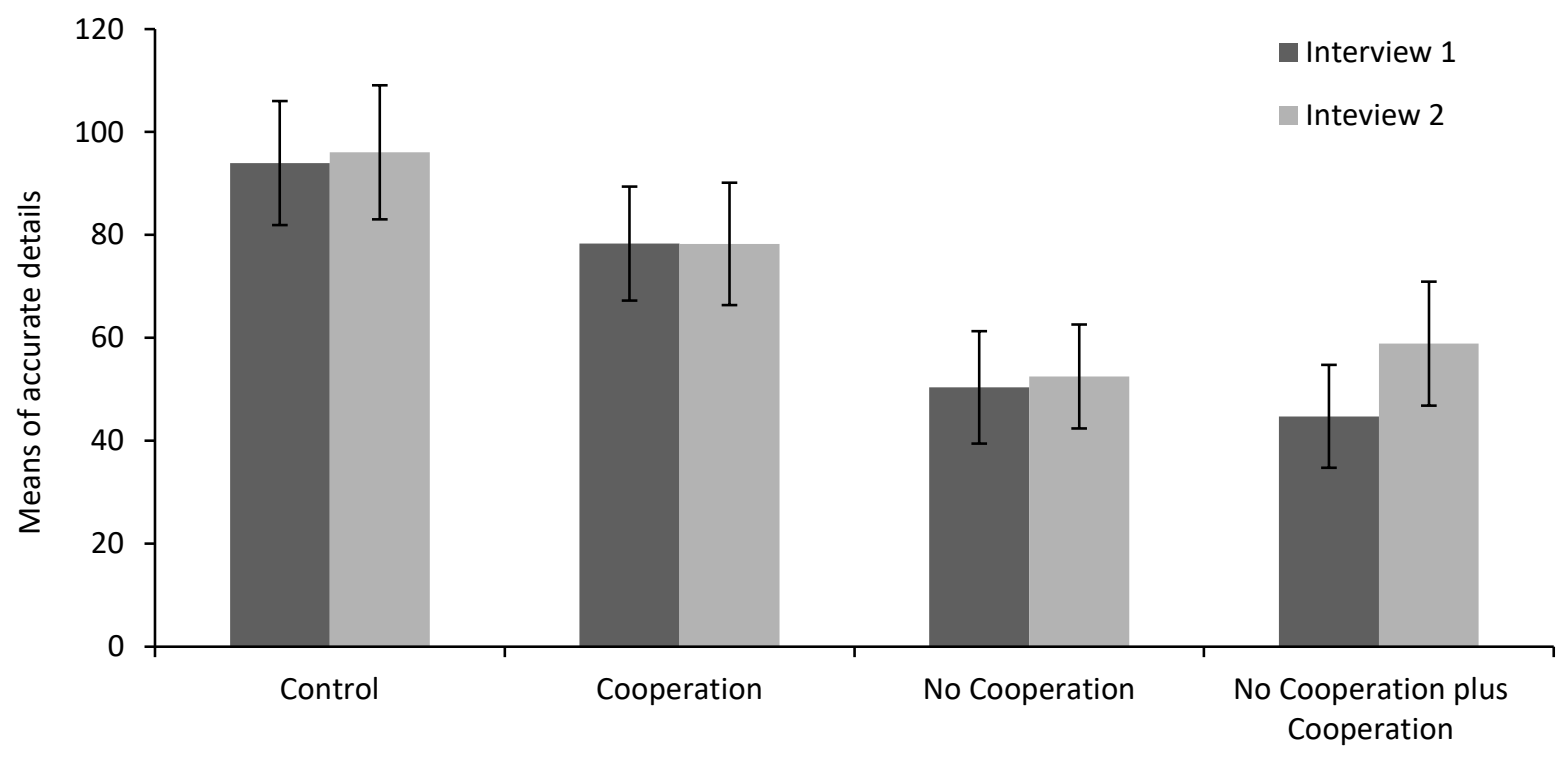

Note. Error bars represent \pm 1.96 standard errors ( $95 \%$ confidence intervals). 


\section{Does Increased Cooperativeness Affect Delayed Disclosure in Interview 2?}

We conducted a between-subjects ANOVA of cooperativeness instructions on information disclosure during the second interview (see Figure 1 for the effect of cooperativeness instructions on information disclosure in both interviews). We found a significant effect of cooperativeness instructions on the information disclosed in the second interview, $F(3,132)=8.01, p<.001, \omega^{2}=.134$ (see Table 2 for descriptive statistics and outcomes of condition comparisons). Follow up post hoc comparisons with Bonferroni corrections showed that information disclosure in the Control condition was significantly higher than the No Cooperation condition, $t(132)=4.36, p<.001, d=1.04,95 \% \mathrm{Cl}[-1.54$, $0.53]$ and the No Cooperation plus Cooperation condition, $t(132)=3.87, p<.001, d=0.92$, $95 \% \mathrm{Cl}[-1.42,-0.42]$. All other pairwise comparisons were not significant $(p>.05)$. Providing only partial support for hypothesis 2, we found that No Cooperation instructions decreased disclosure whereas Cooperation instructions did not lead to higher rates of disclosure compared to the Control condition. Furthermore, those that received a new Cooperation instruction in the No Cooperation plus Cooperation condition did not disclose as much information as those participants in the Control condition during the second interview.

We conducted a paired-sample t-test on the total amount of information disclosed for the No Cooperation plus Cooperation condition across both interviews and found that disclosure significantly increased from the first $(M=58.47, S D=33.19)$ to the second interview $(M=77.59, S D=38.74) ; t(33)=-2.51, p=.017, d=.53,95 \% \mathrm{Cl}[0.05,1.01]$. Providing support for hypothesis 3 , the No Cooperation plus Cooperation instruction to shift from uncooperativeness to cooperativeness in the second interview significantly increased the total amount of information disclosed for that condition. Nonetheless, the previous finding indicated that the new cooperativeness instruction did not elicit overall comparable delayed disclosure. Together, these findings indicate that instructing cooperativeness after initial uncooperativeness can increase information disclosure only to some extent. 
Table 2

Means and Standard Deviations for Information Disclosure and Accuracy in Interview 2 by Condition.

\begin{tabular}{|c|c|c|c|c|}
\hline & \multicolumn{2}{|c|}{ Information Disclosure } & \multicolumn{2}{|c|}{ Accuracy Rate } \\
\hline & $M$ & $S D$ & $M$ & $S D$ \\
\hline Control & $118.12 \mathrm{a}$ & 49.09 & $0.83 a$ & 0.10 \\
\hline Cooperation & $98.79 a, b$ & 45.65 & 0.80 a & 0.09 \\
\hline No Cooperation & $72.44 b$ & 38.32 & $0.74 \mathrm{a}$ & 0.21 \\
\hline No Cooperation plus Cooperation & $77 \cdot 59 b$ & 38.74 & $0.74 \mathrm{a}$ & 0.30 \\
\hline
\end{tabular}

Note. Means sharing a common subscript are not statistically different at $p<.05$ according to post hoc comparisons.

\section{Does Cooperativeness Affect Communication Strategies To Disclose Information?}

Self-report ratings were used to explore the extent to which communication strategies to disclose or withhold information are a function of cooperativeness instructions. To test hypothesis 4, ANOVAs were carried out for each communication strategy, and followed up with Bonferroni-corrected post hoc comparisons. For parsimony, only significant effects are reported (see Table 3 for complete descriptive and inferential statistics and Appendix 8 for non-significant effects). When the assumption of homogeneity of variance was violated, corrected Welch F-ratios were computed and Games-Howell post hoc comparisons calculated. We found that instructed cooperativeness affected participants' willingness to provide accurate information, Welch $F(3,132)=4 \cdot 77, p=.004, \omega^{2}$ $=.089$. Post hoc comparisons revealed that participants in the No Cooperation condition indicated including less accurate information in their statements compared to those in the control condition, $t(132)=3.09, p=.017, d=.75,95 \% \mathrm{Cl}[0.26,1.24]$, and the No Cooperation plus Cooperation condition, $t(132)=-3.03, p=.018, d=.73,95 \% \mathrm{Cl}[0.24,1.23]$. Furthermore, participants reported they included both accurate and inaccurate information in their statements according to cooperativeness instructions, $F(3,132)=4.67, p=.004, \omega^{2}=.075$. 
Chapter 5

Table 3

Means and Standard Deviations of Self-reported Communication Strategies per Condition with Inferential Statistics

\begin{tabular}{|c|c|c|c|c|c|c|c|c|c|c|c|}
\hline & \multicolumn{2}{|c|}{ Control } & \multicolumn{2}{|c|}{ Cooperation } & \multicolumn{2}{|c|}{ No Cooperation } & \multirow{2}{*}{\multicolumn{2}{|c|}{$\begin{array}{l}\text { No Cooperation plus } \\
\text { Cooperation }\end{array}$}} & \multirow[t]{3}{*}{$F(3,132)$} & \multirow[t]{3}{*}{$p$} & \multirow[t]{3}{*}{$\omega^{2}$} \\
\hline & & & & & & & & & & & \\
\hline & $M$ & $S D$ & $M$ & $S D$ & $M$ & $S D$ & $M$ & $S D$ & & & \\
\hline Accurate information & $4.12 \mathrm{a}$ & 0.48 & $3.82 \mathrm{a}, \mathrm{b}$ & 0.58 & $3.62 b$ & 0.82 & $4.15 \mathrm{a}$ & 0.61 & 4.77 & $.004^{*}$ & .089 \\
\hline Inaccurate information & $1.85 \mathrm{a}$ & 0.17 & $1.79 \mathrm{a}, \mathrm{b}$ & 0.17 & $2.41 \mathrm{~b}$ & 0.17 & $2.06 \mathrm{a}, \mathrm{b}$ & 0.17 & 2.67 & .054 & .039 \\
\hline $\begin{array}{l}\text { Combination of accurate and } \\
\text { inaccurate information }\end{array}$ & $2.15 \mathrm{a}$ & 1.08 & $2.06 a$ & 1.07 & $3.03 b$ & 1.43 & $2.21 \mathrm{a}$ & 1.25 & 4.67 & $.004^{*}$ & .075 \\
\hline Complete information & $3.74 \mathrm{a}$ & 0.93 & 3.77 a & 0.74 & $3.27 a$ & 1.08 & $3.82 \mathrm{a}$ & 0.90 & 2.65 & .051 & .035 \\
\hline Incomplete information & $2.59 a$ & 1.05 & $2.56 a$ & 0.79 & 3.03 a & 1.09 & $2.65 a$ & 1.07 & 1.61 & .190 & .013 \\
\hline Statement refuting to engage & $1.24 \mathrm{a}$ & 0.50 & 1.35 a & 0.73 & 1.68 a & 0.98 & $1.24 \mathrm{a}$ & 0.65 & 2.00 & .121 & .037 \\
\hline No response & $1.41 \mathrm{a}$ & 0.70 & $1.41 \mathrm{a}$ & 0.66 & $1.27 \mathrm{a}$ & 0.58 & $1.09 \mathrm{a}$ & 0.29 & 3.96 & $.012 *$ & .030 \\
\hline
\end{tabular}

Note. Means sharing a common subscript are not statistically different at $p<.05$ according to post hoc comparisons. *Asterisks indicate significance at alpha level $p<.05$. 
In particular, post hoc comparisons revealed that participants in the No Cooperation condition more frequently used this communication strategy compared to participants in the Control condition, $t(132)=-3.00, p=.020, d=-.70,95 \% \mathrm{Cl}[-1.19,-0.21]$; the Cooperation condition, $t(132)=-3.30, p=.008, d=-.77,95 \% \mathrm{Cl}[-1.26,-0.28] ;$ and the No Cooperation plus Cooperation condition, $t(132)=2.80, p=.036, d=-.61,95 \% \mathrm{Cl}[-1.10,-0.13]$. In addition, there was a significant effect of cooperativeness instructions on participants that frequently did not provide a response, Welch $F(3,132)=3.96, p=.012, \omega^{2}=.030$. However, post hoc comparisons revealed no significant comparisons across the conditions. In partial support for hypothesis 4, taken together, these findings indicate that the communication strategies used to disclose and withhold information are different when participants receive Cooperation or No Cooperation instructions. Specifically, participants who received No Cooperation instructions in both interviews were more frequently inclined to disclose less accurate information and more inclined to disclose a combination of accurate and inaccurate information in their statements.

\section{Discussion}

We found partial support for the effect of witness cooperativeness on information disclosure during simulated police interviews. In particular, participants who received instructions to not cooperate in both No Cooperation conditions disclosed less information than participants in the Cooperation and Control conditions. Furthermore, we found that cooperativeness instructions only moderately affected the proportion of accurate information disclosed. While most participants disclosed accurate information, participants in the No Cooperation plus Cooperation condition disclosed the least accurate information ( $76-74 \%$ vs. $83-85 \%$ Control, in each of the interviews). Contrary to our prediction, instructions to cooperate did not increase disclosure and accuracy across the interviews. Overall, the uncooperativeness instructions negatively affected information disclosure, and accuracy to a lesser extent. Our findings demonstrate that unwillingness to cooperate can regulate the quantity and quality of the information disclosed when serving as a witness in an investigative interview, in line with previous research on civilian cooperation and crime reporting (Kidd, 1979). Furthermore, our findings provide empirical support for the previously proposed detrimental effect of lack of cooperation on information disclosure in 
investigative interviews (Shepherd \& Griffiths, 2013; Spencer \& Stern, 2001; Westera \& Powell, 2015). This finding highlights the importance of interviewers gaining witness cooperation as lack thereof can negatively affect the outcome of the interview (Vrij et al., 2014)

Our prediction for increased disclosure and accuracy for participants in the Cooperation condition was not supported. It is conceivable this is because participants in the Control condition (no instructions) were forthcoming and disclosed detailed and accurate information by default. This effect could have been enhanced by the type of crime used in this experiment, as burglary is often associated with higher reporting rates (Van Dijk et al., 2007). It is also possible that being requested to act as a key witness and to cooperate with the police in the simulated interview failed to instil a perceived high benefit for disclosing information given the low stakes of the experimental situation and the decline in societal responsibility regarding civic participation (Spencer \& Stern, 2001), thereby explaining why the rates of disclosure were not significantly different in the Cooperation to the Control condition. However, if the manipulation was effective, participants in the Cooperation condition could have inadvertently perceived that acting as a key witness was associated with increased benefits of withholding (rather than disclosing) information given the weight of their account for the investigation. Individuals tend to strategically control disclosure by meta-cognitively assessing how informative and accurate each piece of information is in order to decide whether to report or omit information (Koriat \& Goldsmith, 1994). Given the demands and goals of the current experimental condition, potentially there is an internal request for higher accuracy, at the cost of overall disclosure (Brewer et al., 2018). This latter interpretation of our finding requires further empirical testing, and it is directly relevant for interviewers as it warns them about potential undue responsibility raised by specific instructions that could affect witness accounts.

We also tested the effects of a new instruction to cooperate on delayed disclosure. Participants in the No Cooperation plus Cooperation condition disclosed more information when they were instructed to shift to cooperativeness in the second interview after initial uncooperativeness. However, the instructions to cooperate did not effectively increase disclosure for the No Cooperation plus Cooperation condition compared with the Cooperation and Control conditions. This means that increased cooperativeness can 
increase information disclosure to a limited extent. Therefore, across interviews, increased cooperativeness led to partial information gain compared with securing cooperativeness from the start. Similarly, research on human intelligence gathering indicates that initial cooperation is a predictor of subsequent cooperative behaviour (Christiansen et al., 2018). Conversely, it could explain that some resistance lingered into the second interview as a result of the experimental suspicion of incrimination instilled in the first interview, which is not conducive to cooperation. Considering a continuum between resistance and cooperation (Kelly et al., 2016), this finding indicates a movement towards cooperation given the new Cooperation instruction rather than a complete reversal of the No Cooperation instruction. In operational settings, even a partial shift is a positive investigative outcome in light of the challenging long-lasting effects of uncooperativeness (Alison et al., 2013).

Our complementary analysis showed a significant (albeit small) increase of information disclosure in the second interview across conditions (see Appendix 8), which could be a result of the memory protective effect of repeated recall attempts (Roediger \& Butler, 2011). Moreover, the moderate increased disclosure came at no significant cost for accuracy. This is crucial when evaluating information reported by uncooperative witnesses who later come forward with information. Thus, we caution the interpretation of this result considering the mixed evidence examining the effects of lack of disclosure in other contexts (cf. Mangiulli et al., 2018; Stone et al., 2012). Further examinations should replicate this finding to test specifically whether cooperativeness affects witness memory and delayed disclosure by witnesses. Specifically, we suggest to examine the effects of different strategies used for not reporting (e.g., fabrication vs. omission). Nonetheless, as increasing cooperativeness can facilitate disclosure of previously withheld information, interviewers should aim (and be encouraged) to gain witness cooperation to gather more complete and detailed witness statements.

Lastly, as expected, we found that participants reported engaging in different patterns of communication to strategically disclose accurate information according to their instructed cooperativeness. Participants instructed to not cooperate were less willing to disclose accurate information, and more willing to disclose a combination of accurate and inaccurate information. Similar counter-interrogation strategies have been reported to be 
used to avoid cooperation in intelligence interviews (Alison et al., 2014). Moreover, these patterns of disclosure are different from the interviewer's expectations of witness cooperation in investigative interviews (Antaki \& Stokoe, 2017; Fyfe \& Smith, 2007; Kebbell \& Milne, 1998). This finding is particularly interesting to understand witness cooperation in relation to the interviewer's goal of gathering information. Therefore, future research can examine whether interviewers are affected by the communication strategies used by uncooperative witnesses, and whether investigative interviews are conducted adjusting to the witness cooperativeness.

\section{Limitations and Future Research}

Our findings should be considered within the limitations of this experimental methodology. We used a mock-crime witness paradigm followed by simulated police interviews with a university student sample, which limits the ecological validity of our findings. Acting as a witness in a real crime investigation involves higher stakes, which are associated with competing motivations to cooperate with the police. Therefore, future research should examine how intrinsic cooperation and lack thereof affect information disclosure in a more realistic scenario, in order to replicate the effects of instructed cooperativeness addressed by this research, and be able to better generalise the results to real investigative interviewing practice. Furthermore, we encourage future replications, using larger samples (Lakens \& Evers, 2014), to confirm the reliability of our findings.

The experimental scenario we designed enabled us to examine whether information disclosure varied in relation to instructed cooperativeness. Participants were instructed to cooperate and to not cooperate, and they independently regulated information disclosure. We argued that participants would engage in an analysis of costs and benefits regarding cooperating with the interviewer (e.g., Kidd, 1979), and thus consider whether to disclose or withhold information. While our findings support the effect of uncooperativeness on information disclosure, we cannot unequivocally adjudicate a cost-benefit analysis as the underlying mechanism guiding disclosure behaviour in witness interviews. For that reason, future research ought to explicitly test if this model can in fact explain the willingness to disclose information according to witness cooperativeness. In addition, moving beyond the effect of instructed cooperativeness on the amount or accuracy of the information 
disclosure, research could examine the type of information provided (e.g., central vs peripheral details).

In our research, the cooperativeness instructions were coupled with a designated role aimed at influencing cooperativeness. Participants in the Cooperation condition received instructions to cooperate in combination with a request to act as key and only witnesses in the investigation, whereas participants who received No Cooperation instructions were asked to not cooperate as they risked self-incrimination. While this design allowed us to provide novel insight on the effects of cooperativeness on information disclosure, the individual contributions of each of these factors that regulate cooperation remain to be examined. For instance, further research on the effects of personal responsibility when being the sole versus one of a number of witnesses on information disclosure is warranted (Kidd, 1979). Second, we cannot rule out that participants in the No Cooperation condition may have considered their relationship to the suspect (i.e., a fictitious colleague) when providing their statements. Thus, future research should explicitly test the relationship to the perpetrator (and the victim) as these factors have been found to affect witness cooperation (cf. Spencer \& Stern, 2001). Additionally, given that we only examined cooperativeness after being a mock-witness to a burglary, future research is needed to evaluate whether the observed effects on information disclosure in mock interviews extend to other types of crime, especially considering that type and severity of the crime influence willingness to report crime and become a witness (Fyfe \& Smith, 2007; Nicksa, 2014).

\section{Conclusion}

Our findings provide empirical evidence that witness cooperation partially affects information disclosure in an investigative interview. Specifically, lack of cooperation is detrimental to information gathering as it decreases information disclosure and seems to only moderately decrease accuracy. Moreover, gaining cooperation after initial lack of cooperation can moderately increase information disclosure at no significant cost of accuracy in a delayed disclosure. These results are in line with individual's self-reports of disclosing less accurate information, or a combination of accurate and inaccurate information to strategically control disclosure when trying to not cooperate in the 
Chapter 5

interviews. In light of the current findings, it is imperative that practitioners aim to gain witness cooperation from the outset, as this best facilitates disclosure of information and, accordingly, higher quality witness statements. 


Chapter 6

The Detrimental Effects of Lack of Cooperation in Witness Interviewing 



\section{The Detrimental Effects of Lack of Cooperation in Witness Interviewing}

\section{Cooperation and Lack of Cooperation in Police Witness Interviews}

Individuals who have witnessed a crime hold knowledge of the offence that is of interest to the police and the criminal justice system. Crime witnesses are routinely interviewed to advance investigations, and their accounts can later be used as evidence in court. However, not every witness readily volunteers all the information they remember about the crime. Some witnesses are not willing to become involved in the investigative process and refuse to provide accurate and detailed witness accounts. Therefore, the police greatly rely on witness cooperation to elicit information. Despite its importance for witness evidence gathering, there was no empirical answer as to how does witness cooperation affect the interviewers, interviewees, and the interview outcomes. Therefore, in the current dissertation, I set out to examine the effects of cooperation and lack of witness cooperation in witness interviews. To begin the examination of witness cooperation in police interviews with crime witnesses, I first reviewed the myriad of factors that motivate individuals' decisions to cooperate with the police, as these may determine whether they to disclose information in the context of a witness interview. Then, I introduced a framework for the costs and benefits of crime reporting with which to understand witness cooperation, and I posited a relationship with the interviewing approach in the context of police (investigative) interviews (Chapter 1). Next, in chapters 2 through 5, I presented four studies that, taken together, demonstrate the importance of witness cooperation for effective interviewing in terms of information elicitation. Overall, these findings indicate that the specific aims of this dissertation were partially fulfilled, as will be further elaborated on this discussion chapter. Specifically, I provide an initial examination of witness cooperation and the lack thereof in police interviews with crime witnesses, and I also demonstrate some detrimental consequences of lack of witness cooperation for the interviewing approach and information disclosure, which in turn, decrease the quality of witness statements.

In this chapter, I discuss these main findings of this dissertation in light of their theoretical implications and practical applications, taking into consideration the limitations of this research. Next, I make recommendations for improving witness interviewing practice and identify future research avenues to optimise interviewing of uncooperative witnesses. 


\section{Summary of Findings}

In this section, I will review the four main findings of this dissertation regarding the effects of cooperation and the lack thereof in police witness interviews. The first and second findings concern the need to promote cooperation in interviews of cooperative witnesses and uncooperative witnesses, respectively. Then, I explain the third and fourth findings of this dissertation, which demonstrate how lack of witness cooperation affects the interviewing approach and information disclosure. Below, each finding is further explained in relation to theory and practice.

\section{Interviewing Practice Needs to Promote Cooperation}

The first finding of this dissertation is that interviewing practice needs to promote cooperation to safeguard witness evidence. In Chapter 2, I presented an examination of police witness interviews in the Netherlands that reveals the use of an predominantly direct and controlling interviewing approach characterised by the overuse of closed questions and infrequent use of open questions. In addition, interviewers routinely interrupted the witness's narrative and kept up a straight forward rapid exchange in a question-and-answer format to turn the account into a witness statement. The analysis also revealed that the interviewers employed an inappropriate questioning style that asked more than one question at a time or merely presented predetermined answers as options from which the witness could choose. In sum, there is evidence of insufficient promotion of cooperation in this pattern of questioning, which casts doubt on the effectiveness such interviewing practices. Three theoretical and practical considerations should be kept in mind when interpreting the finding that the current practice of interviewing adult witnesses in the Netherlands follows a direct and often confrontational approach.

First, such interviewing practices are not in line with current evidence-based research on effective interviewing (e.g., Fisher et al., 2011), but are largely consistent with previous archival research on witness interviews as described in Chapter 2 (Clarke \& Milne, 2001; Fisher et al., 1987; Mclean, 1995; Schreiber Compo et al., 2012; Snook \& Keating, 2011; Wright \& Alison, 2004).

Second, conducting a witness interview employing a direct interviewing approach is not conducive to cooperation, and could even render cooperative witnesses uncooperative 
(Collins et al, 2002; Vrij et al., 2014). This direct approach can affect the witness's motivation and opportunity to give a full account. The predominant use of closed questions, along with direct and probing questions, directs the witness account to confirm or deny information provided by the interviewer rather than helping the witness give an account based on their memory of the event (Fisher, 2010). Moreover, constant rapid-fire questions and interruptions restrict information disclosure by placing the witnesses in a passive role of answering specific questions (Clifford \& George, 1996; Fisher \& Geiselman, 2010; Fisher et al., 1989). Specifically, the commanding role of the interviewer represents a failure to transfer control to the interviewee and reduces cooperation. As a result, witnesses become less willing to volunteer remembered information if it is not specifically asked for, anticipating that the information must therefore be irrelevant or to avoid being interrupted (Fisher, 2010; Fisher \& Geiselman, 1992). Moreover, the constant questioning does not respect the interviewee's pace of remembering the event and impedes engagement in effortful and exhaustive internal memory retrieval; rather, the jumping of the interviewer's questions between topics is a distraction (Powell et al., 2005). Consequently, an elaborate account including new information unknown to the police based on the witness's knowledge of how the crime happened is not fully elicited (Fisher \& Geiselman, 1992; Fisher \& Geiselman, 2010; Milne \& Bull, 1999).

Third, direct and accusatorial interviewing approaches reduce memory accuracy. In an investigative interview, individuals engage in recalling a past event during a conversation with the interviewer. The interviewer can intentionally or unintentionally introduce misinformation, and lead the witness into narrowing their account to suit the interviewer's agenda or biased versions of events (Mclean, 1995; Wright \& Alison, 2004). Therefore, an interviewer can alter, fully or partially, the memory of the crime by introducing post-event information in their questions and other utterances (Loftus \& Pickrell, 1995). Given the reconstructive nature of memory, in which a past experience is reconstructed rather than reproduced (Bartlett, 1932), the witness account is prone to contamination by the interviewer, limiting the quality (i.e., accuracy) of the elicited testimony.

In the process of remembering the crime in conversation with the interviewer, the first step after the memory trace is activated is one of memory conversion (Tulving, 1985), in which the retrieved information is validated and believed to have occurred forming a 
memory belief. Such memory can then be communicated to an external source in the form of memory statements (Blank, 2009). At both stages, the memory is susceptible to influence by external sources: in the validation stage, information can be introduced that changes the memory belief, and in the communication stage, the report is subject to modification according to normative influences, leading to strategic reporting of the memory in full or in parts (Blank, 2009). This is why the questions posed by the interviewer can influence whether and what the witness actually reports. Specifically, the predominant use of closed and directive questions, in comparison with open questions, increases inaccuracy. In contrast, obtaining a free witness account using open prompts prior to asking any specific questions elicits more accurate and detailed information from the witness, promoting memory recollection rather than testing the memory recognition of the interviewer's knowledge (Fisher, 1995; Memon et al., 1997b).

During free recall, individuals report more correct information (Memon et al., 1997b) because in the investigative context, individuals volunteer or withhold information that fulfils the interviewer's request for informativeness (i.e., quantity) and accuracy (i.e., quality; Koriat \& Goldsmith, 1994). Thus, the information volunteered during free recall by an individual meets an internal threshold of being informative while maintaining accuracy, whereas when the individual is merely responding to questions, the accuracy criterion becomes more liberal in order to fulfil the demands of being informative upon the request for specific information (Goldsmith et al., 2002).

In addition, a wealth of research on the post-event information effect has demonstrated that certain investigative conditions lead to memory distortion (for reviews see Loftus 2005; Frenda et al., 2011). In particular, the use of suggestive questions and other question types that introduce misleading information (including closed questions, cf. Oxburgh et al., 2010) also increases inaccuracy in witness reports (Sharman \& Powell 2012), even risking eliciting false allegations from witnesses (Kaasa et al., 2013; Loftus \& Pickrell, 1995; Loney \& Cutler, 2016). The incorporation of misleading information into memory reports can occur during retrieval in an investigative interview due to source misattributions. Source monitoring errors arise when an individual cannot discriminate the source of the assimilated information - that is, it is unclear whether a detail stemmed from the individual's own memory or was introduced by the interviewer (Johnson et al., 1993; 
Lindsay, 1994; Leding, 2012). Therefore, the misleading piece of information becomes part of the witness's true recollection of the crime, even if it was not originally remembered by them.

\section{Current Interviewing of Uncooperative Witnesses}

The second contribution of this dissertation is that it provides the first international examination of current experiences of interviewing uncooperative witnesses (Chapter 3 ). Academics and practitioners in the field are at the frontiers still of developing empirically valid specialised interviewing techniques for interviewing witnesses who are uncooperative with the police in criminal investigations. However, practitioners frequently encounter witnesses who are unwilling to disclose information to them (see Chapter 3; Wheeler et al., 2017). Therefore, I examined police officers' experiences of witness interviews in which they need to overcome the challenge of lack of witness cooperation in order to effectively elicit information.

The current approach to interviewing uncooperative witnesses is heterogeneous and at the discretion of the investigation team, according to self-reports. Overall, the police seems to intervene in three domains to motivate cooperation. First, the focus is on interpersonal aspects of the relationship between the interviewer and the witness. In line with previous research, criminal investigators consider it is necessary to build rapport to gain witness cooperation (Gabbert et al., 2020; Vallano et al., 2015; Wheeler et al., 2017). Thus, they aim to establish an interpersonal bond before asking for an account of the crime, as prescribed in evidence-based witness interviewing protocols (e.g., the $\mathrm{Cl}$; Fisher \& Geiselman, 1992). In that phase, interviewers consider important to provide information about the interview and further legal proceedings and to explore every point of resistance in order to seek for solutions. These interviewing practices are beneficial for transferring control from the interviewer to the interviewee and set the expectations of the role of the interviewee as the one actively engaging in memory recall who is in control of reporting information, as they have first-hand knowledge of the crime (Fisher, 1995, 2010; Fisher \& Geiselman, 2010). It is important that the interviewers include instructions to report everything and avoid guessing in order to obtain the most complete and detailed account of the witnessed crime (Fisher \& Geiselman, 1992). Importantly, such explanations 
establish demands for high quantity and accuracy for the disclosure of information. In response, the interviewee engages in metacognitive decisions to omit or report information that fulfils both requirements (Koriat \& Goldsmith, 1994). Second, criminal investigators direct efforts towards the application of special measures and towards the legal mechanisms and frameworks within which a witness cooperates with the police and other parties in the criminal justice system. The police offer witness anonymity incentives, and inform witnesses of and consider legal aspects such as the voluntariness of statements, kindship exemptions, and other legal obligations to cooperate with a criminal investigation. Although the evidence is limited, these techniques may not be beneficial in facilitating accurate reporting (MacDonald et al., 2017a; Tolsma et al., 2012). However, in some jurisdictions, these are legal requirements to make witness accounts admissible as evidence (e.g., R. v. B. (K. G.), 1993). Third, during the interview, to elicit information criminal investigators consider the type of questions to ask and specific techniques such as using moral appeals. Open questions are preferred over closed, direct and leading questions as they elicit more complete and accurate answers (e.g., Fisher et al., 2011; Sharman \& Powell, 2012). The effectiveness of moral appeals in facilitating reporting and accurate recall has received little empirical scrutiny; however, the emphasis seems to be focused on justice for the victim and advising witnesses of their civil duty to cooperate (e.g., Spencer \& Stern, 2001).

In contrast to the analysis of interviewing behaviour in real police interviews and in a laboratory study, the survey yielded findings in relation to the use of question types that were somewhat different. In the survey, criminal investigators considered that direct, leading, and repeated questions were not useful (see Chapter 3 ), whereas in the police and mock police interviews, these types of questions, particularly the direct type, were often asked (see Chapters 2 and 4 respectively). There are alternative explanations for this finding. The discrepancy could have resulted from interviewers' inaccurate estimations of their own interviewing skills (Walsh et al., 2017), insufficient training, and difficulty adhering to evidence-based guidelines, as interviewing is a complex task requiring specialised skills (Oxburgh \& Dando, 2011; Smith et al., 2009; Snook et al., 2012). In addition, the survey responses could be indicating socially desirable responses rather than honest responses, limiting the validity of the responses (see Chapter 3 and the 
'Methodological Considerations' section below). Nonetheless, regarding the use of other types of questions to gain cooperation in order to elicit information, there were no discrepancies. For instance, according to police practitioners' self-reports, open questions were not considered effective at eliciting information from uncooperative witnesses. Correspondingly, it is not surprising that the actual use of open questions was infrequent in both the archival and experimental studies. It is important to consider the discrepancy between self-reported and actual interviewing behaviour given the demonstrated influence of uncooperative witness behaviour on the interviewing approach (see Chapter 4), as explained in the next section.

\section{Lack of Witness Cooperation Negatively Affects Interviewer's Behaviour}

The third important and novel finding of this dissertation is that lack of witness cooperation negatively affects interviewer behaviour. Previous research and the survey findings presented in Chapter 3 indicated that criminal investigators hold expectations of cooperation and negatively perceive lack of witness cooperation, which could influence how an interview is conducted (Antaki \& Stoke, 2017; Fyfe \& Smith, 2007; Roberts, 2010). Thus, I tested the mismatch of interviewer expectations of cooperativeness in a non-police sample of interviewers (see Chapter 4).

Investigator expectancy effects have been shown to affect the interviewing approach in suspect interrogations (Hill et al., 2008; Kassin et al., 2003; Narchet et al., 2011). However, this finding was not replicated in the study presented in Chapter 4. Specifically, prior expectations of lack of witness cooperation did not influence the interviewing approach, failing to lend support to the hypothesised effects of expected cooperativeness on the way in which an interview is planned and conducted. In a laboratory setting, the interviews were conducted using a direct and confrontational approach, against the recommendations of optimal evidence-based witness interviewing (e.g., Fisher et al., 2011; Vrij et al., 2014). The findings from Chapter 4 correspond to those previously described in Chapter 2 regarding the disproportionate use of closed questions and direct questions and, to a lesser extent, leading questions, as well as the infrequent use of open questions. Previous archival evidence reveals similar interviewing performance during police interviewing in various countries (Clarke \& Milne, 2001; Fisher et al., 1987; 
Mclean, 1995; Schreiber Compo et al., 2012; Snook \& Keating, 2011; Wright \& Alison, 2014). A key difference between those studies was in the characteristics of the interviewers, our sample being untrained individuals who were not non-police officers (Chapter 4). Thus, it is likely that the actual challenge of facing uncooperativeness as an obstacle to information elicitation in concert with lack of training is what drove the mock interviewers to follow the direct and confrontational interviewing approach.

Interestingly, I observed that mock-interviewers shifted from a preferred information-gathering interviewing approach in the planning stage of an interview to a direct and confrontational approach when conducting a mock-interview with an uncooperative interviewee. This finding suggested that uncooperativeness affects the interviewer's approach to eliciting information, which is in line with previous research that demonstrated reciprocal influences between the interviewer and the interviewee given the interactive and dynamic nature of an investigative interview (Alison et al., 2013; Kelly et al., 2016). In particular, lack of witness cooperation demands interviewers to be flexible (Bull \& Cherryman, 1996) and adapt their interviewing approach to the interviewee's cooperation throughout the interview in order to maximise the provision of information (Cherryman \& Bull, 2001; Soukara et al., 2002).

Although it is preliminary evidence, it seems as though lack of witness cooperation, by limiting information elicitation can lead to the use of a direct interviewing approach. Based on that experimental finding, I suggest that lack of witness cooperation in police interviews can impede adherence to best-practice interviewing guidelines if interviewers are ill-prepared for the challenge of overcoming resistance to cooperation and reluctance to provide information on the part of initially uncooperative witnesses. In the face of challenges, interviewers resort to poor investigative interviewing practices to re-establish control (Griffiths et al., 2011; Oxburgh \& Dando, 2011). Further evidence confirms that in real cases, a more accusatorial interviewing approach is more likely to be employed with uncooperative witnesses (Davis \& Leo, 2016; Gross \& Gross, 2013). The perils of this interviewing approach, which is more akin to an accusatorial than an informationgathering approach, are to further limit cooperation and to contaminate the witness account, thereby reducing both the amount and accuracy of information, as has previously been discussed. 
Considering that the regular police interviewing approach as revealed in Chapter 2 hampers cooperation, the risk in interviews with uncooperative witnesses is thus the exacerbation of initial uncooperativeness. The differences between planned and utilised interviewing approaches to gathering information in the face of lack of witness cooperation also point to a demand for police practitioners to be trained in interviewing skills, so as not to only gain and maintain cooperation but also to overcome witness resistance to cooperation and reluctance to provide information. In light of this finding, it is imperative to examine the real interviewing of uncooperative witnesses to corroborate findings from the self-report survey of criminal investigators regarding their experience and self-reported interviewing practices with uncooperative witnesses (Chapter 3 ).

\section{Lack of Witness Cooperation Reduces Information Disclosure}

Lastly, the fourth significant finding of this dissertation is that lack of witness cooperation reduces information disclosure. In Chapter 1, diverse reasons that motivate witnesses not to cooperate with the police were described, such as: a relationship with the suspect, a criminal history or risk of self-incrimination, distrust of the police or the criminal justice system, type and severity of the crime, cultural differences, language barriers, witness apathy, and the inconvenience of legal proceedings (cf. Spencer \& Stern, 2001). In addition, an interviewing approach that does not promote cooperation, for instance by controlling and directing the interviewee, as observed in Chapter 2 and 4, not only logically risks reducing cooperativeness but can also increase uncooperativeness (Abbe $\&$ Brandon, 2013; Collins et al., 2002). The findings in Chapter 3 indicated that the police considers lack of witness cooperation detrimental to information elicitation. If this were true, based on the estimated high prevalence of initially uncooperative witnesses in criminal investigations, the incidence of this phenomenon would be considerable in current investigative practice. Therefore, it was important to empirically examine the extent to which cooperativeness regulates information disclosure.

In a laboratory experiment, I found that mock witnesses who were instructed not to cooperate behaved differently (see Chapter 5). In mock police interviews following an information-gathering approach, participants in the uncooperative conditions (i.e., instructed not to cooperate) significantly reduced the amount of information they 
disclosed. Moreover, they reported purposefully reducing the amount of correct information and reporting a combination of accurate and inaccurate information, which lead to a small but significant decrease in accuracy. These findings prove the importance of cooperation from the outset of an interview in order to gather accurate and detailed witness accounts, as lack of cooperation decreased their quality. Furthermore, these findings also indicate the limitations of eliciting information from uncooperative witnesses using current evidence-based interviewing practices. Nonetheless, the application of current best-practice guidelines can decrease the exacerbation of uncooperativeness.

Altogether, in this dissertation, I demonstrated that witness accounts can be impaired during a witness interview due to lack of witness cooperation, whether initially motivated by the individual or resulting from the interviewing approach. In Chapter 1,1 introduced previous models that explain this effect (Homans, 1958; Kidd, 1979; Skogan, 1984). The crime witness's decision to report information to the police results from an appraisal of the costs and benefits associated with their participation in a criminal investigation (Clayman \& Skinns, 2012; Papp et al., 2017). Disclosure of information, therefore, is more likely to occur if the costs of withholding information are perceived to be low and there are anticipated high benefits associated with reporting information. For example, as reported in Chapter 5, in an experimental study, participants who were instructed not to cooperate in order to avoid negative consequences for themselves and the suspect, and who did not receive any benefit from providing information, were less willing to disclose fully detailed and accurate accounts. Relatedly, the interviewing techniques used to increase cooperation described in Chapter 3 indicate that criminal investigators aim to lower the risks associated with providing evidence, for instance, by offering anonymity incentives, and increasing the perceived subjective benefits of reporting information by using moral appeals regarding the importance of witness testimony to secure justice for the victim.

Overall, the findings from Chapter 5 provide preliminary empirical evidence for the cost-benefit mechanism; however, at this stage the effects of cooperation on information disclosure cannot be unequivocally attributed to this internal mechanism. Nonetheless, the findings indicate that lack of witness cooperation reduces information disclosure. The desirable witness behaviour of interest during an investigative interview is disclosure of 
information, and lack of cooperation, understood as the unwillingness to report (Shepherd, 1993), is a determinant of the amount and accuracy of information. Although the results in Chapter 5 did not provide support for the converse effects of instructed cooperativeness in terms of increasing disclosure, this was likely an artefact of the experimental limitations and not due to lack of substantiated theoretical support for the facilitating role of cooperation to increase disclosure, as explained before (Fisher, 2010; Gabbert et al., 2020; Vrij et al., 2014).

In addition, in Chapter 5, I found that while memory reports decreased significantly in terms of the quantity and, to a lesser extent, the quality of their information, the memory trace was somewhat preserved. During mock-witness interviews, individuals who were instructed not to cooperate correctly remembered previously unreported details, but not as many as did those who provided more complete reports from the beginning. However, later reporting was partially reduced in quantity although accurate. Participants also self-reported not having intentionally included incorrect information (e.g., they did not fabricate details). Individuals engaged in recalling crime information, and therefore rehearsed it, in order to report the event, even if not fully accurately. Further research is needed to fully discern what drives the mnemonic effects observed. Tentatively, it seems as though the accurate remembering of previously unreported information is explained by the effectiveness of mental rehearsal, even when unaccompanied by reporting (Anderson \& Green, 2001), in combination with a lack of intentional attempts to avoid and suppress actual memory of the crime (Smith et al., 2013; Otgaar \& Baker, 2018). The aforementioned memory preserving effect explains the accuracy of the account despite late disclosure, although there were also some undermining memory effects. The information that went unreported during the interview was not practised as much as was the reported information, which explains why those details may not have been accessible during the second attempt at retrieval, leading to some forgetting (Anderson et al., 1994; Mangiulli et al., 2019; Stone et al., 2012). In operational settings, this finding highlights the need to promote cooperation from the outset of the interviews to maximise information elicitation. 


\section{Practical Applications}

Police interviewers sometimes face witnesses who are able to remember the witnessed crime, but who are unwilling to provide detailed and accurate witness accounts (Spencer \& Stern, 2001). Even though police officers report that it is common to encounter uncooperative witnesses who can challenge their ability to elicit information (see Chapter 3; Wheeler et al., 2017), research on the investigative interviewing of uncooperative witnesses is scarce. In that context, this dissertation constitutes the first systematic examination of witness cooperation during investigative interviews for the task of eliciting information. The findings emphasise the importance of witness cooperation and the detrimental effects of its lack. Thus, this research contributes to informing investigative interviewing practice with uncooperative witnesses.

The coined distinction between estimator and system variables formulated by Wells (1978) serves to highlight the gaps in which the practice of collecting witness evidence can be improved. Estimator variables refer, for example, to the conditions under which an individual witnesses an event (e.g., distance and lighting), which cannot be changed nor controlled by the legal system, whereas the way in which the police interview a witness - a critical component in an investigation - is directly controlled by the system and thus amenable to change and improvement (Wells et al., 2006). In this section, I first want to emphasise that interviewers can elicit more detailed and accurate information if they use interviewing techniques informed by psychological science to promote cooperation and if they have a sound understanding of how the human memory works.

Abundant memory research has focused on increasing eyewitness memory recall, informing practitioners in the criminal justice system of factors that produce memory errors (see Fisher, 2010 for a review), without equally providing tools that facilitate cooperation or willingness to report. Based on findings from the studies reported in this dissertation, the main take-home message for operational practitioners who conduct witness interviews is that cooperation should not be taken for granted. Second, the focus on cognitive techniques that facilitate retrieval is necessary but not sufficient to effectively elicit information from uncooperative witnesses. Consequently, the interviewing approach needs to be two pronged, focusing first on promoting cooperation and reporting, and then 
on facilitating remembering in order to elicit detailed and accurate witness reports. Importantly, based on findings discussed in Chapters 2 and 4, the predominant use of a directive, controlling, and to some extent confrontational interviewing style, characterised by constantly asking a disproportionate number of closed and direct questions in concert with interruptions, needs to be revisited as it hampers the information elicitation goals (e.g., Launay \& Py, 2015; Vrij et al., 2014).

Considering that not even cooperative witnesses volunteer all the information they remember (Kebbell \& Milne, 1998; Koriat \& Goldsmith, 2004), and the myriad of factors that motivate individuals to decide not to cooperate with the police (see Chapter 1 ), it is undisputable that effective interviewing relies heavily on witness cooperation. Therefore, interviewers need to accept that, in an investigative process, the onus is on them to gain, maintain and recover witness cooperation in order to elicit information. Adopting this goal, however, requires the rectification of the misconceived belief that witnesses have the ability and obligation to provide information about the witnessed crime as required if interviewed by the police (Antaki \& Stokoe, 2017; Fyfe \& Smith, 2007; Roberts, 2010). In particular, based on findings from Chapter 3, we emphasise this recommendation to interviewers in order to avoid potential unfulfilled expectations of witness cooperation (Roberts, 2010). This recommendation provides an opportunity for the interviewer to adjust to witness cooperativeness (and the lack thereof), in the hopes that limited cooperation will not make the interviewer revert to intuitive interviewing or to resort to ineffective interviewing practices in the face of the challenge (see Chapter $4 ;$ Griffiths et al., 2011; Soukara et al., 2002).

A similar tenet is essential in human intelligence gathering following a rapportbased approach, which has been shown to be effective at shifting uncooperative sources such as terrorists towards cooperation and at gaining useful information (Alison et al., 2013, 2014). It is key to consider the interviewee's stance (i.e., cooperativeness and willingness to disclose information) and adapt the interviewing approach accordingly in order to maximise information elicitation (Alison et al., 2014). Securing cooperation from the onset is also crucial given that initial cooperation has been shown to predict subsequent cooperativeness (Christiansen et al., 2018). Based on this evidence, adoption of this 'cooperation first' mindset when interviewing uncooperative witnesses could prove 
successful. In addition, an analysis of the limited but valuable applications of the Cognitive Interview $(\mathrm{Cl})$ to interview uncooperative witnesses is warranted.

\section{Evidence-Based Interviewing Guidelines to Promote Cooperation}

The $\mathrm{Cl}$ is the gold standard for interviewing cooperative witnesses and, in its enhanced version, it provides techniques for facilitating both relational and cognitive aspects that improve a witness account (Fisher \& Geiselman, 1992). The $\mathrm{Cl}$ has been proven to elicit significantly more correct details with just a small increase in errors (Memon et al., 2010), and is overall superior compared to the standard police interview (Fisher et al., 1989). The efficacy of the $\mathrm{Cl}$ has been attributed to the dual effect of its memory-search techniques and rapport with the person guiding the retrieval process (Memon et al., 1997b). However, the $\mathrm{Cl}$ is not superior to a structured interview that incorporates the 'communication' components (e.g., rapport and transfer of control) before a free recall and questioning phase (Memon et al., 1997b). Moreover, the interview phase in which most (accurate) information is collected is free recall (Memon et al., 1997a). Nonetheless, the instructions in the $\mathrm{Cl}$ to report everything and avoid guessing, as well as the context reinstatement technique, benefit information disclosure (Fisher \& Geiselman, 1992). The other two $\mathrm{Cl}$ mnemonics, i.e., change order and perspective, are not routinely used by practitioners (Clarke \& Milne, 2001; Kebbell et al., 1999), and their absence does not significantly reduce the effectiveness of the $\mathrm{Cl}$ (Colomb \& Ginet, 2012; Davis et al., 2005). Altogether these findings suggest that the use of the $\mathrm{Cl}$ as a non-directive interviewing approach in which interviewers employ the techniques that facilitate communication and the establishment of an interviewer-witness relationship could form a basis for how interviewers initially approach an investigative interview with uncooperative witnesses. However, the application and efficacy of the cognitive techniques of the $\mathrm{Cl}$ are indeed limited for uncooperative witnesses who are not willing to engage in the memory retrieval efforts (McCauley \& Santee, 2019; Vrij et al., 2017). It is worth noting that the use of isolated $\mathrm{Cl}$ techniques is in line with the intentions of the $\mathrm{Cl}^{\prime}$ s creators, who have ratified that the $\mathrm{Cl}$ is a flexible toolbox for interviewers rather than an indivisible entity (Fisher, 2010). 
The two viable relational components to implement in interviews with uncooperative witnesses are rapport-building and transfer of control. Rapport-building is an established key component of effective investigative interviewing (for reviews, see Abbe \& Brandon, 2013; Gabbert et al., 2020). Rapport refers to a bond, connection or (working/professional) relationship between interviewer and interviewee (Gabbert et al., 2020), and researchers as well as practitioners agree on its functional role in facilitating cooperation (Vallano et al., 2015). Positive rapport enables communication, puts the witness at ease, builds trusts, encourages motivation to report, and facilitates remembering (Abbe \& Brandon, 2013; Fisher, 1995; Vrij et al., 2014), in turn eliciting more detailed and accurate information (Collins et al., 2002; Vallano \& Schreiber Compo, 2011). Drawing on this empirical evidence, the utility of rapport-building techniques for uncooperative witness interviewing is well founded; nonetheless, research is needed to test the extent to which specific techniques facilitate cooperation and information disclosure with initially uncooperative witnesses (Abbe \& Brandon, 2013). Their current application, however, is highly recommended to gain and maintain cooperation and avoid shifts towards uncooperativeness. Notwithstanding, the difficulties of defining, building, training in, and evaluating rapport (e.g., Gabbert et al., 2020), as well as the potential negative effects when rapport is used in combination with techniques that introduce misinformation to witnesses (Vallano \& Schreiber Compo, 2015; Wright et al., 2015), should be considered.

Transferring of control from the interviewer to the witness facilitates active participation, which also promotes cooperation (Fisher \& Geiselman, 1992). The goal of an investigative interview is for the witness to generate information based on the memorial representation of the witnessed crime, rather than for the interviewer to extract facts that confirm the interviewer's assumptions (Wright \& Alison, 2004). Thus, to manage the social dynamics between the interviewer and the interviewee, the expectations about the interview and the role of the witness as an information generator need to be clearly communicated, along with the investigative needs and ground rules (Fisher, 2010). Previous research has identified the benefits of clarifying roles and matching the expectations and goals of information disclosure through explicit instructions (Douglass et al., 2013). However, as Griffiths and Milne (2010) noted, certain officers deliberately 
retained control of the interview, as they felt they knew the information required for the investigation. In a similar vein, a different sample of interviewers reflected on their style as directive, and was characterised by the use of probing questions to direct the information provided by the interviewee, overall deeming it excessively controlling (Griffiths et al., 2011). Similarly, Oxburgh and Dando (2011) noted that interviewers who over use closed questions in their practice reduce the witness's perceived power, allowing them to remain in control of the interview. Therefore, working on maintaining an open investigative mindset in the interviewer is crucial to transferring control to the interviewee (Fisher \& Geiselman, 2010; Milne \& Bull, 1999; Schollum, 2005; Shepherd, 1991). Afterwards, interviewers can encourage an elaborated free narrative, using open prompts prior to any questions, to be recounted in the witnesses' own words and at their own pace without interruptions (Fisher, 1995, 2010). Then, open follow-up questions can be asked to clarify and, if needed, probe the witness account. These questions elicit new information; however, interviewers should seek external corroboration of this (new) information as accuracy drops in relation to initial recall (Kontogianni et al., 2020).

The proposed application of these evidence-based techniques that promote witness cooperation is in line with the ethos of an information-gathering interviewing protocol, aimed at learning what happened from the interviewee without the use of psychologically manipulative techniques (e.g., Meissner et al., 2012; Milne \& Bull, 1999). Instead, based on rapport and positive confrontation, this interviewing approach elicits more extensive, detailed, and accurate responses using open prompts and avoiding suggestive questions (Vrij et al., 2014). In addition, interviewers following this interviewing approach respond to the interviewee's emotional states and potential resistance (Fisher \& Geiselman, 2010; Shepherd \& Griffiths, 2013). If these arise, it is necessary for interviewers to focus on understanding the causes of resistance in order to overcome it (Risan et al., 2016). Similarly, as reported in Chapter 3 and in previous research (Wheeler et al., 2017), criminal investigators consider it important to explore the reasons for lack of witness cooperation. However, to date, despite being an essential step, further recommendations for executing this task effectively in this particular investigative domain are unavailable. 


\section{Boundaries to Current Interviewing of Uncooperative Witnesses}

Overall, how best to interview uncooperative witnesses in policing contexts remains a problem in practice. Based on the findings in Chapter 5 , it appears that witnesses who are intrinsically motivated not to cooperate would reveal less information even if their testimony were obtained following evidence-based interviewing techniques. Therefore, the information-gathering interviewing approach described in the above recommendations and some evidence-based elements of the current practice as described by criminal investigators (see Chapter 3 ) are beneficial but limited for interviewing uncooperative witnesses. There are also critical shortcomings in the alternative interviewing protocols for interviewing uncooperative witnesses, such as Conversation Management (Shepherd \& Griffiths, 2013), or the application of the Reid Technique (Inbau et al., 2013), which in a nutshell lack empirical support for their efficacy, and decrease the quality of witness evidence (Clifford \& George, 1996; Loney \& Cutler, 2016). In particular, use of the Reid technique can contribute to miscarriages of justice (Gross \& Gross, 2013; Moore et al., 2014; The National Registry of Exonerations, 2020). Therefore, specific techniques that interviewers can add to their repertoire in order to obtain comprehensive and accurate verbal accounts from uncooperative witnesses need to be developed and tested. Practitioners are at the forefront compared with researchers in this regard. Thus, some of the techniques the surveyed criminal investigators mentioned were suitable for gaining cooperation have not undergone empirical scrutiny. In particular, the effectiveness of certain techniques currently employed, such as the use of moral appeals, anonymity incentives, environmental support, and legal reminders used to encourage information disclosure from uncooperative witnesses, is unknown to date (see Chapter 3 ). In this sense, the evidence base on which to develop a protocol for investigative interviewing of uncooperative witnesses is in its infancy. Further development of this body of evidence calls for considerations of the extent to which known techniques from different police and interviewing domains (e.g., Alison et al., 2013; Taylor, 2002) are effective and appropriate for interviewing uncooperative witnesses. It is critical to develop specialised interviewing skills that facilitate cooperation from the onset of the interview, both preventing shifts towards uncooperativeness and promoting shifts towards cooperativeness (i.e., overcoming initial witness reluctance and resistance). 
Transferring knowledge from research in investigative interviewing to police practice is the only way in which the proposed system variable tenet can be fulfilled (Wells, 1978; Wilford \& Wells, 2013), so that the legal system actually improves the current procedures that are under its control. There are two general investigative interviewing considerations for which there are known benefits that would also serve to improve the investigative interviewing of uncooperative witnesses in particular. The first one is training in and knowledge of evidence-based witness interviewing techniques. In Chapter 2, I reveal that current practice in police witness interviewing is not in line with evidence-based interviewing, entailing the risk of ineffective information elicitation. Moreover, regarding the interviewing of uncooperative witnesses, I found elements of a potential discrepancy between self-reported and actual interviewing behaviour (Chapters 3 and 4, respectively). Specifically, in Chapter 4, I describe a shift from an information-gathering interviewing approach to elicit information towards a direct interviewing approach similar to an accusatorial one, once faced with the challenge of overcoming lack of witness cooperation in an experimental setting with a sample of untrained non-police participants. While that finding needs to be replicated in a police sample, there are many police officers who conduct witness interviews without general or specialised training. Specifically, findings in Chapter 3 showed that almost $30 \%$ of the police criminal investigators who regularly conduct witness interviews had not received any training in investigative interviewing, and under $10 \%$ had received specialised training in interviewing uncooperative witnesses. Altogether, these findings indicate that interviewing training is of primary importance. In light of the current ineffective and insufficient training in witness interviewing received by police officers (Clarke \& Milne, 2001; Dando et al., 2008; Snook et al., 2012), which degrades interviewing performance (e.g., Clifford \& George, 1996), efforts should focus on overcoming the shortcomings of previous training initiatives (e.g., mandatory and continued training, theory and practice sessions, multiple training sessions, and regular feedback and supervision; see Lamb, 2016; Powell, 2008). The second recommendation for witness interviewing practice concerns interviewing outcomes, which I develop in the next section. 


\section{Consequences for Witness Testimony}

In this dissertation, I identified the potential problems in witness statements resulting from interviews in which cooperation is not promoted. Nonetheless, practitioners in the criminal justice system need to establish the facts of how crimes take place based on these accounts, which sometimes questionably reflect what the witnesses reported. An important safeguard when evaluating witness evidence is to have access to the whole interview process (Wells et al., 2006). In this way, all questions and answers can be scrutinised. Therefore, the second recommendation is to introduce mandatory digital recording of all witness interviews, not only to guarantee the integrity of the witness statement and facilitate its reproduction, but also to reveal how the witness evidence was obtained, thereby enriching its evidential value (Gabbert et al., 2018; Horselenberg \& Van Koppen, 2011; Milne \& Shaw, 1999; Milne et al., 2011). An additional advantage of this policy would be the increased adherence to ethical and evidence-based interviewing (e.g., Milne \& Shaw, 1999). Research community advocacy of the same policy for the recording of suspect interrogations to avoid false confessions led to significant reforms of the criminal justice system and increased transparency of police practices (Kassin et al., 2010). In recorded custodial interrogations of suspects, the use of coercive interrogation practices was found to be reduced (Kassin et al., 2014), without affecting the disclosure of incriminating information (Kassin et al., 2019). Until this reform is implemented, the decision-making of triers of fact will benefit from independent corroborating evidence when evaluating the testimony of (uncooperative) witnesses given that written witness statements are demonstrably of limited quality. Unlike audio-visual recordings, written records of witness interviews preclude the representation of the whole interviewing process and are subjected to bias, which can lead to decreased accuracy and completeness and affect judicial decision-making (De Keijser et al., 2012; Heaton-Armstrong \& Wolchever, 1992; Mclean, 1995; Malsch et al., 2018). Importantly, admitting a videorecorded police interview as evidence is crucial in criminal cases in which uncooperative witnesses are unwilling to provide their testimony in court (Milne et al., 2011; Spencer \& Stern, 2001). 


\section{Methodological Considerations}

This dissertation is the first to systematically examine the effects of cooperation and the lack thereof in investigative interviews with uncooperative witnesses. To study this topic, I conducted quantitative and qualitative research including archival, survey, and experimental methodologies using police and non-police samples that analysed cooperation from the interviewer and interviewee standpoints in witness (mock) interviews. The findings of this dissertation should therefore be interpreted in light of these characteristics and limitations.

Witness interviewing procedures are unique in every jurisdiction (Walsh et al., 2016). As such, the findings of the analysis of police interviewing practice presented in this dissertation arguably only apply to the studied contexts of the Netherlands, Sweden, and England and Wales, although findings have been framed within a broader international context when possible (e.g., see Chapter 2). Participation from other countries was also actively sought for the survey of criminal investigators; however, the attempts were unsuccessful (see original sample in Chapter 3). In general, investigative interviewing research, and police research more broadly, depends on cooperation between law enforcement agencies and the academic sphere and that relationship is inconsistent at best (cf. Bradley \& Nixon, 2009). Therefore, for the purposes of an initial examination of cooperation in witness interviews, the alliances between and contributions of diverse police forces were of outmost significance. In addition, previous research has demonstrated similarities in investigative practices and interviewing traditions across countries (Kelly et al., 2013; Miller et al., 2018), extending the generalisability of the findings. Similar to previous research, the present analysis of the effectiveness of current practice is based on scientific evidence from psychological research, more specifically, from applied memory research, which also broadens the interpretation and implications of the findings to more general aspects of human cognition and behaviour (e.g., Vrij et al., 2014). However, further analysis of diverse investigative interviewing practices is needed to share best practices and, importantly, to better understand cooperation in the contexts in which they occur, considering it is a behaviour intimately influenced by the relationship 
between citizens and the police (McCarthy et al., 2020; Papp et al., 2017; Tyler \& Fagan, 2008).

The first two studies in this dissertation benefited from including the police perspective. First, in Chapter 2, I presented an archival analysis of witness interview transcripts. Such a source offers researchers the possibility of examining a witness interview under the natural conditions in which it occurs, without interference from the experimenter. However, as the data set was not gathered for the purpose of scientific research, there was less of an opportunity to conduct explanatory research (Alison et al., 2001). Therefore, the analysis presented in Chapter 2 only provided a snapshot of how the complex phenomenon of interviewing took place in terms of the question types employed by the interviewers according to interview transcripts. The choice of a quantitative approach for the analysis adhering to conventions from similar research on the operationalisation of the variables (e.g., types of questions; Wright \& Alison, 2004), limited the susceptibility to the researcher's subjective inferences in interpreting the data. However, in the comparative analysis of the current research in relation to other countries' interviewing practices, it became evident that some of the observed variations in interviewing performance may represent differences due to the coding protocol rather than strictly reflecting differences in interviewing practices (Oxburgh et al., 2010). Nonetheless, using unobstructed measures of the interviewing phenomenon is meritorious, especially in combination with conventional controlled research paradigms (Alison et al., 2001) and in light of the dearth of archival witness interviewing research.

In Chapter 3, I presented the findings of a survey of police practitioners. Findings from self-reported interviewing practices are not necessarily an indicator of actual interviewing practice given that respondents' estimations of their interviewing performance can be inaccurate (Walsh et al., 2017). This limitation is particularly relevant given the discrepancy between the self-report data in Chapter 3 and the actual interviewing behaviour in Chapter 4. However, the characteristics of the samples may explain those differences (e.g., a police vs. non-police sample). Furthermore, the results in Chapter 3 indicate adherence to both evidence-based and non-evidence-based interviewing (Hirn et al., 2015), which does not seem to indicate deliberately deceptive intentions on the part of the respondents to portray their current interviewing practice as 
better than it is in reality. The latter point is of concern when utilising a self-reporting methodology, as it is susceptible to desirability bias (Stockemer, 2019). However, the observed response pattern was not uniformly indicative of effective interviewing behaviour. In addition, respondents were assured anonymity, which has been argued to reduce social desirability bias (Levine \& Parkinson, 2014). Nonetheless, future examination of recorded police interviews with uncooperative witnesses is necessary to replicate the findings. The findings in Chapter 3 can also be criticised for being descriptive and not providing an explanatory analysis; this is due to the non-experimental nature of the methodology, which produces normative knowledge (Stockemer, 2019). By including criminal investigators working in different jurisdictions, the results also allowed for country comparisons. Another limitation of this study was the use of a non-probability sample (e.g., convenience sampling), which can lead to sampling bias, as the researchers who completed the questionnaire initially belonged to the professional network of the research team. However, after snowball sampling, the final total sample was large and extended beyond our professional contacts, which likely reduced the potential bias. Lastly, it is worth noting that a few items in the questionnaire were complex or included negative questions, which is unadvisable in surveys as these characteristics reduce the specificity of items (Stockemer, 2019). However, to check for clarity, the survey was piloted and adapted in meaning in the translated versions. Overall, as the aims of the survey were exploratory, these aims were fulfilled and provided new insights into the police experience of interviewing uncooperative witnesses internationally.

In this dissertation, I particularly identified the consequences of lack of witness cooperation in two laboratory experiments (Chapters 3 and 4). Both experiments provided novel insights into the detrimental effects of lack of cooperation on the interviewer and the interviewee. As with other laboratory research on investigative interviewing, ecological validity was a necessary trade-off in order to study the effect of interest in isolation and to control confounds that would be present in real police practice (Chae, 2010; Kvavilashvili \& Ellis, 2004). In the two experiments included in this dissertation, participants conducted mock witness interviews in a laboratory within a university setting, which does not realistically resemble the 'ecology' of an interview in a police criminal investigation (Levine, 2018). Moreover, the large majority of participants belonged to a sample of 
university students. This is of particular concern for the experiment described in Chapter 4, as it aimed to test the expectations regarding witness cooperation in the interviewing approach, which would preferably have included police investigators as participants. In the sub-discipline of Legal Psychology, conducting 'low-stakes' experimental interviewing research and the use of non-police samples are common and fruitful. While this approach limits the generalisability of the findings from individual studies to practice, it contributes to cumulative scientific knowledge with practical implications. A combined theoretical and applied approach is necessary to solve important practical issues of applied memory in the legal process, whose solutions rest on sound psychological theory and methodology (Chae, 2010; Otgaar et al., 2013). Simulation research is popular, and will likely continue to be the norm, because of the enormous legal, logistical, and feasibility problems of forging collaborations with practitioners in which experimental manipulations can be introduced (Bornstein, 1999; see Hope et al., 2011; Kassin et al., 2019, for selected exceptions). Importantly, the development of theory requires temporary distance from 'real-world' settings to examine the mechanisms in play in the behavioural interactions that naturally occur in investigative interviews, to enable later testing of the contributions made in more ecological research settings (Diamond, 1997; Nahari et al., 2019). In light of the problematic knowledge and acceptance of evidence-based memory and interviewing research by practitioners in the criminal justice system, it is incumbent on researchers to persuade practitioners of the value of experimental and simulation research in order to increase the incorporation of its findings in practice (Bradley \& Nixon, 2009; Diamond, 1997; Oxburgh \& Dando, 2011). Thus, notwithstanding their limitations, the experimental studies in this dissertation provide valuable insights into the effects of lack of cooperation on information disclosure and interviewer approach, and were complementary to the archival and survey studies. Nonetheless, the current experimental research needs to be replicated while incorporating more realistic characteristics of participating in a real police investigations, for instance, by introducing police practitioners as interviewer participants and a diverse sample of individuals more representative of the witnesses in the criminal justice system.

In particular, the experiments described in Chapters 4 and 5 are two of the few that use experimental designs to examine the interviewing of uncooperative interviewees (see 
Brimbal et al., 2019; Dando \& Ormerod, 2019; Duke et al., 2018; Granhag et al., 2015, for exceptions). However, in Chapter 5, cooperation was manipulated using instructions that artificially test the construct and do not fully capture the competing motivations and the subjective evaluations of costs and benefits of witnesses in criminal investigations. Nonetheless, this experimental design allowed for the examination of actual reporting behaviour in a mock interview, overcoming the limitations of past related research that only investigated witnesses' prospective willingness (i.e., behavioural intentions) to report crime using surveys or hypothetical vignette methodologies (Nicksa, 2014; Tolsma et al., 2012)

A final critique is that in this dissertation the examination of lack of witness cooperation did not include an evaluation of police interviews with 'real' uncooperative witnesses. In the experimental study described in Chapter 4 , the uncooperative witness was a confederate in the study. Moreover, in Chapter 2, I present an archival analysis of adult witness interviews; however, the cooperativeness of the sample of witnesses was unknown. In general, archival studies of witness interviews are rare (Launay \& Py, 2015). Notably, the sample was convenient and did not constitute a sample of 'uncooperative' witnesses (umbrella term including 'reluctant' and 'intimidated' witnesses, see Chapter 1 ). Therefore, the research based on police data in this dissertation merely focused on the assessment (i.e., not intervention) of cooperation in general witness interviewing, rather than on evaluating or testing specific techniques to interview uncooperative witnesses. Without further observational or experimental findings providing evidence of the efficacy of techniques to overcome lack of witness cooperation, it would be premature to venture any provision of interviewing guidelines. However, the present examination of current practice in light of the experimental findings and the previous evidence base regarding how to gain and maintain witness cooperation provides a basis for offering recommendations by which police practitioners can avoid exacerbating uncooperativeness and can increase cooperativeness, and for identifying relevant gaps in knowledge that require further research to optimally overcome the initial lack of witness cooperation. 


\section{Future Directions}

It goes without saying that if recordings of interviews with uncooperative witnesses were available, the logical next step in this research would be to conduct an analysis similar to that presented in Chapter 2 using such material. That evaluation would allow: a) to contrast the results of the survey presented in Chapter 3 to current practice; b) to confirm whether lack of witness cooperation influences the interviewing approach, as suggested by the preliminary evidence in Chapter $4 ;$ and c) to discern differences between the techniques employed with cooperative and uncooperative witnesses, in order to inform specialised interviewing training.

The surveyed criminal investigators reported the use of some interviewing techniques in practice such as moral appeals, legal warnings and anonymity incentives that have not yet received empirical support for their effects in terms of gaining cooperation or eliciting accurate information (see Chapter 3). First, police practitioners mentioned that, for instance, they invite witnesses to consider the negative consequences of lack of witness testimony for securing justice for the victims. On one hand, such requests may increase cooperation, but, at the same time, such technique could reduce disclosure as the accuracy criterion might be heightened, given the highlighted legal context and consequences (Brewer, et al., 2018; Koriat \& Goldsmith, 1994). On the other hand, moral appeals may be effective and could be tested by examining specific persuasion techniques that increase the witness' willingness to report (Knowles \& Linn, 2004); however, their application can lead to memory errors (Leding, 2012) of critical relevance in the criminal justice system, warranting investigation of their use. Second, the use of legal warnings as part of procedural requirements to prevent withholding of information, making a false statements (i.e., perjury), and future retractions by uncooperative witnesses may inhibit rapport-building and decrease cooperation and information disclosure (Luther et al., 2015; MacDonald et al., 2017a; Snook \& Keating, 2011). However, rapport-building techniques prior to the administration of legal warnings may mitigate those possible negative effects (MacDonald et al., 2017a). It is important to test whether these effects occur in simulated interviews, as previous research has used archival and vignette methodologies. Third, anonymity incentives are reportedly commonly used by police to reduce the fear of 
retaliation from the suspect. The effect of anonymity on the intention to report crimes has not been substantiated (Aiello, 2019; Tolsma et al., 2012), except in certain social and political contexts (McCarthy et al., 2020). Therefore, future research is warranted to determine the benefits, if any, of anonymity incentives in interviews with uncooperative witnesses.

To build on the findings of Chapter 4 , and overcome its limitations, I propose two alternatives. The first would be a direct replication but utilising a police sample to explore how lack of cooperation influences information elicitation. This variant could also test the effect of training and not training of police interviewers. A second alternative would test the effectiveness of an information-gathering approach versus the direct police interviewing approach to interviewing uncooperative witnesses. A concern in the previous experiment was the use of only one confederate, thereby reducing generalisability (see Chapter 4). Therefore, in future research, the design would include two groups of participant witnesses, i.e., cooperative and uncooperative, creating a $2 \times 2$ factorial design to discern the effects of the two distinct interviewing approaches on information disclosure according to cooperativeness.

An alternative outside the laboratory setting, and in collaboration with the police, would be to incorporate and test known effective techniques used for overcoming lack of cooperation (e.g., Alison et al., 2013, 2014). Witnesses identified as uncooperative could be interviewed a second time by an interviewer trained in rapport-based interpersonal techniques (i.e., motivational interviewing skills and adaptive interpersonal behaviours; see Alison et al., 2013 for a review). Such design would allow the measurement of new elicited investigative leads, due to the manipulation in the second interview in contrast to the first one. If sufficient support is found, to overcome the limitations of lack of ground truth and case-specific characteristics, a controlled comparison of training versus no training should follow. That second evaluation could be restricted again to an experimental setting in consideration of ethical and methodological rigour. Mock-witness participants could complete Duke et al.'s (2018) rapport scale measuring Attentiveness, Trust/Respect, Expertise, Cultural Similarity, and Connected Flow to evaluate the perceived effect of both interviewing conditions from the perspective of the interviewees. Rapport has been identified as a predictor of willingness to cooperate, as measured by the Commitment to 
Communicate subscale (Duke et al., 2018). Such measurements could shed light on the effectiveness of rapport in increasing cooperation and, in turn, information disclosure.

The efficacy of training and interviewing performance has been associated with individual differences (see Akca \& Eastwood, 2019 for a review). Building rapport when an interviewee is deliberately resisting it may also be associated with the personal characteristics of the interviewer. In prior research, it has been suggested that cooperation an effective interviewer must be versatile to know which rapport-building behaviour to apply to each interviewee in each interaction (Alison et al., 2013; Christiansen et al., 2018), as well as being flexible to tailor and adapt the interviewing approach throughout the interviews (Soukara et al., 2002). The ability to display empathy has also been found to be beneficial when conducting humane information-gathering interviews (Holmberg \& Christianson, 2002) and to somewhat influence information elicitation (see Dando \& Oxburgh, 2016). In sum, the evidence indicates that exploring individual differences could help identify interviewers who can cope better with a more complex interview in which witness resistance is expected. Utilising a round-robin design (see Hudson et al., 2018), an experimental design could include a group of participant interviewers who complete individual differences measures and interview mock witnesses. The group conditions of the mock witnesses could belong to different cooperativeness conditions, allowing for the examination of both the interviewer's and interviewee's variance in information elicitation. In view of the effects of cooperation on information disclosure, and considering cooperation in terms of the cooperativeness-uncooperativeness continuum (see Chapter $1_{i}$ Kelly et al., 2016), it is important to examine shifts from uncooperativeness to cooperativeness. Witnesses are often interviewed more than once (e.g., by police, by the investigative judge, and in court), and their cooperativeness can change from one interview to another, potentially leading to the gaining of new information. It is of theoretical relevance whether non-reported information is remembered (see Chapter 5), and of practical relevance to evaluate the accuracy of testimony from uncooperative witnesses who come forward with a late disclosure, for instance, when allegiances with the suspect have changed (Davis et al., 2014).

Individuals use different communication strategies to avoid cooperation (Alison et al., 2013, 2014; Granhag et al., 2015). From the results in Chapter 5, it seems that 
participants withheld information and did not provide much inaccurate information in the No Cooperation conditions, given that in their statements information disclosure dropped at no cost to accuracy. Afterwards, when prompted with a Cooperation instruction, participants accurately remembered some of the previously unreported information. In Chapter 5, participants self-reported that when instructed not to cooperate, they did not report inaccurate information (i.e., fabrication/commissions). Instead, participants strategically controlled disclosure by avoiding volunteering too much accurate information (i.e., omissions) and reported a combination of accurate and inaccurate information (i.e., embedded lies). These communication strategies are in line with commonly used deceptive strategies to withhold information (Dynel, 2018; Strömwall et al., 2006; Verigin et al., 2019).

There are different mnemonic consequences of not disclosing crime-related information depending on the strategy used, which can be simply denying an (aspect of an) event, omitting information, or fabricating an alternative account (Otgaar et al., 2014; 2018). Otgaar and Baker (2018) proposed that omission errors can lead to forgetting due to lack of rehearsal whereas commission errors can lead to fabricating false memories due to source misattributions. Building on these distinctions, in a future experiment, one could provide different instructions (e.g., false denial, omission, and fabrication) to participants in multiple No Cooperation conditions, following an experimental design similar to that of the previous study described in Chapter 5, to examine the memorial consequences of the different communication strategies. Such an examination would provide the criminal justice system with insights into internal factors (rather than the already studied external factors, such as the interviewing approach) that can hamper the accuracy of statements of uncooperative witnesses, according to the deceptive strategies each individual uses to regulate disclosure (Otgaar \& Baker, 2018). In that proposed future avenue of research, it would also be of relevance to jointly explore the different communication strategies used by uncooperative witnesses according to the type of crime witness and their intrinsic reasons to avoid cooperation (see Chapter 1 ).

Lastly, another stream of research elucidating the willingness to cooperate and report information would be to analyse the public perceptions of the application of certain interviewing techniques during witness interviews. In Chapter 1 , the review of the factors 
that influence citizen cooperation with the police indicated that police legitimacy and perceived effectiveness are determinants of compliance with policing actions (Papp et al., 2017; Tyler and Fagan, 2008). Acting as a witness and reporting information during an investigative interview are therefore likely to be influenced by these factors. In a related research, Jones and Brimbal (2017) found that, according to the public opinion, police accusatorial techniques are the least accepted and most ineffective for interrogating suspects. However, such perceptions were also found to be dependant of individual differences. In addition, recent research has revealed that the police use of coercion techniques in witness interviews is negatively perceived by lay persons (Fallon \& Snook, 2020). Conducting similar research that evaluates perceptions of a wider range of witness interviewing techniques (i.e., question types, rapport-building, and perjury warning) could be informative in jurisdictions with jury systems that evaluate witness testimony. Moreover, the findings of such research could also reveal citizens' intentions to disclose information if they become crime witnesses and are interviewed by the police. In that way, this future research could serve to evaluate the perceived effectiveness of witness interviewing techniques in gaining cooperation and disclosing information.

\section{Final Remarks}

More than a century ago, Whipple noted that not everything observed by an individual who witnessed a crime will be reported to the police, as a witness report is not a direct replica of the event and is prone to error (Whipple, 1909). This assertion remains true to this day and guides investigative interviewing research and evidence-based policing. For the last 30 years, psychology has zealously deepened our understanding of memory and developed techniques to help police officers facilitate the most complete, accurate, and detailed witness accounts in order to advance criminal investigations and ethically secure voluntary and reliable evidence. In this dissertation, I demonstrate that cooperation is to some extent a determinant of effectively achieving these investigative goals. However, promoting cooperation in witness interviews does not seem to have been a priority for either researchers or police practitioners. Taken together, the findings of this dissertation shed light on the effects of witness uncooperativeness on the interviewing approach, as well as on the detrimental effects on witness cooperation in interviews in which directive 
and controlling questioning is the approach used to elicit a witness statement. Conversely, I provide evidence that lack of witness cooperation decreases disclosure and, to a lesser extent, accuracy, by the interviewee even when following evidence-based interviewing is followed, emphasising the limits of current interviewing guidelines to effectively eliciting information. These findings demand the development of specific techniques to overcome lack of witness cooperation that in turn facilitate reporting. I also suggested a model of understanding disclosure by a witness resulting from a subjective evaluation of low costs associated with cooperating with the police and high benefits from providing crime information. Relatedly, the interviewer's behaviour and techniques can modulate the witness's cost-benefit analysis to elicit information. For instance, when interviewing an uncooperative witness, establishing rapport and exploring the reasons for the witness's lack of initial cooperation can increase the witness's subjective benefits from cooperation. In combination, asking non-leading open questions can avoid increasing any risks perceived by the witness. Interviewers at a minimum should avoid exacerbating the subjective costs of cooperation that, for example, conducting an accusatorial-style interview, in which mainly closed and directive questions are asked at a rapid pace in a controlling style, can provoke.

Witness cooperation cannot be taken for granted. Interviewers must be fully equipped to facilitate cooperation, in terms of encouraging the witness's willingness to report, otherwise cognitive techniques that enhance memory recall may be futile. To elicit a witness account, interviewers are advised to follow the ethos of an informationgathering interviewing approach and to conduct a witness interview employing rapportbased techniques in combination with the use of non-leading open prompts as these techniques facilitate cooperation and protect memory. Such an interviewing approach does not preclude the interviewer from clarifying or challenging the account if needed, but simply prescribes a non-accusatorial and non-leading style for it.

Further research is still needed to fulfil current operational needs that stem from the detrimental effects of lack of witness cooperation on information elicitation goals, and in order to guarantee the ethical and effective interviewing of uncooperative witnesses. Nonetheless, in this dissertation, I highlighted a number of ways to improve current interviewing practice in order to promote cooperation, which in turn, maximises 
information elicitation that benefits criminal investigations and enhances the evidential value of witness testimony. 

Chapter 7

Valorisation Addendum

Witness Cooperation Matters:

Psycho-legal Contributions with Societal Impact 



\section{Witness Cooperation Matters: Psycho-legal Contributions with Societal Impact}

"Research that produces nothing but books will not suffice". - Kurt Lewin

Aligning to the vision captured in the above quote, this valorisation addendum is part of the association of Dutch universities' tasks for the academic community to produce scientific research that can be applicable and available for economic and societal utilisation (Vereniging van Nederlandse Universiteiten, 2013). As such, it imposes a mandatory, aposteriori reflection on the value of any scientific developments and advancements achieved stemming from this doctoral research. Psycho-legal research, however, is one of the applied disciplines in Psychology that inherently has implications for society, and in this dissertation, such considerations were a forethought that informed the overall aim of the research presented herein. As described in Chapter 1, the aim to gain an initial understanding of the effects of witness cooperation in a police interview has practical applications for interviewing practice and subsequent legal decision making based on the elicited witness evidence (see also Chapter 6). In this chapter, I describe different aspects concerning the valorisation of this doctoral programme of research and conclude with the potential obstacles and opportunities for the implementation of findings from this dissertation in particular, and of research in Legal Psychology in general.

\section{Research Relevance}

Police interviewing practices in pre-trial criminal investigations are relevant to the society at large in the pursuit of justice. Specifically, information from individuals who witness a crime open lines of investigation for the police and can later be used as evidence. In Chapter 2 of this thesis, the evaluations of current interviewing practice from different jurisdictions and in the Netherlands indicate that evidence-based interviewing techniques are not sufficiently implemented in practice when officers conduct witness interviews. As it was further discussed in Chapter 6, the risk of a direct and confirmatory interviewing approach is eliciting inaccurate witness accounts of a crime with direct consequences for the resolution of a crime investigation and for subsequent legal decision-making. Based on these findings, the importance of advocating for an ethical and evidence-based interviewing practice becomes an apparent necessity for the administration of justice. 
As mentioned above, the importance of obtaining accurate statements is selfevident to achieve the investigative goals, and the wrongful conviction cases based on erroneous and false testimony from witnesses further demonstrate the necessity to effectively elicit witness information and obtain best evidence (Gross \& Gross, 2013; The National Registry of Exonerations, 2020). Unreliable witness evidence leading to miscarriages of justice also wreak havoc in the lives of innocent persons convicted for crimes they did not commit, their families, and communities even beyond their exoneration (Thompson et al., 2011). Furthermore, the societal cost is grave considering that not only is justice not served for that crime's victims, a wrongful exoneration enables the perpetrator to continue to commit additional crimes threatening public safety (Norris et al., 2020). Lastly, wrongful convictions represent a failure in the justice system, with associated unfavourable public opinion and overtime an erosion of police legitimacy if the injustices are attributed to wrongdoing by the police (Mazerolle et al., 2013; Sunshine \& Tyler, 2003). Relevant to this thesis, such detrimental effects on the relationship between citizens and the police negatively influences their cooperation in a police investigation and can deter their willingness to provide information as a witness during a police interview (see Chapter 1). Thereby, perpetuating obstacles to gain witness cooperation, which hampers information elicitation.

\section{Research Innovation}

This research aimed to include a comprehensive overview of what is known about cooperation in witness interviews, a topic that has been neglected by academics and practitioners. As outlined in the beginning of the dissertation, previous research on witness interviewing has mainly focused on facilitating recall rather than influencing the willingness to report (see Chapter 1). The application of such distinction guiding this research on witnesses in particular was a novel opportunity to develop theoretical and practical knowledge about witness cooperation and the implications of lack of cooperation in the interview room.

To my knowledge, this is the first empirical treatise devoted entirely to this topic, and part of a handful of contemporary related research. One of the unique factors of this dissertation was the possibility to provide experimental evidence supporting the effects of 
lack of witness cooperation in the interviewer and the interviewee (see Chapters 4 and 5 respectively). Regarding the latter, this research revealed the limited effectiveness of the evidence-based techniques for interviewing uncooperative witnesses, highlighting the need for further research in this area and the limitations in current practice. This preliminary evidence was complemented by an archival analysis of current witness interviewing practice and a survey of criminal investigators to examine their experience gaining cooperation and overcoming lack thereof in order to elicit information. This methodological approach allowed the provision of an international overview of police perceptions concerning these topics that can guide a collaborative research agenda in different countries.

Altogether, this dissertation also served to review the previous assumption of cooperativeness from witnesses by providing insights into initial uncooperativeness and its implications in the interview room. Such a shift in the consideration of witnesses has direct implications for interviewing practice and beyond, for the management of witnesses in the criminal justice system (see Chapter 6). Considering that witness cooperation is not granted and should be promoted, in order to increase accurate recall and report, this $\mathrm{PhD}$ research builds on, and expands previous strong theoretical research on eyewitness memory (e.g., Blank, 2009; Koriat \& Goldsmith, 1994; Loftus, 2005).

\section{Target Groups}

There are problems with implementing current evidence-based interviewing techniques in practice (see Chapter 2), which reveal that previous investigative interviewing research needs to be disseminated further so that such knowledge can be utilised by police academies in interviewing training. By providing an examination of previous empirical research that promotes cooperation in the interview room, the academic contributions from this dissertation are pertinent to police institutions to evaluate current practice, and consider the effects of lack of cooperation. Similarly, these benefits can extend to any institution, whether public or private, investigating events for which effective elicitation of accurate information is a priority. However, it is too early to provide specific original recommendations on how to, rather than how not to, interview uncooperative witnesses based on the programme of research of this dissertation. 
The conclusions of this dissertation indicate that implementing current evidencebased techniques to interview uncooperative witnesses can be of limited use to effectively overcome resistance (see Chapter 5). Therefore, more research is needed to equip police investigators with techniques that adhere to an information-gathering approach and effectively elicit information despite lack of witness cooperation and its detrimental effects to the interviewing approach and information disclosure. In that goal, this dissertation is only a foundation for future collaborative efforts between academics and police practitioners to develop and test effective techniques to elicit information from uncooperative witnesses.

Considering the above explained ramifications of witness accounts in the criminal justice system, this research can also be relevant to state institutions, and other governmental level institutions, tasked with promoting justice, security, governance, and human rights; as well as relevant non-state organisation advocating for strengthening the rule of law and social justice. Beyond the users of this research, potential reforms and process optimisation in police interviews and how witness evidence is evaluated can benefit how citizens are treated by the police, expanding the interest of this research to the society as a whole.

\section{Activities and Products}

The mixed methodology approach in this dissertation in which I included relevant research outside the laboratory allowed me to have a better understanding of witness cooperation in the actual interview room. Admittedly, I thought theoretically it was an interesting topic to study, but I was missing whether in practice witnesses were indeed uncooperative, and what happened next. Thus, at the beginning of my PhD project, in order to inform the programme of research, I started informal conversations with police practitioners, which were followed by semi-structured interviews. Given their positive responses of interest in the research problem, I, together with my supervisors, sought police contacts more widely to establish collaborations. After some unanswered emails, we were able to gather access to archival data and to find international respondents to a survey. As a result, research presented in Chapter 2 and 3 represent some of the experiences and expertise of police officers in the Netherlands, Sweden and England, interviewing 
cooperative and uncooperative witnesses. Findings of this research has been communicated to our partners in the Police (Chapter 2), and country-reports will be distributed together with the journal article (Chapter 3 ) to the police practitioners, who facilitated data collection of the survey, and to those respondents who contacted us after their participation indicating interest in this research topic.

To celebrate other research in the field that is focused on police experience, expertise, and practice, last year during the conference of the European Association of Psychology and Law, which gathers academics and professionals in the field, I organised a symposium show casing empirical research relevant to investigative practice. Either in survey or experimental designs, the six research projects included in the symposium presented first-hand data from police officers about their practice in complex criminal investigations across the world (e.g., North-America, Europe, and Asia), including the interviewing of uncooperative witnesses. In the organisation of this activity, I actively sought to represent the diverse community of researchers in our field.

\section{Research Dissemination}

The doctoral research included in this dissertation (Chapter 1 through 5 ) has been written in journal-style manuscripts to disseminate in peer-review academic journals. The chosen outlets also include dissemination beyond the academic circle, as the chosen journal's target audiences include police, legal professionals and policy makers. Findings and wider implications of the research has been amplified by choosing to publish with openaccess, making the research available for free to all target groups. Furthermore, prior to publication, the research has been subjected to scrutiny by peers during international academic conferences, as well as conferences gathering police practitioners and stakeholders in Belgium, Finland, Portugal, Norway, Spain, and in a virtual conference.

As a researcher interested in scientific communication to the wider community, I have also organised public lectures, and presented my research in events engaging lay audiences in the Netherlands and England. In addition, as part of my outreach activities, I have presented my research, and delivered workshops to young scientists pursuing STEM studies in Latin America. Specifically, to promote education and research in Legal 
Psychology, I have also been a guest speaker and delivered workshops to undergraduate students at my affiliated universities in the Netherlands and Sweden.

\section{Research Implementation}

The empirical examination of social and cognitive issues concerning verbal testimony of witnesses in legal proceedings has been of interest since the beginnings of Legal Psychology. Hugo Münsterberg (1908) discussed the practical service of experimental psychology in his seminal work, On the Witness Stand: Essays on Psychology and Crime. Münsterberg also anticipated problems with the application of psychological research in the legal sphere and encouraged popular dissemination, so that public opinion would exert pressure for the application of Psychology to the field of Law. Scholars in our field (but also in other sciences) have not always succeeded in this endeavour to communicate science widely and to translate science into practice. Nonetheless, thirty years ago, police reform on interrogations began after public scrutiny over miscarriages of justice, and some of the contributions from psychological science gained momentum to be implemented and led the change to establish evidence-based investigative interviewing (Kassin et al., 2010; Vrij et al., 2017; Williamson, 2003). However, there are still critical problems with knowledge dissemination and implementation of research in police (investigative) interviewing of witnesses (see Chapter 2). In this context, the potential impact and implications for the valorisation of this programme of research concerning interviewing of uncooperative witnesses could be limited. Moving forward, to obtain a different outcome, and following the theme of this dissertation, we need to achieve better cooperation between scientists and practitioners. For that, both researchers and practitioners need to focus on improving interviewing practice. Such cooperation would not occur in a vacuum thus, it is key to consider the institutional contexts and support (financial and otherwise) needed to actually have influence in research implementation. Action research models in which police practitioners and science researchers participate jointly in the whole execution of a research project that is problem-oriented and solution-driven have been proposed as alternatives to create productive and durable alliances between social scientists and police departments that lead to ethical evidence-based policing (Kerrison et al., 2019). An example of a local initiative with the potential to amend the common fracture between the academic 'ivory 
tower' and the Police (cf. Bradley \& Nixon, 2009), is the recently announced research programme: 'What works in policing: towards evidence policing in the Netherlands' between the National Police, the Police Academy, the Ministry of Justice and Security, and the Netherlands Institute for the Study of Crime and Law Enforcement, as well as universities from the Netherlands and abroad (Netherlands Institute for the Study of Crime and Law Enforcement, n.d.). Perhaps is the naiveté of an earlier career researcher, but I hope that more sustainable partnerships occur in each country that materialise funding to conduct this type of interviewing research and facilitate successful implementation of evidence-based interviewing practice. 



\section{References}

Abbe, A., \& Brandon, S. E. (2013). The role of rapport in investigative interviewing: A review. Journal of Investigative Psychology and Offender Profiling, 10(3), 237-249. https://doi.org/10.1002/jip.1386

Abbe, A., \& Brandon, S. E. (2014). Building and maintaining rapport in investigative interviews. Police Practice and Research, 15(3), 207-220. https://doi.org/10.1080/15614263.2013.827835

Adams-Quackenbush, N. M., Horselenberg, R., Tomas, F., \& van Koppen, P. (2019). Detecting guilt-presumption in a police-suspect interview: An evaluation of the questions in a murder case. Investigative Interviewing: Research and Practice, 10(1), 37-60.

Aiello, M. F. (2019). Should I call for help?: Examining the influences of situational factors and bystander characteristics on reporting likelihood, Journal of School Violence, 18(2), 163-175. https://doi.org/10.1080/15388220.2018.1428195

Akca, D., \& Eastwood, J. (2019). The impact of individual differences on investigative interviewing performance: A test of the police interviewing competencies inventory and the five factor model [Advance publication]. Police Practice and Research. https://doi.org/10.1080/15614263.2019.1644177

Alison, L. J., Alison, E., Noone, G., Elntib, S., \& Christiansen, P. (2013). Why tough tactics fail and rapport gets results: Observing Rapport-Based Interpersonal Techniques (ORBIT) to generate useful information from terrorists. Psychology, Public Policy, and Law, 19(4), 411- 431. https://doi.org/10.1037/a0034564

Alison, L. J., Snook, B., \& Stein, K. L. (2001). Unobtrusive measurement: Using police information for forensic research. Qualitative Research, 1(2), 241-254. https://doi.org/10.1177/146879410100100208

Alison, L., Alison, E., Noone, G., Elntib, S., Waring, S., \& Christiansen, P. (2014). The efficacy of rapport-based techniques for minimizing counter-interrogation tactics amongst a field sample of terrorists. Psychology, Public Policy, and Law, 20(4), 421-430. https://doi.org/10.1037/lawo000021

Anderson, M. C., \& Green, C. (2001). Suppressing unwanted memories by executive control. Nature, 410, 366-369. https://doi.org/10.1038/35066572

Anderson, M. C., Bjork, R. A., \& Bjork, E. L. (1994). Remembering can cause forgetting: retrieval dynamics in long-term memory. Journal of Experimental Psychology: Learning, Memory, and Cognition, 20(5), 1063-1087. https://doi.org/10.1037/02787393.20.5.1063 
Antaki, C., \& Stokoe, E. (2017). When police treat straightforward answers as uncooperative. Journal of Pragmatics, 117, 1-15. https://doi.org/10.1016/j.pragma.2017.05.012

Ash, M. (1972). On witnesses: A radical critique of criminal court procedures. Notre Dame Law Review, 48(2), 386-425. Retrieved from http://scholarship.law.nd.edu/ndlr/vol48/iss2/6

Ask, K., \& Granhag, P. A. (2007). Motivational bias in criminal investigators' judgments of witness reliability. Journal of Applied Social Psychology, 37(3), 561-591. https://doi.org/10.1111/j.1559-1816.2007.00175.x

Baldwin, J. (1993). Police interview techniques: Establishing truth or proof? The British Journal of Criminology, 33(3), 325-352. https://doi.org/10.1093/oxfordjournals.bjc.a048329

Bartlett, F. C. (1932). Remembering: A study in experimental and social psychology. Cambridge University Press.

Bierhoff, H. W. (2002). Prosocial behaviour. Psychology Press.

Blank, H. (2009). Remembering: A theoretical interface between memory and social psychology. Social Psychology, 40(3), 164-175. https://doi.org/10.1027/1864$9335 \cdot 40.3 .164$

Boon, R., Odinot, G., Horselenberg, R., \& Geijsen, K. (2016). Van verhoor naar forensisch interview [From interrogation to forensic interview]. Het Tijdschrift voor de Politie, $78(4), 20-25$.

Bornstein, B. H. (1999). The ecological validity of jury simulations: Is the jury still out? Law and Human Behavior, 23(1), 75-91. https://doi.org/10.1023/A:1022326807441

Bowles, R., Reyes, M. G., \& Garoupa, N. (2009). Crime reporting decisions and the costs of crime. European Journal on Criminal Policy and Research, 15(4), 365-377. https://doi.org/10.1007/s10610-009-9109-8

Bradley, D., \& Nixon, C. (2009). Ending the 'dialogue of the deaf': Evidence and policing policies and practices. An Australian case study. Police Practice and Research: An International Journal, 10(5-6), 423-435. https://doi.org/10.1080/13218719.2014.951112

Braun, V., \& Clarke, V. (2006). Using thematic analysis in psychology. Qualitative Research in Psychology, 3(2), 77-101. https://doi.org/10.1191/1478088706qpo630a

Brewer, N., Vagadia, A. N., Hope, L., \& Gabbert, F. (2018). Interviewing witnesses: Eliciting coarse-grain information. Law and Human Behaviour, 42(5), 458-471. https://doi.org/10.1037/lhbooo0294 
Brimbal, L., Dianiska, R. E., Swanner, J. K., \& Meissner, C. A. (2019). Enhancing cooperation and disclosure by manipulating affiliation and developing rapport in investigative interviews. Psychology, Public Policy, and Law, 25(2), 107-115. https://doi.org/10.1037/lawooo0193

Bull, R., \& Cherryman, J. (1996). Helping to identify skills gaps in specialist investigative interviewing: Enhancement of professional skills. Home Office, Research, Development and Statistics Directorate.

Cabell, J. J., Moody, S. A., \& Yang, Y. (2020). Evaluating effects on guilty and innocent suspects: An effect taxonomy of interrogation techniques. Psychology, Public Policy, and Law, 26(2), 154-165. https://doi.org/10.1037/law0000224

Camerer, C. F., \& Loewenstein, G. (2003). Behavioral economics: Past, present, future. In C. F. Camerer, G. Loewenstein, \& M. Rabin (Eds.), Advances in Behavioral Economics (pp. 3-52). Princeton University Press. https://doi.org/10.2307/j.ctvcm4j8j.6

Cannavale, F. J., \& Falcon, W. (1976). Improving witness cooperation: Summary report of the District of Columbia witness survey and a handbook of witness management. US Government Printing Office.

Centraal Bureau voor de Statistiek (February, 2020). Veiligheidsmonitor 2019 [Safety Monitor 2019]. https://www.cbs.nl/nl-nl/publicatie/2020/10/veiligheidsmonitor-2019

Central Planning and Training Unit. (1992). Investigative interviewing: A guide to interviewing. Central Planning and Training Unit.

Chae, Y. (2010). Application of laboratory research on eyewitness testimony. Journal of Forensic Psychology Practice, 10(3), 252-261. https://doi.org/10.1080/15228930903550608

Cherryman, J., \& Bull, R. (2001). Police officers' perceptions of specialist investigative interviewing skills. International Journal of Police Science \& Management, 3(3), 199212. https://doi.org/10.1177/146135570100300302

Christiansen, P., Alison, L., \& Alison, E. (2018). Well begun is half done: Interpersonal behaviours in distinct field interrogations with high-value detainees. Legal and Criminological Psychology, 23(1), 68-84. https://doi.org/10.1111/lcrp.12111

Christianson, S. Å., \& Bylin, S. (1999). Does simulating amnesia mediate genuine forgetting for a crime event? Applied Cognitive Psychology, 13(6), 495-511. https://doi.org/10.1002/(SICl)1099-0720(199912)13:6<495::AID-ACP615>3.0.CO;2-0 
Clarke, C., \& Milne, R. (2001). A national evaluation of the PEACE investigative interviewing course. Home Office. http://www.researchgate.net/profile/Colin Clarke3/publication/263127370 National Evaluation_of_the_PEACE

Clayman, C. \& Skinns, L. (2012). To snitch or not to snitch? An exploratory study of the factors influencing whether young people actively cooperate with the police. Policing and Society: An International Journal of Research and Policy, 22(4), 460-480. https://doi.org/10.1080/10439463.2011.641550

Clifford, B. R. \& George, R. (1996). A field evaluation of training in three methods of witness/victim investigative interviewing. Psychology, Crime and Law, 2(3), 231-248. https://doi.org/10.1080/10683169608409780

Cohen, J. (1988). Statistical power analysis for the behavioral sciences. Erlbaum.

Collins, R., Lincoln, R., \& Frank, M. G. (2002). The effect of rapport in forensic interviewing. Psychiatry, Psychology and Law, 9(1), 69-78. https://doi.org/10.1375/pplt.2002.9.1.69

Colomb, C., \& Ginet, M. (2012). The Cognitive Interview for use with adults: An empirical test of an alternative mnemonic and of a partial protocol. Applied Cognitive Psychology, 26(1), 35-47. https://doi.org/10.1002/acp.1792

Confrey, M. (2017, July). Interviewing the reluctant, intimidated, and hostile [Paper presentation]. 2017 Conference of the International Investigative Interviewing Research Group, Monterey Bay, California, United States.

Dando, C. J., \& Ormerod, T. C. (2019). Noncoercive human intelligence gathering. Journal of Experimental Psychology: General, 149(8), 1435-1448. https://doi.org/10.1037/xgeo000724

Dando, C. J., \& Oxburgh, G. E. (2016). Empathy in the field: Towards a taxonomy of empathic communication in information gathering interviews with suspected sex offenders. The European Journal of Psychology Applied to Legal Context, 8(1), 27-33. https://doi.org/10.1016/j.ejpal.2015.10.001

Dando, C., Wilcock, R., \& Milne, R. (2008). The cognitive interview: Inexperienced police officers' perceptions of their witness/victim interviewing practices. Legal and Criminological Psychology, 13(1), 59-70. https://doi.org/10.1348/135532506X162498

Dando, C., Wilcock, R., \& Milne, R. (2009). The cognitive interview: Novice police officers' witness/victim interviewing practices. Psychology, Crime and Law, 15(8), 679-696. https://doi.org/10.1080/10683160802203963 
Darley, J. M., \& Fazio, R. H. (1980). Expectancy confirmation processes arising in the social interaction sequence. American Psychologist, 35(10), 867-881. https://doi.org/10.1037/0003-066X.35.10.867

Davis, D., \& Leo, R. (2016). A damning cascade of investigative errors. University of San Francisco Law Research Paper, 2, 1-48. https://papers.ssrn.com/sol3/papers.cfm?abstract_id=2693354

Davis, M. R., McMahon, M., \& Greenwood, K. M. (2005). The efficacy of mnemonic components of the cognitive interview: Towards a shortened variant for time-critical investigations. Applied Cognitive Psychology, 19(1), 75-93. https://doi.org/10.1002/acp.1048

Davis, R. C. (1983). Victim/witness noncooperation: A second look at a persistent phenomenon. Journal of Criminal Justice, 11(4), 287-299.

https://doi.org/10.1016/0047-2352(83)g0069-7

Davis, R. C., Jensen III, C. J., Burgette, L., \& Burnett, K. (2014). Working smarter on cold cases: Identifying factors associated with successful cold case investigations. Journal of Forensic Sciences, 59(2), 375-382. https://doi.org/10.1111/1556-4029.12384

De Keijser, J., Malsch, M., Kranendonk, R., \& De Gruijter, M. (2012). Written records of police interrogation: Differential registration as determinant of statement credibility and interrogation quality. Psychology, Crime and Law, 18(7), 613-629. https://doi.org/10.1080/1068316X.2010.526119

De La Fuente Vilar, A., Horselenberg, R., Strömwall, L. A., Landström, S., Hope, L., \& van Koppen P. J. (2020). Effects of Cooperation on Information Disclosure in MockWitness Interviews. Legal and Criminological Psychology, 25(2), 133-149. https://doi.org/10.1111/lcrp.12167

Diamond, S. S. (1997). Illuminations and shadows from jury simulations. Law and Human Behavior, 21(5), 561-571. https://doi.org/10.1023/A:1024831908377

Douglass, A. B., Brewer, N., Semmler, C., Bustamante, L., \& Hiley, A. (2013). The dynamic interaction between eyewitnesses and interviewers: The impact of differences in perspective on memory reports and interviewer behavior. Law and Human Behavior, 37(4), 290-301. https://doi.org/10.1037//hboo00034

Dreissen, W., Nauta, O., \& Terpstra, J. (2012). Anonimiteit in het strafproces [Anonymity in criminal proceedings]. Retrieved from: https://www.wodc.nl/onderzoeksdatabase/anonimiteit-in-het-strafproces.aspx 
Dubelaar, M. J. (2014). Betrouwbaar getuigenbewijs: Totstandkoming en waardering van strafrechtelijke getuigenverklaringen in perspectief [Reliable witness evidence: Perspectives on the production and assessment of witness testimony in criminal cases] [Doctoral dissertation, Leiden University]. https://openaccess.leidenuniv.nl/handle/1887/23625

Duke, M. C., Wood, J. M., Bollin, B., Scullin, M., \& LaBianca, J. (2018). Development of the rapport scales for investigative interviews and interrogations (RS3i): Interviewee version. Psychology, Public Policy, and Law, 24(1), 64-79. https://doi.org/10.1037/lawooo0147

Dynel, M. (2018). To say the least: Where deceptively withholding information ends and lying begins. Topics in Cognitive Science, 1-28. https://doi.org/10.1111/tops.12379

Evans, J. R., Meissner, C. A., Brandon, S. E., Russano, M. B., \& Kleinman, S. M. (2010). Criminal versus HUMINT interrogations: The importance of psychological science to improving interrogative practice. The Journal of Psychiatry and Law, 38 (1-2), 215249. https://doi.org/10.1177/009318531003800110

Fallon, L., \& Snook, B. (2020). Beyond common sense and human experience: Lay perceptions of witness coercion. Criminal Justice and Behavior, 47(2), 208-221. https://doi.org/10.1177/0093854819892654

Fisher, R. P. (1995). Interviewing victims and witnesses of crime. Psychology, Public Policy, and Law, 1(4), 732-764. https://doi.org/10.1037/1076-8971.1.4-732

Fisher, R. P. (2010). Interviewing cooperative witnesses. Legal and Criminological Psychology, 15(1), 25-38. https://doi.org/10.1348/135532509X441891

Fisher, R. P., \& Geiselman, R. (1992). Memory-enhancing techniques for investigative interviewing: The cognitive interview. Charles $C$. Thomas, Publisher.

Fisher, R. P., \& Geiselman, R. E. (2010). The cognitive interview method of conducting police interviews: Eliciting extensive information and promoting therapeutic jurisprudence. International Journal of Law and Psychiatry, 33(5-6), 321-328. https://doi.org/10.1016/j.ijlp.2010.09.004

Fisher, R. P., \& Schreiber, N. (2007). Interview protocols for improving eyewitness memory. In M. P. Toglia, J. D. Read, D. F. Ross, \& R. C. L. Lindsay (Eds.), The handbook of eyewitness psychology, Vol I: Memory for events (pp. 53-80). Psychology Press. https://doi.org/10.4324/9781315086309

Fisher, R. P., Geiselman, R. E., \& Amador, M. (1989). Field test of the Cognitive Interview: Enhancing the recollection of actual victims and witnesses of crime. Journal of Applied Psychology, 74(5), 722-727. https://doi.org/10.1037/0021-9010.74.5.722 
Fisher, R. P., Geiselman, R. E., \& Raymond, D. S. (1987). Critical analysis of police interview techniques. Journal of Police Science and Administration, 15(3), 177-185.

Fisher, R. P., Milne, R., \& Bull, R. (2011). Interviewing cooperative witnesses. Current Directions in Psychological Science, 20(1), 16-19. https://doi.org/10.1177/og63721410396826

Frenda, S. J., Nichols, R. M., \& Loftus, E. F. (2011). Current issues and advances in misinformation research. Current Directions in Psychological Science, 20(1), 20-23. https://doi.org/10.1177/0963721410396620

Fyfe, N., \& Smith, K. (2007). Victims and witnesses in criminal investigations. In T. Newburn, T. Williamson, \& A. Wright (Eds.), Handbook of criminal investigation (pp. 450-465). Routledge. https://doi.org/10.4324/9780203118177.ch18

Gabbert, F., Hope, L., \& Confrey, M. (2018). Witness testimony. In A. Griffiths \& R. Milne, (Eds.). The Psychology of Criminal Investigations. Routledge.

Gabbert, F., Hope, L., \& Fisher, R. P. (2009). Protecting eyewitness evidence: Examining the efficacy of a self-administered interview tool. Law and Human Behavior, 33(4), 298307. https://doi.org/10.1007/s10979-008-9146-8

Gabbert, F., Hope, L., Luther, K., Wright, G., Oxburgh, G., \& Ng, M. (2020). Exploring the use of rapport in professional information-gathering contexts via systematically mapping the evidence base. Manuscript submitted for publication.

Gabbert, F., Hope, L., Oxburgh, G., Wright, G. La Rooy, D., McGregor, A., Caso, A., \& Nardi, D. (2016). Interviewing witnesses searchable systematic map. https://www.iiirg.org/database-search-guidelines/victims-witnesses-searchabledatabasel

Geijsen, K. (2018). Persons at risk during interrogations in police custody [Doctoral dissertation, Maastricht University]. https://cris.maastrichtuniversity.nl/en/publications/persons-at-risk-duringinterrogations-in-police-custody-different

Geiselman, R. E., Fisher, R. P., Firstenberg, I., Button, L. A., Sullivan, S., Avetissian, I., \& Prosk, A. (1984). Enhancement of eyewitness memory: An empirical evaluation of the cognitive interview. Journal of Police Science and Administration, 12(1), 74-80.

Giebels, E., Oostinga, M. S. D., Taylor, P. J., \& Curtis, J. L. (2017). The cultural dimension of uncertainty avoidance impacts police-civilian interaction. Law and Human Behavior, 41(1), 93-102. https://doi.org/10.1037/lhboo00227

Goldsmith, A. (2005). Police reform and the problem of trust. Theoretical Criminology, 9(4), 443-470. https://doi.org/10.1177/1362480605057727 
Goldsmith, M., Koriat, A., \& Weinberg-Eliezer, A. (2002). Strategic regulation of grain size memory reporting. Journal of Experimental Psychology: General, 131(1), 73-95. https://doi.org/10.1037/oog6-3445.131.1.73

Goudriaan, H. (2006). Reporting crime: Effects of social context on the decision of victims to notify the police [Doctoral dissertation, Leiden University]. https://openaccess.leidenuniv.nl/handle/1887/4410

Goudriaan, H., Lynch, J. P., \& Nieuwbeerta, P. (2004). Reporting to the police in western nations: A theoretical analysis of the effects of social context. Justice Quarterly, 21(4), 933-969. https://doi.org/10.1080/07418820400096041

Granhag, P. A., Oleszkiewicz, S., Strömwall, L. A., \& Kleinman, S. M. (2015). Eliciting intelligence with the Scharff technique: Interviewing more and less cooperative and capable sources. Psychology, Public Policy, and Law, 21(1), 100-110. https://doi.org/10.1037/lawoo00030

Granhag, P. A., Strömwall, L. A., \& Montecinos, S. C. (2013). Polisens förhör med misstänkta: Svensk utbildning i internationell belysning [Police interrogations with suspects: Swedish education in international lighting]. Rikspolisstyrelsens Utvärderingsfunktion, Report 2013, 7, 1-50. https://www.psy.gu.se/digitalAssets/1471/1471528 rps-rapport-f--rh--r.pdf

Grice, H. P. (1975). Logic and conversation. In P. Cole \& J. L. Morgan (Eds.), Speech acts (pp. 41-58). Brill. https://doi.org/10.1163/9789004368811_003

Griffiths, A. (2008). An examination into the efficacy of police advanced investigative interview training? [Doctoral dissertation, University of Portsmouth]. https://ethos.bl.uk/OrderDetails.do?uin=uk.bl.ethos.594174

Griffiths, A., \& Milne, R. (2006). Will it all end in tiers? Police interviews with suspects in Britain. In T. Williamson (Ed.), Investigative interviewing: Rights, research, regulation (pp. 167-189). Willan.

Griffiths, A., \& Milne, R. (2010). The application of cognitive interview techniques as part of an investigation. In C. A. Ireland \& M. J. Fisher (Eds.), Consultancy and Advising in Forensic Practice (pp. 71-9o). Wiley. https://doi.org/10.1002/9780470661505.ch5

Griffiths, A., Milne, B., \& Cherryman, J. (2011). A question of control? The formulation of suspect and witness interview question strategies by advanced interviewers. International Journal of Police Science and Management, 13(3), 255-267. https://doi.org/10.1350/ijps.2011.13.3.219

Gross, A. \& Gross, S. (2013). Witness recantation study: Preliminary findings. The National Registry of Exonerations. http://repository.law.umich.edu/cgi/viewcontent.cgi?article=10go\&context=other 
Gudjonsson, G. H. (2010). Psychological vulnerabilities during police interviews. Why are they important? Legal and criminological Psychology, 15(2), 161-175. https://doi.org/10.1348/135532510X500064

Guerra-Thompson, S. (2012). Judicial gatekeeping of police-generated witness testimony. Journal of Criminal Law and Criminology, 102(2), 329-396. https://heinonline.org/HOL/LandingPage?handle=hein.journals/jclc102\&div=16\&id= \&page $=$

Hanway, P., Akehurst, L. A., Vernam, Z., \& Hope, L. (in press). The effects of cognitive load during an investigative interviewing task on mock interviewers' recall of information. Legal and Criminological Psychology.

Heaton-Armstrong, A., \& Wolchover, D. (1992). Recording witness statements. Criminal Law Review, 160-172.

Hershkowitz, I., Orbach, Y., Lamb, M. E., Sternberg, K. J., \& Horowitz, D. (2006). Dynamics of forensic interviews with suspected abuse victims who do not disclose abuse. Child Abuse and Neglect, 30(7), 753-769. https://doi.org/10.1016/j.chiabu.2005.10.016

Hill, C., Memon, A., \& McGeorge, P. (2008). The role of confirmation bias in suspect interviews: A systematic evaluation. Legal and Criminological Psychology, 13(2), 375371. https://doi.org/10.1348/135532507X238682

Hirn Mueller, D., Schreiber Compo, N., Molina, J., Bryon, A., \& Pimentel, P. S. (2015). Productive and counterproductive interviewing techniques: Do law enforcement investigators know the difference? Psychology, Public Policy, and Law, 21(3), 295308. https://doi.org/10.1037/law0000047

Holmberg, U., \& Christianson, S. Å. (2002). Murderers' and sexual offenders' experiences of police interviews and their inclination to admit or deny crimes. Behavioral Sciences \& the Law, 20(1-2), 31-45. https://doi.org/10.1002/bsl.470

Homans, G. C. (1958). Social behavior as exchange. American Journal of Sociology, 63(6), 597-606. https://doi.org/10.1086/222355

Hoogesteyn, K., Meijer, E. H., \& Vrij, A. (2020a). Examining witness interview environments [Advance online publication]. Journal of Investigative Psychology and Offender Profiling. https://doi.org/10.1002/jip.1549

Hoogesteyn, K., Meijer, E. H., \& Vrij, A. (2020b). Utility and effectiveness of the context manipulation techniques: Police investigators' perspectives [Advance online publication]. Journal of Police and Criminal Psychology.

https://doi.org/10.1007/s118g6-020-09374-2 
Hope, L. \& Gabbert, F. (2019). Interviewing witnesses and victims. In N. Brewer \& A. Bradfield Douglass (Eds.), Psychological science and the law. Guilford Publications.

Hope, L., Gabbert, F., \& Fisher, R. P. (2011). From laboratory to the street: Capturing witness memory using the Self-Administered Interview. Legal and Criminological Psychology, 16(2), 211-226. https://doi.org/10.1111/j.2044-8333.2011.02015.X

Hope, L., Gabbert, F., \& Fraser, J. (2013). Postincident conferring by law enforcement officers: Determining the impact of team discussions on statement content, accuracy, and officer beliefs. Law and Human Behavior, 37(2), 117-127. https://doi.org/10.1037/lhbooooo19

Hope, L., Mullis, R., \& Gabbert, F. (2013). Who? What? When? Using a timeline technique to facilitate recall of a complex event. Journal of Applied Research in Memory and Cognition, 2(1), 20-24.

Horselenberg, R., \& van Koppen, P. J. (2011). Een opname van het verhoor is de verbalisants beste vriend [A tape of the interrogation is the policeman's best friend]. Tijdschrift Voor de Politie, 73(5), 23-26.

Inbau, F. E., Reid, J. E., Buckley, J. P. \& Jayne, B. C. (2013). Criminal interrogation and confessions. Jones \& Bartlett Learning.

Jakobsen, K. K., Fahsing, I., \& Ross Af Hjelmsäter, E. (2016). Investigative interviewing in Scandinavia-Witnesses and victims. In D. Walsh, G. E. Oxburgh, A. D. Redlich, \& T. Myklebust (Eds.), International developments and practices in investigative interviewing and interrogation - Volume 1: Victims and witnesses (pp. 199-208). Routledge.

Johnson, M. K., Hashtroudi, S., \& Lindsay, D. S. (1993). Source monitoring. Psychological Bulletin, 114(1), 3-28. https://doi.org/10.1037/0033-2909.114.1.3

Jones, A. M., \& Brimbal, L. (2017). Lay perceptions of interrogation techniques: Identifying the role of Belief in a Just World and Right Wing Authoritarianism. Journal of Investigative Psychology and Offender Profiling, 14(3), 260-280. https://doi.org/10.1002/jip.1476

Kaasa, S. O., Cauffman, E., Clarke-Stewart, K. A. \& Loftus, E. F. (2013). False accusations in an investigative context: Differences between suggestible and non-suggestible witnesses. Behavioral Sciences \& the Law, 31(5), 574-592. https://doi.org/10.1002/bsl.2075

Kassin, S. M., Drizin, S. A., Grisso, T., Gudjonsson, G. H., Leo, R. A., \& Redlich, A. D. (2010). Police-induced confessions: Risk factors and recommendations. Law and Human Behavior, 34(1), 3-38. https://doi.org/10.1007/s10979-009-9188-6 
Kassin, S. M., Goldstein, C. C., \& Savitsky, K. S. (2003). Behavioral confirmation in the interrogation room: On the dangers of presuming guilt. Law and Human Behavior, 27(2), 187-203. https://doi.org/10.1023/A:1022599230598

Kassin, S. M., Kukucka, J., Lawson, V. Z., \& DeCarlo, J. (2014). Does video recording alter the behavior of police during interrogation? A mock crime-and-investigation study. Law and Human Behavior, 38(1), 73-83. https://doi.org/10.1037//hbooo0047

Kassin, S. M., Russano, M. B., Amrom, A. D., Hellgren, J., Kukucka, J., \& Lawson, V. Z. (2019). Does video recording inhibit crime suspects? Evidence from a fully randomized field experiment. Law and Human Behavior, 43(1), 45-55. https://doi.org/10.1037/lhboooo319

Kebbell, M. R., \& Milne, R. (1998). Police officers' perceptions of eyewitness performance in forensic investigations. The Journal of Social Psychology, 138(3), 323-330. https://doi.org/10.1080/00224549809600384

Kelly, C. E., Miller, J. C., \& Redlich, A. D. (2016). The dynamic nature of interrogation. Law and Human Behavior, 40(3), 295-309. https://doi.org/10.1037/lhboo00172

Kelly, C. E., Miller, J. C., Redlich, A. D., \& Kleinman, S. M. (2013). A taxonomy of interrogation methods. Psychology, Public Policy, and Law, 19(2), 165-178. https://doi.org/10.1037/a0030310

Kerrison, E. M., Goff, P. A., Burbank, C., \& Hyatt, J. M. (2019). On creating ethical, productive, and durable research partnerships with police officers and their departments: a case study of the National Justice Database. Police Practice and Research, 20(6), 567-584. https://doi.org/10.1080/15614263.2019.1657627

Kidd, R. F. (1979). Crime reporting: toward a social psychological model. Criminology, 17(3), 380-394. https://doi.org/10.1111/j.1745-9125.1979.tbo1303.x

Kim, S., Alison, L., \& Christiansen, P. (2020). Observing rapport-based interpersonal techniques to gather information from victims. Psychology, Public Policy, and Law, 26(2), 166-175. http://dx.doi.org/10.1037/lawo000222

Kleider-Offutt, H. M., Clevinger, A. M., \& Bond, A. D. (2016). Working memory and cognitive load in the legal system: Influences on police shooting decisions, interrogation and jury decisions. Journal of Applied Research in Memory and Cognition, 5(4), 426-433. https://doi.org/10.1016/j.jarmac.2016.04.008

Knowles, E. S., \& Linn, J. A. (2004). Approach-avoidance model of persuasion: Alpha and omega strategies for change. In E. Knowles \& J. Linn (Eds.), Resistance and persuasion (pp. 117-148). Psychology Press. 
Kontogianni, F., Hope, L., Taylor, P. J., Vrij, A., \& Gabbert, F. (2020). "Tell me more about this...": An examination of the efficacy of follow-up open questions following an initial account. Applied Cognitive Psychology, 34(5), 972-983. https://doi.org/10.1002/acp.3675

Koo, T. K., \& Li, M. Y. (2016). A guideline of selecting and reporting intraclass correlation coefficients for reliability research. Journal of Chiropractic Medicine, 15(2), 155-163. https://doi.org/10.1016/j.jcm.2016.02.012

Koriat, A., \& Goldsmith, M. (1994). Memory in naturalistic and laboratory contexts: Distinguishing the accuracy-oriented and quantity-oriented approaches to memory assessment. Journal of Experimental Psychology: General, 123(3), 297-315. https://doi.org/10.1037/oog6-3445.123.3.297

Kvavilashvili, L., \& Ellis, J. (2004). Ecological validity and twenty years of real-life/laboratory controversy in memory research: A critical (and historical) review. History and Philosophy of Psychology, 6, 59-80. http://researchprofiles.herts.ac.uk/portal/en/journals/history-and-philosophy-ofpsychology (gc63c84f-b715-4cfb-ag6f-65f42aao7of3).html

Lakens, D. (2014, December 19). Observed power, and what to do if your editor asks for post-hoc power analyses. The 20\% Statistician. http://daniellakens.blogspot.com/search?q=post-hoc

Lakens, D., \& Evers, E. R. (2014). Sailing from the seas of chaos into the corridor of stability: Practical recommendations to increase the informational value of studies.

Perspectives on Psychological Science, 9(3), 278-292. https://doi.org/10.1177/1745691614528520

Lamb, M. E. (2016). Difficulties translating research on forensic interview practices to practitioners: Finding water, leading horses, but can we get them to drink? American Psychologist, 71(8), 710-718. https://doi.org/10.1037/ampoooo039

Lamb, M. E., La Rooy, D. J., Malloy, L. C., \& Katz, C. (Eds.). (2011). Children's testimony: A handbook of psychological research and forensic practice ( $2^{\text {nd }} \mathrm{Ed}$.). John Wiley \& Sons. https://doi.org/10.1002/9781119998495

Launay, C., \& Py, J. (2015). Methods and aims of investigative interviewing of adult witnesses: An analysis of professional practices. Pratiques Psychologiques, 21(1), 5570. https://doi.org/10.1016/j.prps.2014.11.001

Leding, J. K. (2012). False memories and persuasion strategies. Review of General Psychology, 16(3), 256-268. https://doi.org/10.1037/a0027700

Levine, G., \& Parkinson, S. (2014). Experimental methods in psychology. Psychology Press. https://doi.org/10.4324/9781315806600 
Levine, T. R. (2018). Ecological validity and deception detection research design.

Communication Methods and Measures, 12(1), 45-54.

https://doi.org/10.1080/19312458.2017.1411471

Lewin, K. (1946). Action research and minority problems. Journal of Social Issues, 2(4), 3446. https://doi.org/10.1111/j.1540-4560.1946.tbo2295.x

Lindeman, P. (2020, January 6). Racisme? Nee, gewone woede bij mishandeling vluchtelingen in Enschedese volkswijk Dolphia [Racism? No, ordinary anger with mistreatment of refugees in the Dolphia neighborhood of Enschede]. Tubantia.

https://www.tubantia.nl/enschede/racisme-nee-gewone-woede-bij-mishandelingvluchtelingen-in-enschedese-volkswijk-dolphia af5a181al

Lindsay, D. S. (1994). Memory source monitoring and eyewitness testimony. In D. F. Ross, J. D. Read, \& M. P. Toglia (Eds.), Adult eyewitness testimony: Current trends and developments, (pp. 27-55). Cambridge University Press. https://doi.org/10.1017/CBO9780511759192

Loftus, E. F. (1975). Leading questions and the eyewitness report. Cognitive Psychology, 7(4), 560-572. https://doi.org/10.1016/0010-0285(75)g0023-7

Loftus, E. F. (2005). Planting misinformation in the human mind: A 30-year investigation of the malleability of memory. Learning \& Memory, 12(4), 361-366.

https://doi.org/10.1101//m.94705

Loftus, E. F., \& Pickrell, J. E. (1995). The formation of false memories. Psychiatric Annals, 25(12), 720-725. https://doi.org/10.3928/0048-5713-19951201-07

https://doi.org/10.1558/s|l.2001.8.2.44

Loney, D. M. \& Cutler, B. L. (2016). Coercive interrogation of eyewitnesses can produce false accusations. Journal of Police and Criminal Psychology, 31(1), 29-36.

https://doi.org/10.1007/s118g6-015-9165-6

Luther, K., Snook, B., MacDonald, S., \& Barron, T. (2015). Securing the admissibility of witness statements: estimating the complexity and comprehension of Canadian "KGB warnings". Journal of Police and Criminal Psychology, 30(3), 166-175. https://doi.org/10.1007/s118g6-014-9147-0

MacDonald, S., Keeping, Z., Snook, B., \& Luther, K. (2017a). Do not lie to me, or else: The effect of a turncoat warning and rapport building on perceptions of police interviewers. Journal of Police and Criminal Psychology, 32(3), 263-277. https://doi.org/10.1007/s118g6-016-9219-4

MacDonald, S., Snook, B., \& Milne, R. (2017b). Witness interview training: A field evaluation. Journal of Police and Criminal Psychology, 32(1), 77-84.

https://doi.org/10.1007/s118g6-016-9197-6 
Malsch, M., Kranendonk, P. R., De Keijser, J. W., Komter, M. L., Boer, M. D., \& Elffers, H. (2018). Reporting on Police Interrogations: Selection effects and bias related to the use of text, video and audiotape. Investigative Interviewing: Research and Practice, $9(1), 61-76$.

Mangiulli, I., Lanciano, T., Van Oorsouw, K., Jelicic, M., \& Curci, A. (2019). Do reminders of the crime reverse the memory-undermining effect of simulating amnesia? Memory \& Cognition, 47(7), 1375-1385. https://doi.org/10.3758/s13421-019-00939-z

Mangiulli, I., Van Oorsouw, K., Curci, A., Merckelbach, H., \& Jelicic, M. (2018). Feigning amnesia moderately impairs memory for a mock crime video. Frontiers in Psychology, 9, 1-9. https://doi.org/10.338g/fpsyg.2018.00625

Maynard, W. (1994). Witness intimidation: Strategies for prevention. Home Office Police Department.

Mazerolle, L., Antrobus, E., Bennett, S., \& Tyler, T. R. (2013). Shaping citizen perceptions of police legitimacy: A randomized field trial of procedural justice. Criminology, 51(1), 33-63. https://doi.org/10.1111/j.1745-9125.2012.00289.x

McCarthy, L., Gehlbach, S., Frye, T. \& Buckley, N. (2020). Who reports crime? Citizen engagement with the police in Russia and Georgia [Advance publication]. EuropeAsia Studies. http://dx.doi.org/10.2139/ssrn.2464171

McCauley, M. R., \& Santee, A. C. (2019). Viewing the cognitive interview through the lens of self-determination theory. In J. J. Dickinson, N. Schreiber Compo, R. Carol, B. L. Schwartz, \& M. McCauley (Eds.), Evidence-based Investigative Interviewing: Applying Cognitive Principles (pp. 234-251). Routledge. https://doi.org/10.4324/9781315160276-13

McGraw, K. O., \& Wong, S. P. (1996). Forming inferences about some intraclass correlation coefficients. Psychological Methods, 1(1), 30-46. https://doi.org/10.1037/1082$989 X .1 .1 .30$

Mclean, M. (1995). Quality investigation: Police interviewing of witnesses. Medicine, Science and the Law, 35(2), 116-122. https://doi.org/10.1177/002580249503500205

Meissner, C. A., Redlich, A. D., Bhatt, S., \& Brandon, S. (2012). Interview and interrogation methods and their effects on true and false confessions. Campbell Systematic Reviews, 8(1), 1-53. https://doi.org/10.4073/csr.2012.13

Memon, A., Meissner, C. A., Fraser, J. (2010). The Cognitive Interview: A meta-analytic review and study space analysis of the past 25 years. Psychology, Public Policy, and Law, 16(4), 340-372. https://doi.org/10.1037/a0020518 
Memon, A., Wark, L., Bull, R. \& Koehnken, G. (1997a). Isolating the effects of the Cognitive Interview techniques. British Journal of Psychology, 88(2), 179-198. https://doi.org/10.1111/j.2044-8295.1997.tbo2629.x

Memon, A., Wark, L., Holley, A., Bull, R., \& Koehnken, G. (1997b). Eyewitness performance in cognitive and structured interviews. Memory, 5(5), 639-656. https://doi.org/10.1080/741941481

Miller, J. C., Redlich, A. D., \& Kelly, C. E. (2018). Accusatorial and information-gathering interview and interrogation methods: A multi-country comparison. Psychology, Crime and Law, 24(9), 935-956. https://doi.org/10.1080/1068316X.2018.1467909

Milne, R. D., \& Bull, R. (1999). Investigative Interviewing: Psychology and Practice. Wiley.

Milne, R., \& Shaw, G. (1999). Obtaining witness statements: the psychology, best practice and proposals for innovation. Medicine, Science and the Law, 39(2), 127-138. https://doi.org/10.1177/002580249903900207

Milne, B., Roberts, K. A., Westera, N. J., \& Kebbell, M. R. (2011). Interviewing witnesses: do investigative and evidential requirements concur? The British Journal of Forensic Practice.

Ministry of Justice (2011). Achieving best evidence in criminal proceedings: Guidance on interviewing victims and witnesses, and guidance on using special measures. Ministry of Justice. https://www.cps.gov.uk/legal-guidance/achieving-best-evidencecriminal-proceedings-guidance-interviewing-victims-and

Moore, T. E., Cutler, B. L., \& Shulman, D. (2014). Shaping eyewitness and alibi testimony with coercive interview practices. The Champion, 8, 34-40. http://www.law.northwestern.edu/legalclinic/wrongfulconvictions/events/document s/Moore,\%20Cutler\%20Shulman,\%202014.pdf

Moston, S., \& Engelberg, T. (1993). Police questioning techniques in tape recorded interviews with criminal suspects. Policing and Society: An International Journal of Research and Policy, 3(3), 223-237. https://doi.org/10.1080/10439463.1993.9964670

Murphy, K., \& Cherney, A. (2012). Understanding cooperation with police in a diverse society. British Journal of Criminology, 52(1), 181-201. https://doi.org/10.1093/bjc/azro65

Nahari, G., Ashkenazi, T., Fisher, R. P., Granhag, P. A., Hershkowitz, I., Masip, J., Meijer, E. H., Nisin, Z., Sarid, N., Taylor, P. J., Verschuere, B., \& Vrij, A. (2019). 'Language of lies': Urgent issues and prospects in verbal lie detection research. Legal and Criminological Psychology, 24(1), 1-23. https://doi.org/10.1111/lcrp.12148 
Narchet, F. M., Meissner, C. A., \& Russano, M. B. (2011). Modeling the influence of investigator bias on the elicitation of true and false confessions. Law and Human Behavior, 35(6), 452-465. https://doi.org/10.1007/s10979-010-9257-x

National Institute of Justice (1999). Eyewitness evidence: A guide for law enforcement. U.S. Department of Justice. https://nij.ojp.gov/library/publications/eyewitness-evidenceguide-law-enforcement

National Police Improvement Agency (2009). National Investigative Interviewing Strategy. Association of Chief Police Officers.

Neequaye, D. A., \& Luke, T. J. (2018). Management of disclosure-costs in intelligence interviews. Open Science Framework. https://osf.io/dfr5v/

Neequaye, D. A., \& Mac Giolla, E. (2020). What is this Thing we Call Rapport?. Manuscript under preparation.

Netherlands Institute for the Study of Crime and Law Enforcement (n.d.). Evidence-based Policing. https://nscr.nl/en/theme/evidence-based-policing/

Nicksa, S. C. (2014). Bystander's willingness to report theft, physical assault, and sexual assault: The impact of gender, anonymity, and relationship with the offender. Journal of Interpersonal Violence, 29(2), 217-236. https://doi.org/10.1177/0886260513505146

Norris, R. J., Weintraub, J. N., Acker, J. R., Redlich, A. D., \& Bonventre, C. L. (2020). The criminal costs of wrongful convictions: Can we reduce crime by protecting the innocent? Criminology \& Public Policy, 19(2), 367-388. https://doi.org/10.1111/17459133.12463

Odinot, G., Boon, R., \& Wolters, L. (2015). Het episodisch geheugen en getuigenverhoor [The episodic memory and witness examination]. Tijdschrift voor Criminologie, 57(3), 279-299. https://doi.org/10.5553/TvC/0165182X2015057003001

Office for National Statistics (June, 2019). Reasons for not reporting crime to the police, year ending March 2018 Crime Survey for England and Wales. https://www.ons.gov.uk/peoplepopulationandcommunity/crimeandjustice/adhocs/o 10096 reasonsfornotreportingcrimetothepoliceyearendingmarch2018crimesurveyfor englandandwales

Oleszkiewicz, S., Granhag, P. A., \& Cancino Montecinos, S. (2014). The Scharff-technique: Eliciting intelligence from human sources. Law and Human Behavior, 38(5), 478-489. https://doi.org/10.1037/lhboo00085 
Orbach, Y., Shiloach, H., \& Lamb, M. E. (2013). Reluctant disclosers of child sexual abuse. In M. E. Pipe, M. E. Lamb, Y. Orbach, \& A. C. Cederborg (Eds.), Child sexual abuse: Disclosure, delay, and denial (pp. 125-144). Psychology Press.

Oostinga, M. S., Giebels, E., \& Taylor, P. J. (2018). 'An error is feedback': the experience of communication error management in crisis negotiations. Police Practice and Research, 19(1), 17-30. https://doi.org/10.1080/15614263.2017.1326007

Otgaar, H., \& Baker, A. (2018). When lying changes memory for the truth. Memory, 26(1), 214. https://doi.org/10.1080/09658211.2017.1340286

Otgaar, H., Howe, M. L., Memon, A., \& Wang, J. (2014). The development of differential mnemonic effects of false denials and forced confabulations. Behavioral Sciences \& the Law, 32(6), 718-731. https://doi.org/10.1002/bsl.2148

Otgaar, H., La Rooy, D., Horselenberg, R., Hershkowitz, I., de Ruiter, C., Blezer, L., Kidane, R., \& Kollau, R. (2019). Assessing the quality of child investigative interviewing in the Netherlands. Applied Cognitive Psychology, 33(5), 889-897. https://doi.org/10.1002/acp.3521

Otgaar, H., Sauerland, M., \& Petrila, J. P. (2013). Novel shifts in memory research and their impact on the legal process: Introduction to the special issue on memory formation and suggestibility in the legal process. Behavioral Sciences \& the Law, 31(5), 531-540. https://doi.org/10.1002/bsl.2095

Oxburgh, G. E., Myklebust, T., \& Grant, T. (2010). The question of question types in police interviews: a review of the literature from a psychological and linguistic perspective. International Journal of Speech, Language and the Law, 17(1), 45-66. https://doi.org/10.1558/ijsll.v17i1.45

Oxburgh, G., \& Dando, C. J. (2011). Psychology and interviewing: What direction now in our quest for reliable information? British Journal of Forensic Practice, 13(2), 135-147. https://doi.org/10.1108/14636641111134378

Papp, J., Smith, B., Wareham, J., \& Wu, Y. (2017). Fear of retaliation and citizen willingness to cooperate with police. Policing and Society, 29(6), 1-17. https://doi.org/10.1080/10439463.2017.1307368

Pearse, J., \& Gudjonsson, G. H. (1999). Measuring influential police interviewing tactics: A factor analytic approach. Legal and Criminological Psychology, 4(2), 221-238. https://doi.org/10.1348/135532599167860

Politie (2018, January 08). Wegens succes geprolongeerd: De coldcasekalender [Prolonged because of success: The cold case calendar].

https://www.politie.nl/nieuws/2018/januari/8/oo-coldcasekalender-wegens-succesgeprolongeerd.html 
Politie (2019a, June 3). Politie verstuurt SMS-bom in onderzoek naar incident in wijk Dolphia [Police send SMS bomb in investigation of incident in Dolphia district].

https://www.politie.nl/nieuws/2019/juni/3/o2-politie-verstuurt-sms-bom-inonderzoek-naar-incident-in-wijk-dolphia.html

Politie (2019b, June 14). Verdachten van incident Dolphia in vrijheid gesteld [Suspects of the Dolphia incident released]. https://www.politie.nl/nieuws/2019/juni/14/02-enschedeverdachten-van-incident-dolphia-in-vrijheid-gesteld.html

Politie (n.d.). Achtergrondinformatie over cold cases [Background information on cold cases]. https://www.politie.nl/themas/informatie-over-cold-cases.html\#alinea-titlewaardoor-worden-zaken-soms-jaren-later-alsnog-opgelost

Powell, M. B. (2008). Designing effective training programs for investigative interviewers of children. Current Issues in Criminal Justice, 20(2), 189-208. https://doi.org/10.1080/10345329.2008.12035804

Powell, M., Fisher, R. P., \& Wright, R. (2005). Investigative interviewing. In N. Brewer \& K. D. Williams (Eds.), Psychology and law: An empirical perspective (pp. 11-42). Guildford Press.

R. v. B. (K. G.) (1993). 1 S. C. R. 740. https://scc-csc.lexum.com/scc-csc/scccsc/en/item/973/index.do

R. v. Morgan. (2013). ONSC 6462, O. J. No. 5827.

Ridley, A. M., Gabbert, F., \& La Rooy, D. J. (Eds.) (2013). Suggestibility in legal contexts: Psychological research and forensic implications. Wiley-Blackwell. https://doi.org/10.1002/9781118432907

Risan, P., Binder, P. E., \& Milne, R. (2016). Regulating and coping with distress during police interviews of traumatized victims. Psychological Trauma: Theory, Research, Practice, and Policy, 8(6), 736-744. https://doi.org/10.1037/traoooo119

Rivard, J. R., Pena, M. M., \& Schreiber Compo, N. (2016). "Blind" interviewing: Is ignorance bliss? Memory, 24(9), 1256-1266. https://doi.org/10.1080/09658211.2015.1098705

Roberts, K. (2010). Great expectations: Relations of trust and confidence in police interviews with witnesses of crime. Policing: A Journal of Policy and Practice, 4(3), 265-272. https://doi.org/10.1093/police/paq022

Rock, F. (2001). The genesis of a witness statement. Forensic Linguistics, 8, 44-72. https://doi.org/10.1558/s|l.2001.8.2.44 
Roediger, III, H. L., \& Butler, A. C. (2011). The critical role of retrieval practice in long-term retention. Trends in Cognitive Sciences, 15(1), 20-27.

https://doi.org/10.1016/j.tics.2010.09.003

Rohmensen, G. J. (2019, May 12). Hoe die ruzie met een Syrisch gezin ontspoorde? De Enschedese omwonenden zwijgen als het graf [How did that fight with a Syrian family derail? The residents of Enschede are silent as the grave]. Trouw.

https://www.trouw.nl/nieuws/hoe-die-ruzie-met-een-syrisch-gezin-ontspoorde-deenschedese-omwonenden-zwijgen-als-het-graf -b112d4078/

Rosenbaum, D. P., Schuck, A. M., Costello, S. K., Hawkins, D. F., \& Ring, M. K. (2005). Attitudes toward the police: The effects of direct and vicarious experience. Police Quarterly, 8(3), 343-365. https://doi.org/10.1177/1098611104271085

Schollum, M. (2005). Investigative interviewing: The literature. New Zealand Police. https://www.police.govt.nz/about-us/publication/investigative-interviewingliterature

Schreiber Compo, N., Hyman Gregory, A., \& Fisher, R. (2012). Interviewing behaviors in police investigators: A field study of a current US sample. Psychology, Crime and Law, 18(4), 359-375. https://doi.org/10.1080/1068316X.2010.494604

Sharman, S. J. \& Powell, M. B. (2012). A comparison of adult witnesses' suggestibility across various types of leading questions, Applied Cognitive Psychology, 26(1), 48-53. https://doi.org/10.1002/acp.1793

Shepherd, E. \& Griffiths, A. (2013). Investigative Interviewing. The Conversation Management Approach (3rd ed.). Oxford University Press.

Shepherd, E. (1991). Ethical interviewing. Policing, 7, 42-60.

Shepherd, E. (1993). Resistance in interviews: The contribution of police perceptions and behaviour. Issues in Criminological \& Legal Psychology, 18, 5-12.

Skogan, W. G. (1984). Reporting crimes to the police: The status of world research. Journal of Research in Crime and Delinquency, 21(2), 113-137. https://doi.org/10.1177/0022427884021002003

Smeets, T., Candel, I., \& Merckelbach, H. (2004). Accuracy, completeness, and consistency of emotional memories. The American Journal of Psychology, 117(4), 595-6og. https://doi.org/10.2307/4148994

Smith, M. A., Roediger III, H. L., \& Karpicke, J. D. (2013). Covert retrieval practice benefits retention as much as overt retrieval practice. Journal of Experimental Psychology: Learning, Memory, and Cognition, 39(6), 1712-1725. https://doi.org/10.1037/a0033569 
Smith, R. M., Powell, M. B., \& Lum, J. (2009). The relationship between job status, interviewing experience, gender, and police officers' adherence to open-ended questions. Legal and Criminological Psychology, 14(1), 51-63. https://doi.org/10.1348/135532507X262360

Snook, B., \& Keating, K. (2011). A field study of adult witness interviewing practices in a Canadian police organization. Legal and Criminological Psychology, 16(1), 160-172. https://doi.org/10.1348/135532510X497258

Snook, B., House, J. C., MacDonald, S., \& Eastwood, J. (2012). Police witness interview training, supervision, and feedback: Survey of Canadian police officers. Canadian Journal of Criminology and Criminal Justice, 54(3), 363-372. https://doi.org/10.3138/cjccj.2011.E.13

Soukara, S., Bull, R., \& Vrij, A. (2002). Police detectives' aims regarding their interviews with suspects: Any change at the turn of the millennium? International Journal of Police Science \& Management, 4(2), 101-114. https://doi.org/10.1177/146135570200400202

Spencer, S., \& Stern, B. (2001). Reluctant witness. Institute for Public Policy Research.

Stockemer, D. (2019). Quantitative methods for the social sciences: A practical introduction with examples in SPSS and Stata. Springer. https://doi.org/10.1007/978-3-319-991184

Stone, C. B., Coman, A., Brown, A. D., Koppel, J., \& Hirst, W. (2012). Toward a science of silence the consequences of leaving a memory unsaid. Perspectives on Psychological Science, 7(1), 39-53. https://doi.org/10.1177/1745691611427303

Strömwall, L. A., Hartwig, M., Granhag, P. A. (2006). To act truthfully: Nonverbal behaviour and strategies during a police interrogation. Psychology, Crime and Law, 12(2), 207219. https://doi.org/10.1080/10683160512331331328

Sun, X., Punjabi, P. V., Greenberg, L. T., \& Seamon, J. G. (2009). Does feigning amnesia impair subsequent recall? Memory \& Cognition, 37(1), 81-89. https://doi.org/10.3758/MC.37.1.81

Sunshine, J., \& Tyler, T. R. (2003). The role of procedural justice and legitimacy in shaping public support for policing. Law and Society Review, 37(3), 515-548. https://doi.org/10.1111/1540-5893.3703002

Swanner, J. K., Beike, D. R., \& Cole, A. T. (2010). Snitching, lies and computer crashes: An experimental investigation of secondary confessions. Law and Human Behavior, 34(1), 53-65. https://doi.org/10.1007/s10979-008-9173-5 
Takarangi, M. K., Parker, S., \& Garry, M. (2006). Modernising the misinformation effect: The development of a new stimulus set. Applied Cognitive Psychology, 20(5), 583-590. https://doi.org/10.1002/acp.1209

Taylor, P. J. (2002). A cylindrical model of communication behavior in crisis negotiations. Human Communication Research, 28(1), 7-48. https://doi.org/10.1111/j.14682958.2002.tboo797.x

Taylor, S. C., \& Gassner, L. (2010). Stemming the flow: Challenges for policing adult sexual assault with regard to attrition rates and under-reporting of sexual offences. Police Practice and Research: An International Journal, 11(3), 240-255. https://doi.org/10.1080/15614260902830153

Te Bogt, A., \& Timmers, F. (2019, May 10). Vluchtelingen belaagd in eigen huis in Enschede [Refugees attacked in their own house in Enschede]. Tubantia. https://www.ad.nl/binnenland/vluchtelingen-belaagd-in-eigen-huis-inenschede a844bfgzl

The National Registry of Exonerations (2020). Percentage of Exonerations by Contributing Factor. https://www.law.umich.edu/special/exoneration/Pages/ExonerationsContribFactors ByCrime.aspx

Thompson, A. M., Molina, O. R., \& Levett, L. M. (2011). After exoneration: An investigation of stigma and wrongfully convicted persons. Albany Law Review, 75, 1373-1414

Timmers, F. (2019, June 12). Romy (18) aangehouden na mishandeling Syrisch gezin in Enschede: 'Politie gebruikte mijn dochter als lokaas' [Romy (18) arrested after mistreatment of Syrian family in Enschede: 'Police used my daughter as bait']. Tubantia. https://www.tubantia.nl/enschede/romy-18-aangehouden-namishandeling-syrisch-gezin-in-enschede-politie-gebruikte-mijn-dochter-alslokaas a8df6cof/

Tolsma, J., Blaauw, J., \& Te Grotenhuis, M. (2012). When do people report crime to the police? Results from a factorial survey design in the Netherlands, 2010. Journal of Experimental Criminology, 8, 117-134. https://doi.org/10.1007/S11292-011-9138-4

Tulving, E. (1985). Elements of episodic memory. Oxford University Press.

Tyler, T. R., \& Fagan, J. (2008). Legitimacy and cooperation: Why do people help the police fight crime in their communities. Ohio State Journal of Criminal Law, 6, 231-275. https://digitalcommons.law.yale.edu/fss_papers/3037/ 
Vallano, J. P., \& Schreiber Compo, N. (2011). A comfortable witness is a good witness: Rapport-building and susceptibility to misinformation in an investigative mockcrime interview. Applied Cognitive Psychology, 25(6), 960-970. https://doi.org/10.1002/acp.1789

Vallano, J. P., \& Schreiber Compo, N. (2015). Rapport-building with cooperative witnesses and criminal suspects: A theoretical and empirical review. Psychology, Public Policy, and Law, 21(1), 85-89. https://doi.org/10.1037/lawo000035

Vallano, J. P., Evans, J. R., Schreiber Compo, N., \& Kieckhaefer, J. M. (2015). Rapportbuilding during witness and suspect interviews: A survey of law enforcement. Applied Cognitive Psychology, 29(3), 369-380. https://doi.org/10.1002/acp.3115

Van Amelsvoort, A., Rispens, I., \& Grolman, H. (2015). Handleiding verhoor [Handbook of Interrogation] (6th Ed.). Reed Business Information.

Van Dijk, J., Van Kesteren, J., \& Smit, P. (2007). Criminal Victimisation in International Perspective: Key findings from the 2004-2005 ICVS and EU ICS. Boom Juridische publishers. https://repository.tudelft.nl/view/wodc/uvid:egaf6c3f-26oa-4d5c-9d3f1b2100a233fo

Van Koppen, P. J. \& Malsch, M. (2008). Het praktisch nut van de rechtspsychologie [The practical use of legal psychology]. Kluwer.

Van Koppen, P. J. \& Penrod, S. D. (2003) Adversarial or inquisitorial: Comparing systems. In: P. J. van Koppen \& S. D. Penrod (Eds.), Adversarial versus inquisitorial justice: Psychological perspectives on criminal justice systems (pp. 2-20). Plenum. https://doi.org/10.1007/978-1-4419-9196-6

Van Oorsouw, K., \& Merckelbach, H. (2004). Feigning amnesia undermines memory for a mock crime. Applied Cognitive Psychology, 18(5), 505-518. https://doi.org/10.1002/acp.999

Van Oorsouw, K., \& Merckelbach, H. (2006). Simulating amnesia and memories of a mock crime. Psychology, Crime and Law, 12(3), 261-271. https://doi.org/10.1080/10683160500224477

Vanderhallen, M., Vervaeke, G., \& Holmberg, U. (2011). Witness and suspect perceptions of working alliance and interviewing style. Journal of Investigative Psychology and Offender Profiling, 8(2), 110-130. https://doi.org/10.1002/jip.138

Vereniging van Nederlandse Universiteiten (VSNU) (2013). Een Raamwerk Valorisatieindicatoren [A Framework of Valorisation Indicators]. VNSU 
Verigin, B. L., Meijer, E. H., Bogaard, G., \& Vrij, A. (2019). Lie prevalence, lie characteristics and strategies of self-reported good liars. PLoS One, 14(12). https://doi.org/10.1371/journal.pone.0225566

Vrij, A., Hope, L. \& Fisher R. P. (2014). Eliciting reliable information in investigative interviews. Policy Insights from Behavioral and Brain Sciences, 1(1), 129-136. https://doi.org/10.1177/2372732214548592

Vrij, A., Meissner, C. A., Fisher, R. P., Kassin, S. M., Morgan III, A., Kleinman, S. M. (2017). Psychological perspectives on interrogation. Perspectives on Psychological Science, 12(6), 927-955. https://doi.org/10.1177/1745691617706515

Walsh, D., King, M., \& Griffiths, A. (2017). Evaluating interviews which search for the truth with suspects: But are investigators' self-assessments of their own skills truthful ones? Psychology, Crime and Law, 23(7), 647-665. https://doi.org/10.1080/1068316X.2017.1296149

Walsh, D., Oxburgh, G. E., Redlich, A. D. \& Myklebust, T. (2016). International developments and practices in investigative interviewing and interrogation - Volume 1: Victims and witnesses. Routledge.

Wellford, C. F., Cronin, J. M., Brandl, S., Bynum, T., Eversen, T., \& Galeria, S. (1999). An analysis of variables affecting the clearance of homicides: A multistate study. Justice Research and Statistics Association.

Wells, G. L. (1978). Applied eyewitness-testimony research: System variables and estimator variables. Journal of Personality and Social Psychology, 36(12), 1546-1557. https://doi.org/10.1037/0022-3514.36.12.1546

Wells, G. L., Memon, A., \& Penrod, S. D. (2006). Eyewitness evidence improving its probative value. Psychological Science in the Public Interest, 7(2), 45-75. https://doi.org/10.1111/j.1529-1006.2006.00027.x

Westera, N., \& Powell, M. (2015). Improving Communicative Practice: Beyond the Cognitive Interview for Adult Eyewitnesses. In G. Oxburgh, T. Myklebust, T. Grant, \& R. Milne (Eds.), Communication in investigative and legal contexts: Integrated approaches from forensic psychology, linguistics and law enforcement (pp. 337-358). Wiley Blackwell. https://doi.org/10.1002/9781118769133.ch15

Wheeler, R., Gabbert, F., Clayman, S \& Jones, S. (2017, July). Information gathering with reluctant witnesses: A practitioner survey [Paper presentation]. 2017 Conference of the International Investigative Interviewing Research Group, Monterey Bay, California, United States.

Whipple, G. M. (1909). The observer as reporter: A survey of the 'psychology of testimony'. Psychological Bulletin, 6(5), 153-170. https://doi.org/10.1037/hoo71084 
Wilford, M. M., \& Wells, G. L. (2013). Eyewitness system variables. In B. L. Cutler (Ed.), Reform of eyewitness identification procedures (pp. 23-43). American Psychological Association. https://doi.org/10.1037/14094-002

Williamson, T. M. (1993). From interrogation to investigative interviewing; strategic trends in police questioning. Journal of Community \& Applied Social Psychology, 3(2), 89-99. https://doi.org/10.1002/casp.2450030203

Wright, A. M., \& Alison, L. (2004). Questioning sequences in Canadian police interviews: Constructing and confirming the course of events? Psychology, Crime and Law, 10(2), 137-154. https://doi.org/10.1080/1068316031000099120

Wright, D. S., Nash, R. A., \& Wade, K. A. (2015). Encouraging eyewitnesses to falsely corroborate allegations: Effects of rapport-building and incriminating evidence. Psychology, Crime and Law, 21(7), 648-66o. https://doi.org/10.1080/1068316X.2015.1028543

Yang, Y., Guyll, M., \& Madon, S. (2017). The interrogation decision-making model: A general theoretical framework for confessions. Law and Human Behavior, 41(1), 8092. https://doi.org/10.1037//hboo00220 




\section{Summaries}





\section{Summary}

Crime witnesses hold relevant knowledge of the offence that may otherwise be unavailable to the police, making their accounts critical for successful investigations and, later, as evidence in court. To elicit accurate and detailed witness accounts, the police rely on witness cooperation, which is not always granted. The extent to which witness cooperation affects effective interviewing had not been systematically examined before. The aim of this PhD dissertation was to provide an initial examination of witness cooperation and the lack thereof in police interviews with crime witnesses. In the introduction, I reviewed the factors that determine witness cooperation with the police, and put these in relation to the witness's willingness to report information in an investigative interview context. Furthermore, I introduced a cost-benefit analysis model (Kidd, 1979; Skogan, 1984) with which to understand information disclosure in relation to the interviewing approach.

The first specific aim of this dissertation was to examine how police investigators gain cooperation in current witness interviewing practices. Accordingly, I conducted an analysis of archival police interviews of adult witnesses in the Netherlands $(N=21)$. Findings revealed that the witness is often not listened to, is interrupted frequently, and is typically questioned about specific knowledge using closed, directive, and leading questions (Chapter 2). The observed pattern of interviewing is not in line with evidence-based interviewing approaches that aim to gain cooperation and facilitate memory recall (Fisher, 1995, 2010). However, it is consistent with prior archival studies in other jurisdictions (Clarke \& Milne, 2001; Mclean, 1995; Schreiber Compo et al., 2012; Snook \& Keating, 2011; Wright \& Alison, 2004). A direct and rather confrontational approach to interviewing risks producing a shift towards uncooperativeness in initially cooperative witnesses, and a direct failure to gain cooperation, or an exacerbation of resistance, in initially uncooperative witnesses (Collins et al., 2012; Vallano \& Schreiber Compo, 2015). Consequently, a lack of promotion of witness cooperation in practice can jeopardise the goal of information elicitation in investigative interviews. Furthermore, it can also reduce memory accuracy (Fisher et al., 2011; Gabbert et al., 2020; Vrij et al., 2014). 
The second specific aim of this dissertation was to examine the police experience of interviewing uncooperative witnesses, for which I conducted a survey of criminal investigators $(N=274)$ who conduct witness interviews in the Netherlands, Sweden, and England and Wales. The findings highlighted deficient training and minimal guidance on how to conduct interviews with uncooperative witnesses (Chapter 3). Overall, the surveyed criminal investigators preferred an information-gathering interviewing approach and favoured rapport-building techniques to encourage witness information disclosure (Vallano et al., 2015; Wheeler et al., 2017). Second, criminal investigators also direct efforts to the application of legal and special measures in interviews with uncooperative witnesses, such as anonymity incentives and kindship exemptions. Third, criminal investigators consider the type of questions to ask: open questions are preferred to closed, direct, and leading questions as they elicit more complete and accurate answers (e.g., Fisher et al., 2011; Sharman \& Powell, 2012). However, practitioners questioned the effectiveness of open questions in gathering information in the face of lack of witness cooperation (Chapter 3 ). This finding can be explained by the science-practice gap, which indicates that some police officers hold erroneous knowledge about episodic memory and interviewing (Odinot et al., 2015). Lastly, the surveyed criminal investigators reported the use of some interviewing techniques in practice, such as moral appeals, legal warnings, and anonymity incentives, which have not yet received empirical support for their effects in terms of promoting cooperation or in effectively eliciting accurate information.

For the third specific aim of examining the effects of witness cooperation, I first conducted a laboratory experiment $(N=109)$, in which I examined the effects of expectations of witness cooperation on interviewing (Antaki \& Stoke, 2017; Fyfe \& Smith, 2007; Roberts, 2010), based on previous investigator's expectancy effects affecting suspect interrogations (Hill et al., 2008; Kassin et al., 2003; Narchet et al., 2011). No support was found for the influence of expectations of witness cooperation on how interviews were planned and conducted. Instead, all interviews were conducted in a direct manner. The observed disproportionate use of closed questions and direct questions, and to a lesser extent, leading questions, and the infrequent use of open questions constituted an approach more akin to an accusatorial rather than an information-gathering interviewing approach. Facing an uncooperative witness produced a shift from a planned information- 
gathering approach to interviewing to an accusatorial approach in the interview (Chapter 4), thereby indicating that witness cooperation indeed affects interviewing behaviour. In practice, therefore, lack of witness cooperation in police interviews could impede adherence to best-practice interviewing guidelines if interviewers are ill-prepared for the challenge of overcoming witness reluctance to provide information from initially uncooperative witnesses. Resorting to poor investigative interviewing practices could be an attempt to reestablish control over the interviewee (Griffiths et al., 2011; Oxburgh \& Dando, 2011), which can reduce both the amount and the accuracy of information elicited.

Lastly, in another laboratory experiment $(N=136)$, I demonstrated that lack of witness cooperation reduces both information disclosure and, to a lesser extent accuracy, even under optimal interviewing conditions (Chapter 5). Moreover, self-reported communication strategies of purposefully reducing the amount of correct information and reporting a combination of accurate and inaccurate information are consistent with the reduction in the amount of information disclosed. The use of such communication strategies also corresponds to the small but significant decrease in accuracy.

Altogether, the findings in this dissertation demonstrate that witness cooperation is to some extent a determinant of interviewer and interviewee behaviour and, consequently, of interview outcomes. In particular, lack of witness cooperation has detrimental effects on information disclosure and challenges the use of effective interviewing techniques, calling into question the quality of the elicited witness accounts (Chapter 6). An interviewing approach that promotes witness cooperation is recommended in police interviewing practice to avoid generating or exacerbating witnesses' unwillingness to report information relevant to criminal investigations and subsequent legal proceedings. Further research is needed to validate specialised interviewing techniques that overcome lack of witness cooperation in order to ethically and effectively facilitate information elicitation. Such techniques should aim to increase the witness's perceived benefits from cooperating with the police and to reduce the perceived risks associated with the individual's decision to provide information in an investigative interview. In light of these conclusions, legal decision making based on witness testimony should include the evaluation of how such evidence was obtained, in order to consider the effects of witness cooperation on disclosure and on the interviewing approach used. Such evaluation could be facilitated by making the 
mandatory recording of witness interviewing statutory, which may also promote the translation of effective evidence-based interviewing into practice. 



\section{Samenvatting - Summary in Dutch}

Getuigen van misdrijven beschikken over relevante kennis van een strafbaar feit, dat relevant is voor de politie. Daardoor zijn hun verklaringen van cruciaal belang voor succesvol politie-onderzoek en later als bewijsmateriaal in de strafzaak. Om accuraat en gedetailleerde getuigenverklaringen te verkrijgen, behoeft de politie de medewerking van getuigen. Die wordt niet altijd verleend. De mate waarin medewerking van getuigen van invloed is op effectief verhoren en andersom werd niet eerder systematisch onderzocht.

Het doel van dit proefschrift was om een eerste onderzoek te doen naar de medewerking van getuigen en het gebrek aan medewerking in politieverhoren met getuigen van misdrijven. In de inleiding heb ik een overzicht gegeven van de achterliggende oorzaken die de medewerking van getuigen met de politie bepalen. Vervolgens heb ik die in verband gebracht met de bereidheid van getuigen om informatie te melden in de context van een verhoor. Verder heb ik een kosten-batenanalysemodel geïntroduceerd (Kidd, 1979; Skogan, 1984), om de onthulling van informatie in relatie tot de manier van benaderen tijdens een verhoor te begrijpen.

Het eerste specifieke doel van dit proefschrift was om te onderzoeken hoe politierechercheurs samenwerking zoeken met getuigen. Zo heb ik een analyse uitgevoerd van politieverhoren van volwassen getuigen in Nederland $(N=21)$. Uit de bevindingen bleek dat er vaak niet naar de getuige wordt geluisterd, de getuige vaak wordt onderbroken en meestal wordt ondervraagd over specifieke kennis met gesloten, suggestieve vragen (Hoofdstuk 2). Het waargenomen patroon van verhoren komt niet overeen met de kennis die bestaat op basis van wetenschappelijke benaderingen van verhoren gericht op samenwerking en het vergemakkelijken van het herinneren van gebeurtenissen (Fisher, 1995, 2010). Het komt echter wel overeen met eerdere archiefonderzoeken in andere jurisdicties (Clarke \& Milne, 2001; Mclean, 1995; Schreiber Compo et al., 2012; Snook \& Keating, 2011; Wright \& Alison, 2004). Een directe en nogal confronterende manier van verhoren kan van coöperatieve getuigen niet-meewerkende getuigen maken, of kan het verzet bij niet meewerkende getuigen vergroten (Collins et al., 2012; Vallano et al., 2015). Om die reden kan een gebrek aan bevordering van de medewerking van getuigen het doel om informatie aan het licht te brengen in verhoren in gevaar brengen. Bovendien kan het de 
nauwkeurigheid van het geheugen verminderen (Fisher et al., 2011; Gabbert et al., 2020; Vrij et al., 2014).

Het tweede specifieke doel van dit proefschrift betreft het onderzoeken van de ervaring van de politie met het verhoren van niet-meewerkende getuigen. Daarvoor heb ik een enquête afgenomen bij rechercheurs $(N=274)$ die getuigenverhoren afnemen in Nederland, Zweden en Engeland en Wales. De bevindingen wezen op een gebrekkige training en minimale begeleiding bij het voeren van verhoren met niet-meewerkende getuigen (Hoofdstuk 3). Over het algemeen gaven de ondervraagde rechercheurs de voorkeur aan een informatie vergarende benadering en technieken voor het opbouwen van een vertrouwensrelatie, om zo het geven van informatie te stimuleren (Vallano et al., 2015; Wheeler et al., 2017). Ten tweede richten de rechercheurs zich ook op de toepassing van wettelijke en speciale maatregelen, om niet-meewerkende getuigen te ondervragen. Voorbeelden daarvan zijn het aanbieden van anonimiteit en verschoningsrecht. Ten derde overwegen rechercheurs het soort vragen dat ze moeten stellen. Open vragen hebben de voorkeur boven gesloten, directe en leidende vragen, omdat ze volledigere en accuratere antwoorden opleveren (bijvoorbeeld Fisher et al., 2011; Sharman \& Powell, 2012). De doeltreffendheid van open vragen om informatie te verzamelen bij gebrek aan medewerking van getuigen werd echter in twijfel getrokken door de meningen van beoefenaars (Hoofdstuk 3). Deze bevinding kan worden verklaard door de kloof tussen wetenschap en praktijk, wat aangeeft dat sommige politieagenten onjuiste kennis hebben over het episodisch geheugen en verhoren (Odinot et al., 2015). Ten slotte rapporteerden de ondervraagde rechercheurs het gebruik van een aantal verhoortechnieken in de praktijk, zoals morele oproepen, juridische waarschuwingen en anonimiteit, die nog geen empirische steun hebben gekregen voor hun effect op het bevorderen van samenwerking of het effectief verkrijgen van accurate informatie.

Voor het derde specifieke doel om de effecten van medewerking van getuigen te onderzoeken, heb ik eerst een laboratoriumexperiment uitgevoerd $(\mathrm{N}=109)$. Hierin heb ik het effect van verwachtingen van medewerking van getuigen in verhoren onderzocht, op basis van de effecten die de verhoorder verwachtte en de invloed daarvan op verdachte ondervragingen (Hill et al., 2008; Kassin et al., 2003; Narchet et al., 2011). Er werd geen steun gevonden voor de invloed van verwachtingen van medewerking van getuigen op de 
manier waarop verhoren werden gepland en uitgevoerd. In plaats daarvan werden alle verhoren op een directe manier afgenomen. Het waargenomen onevenredige gebruik van gesloten vragen, directe vragen en in mindere mate leidende vragen, waarbij daarnaast tevens weinig gebruik wordt gemaakt van open vragen, is een benadering die meer lijkt op een beschuldigende dan op een informatie vergarende verhoorbenadering. Geconfronteerd worden met een niet-meewerkende getuige veroorzaakte een verschuiving van een geplande, informatie vergarende benadering van verhoren, naar een beschuldigende benadering in het verhoor (Hoofdstuk 4). Dit toont aan dat de medewerking van getuigen wordt beïnvloed door het verhoorgedrag. In de praktijk zou het gebrek aan medewerking van getuigen in politieverhoren de naleving van de richlijnen voor het verhoren kunnen belemmeren, indien verhoorders slecht voorbereid zijn op de vitdaging om de terughoudendheid van getuigen te overwinnen en informatie te verzamelen bij eerder nietmeewerkende getuigen. Terugvallen op slechte verhoorpraktijken zou een poging kunnen zijn om de controle over de geïnterviewde te herstellen (Griffiths et al., 2011; Oxburgh \& Dando, 2011), wat zowel de hoeveelheid als de nauwkeurigheid van informatie kunnen verminderen.

Ten slotte heb ik in een ander laboratoriumexperiment $(N=136)$ aangetoond dat het gebrek aan samenwerking zowel het openbaren van informatie als ook de nauwkeurigheid in mindere mate laat afnemen, zelfs onder optimale gespreksomstandigheden (Hoofdstuk 5). Bovendien zijn zelfgerapporteerde communicatiestrategieën om de hoeveelheid correcte informatie doelgericht te reduceren en een combinatie van accuraat en onjuiste informatie te rapporteren in overeenstemming met de vermindering van de hoeveelheid verstrekte informatie. Het gebruik van dergelijke communicatiestrategieën komt ook overeen met de kleine maar significante afname van de nauwkeurigheid.

Al met al laten de bevindingen in dit proefschrift zien dat de medewerking van getuigen tot op zekere hoogte een bepalende factor is voor het verhoren en het daarmee samenhangende gedrag van geïnterviewden. Dit betekent dat het vervolgens ook consequenties heeftvoor de resultaten van verhoren. Met name het gebrek aan medewerking van getuigen heeft nadelige gevolgen voor de openbaarmaking van informatie en vormt een uitdaging voor het gebruik van effectieve verhoortechnieken, waarbij uiteindelijk de kwaliteit van de getuigenissen in twijfel wordt gebracht (Hoofdstuk 
6). Een verhoorbenadering die de medewerking van getuigen bevordert wordt aanbevolen in de politieverhorende praktijk, om te voorkomen dat getuigen onwelwillend zijn om informatie te melden die relevant is voor opsporingsonderzoeken en daaropvolgende gerechtelijke procedures. Verder onderzoek is nodig om gespecialiseerde verhoortechnieken te valideren, die het gebrek aan getuigenmedewerking verhelpen om het ontlokken van informatie op een ethische en effectieve manier te vergemakkelijken. Dergelijke technieken moeten erop gericht zijn de vermeende voordelen van de samenwerking met de politie te vergroten en de vermeende risico's in verband met het besluit van het individu om informatie te verstrekken in een verhoor te verminderen. In het licht van deze conclusies moet juridische besluitvorming op basis van getuigenverklaringen een evaluatie omvatten, die ingaat op hoe bewijs is verkregen. Dit is noodzakelijk om de effecten van medewerking van getuigen op openbaarmaking en de gehanteerde benadering te onderzoeken. Een dergelijke evaluatie kan worden vergemakkelijkt door registratie van getuigenverhoren wettelijk verplicht te stellen, wat ook de vertaling van effectief, evidence-based verhoren in de praktijk kan bevorderen. 


\section{Sammanfattning - Summary in Swedish}

Personer som bevittnat ett brott har viktig kunskap om brottet som annars kan vara oåtkomlig för polisen. Deras redogörelser kan vara av avgörande betydelse för en framgångsrik utredning, och därefter som bevismaterial i domstolen. För att få fram tillförlitliga och detaljerade vittnesberättelser är polisen starkt beroende av samarbetsvilja hos vittnena, något som inte alltid visas. I hur hög grad vittnens samarbetsvilja påverkar intervjuns effektivitet har emellertid inte tidigare systematiskt undersökts. Syftet med denna doktorsavhandling var därför att utföra en första undersökning av vittnens samarbetsvilja eller ovilja i polisintervjuer med vittnen till brott. Inledningsvis gjorde jag en översikt över orsaker som avgör vittnens vilja att samarbeta med polisen, och satte dessa i relation till vittnenas villighet att lämna information under en utredande intervju. Vidare begagnade jag mig av en modell för kostnads-nyttoanalys (Kidd, 1979; Skogan, 1984), för att få en förståelse för informationslämnande i relation till den valda intervjumetodiken.

Avhandlingens första specifika syfte var att undersöka hur polisens utredare når samarbetsvilja genom nuvarande intervjupraxis. Jag utförde en analys av arkiverade polisintervjuer med vuxna vittnen i Nederländerna $(N=21)$. Resultaten visade att polisen ofta inte lyssnade på vittnena, att vittnena ofta blev avbrutna, och att slutna, direkta och ledande frågor användes för att fråga om specifik information (Kapitel 2). Det intervjumönster som framkom ligger inte i linje med evidensbaserade intervjumetoder som syftar till att nå samarbete och förbättra minnesbilden (Fisher, 1995, 2010). Det stämmer emellertid överens med tidigare arkivstudier i andra jurisdiktioner (Clarke \& Milne, 2001; Mclean, 1995; Schreiber Compo et al., 2012; Snook \& Keating, 2011; Wright \& Alison, 2004). En direkt och ganska konfrontativ intervjumetod riskerar att leda till att samarbetsvilliga vittnen blir mer ovilliga, och till total oförmåga att nå samarbete, eller - när vittnet från början inte visat sig samarbetsvillig - till ökat motstånd (Collins et al., 2012; Vallano \& Schreiber Compo, 2015). Följaktligen kan brist på uppmuntran till samarbetsvilja hos vittnen underminera syftet att utvinna information vid utredande intervjuer. Vidare kan tillförlitligheten hos minnesbilden minskas (Fisher et al., 2011; Gabbert et al., 2020; Vrij et al., 2014). 
Avhandlingens andra specifika syfte var att utforska polisens erfarenheter av att intervjua samarbetsovilliga vittnen. Jag genomförde en enkätundersökning av brottsutredare $(N=274)$ som utför intervjuer med vittnen i Nederländerna, Sverige, England och Wales. Resultaten visar på otillräcklig utbildning och minimal vägledning i hur intervjuer med samarbetsovilliga vittnen bör genomföras (Kapitel 3). Generellt föredrog de medverkande brottsutredarna en informationssökande intervjumetod och förespråkade relationsskapande insatser för att underlätta för vittnen att ge upplysande information (Vallano et al., 2015; Wheeler et al., 2017). Brottsutredare bemödar sig också om att använda rättsliga och för ändamålet särskilda åtgärder vid intervjuer med samarbetsovilliga vittnen, såsom anonymitetslöften och släktskapsundantag. Vidare överväger brottsutredare vilka sorters frågor de bör ställa. Öppna frågor föredras framför slutna, direkta och ledande frågor, eftersom de öppna genererar fullständigare och mer tillförlitliga svar (t.ex. Fisher et al., 2011; Sharman \& Powell, 2012). Emellertid ställde sig dessa utredare tveksamma till om öppna frågor var ett effektivt sätt att samla information när vittnet var ovilligt att samarbeta (Kapitel 3). Detta resultat kan förklaras av gapet mellan vetenskap och praktik, vilket tyder på att vissa poliser har felaktig kunskap om episodiskt minne och intervjuarbete (Odinot et al., 2015). Slutligen rapporterade de medverkande brottsutredarna om att de i praktiken använde vissa intervjutekniker, som moralisk vädjan, rättsliga varningar och anonymitetslöften. Empiriskt stöd saknas dock ännu för hur effektiva dessa är i att uppmuntra samarbete eller frambringa tillförlitlig information.

För avhandlingens tredje specifika syfte, att undersöka effekten av samarbetsvilja hos vittnen, utförde jag först ett laboratorieexperiment $(N=109)$, där jag undersökte den effekt som förväntan om samarbetsvilja hos vittnet hade på intervjun (Antaki \& Stoke, 2017; Fyfe \& Smith, 2007; Roberts, 2010), baserat på hur förhör med misstänkta påverkas av förväntanseffekter hos förhörsledaren (Hill et al., 2008; Kassin et al., 2003; Narchet et al., 2011). Det framkom inget stöd för att förväntningar om samarbetsvilja hos vittnet påverkade hur intervjuer planerades och genomfördes. I stället genomfördes alla intervjuer med direkt intervjumetodik. Det observerade oproportionerliga höga användandet av slutna och direkta frågor och, i mindre utsträckning, ledande frågor, samt det sparsamma användandet av öppna frågor, visar en ansats som är mer besläktad med en anklagande än med en informationssökande metod. Mötet med ett samarbetsovilligt vittne ledde till en 
omställning från en planerad informationssökande intervjuansats till en anklagande intervjustil (Kapitel 4), vilket indikerar att vittnets samarbetsvilja påverkar intervjubeteendet. Avsaknad av samarbetsvilja hos vittnen under polisintervjuer kunde göra det svårare att följa riktlinjer för bästa praxis vid intervjuer om intervjuarna var dåligt förberedda inför utmaningen att få samarbetsovilliga vittnen att lämna information. Att då tillgripa mindre god praxis för utredandeintervju kunde vara ett försök att återupprätta kontroll över den intervjuade (Griffiths et al., 2011; Oxburgh \& Dando, 2011), något som kan reducera både mängden av information och dess tillförlitlighet.

Slutligen demonstrerade jag, i ett annat laboratorieexperiment $(N=136)$, att bristande samarbete minskar både mängden vunnen information och, i mindre utsträckning, informationens tillförlitlighet, även under optimala omständigheter för intervjun (Kapitel 5). Av vittnen självrapporterade kommunikationsstrategier, avsedda att avsiktligt minska mängden korrekt information och rapportera en kombination av korrekt och felaktig information, stämmer dessutom överens med en minskning av mängden lämnade upplysningar. Användande av sådana kommunikationsstrategier sammanfaller också med en liten, men signifikant, minskning av tillförlitligheten i de lämnade uppgifterna.

Sammantaget demonstrerar resultaten i denna avhandling att samarbetsvilja hos vittnen i viss utsträckning fungerar som en avgörande faktor för intervjuandet och den intervjuades beteende, och följaktligen för utfallet av intervjun. I synnerhet har brist på samarbetsvilja hos vittnen negativa effekter på lämnande av information och utgör en utmaning för användandet av effektiva intervjumetoder, vilket ifrågasätter kvaliteten på de erhållna vittnesberättelserna (Kapitel 6). En ansats i polisens intervjupraxis som främjar samarbetsvilja hos vittnena rekommenderas för att undvika att skapa eller förstärka ovilja hos vittnen att rapportera information som är relevant för brottsutredningar och efterföljande rättsliga förfaranden. Ytterligare forskning krävs för att validera intervjumetoder som specifikt kan övervinna bristande samarbetsvilja hos vittnen i avsikt att på ett etiskt och effektivt sätt underlätta utvinnande av information. Sådana metoder bör syfta till att öka upplevda fördelar för vittnet att samarbeta med polisen och minska upplevda risker associerade med individens beslut att tillhandahålla information vid en utredande intervju. I ljuset av dessa slutsatser bör juridiskt beslutsfattande baserat på 
vittnesmål inkludera en utvärdering av hur sådant bevismaterial införskaffades, för att kunna ta i beaktande hur vittnets samarbetsvilja kan ha påverkat både lämnandet av upplysningar och utredarens intervjumetodik. En sådan utvärdering kan underlättas av lagstiftning om obligatorisk inspelning av vittnesintervjuer, något som också skulle kunna uppmuntra att effektiva och evidensbaserade intervjumetoder tillämpas i praktiken. 


\section{Resumen - Summary in Spanish}

Los individuos que son testigos de un crimen tienen un conocimiento relevante sobre el delito cometido que puede no estar disponible para la policía de otra manera, por lo que sus reportes de lo sucedido son fundamentales para el éxito en las investigaciones, y más tarde, como evidencia en el juicio. Para obtener reportes de testigos que sean precisos y detallados, la policía depende en gran medida de la cooperación de testigos, la cual no siempre es concedida. Anteriormente no se había examinado sistemáticamente la medida en que la cooperación de testigos afecta la efectividad de la entrevista. El objetivo de esta disertación doctoral fue, por lo tanto, proporcionar un estudio inicial de la cooperación de testigos y la falta de ella durante las entrevistas policiales a testigos de delitos. En la introducción, realicé una revisión de los factores que determinan la cooperación de los testigos con la policía, los cuales fueron puestos en relación con la voluntad de reportar información en el contexto de entrevistas investigativas de testigos. Además, introduje un modelo de análisis de costos y beneficios (Kidd, 1979; Skogan, 1984) con el cual entender la decisión de divulgar información por parte de testigos en respuesta al enfoque utilizado al conducir la entrevista investigativa.

El primer objetivo específico de esta disertación fue examinar cómo los investigadores policiales entablan la cooperación de testigos al entrevistarles. Para este fin, realicé un análisis de entrevistas policiales a testigos adultos en los Países Bajos $(N=21)$. Los hallazgos revelaron que a menudo no se escucha al testigo, se le interrumpe con frecuencia y, por lo general, se le cuestiona sobre datos específicos mediante preguntas cerradas, directas, y sugerentes (Capítulo 2). El patrón observado en las entrevistas no coincide con los modelos de entrevistas basados en la evidencia científica, que buscan entablar una cooperación y facilitar los recuerdos de las y los testigos (Fisher, 1995, 2010). Sin embargo, este patrón es consistente con previos estudios de archivo acerca de entrevistas a testigos en otras jurisdicciones (Clarke y Milne, 2001; Mclean, 1995; Schreiber Compo et al., 2012; Snook y Keating, 2011; Wright y Alison, 2004). Un enfoque directo y más bien confrontativo en las entrevistas policiales conlleva el riesgo de provocar un cambio hacia la falta de cooperación por parte de los testigos que inicialmente cooperan, y un fracaso directo para lograr entablar cooperación, o una exacerbación de la resistencia, por parte de los testigos 
que inicialmente no cooperan (Collins et al., 2012; Vallano \& Schreiber Compo, 2015). En consecuencia, la falta de promoción de la cooperación de testigos en la práctica puede poner en peligro el objetivo de obtener información en entrevistas investigativas. Además, puede reducir la precisión de los recuerdos (Fisher et al., 2011; Gabbert et al., 2020; Vrij et al., 2014).

El segundo objetivo específico de esta disertación fue examinar la experiencia policial al entrevistar a testigos que no cooperan, para lo cual realicé una encuesta a investigadores criminales $(N=274)$ que realizan entrevistas a testigos en los Países Bajos, Suecia, e Inglaterra y Gales. Los hallazgos destacan una capacitación deficiente y una orientación mínima sobre cómo realizar entrevistas con testigos que no cooperan (Capítulo 3). En general, las y los investigadores criminales encuestados manifestaron que prefieren un enfoque para conducir entrevistas basado en la recopilación de información, y a su vez favorecen técnicas para construir rapport que alientan la divulgación de información por parte de testigos (Vallano et al., 2015; Wheeler et al., 2017). En segundo lugar, las y los investigadores criminales también reportaron que dedican esfuerzos a la aplicación de medidas legales y especiales en las entrevistas a testigos que no cooperan, tales como ofertas de anonimato y exenciones para familiares. Tercero, las y los investigadores criminales consideraron el tipo de preguntas que deben formularse, y declararon que: prefieren utilizar preguntas abiertas a preguntas cerradas, directas y sugerentes, ya que las primeras generan respuestas más completas y precisas (Fisher et al., 2011; Sharman y Powell, 2012). Sin embargo, las opiniones de las y los profesionales cuestionaron la efectividad de las preguntas abiertas para la recopilación de información ante la falta de cooperación de testigos (Capítulo 3). Este hallazgo puede explicarse por la brecha entre la ciencia y la práctica que indica que algunos agentes de policía tienen un conocimiento erróneo sobre la memoria episódica y cómo conducir entrevistas (Odinot et al., 2015). Por último, las y los investigadores criminales encuestados indicaron el uso de algunas técnicas para entrevistar, tales como las apelaciones a la moral, advertencias legales y ofertas de anonimato, cuyos efectos aún no han recibido apoyo empírico para la promoción de la cooperación ni para obtener información precisa de manera efectiva.

El tercer objetivo específico fue examinar los efectos de la cooperación de testigos, a través de un experimento de laboratorio $(N=109)$ en el que examiné los efectos de las 
expectativas acerca de la cooperación de testigos en la conducción de entrevistas (Antaki y Stoke, 2017; Fyfe y Smith, 2007 ; Roberts, 2010), basándome en los efectos de las expectativas de investigadores que afectan las interrogaciones a sospechosos (Hill et al., 2008; Kassin et al., 2003; Narchet et al., 2011). No se encontró evidencia sobre la influencia de las expectativas acerca de la cooperación de testigos en la planificación ni en el desarrollo de las entrevistas. En cambio, todas las entrevistas se realizaron de una manera directa. Los resultados indicaron un uso desproporcionado de preguntas cerradas y preguntas directas, y en menor medida, de preguntas sugerentes, y el uso infrecuente de preguntas abiertas - los cuales, en conjunto, son característicos de un estilo de entrevistar más parecido al enfoque acusatorio que al abordaje enfocado en la recopilación de información. El enfrentarse a una o un testigo que no coopera produjo un cambio del enfoque planificado de recopilación de información a una entrevista conducida con un enfoque acusatorio (Capítulo 4), lo cual indica que la cooperación de testigos afecta el comportamiento al conducir una entrevista. En la práctica, por lo tanto, la falta de cooperación de testigos en entrevistas policiales podría impedir el cumplimiento con las guías de mejores prácticas para conducir entrevistas si las y los entrevistadores están mal preparados para el desafío de superar la renuencia a proporcionar información por parte de testigos que inicialmente no cooperan. Recurrir a prácticas deficientes para conducir entrevistas investigativas podría ser un intento de restablecer el control sobre la o el entrevistado (Griffiths et al., 2011; Oxburgh y Dando, 2011), las cuales pueden reducir tanto la cantidad como la precisión de la información obtenida.

Por último, a través de otro experimento de laboratorio $(N=136)$, demostré que la falta de cooperación reduce tanto la divulgación de información como, en menor medida, la precisión, incluso al conducir la entrevista en condiciones óptimas (Capítulo 5). Además, el uso de estrategias de comunicación para reducir deliberadamente la cantidad de información correcta, y para reportar una combinación de información precisa e inexacta, de acuerdo a auto-reportes, es consistente con la reducción en la cantidad de información divulgada. El uso de tales estrategias de comunicación también corresponde con la pequeña pero significativa disminución en la precisión de la información.

En conjunto, los resultados de esta disertación demuestran que la cooperación de los testigos es, en cierta medida, un determinante del comportamiento de la persona 
entrevistada y del entrevistador o entrevistadora y, en consecuencia, de los resultados de la entrevista. En particular, la falta de cooperación de testigos tiene efectos perjudiciales en la divulgación de información y desafía el uso de técnicas para entrevistar efectivas, cuestionando la calidad de los reportes de testigos obtenidos (Capítulo 6). Para la práctica policial de entrevistas investigativas, se recomienda un enfoque que promueva la cooperación de testigos para evitar generar o exacerbar la falta de voluntad para proveer información relevante de parte de testigos durante investigaciones penales y procedimientos judiciales posteriores. Se necesita más investigación científica para validar técnicas de entrevista especializadas en superar la falta de cooperación de testigos, que faciliten de manera ética y efectiva la elicitación de información. Dichas técnicas deberían apuntar a aumentar los beneficios percibidos por la o el testigo acerca de su cooperación con la policía, y reducir los riesgos asociados con la decisión del individuo de proporcionar información en una entrevista investigativa. A la luz de estas conclusiones, la toma de decisiones legales basadas en el testimonio de testigos debe incluir la evaluación de cómo se obtuvo dicha evidencia para considerar los efectos de la cooperación de testigos en la divulgación de información y en el enfoque utilizado al conducir la entrevista. Dicha evaluación se podría facilitar haciendo que la obligatoriedad de grabar toda entrevista a testigos sea un requerimiento legal, lo que también podría promover la aplicación de técnicas efectivas basadas en la evidencia al conducir entrevistas investigativas. 


\section{Acknowledgements}

"Las palabras nunca alcanzan cuando lo que hay que decir desborda el alma". [Words never reach when what has to be said overflows the soul]. - Julio Cortázar

Robert \& Peter, I am indebted to you for trusting me and guiding me to become an independent researcher. My most heartfelt thank you for your support and confidence in me during these last few years, and especially for your reassurance when I needed it the most. I want to thank you as well for enriching this journey with joyful moments outside the office. My appreciation also goes to you, and your collaborators, for envisioning the House of Legal Psychology and allowing a new generation of diverse academics to join the field.

Leif \& Sara, thank you for supporting my work and for lending me your expertise to improve it. I look back fondly on the times shared in Gothenburg, tack så mycket!

Lorraine, thank you for welcoming me to the HAC lab and for your guidance during my Portsmouth semester. I am very grateful for your mentorship and our continued collaboration.

My PhD research would not have been completed without the contribution of many research participants, police officers, assistants and professionals - thank you for supporting my research. Thanks to my research assistants for all your effort and time, in particular to Joan-Sophie, Koen and Asia. Marko Jelicic, thank you for always lending me a hand with my Ethics applications. Thank you Danique for your help with the translation to Dutch of this thesis' summary. Thanks to Ann, Linda, Liz and Stephen for your help during my mobility periods. Dear Chantal, thanks for your amazing assistance and ongoing support. The academic staff from the UM Forensic Psychology Section hold a special place in my heart for inspiring me to continue my academic pursues. Special thanks to Henry, for your enthusiastic support over the years. Thanks for the financial support to the Erasmus Mundus - House of Legal Psychology programme.

Having done this PhD as part of the 'House' has been such a privilege (most of the time). Thank you to the fellow PhD candidates for contributing to the village in which we all blossomed. Special thanks to Nikky, Enide and Nkansah for helping me survive the Law 
experience. I appreciate our supportive (and ranting) sessions as well as the fun memories during conference-trips. Sergii, thank you for your always-uplifting support and kindness.

Kathy and Bri, I am beyond thankful for having experienced our PhD journeys together. I loved all the bubbles and tears shared knowing we would always push forward together. Bri, I am still in awe of how things have whirled since we met in Canada - I am so proud of you and so appreciative of your unconditional friendship. Kathy querida, la mejor conexión Latina estos años, gracias por tu amistad incondicional, y por tu sencillez característica que no le hace justicia a tu brillantez.

The rainy days in Portsmouth and Gothenburg were lightened up by terrific colleagues. Feni, Gary, Renan, Eva, and Pam, thank you for making me feel at home in Portsmouth, and for the boundless support from you and all members of the HAC lab. A massive thank you as well to the members of the inspirational CLIP group, especially to Timothy and Erik. Meghana and David, thank you both for your unconditional support and for sharing the Swedish ride with me - I am so appreciative of our little community in the office and at home.

Without the unwavering support from my friends and family, I would not have been able to finish this project in one piece. To my wonderful friends - you know who you are, thanks for your patience during these workaholic years. Most importantly thank you for the much needed fun breaks and memorable trips. Mi Lila querida y Kus de mi corazón - desde nuestra adolescencia vamos acompañándonos en nuestros devenires adultos. Gracias por su apoyo fiel y constante desde siempre, son les mejores amigues que podría pedir en la vida. Sobre todo, les agradezco la barra constante a la distancia, y su aceptación ante todo el espectro de emociones desatadas durante el doctorado.

A mi papá, mamá y a mi hermana, mi infinita gratitud por su amor puro e infinito apoyo. Gracias mil por impulsarme siempre y sin reparo - les amo y agradezco con el alma. Ustedes junto al resto de la familia me recuerdan lo que es realmente importante en la vida. Sin su ejemplo de perseverancia y esfuerzo, no hubiera llegado aquí. Salud por la Emilita, Chelita, José Hugo, Jimmy, Martha y Toto, con quienes también quisiera compartir este logro. Esta tesis está dedicada a Ana y Manuel, quienes me influenciaron para que crezca con la seguridad de que la educación es lo más valioso por lo cual luchar. 


\section{Curriculum Vitae}

Alejandra De La Fuente Vilar was born on May 20, 1988 in Santa Cruz de la Sierra, Bolivia. In 2005, she finished secondary school in her hometown, followed by a cultural exchange year in Harrogate, England, where she earned her Advanced Level certificates. Alejandra completed a first degree in Performing Arts in 2011. In 2012, she earned a licenseaccrediting Bachelor of Arts in Psychology from the University of Buenos Aires, Argentina. Prior to her postgraduate education, Alejandra gained professional work experience assisting psychologists court-appointed as expert witnesses in civil and criminal cases, and completed a clinical placement at a drug-rehabilitation centre with forensic outpatients. In 2013, she moved to the Netherlands to pursue a master's degree, upon receiving the Maastricht University High-Potential Scholarship. Alejandra completed a clinical forensic placement working with offenders with a mental illness in the United Kingdom and was a visiting international research student at the University of British Columbia in Canada. In 2015, she graduated with a Master of Science in Forensic Psychology from Maastricht University, the Netherlands. After a year of academic and clinical research experience, Alejandra started the Erasmus Mundus joint doctoral degree at the House of Legal Psychology funded by the European Commission. In 2016, she was appointed as a PhD candidate in Legal Psychology at Maastricht University and the University of Gothenburg, Sweden. Whilst completing her PhD research, she was a visiting researcher at the University of Portsmouth in England. For research included in this dissertation, Alejandra won presentation student awards at the 2018 conference of the European Association of Psychology and Law (EAPL) and at the 2019 conference of the international Investigative Interviewing Research Group. She has also secured funding for her independent research on the investigative interviewing of uncooperative witnesses from the EAPL and the American Psychology and Law Society. 


\section{PhD Research Dissemination}

\section{Publications}

\section{Book chapter}

De La Fuente Vilar, A. (in press). Navigating New Waters: Lack of Cooperation in Witness Interviews. In R. Horselenberg, V. van Koppen, \& J. de Keijser (Eds.), Bakens in de Rechtspsychologie [Beacons in Legal Psychology]: Liber Amicorum Peter van Koppen (pp. 1-19). Boomuitgevers.

\section{Peer-reviewed journal articles}

De La Fuente Vilar, A., Horselenberg, R., Strömwall, L. A., Landström, S., Hope, L., \& van Koppen, P. J. (2020). Effects of Cooperation on Information Disclosure in MockWitness Interviews. Legal and Criminological Psychology, 25(2), 133-149. https://doi.org/10.1111/lcrp.12167

\section{Manuscripts under peer-review}

De La Fuente Vilar, A., Horselenberg, R., Landström, S., \& van Koppen, P. J. (2020). Lack of Witness Cooperation in Investigative Interviews: An International Survey of Criminal Investigators. Manuscript submitted for publication.

De La Fuente Vilar, A., Horselenberg, R., Hope, L., Strömwall, L. A., \& van Koppen, P. J. (2020). Unfulfilled Expectations of Cooperation in Witness Interviews. Manuscript submitted for publication.

De La Fuente Vilar, A., Horselenberg, R., \& van Koppen, P. J. (2020). Quality Evidence from the Interview Room: An Archival Study of Adult Witness Interviews. Manuscript submitted for publication.

De La Fuente Vilar, A. (2020). Towards a Model of Witness Cooperation in Investigative Interviews. Manuscript submitted for publication. 


\section{Manuscript in preparation}

De La Fuente Vilar, A., Horsu, J. S., \& Horselenberg, R. (2020). The Influence of Perceptions of Law Enforcement and Interviewing Approach on Willingness to Disclose Information. Manuscript in preparation.

\section{Conference Presentations and Symposia}

De La Fuente Vilar, A., Horselenberg, R., \& van Koppen, P. J. (2020, September 23-25). Quality Evidence from the Interview Room: An Archival Study of Adult Witness Interviews [Blitz talk]. Virtual Conference of the European Association of Psychology and Law.

De La Fuente Vilar, A. (2019, July 17-20). Complex Criminal Investigations: Pitfalls and Opportunities in Police Investigative Practice [Symposium]. Conference of the European Association of Psychology and Law, Santiago de Compostela, Spain.

De La Fuente Vilar, A., Horselenberg, R., Landström, S., Strömwall, L. A., \& van Koppen, P. J. (2019, July 17-20). Gaining Witness Cooperation: An International Survey of Investigative Interviewers [Paper presentation]. Conference of the European Association of Psychology and Law, Santiago de Compostela, Spain.

De La Fuente Vilar, A., Horselenberg, R., Hope, L., Strömwall, L. A., Landström, S., \& van Koppen, P. J. (2019, June 26-28). The Burden of Unfulfilled Expectations: Challenges of Interviewing Witnesses who Fail to Cooperate [Paper presentation]. Conference of international Investigative Interviewing Research Group, Stavern, Norway.

De La Fuente Vilar, A., Horselenberg, R., \& van Koppen P. J. (2018, July 4-6). What if Witnesses are Uncooperative? - A Glimpse on Current Interviewing Practice in The Netherlands [Paper presentation]. Conference of the annual meeting of the international Investigative Interviewing Research Group, Porto, Portugal.

Hoogesteyn, K. \& De La Fuente Vilar, A. (2017, December 1). Memory Challenges in Witness Interviews. Lecture for the general public delivered at the 'Crime and Minds: Psychology and the Law' event at the University of West London, London, United Kingdom. 
De La Fuente Vilar, A., Horselenberg, R., Strömwall, L. A., Landström, S., Hope, L., \& van Koppen P. J. (2018, June 26-29). Uncooperative Witnesses and their Inclination to Disclose Information [Paper presentation]. Conference of the European Association of Psychology and Law, Turku, Finland.

De La Fuente Vilar, A., Horselenberg, R., Strömwall, L. A., Landström, S., Hope, L., \& van Koppen, P. J. (2017, May 28-31). Memory of Uncooperative Witnesses [Pitch presentation]. Conference of the European Association of Psychology and Law, Mechelen, Belgium. 

Appendices 


\title{
Appendix 1
}

Chapter 3

\section{Survey for Criminal Investigators - Original version in English}

\section{Research Project: Investigative Interviews with Uncooperative Witnesses}

We appreciate your interest in our research and ask you to consider the following information before you take part in this survey:

\begin{abstract}
Aim of the study
We aim to learn about interviewing strategies to elicit information from uncooperative witnesses. Uncooperative witnesses are unwilling to be involved in criminal investigations and refuse to provide valid information to aid with cases. For example, witnesses who are reluctant to talk, resistant to disclose information, as well as witnesses who have been intimidated or are hostile towards the police.

In addition, we want to learn about interviewers' perceptions of uncooperative witnesses and their beliefs about witnesses' motives for a lack of cooperation.
\end{abstract}

\section{What do you have to do?}

Answer questions regarding interviewing witnesses who do not want to cooperate with criminal investigations. There are no right or wrong answers.

\section{Who can take part?}

Any police officer who conducts witness interviews can take part in this short survey.

\section{Consent to participate}

Your participation is entirely voluntary and you have the right to withdraw your participation at any point for any reason without any consequences.

\section{Duration and compensation}

The study is self-paced and takes approximately 20 minutes to complete. Your participation is entirely voluntary and ad honorem.

\section{Confidentiality}

Your responses will not be shared with your workplace, and will remain anonymous and confidential. This survey does not ask for any identifying personal information. However, full anonymity cannot be guaranteed as geographical location will be requested. Findings from this research will be reported on a group basis. Your privacy will be protected at all times. 


\section{Who is conducting and financing this research?}

This research is being conducted by researchers from Maastricht University, the University of Portsmouth and University of Gothenburg, and it is financed by a fellowship from The House of Legal Psychology.

\section{Ethical approval}

This research has received ethical approval by the board of the Ethical Review Committee Inner City from Maastricht University (reference number: ERCIC_031_20_03_2017). If you have any questions and would like to discuss the research, please contact: Alejandra De La Fuente Vilar by email, to: a.delafuentevilar@maastrichtuniversity.nl

Thank you very much in advance for your time and contribution! 


\section{Declaration of Consent}

For participation in the research study:

\section{"Investigative Interviews with Uncooperative Witnesses"}

I have been informed of the purpose of this study. I have read the written information and have had the opportunity to ask questions about the study. I have been able to think about my participation in the study, and understand that it is completely voluntary. I know that I have the right to withdraw my consent and leave the study at any time without having to give a reason and without any penalty or consequences. I am aware and agree that results of this study may be published and / or presented at meetings or academic conferences. I give my permission for my anonymous data, which does not identify me, to be disseminated and used for further scientific research.

$\square$ I agree to participate in the study: "Investigative Interviews with Uncooperative Witnesses". 


\section{Research project: Investigative Interviews with Uncooperative Witnesses}

1. What is your age?

2. What is your gender?

3. What is the highest level of education you achieved?

4. In which country do you work as a police officer?

5. In which police unit do you work?

6. Please indicate your job position/function

7. For how long have you been a police officer?

8. Do you conduct interviews?: (please check all that apply)

$\square$ No, I don't conduct interviews

$\square$ Yes, with suspects

$\square$ Yes, with victims

$\square$ Yes, with witnesses

$\square$ Yes, with vulnerable interviewees, please indicate

If No, skip to question 10

9. How many witness interviews, on average, do you conduct per week?

10. At your police station, how often are the witness interviews recorded?

$\square$ Never $\quad \square$ Sometimes $\quad \square$ About half the time $\quad \square$ Most of the time $\quad \square$ Always

If 'Never', skip to question 13.

11. Please indicate when the interviews with witnesses are audio recorded:

12. Please indicate when the interviews with witnesses are audio and video recorded:

13. Have you received training in how to conduct investigative interviews?

$\square$ Yes

$\square$ No

If yes, please indicate what training you have completed in interviewing witnesses:

14. Have you received special training in interviewing uncooperative witnesses?

$\square$ Yes

$\square$ No

If yes, please indicate what training you have completed in interviewing uncooperative witnesses: 
15. At your police station, uncooperative witnesses are interviewed by interviewers with special training

$\square$ Never $\quad \square$ Sometimes $\quad \square$ About half the time $\quad \square$ Most of the time $\quad \square$ Always

16. How often do you encounter uncooperative witnesses in your practice?

$\square$ Never $\square$ Sometimes $\square$ About half the time $\quad \square$ Most of the time $\square$ Always

17. What do you believe are the reasons for witnesses to be uncooperative?

(Multiple answers possible)

\begin{tabular}{|l|l|l|l|l|l|}
\hline & Never & Sometimes & $\begin{array}{c}\text { About half } \\
\text { the time }\end{array}$ & $\begin{array}{l}\text { Most of } \\
\text { the time }\end{array}$ & Always \\
\hline They are relatives of the suspect & & & & \\
\hline They know the suspect & & & & \\
\hline $\begin{array}{l}\text { They are avoiding self- } \\
\text { incrimination }\end{array}$ & & & & \\
\hline They have a criminal history & & & & \\
\hline $\begin{array}{l}\text { They are afraid of retaliation from } \\
\text { the suspect/perpetrator }\end{array}$ & & & & \\
\hline $\begin{array}{l}\text { They distrust the police } \\
\text { They have been a victim in the past }\end{array}$ & & & & \\
\hline $\begin{array}{l}\text { They do not want to be } \\
\text { inconvenienced and spend their } \\
\text { time in legal procedures }\end{array}$ & & & & \\
\hline They are from a different culture & & & & \\
\hline $\begin{array}{l}\text { They have a history of mental } \\
\text { illness or a disability }\end{array}$ & & & & \\
\hline $\begin{array}{l}\text { They have to keep a professional } \\
\text { secrecy (e.g., GPs, social workers) }\end{array}$ & & & & \\
\hline
\end{tabular}


18. How often do you encounter uncooperative witnesses doing the following during an investigative interview?:

\begin{tabular}{|l|l|l|l|l|l|}
\hline Refusing to talk & Never & Sometimes & $\begin{array}{c}\text { About half } \\
\text { the time }\end{array}$ & $\begin{array}{l}\text { Most of } \\
\text { the time }\end{array}$ & Always \\
\hline Saying as little as possible & & & & \\
\hline $\begin{array}{l}\text { Providing a bare minimum of } \\
\text { information (not too much nor too } \\
\text { little) }\end{array}$ & & & & \\
\hline $\begin{array}{l}\text { Providing irrelevant information } \\
\text { Providing inaccurate information } \\
\text { (e.g., fabrication, lies) }\end{array}$ & & & & \\
\hline Providing incomplete information & & & & \\
\hline Providing inconsistent information & & & & & \\
\hline
\end{tabular}

19. Please indicate the extent to which you agree with the following statements:

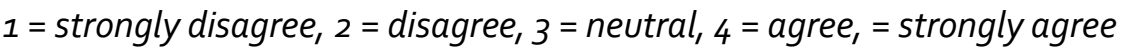

\begin{tabular}{|c|c|c|c|c|c|}
\hline & 1 & 2 & 3 & 4 & 5 \\
\hline & SD & $\mathrm{D}$ & $\mathrm{N}$ & A & SA \\
\hline Civilians cannot refuse to talk to the police if they witness a crime & & & & & \\
\hline $\begin{array}{l}\text { Lack of cooperation prevents the police from eliciting information } \\
\text { that helps the investigation }\end{array}$ & & & & & \\
\hline $\begin{array}{l}\text { If a witness continuously refuses to cooperate, it feels like talking } \\
\text { to a suspect }\end{array}$ & & & & & \\
\hline An uncooperative witness is hiding something & & & & & \\
\hline It is my job to convince the witness to provide a statement & & & & & \\
\hline $\begin{array}{l}\text { It is my role as an interviewer to make sure that witnesses are } \\
\text { stress-free before starting the interview }\end{array}$ & & & & & \\
\hline $\begin{array}{l}\text { You need to invest time in establishing a relationship with } \\
\text { uncooperative witnesses to gain their trust and cooperation }\end{array}$ & & & & & \\
\hline $\begin{array}{l}\text { To overcome witness resistance, it is best to ask the witness for } \\
\text { the reasons for his/her unwillingness to cooperate }\end{array}$ & & & & & \\
\hline $\begin{array}{l}\text { Providing information about the procedure at the start of the } \\
\text { interview increases witness cooperation }\end{array}$ & & & & & \\
\hline $\begin{array}{l}\text { Open questions are not effective when someone does not want to } \\
\text { voluntarily disclose information in the interview }\end{array}$ & & & & & \\
\hline $\begin{array}{l}\text { It is a good tactic to confront uncooperative witnesses with what } \\
\text { you already know about the crime and only seek confirmation }\end{array}$ & & & & & \\
\hline $\begin{array}{l}\text { Witnesses should not avoid your question. You have to push and } \\
\text { ask it again to get an answer }\end{array}$ & & & & & \\
\hline
\end{tabular}




\begin{tabular}{|l|l|l|l|}
\hline $\begin{array}{l}\text { It is smart to use a leading question as bait to get an } \\
\text { uncooperative witness to start talking }\end{array}$ & & & \\
\hline $\begin{array}{l}\text { Making a moral appeal about the victim persuades witnesses to } \\
\text { cooperate }\end{array}$ & & \\
\hline $\begin{array}{l}\text { You can convince witnesses to talk, by appealing to their sense of } \\
\text { responsibility when their statement is the only evidence in the } \\
\text { case. }\end{array}$ & & & \\
\hline $\begin{array}{l}\text { To get uncooperative witnesses to give a statement, you can offer } \\
\text { some anonymity (e.g., not writing their real address) }\end{array}$ & & \\
\hline $\begin{array}{l}\text { With uncooperative witnesses it works better to do the interview } \\
\text { outside the police station }\end{array}$ & & \\
\hline $\begin{array}{l}\text { Interviewers should remind witnesses who are related to the } \\
\text { suspect that their statement is voluntary }\end{array}$ & & \\
\hline $\begin{array}{l}\text { It is good practice to ask uncooperative witnesses not to lie, and } \\
\text { to warn them of the risk of perjury }\end{array}$ & & \\
\hline $\begin{array}{l}\text { Uncooperative witnesses need to be reminded of the legal } \\
\text { consequences of withholding information about a crime }\end{array}$ & & \\
\hline
\end{tabular}

20. Imagine you are going to interview a key witness in an ongoing investigation. You are just about to conduct the first interview. The witness is, however, not willing to share critical information and is uncooperative throughout the interview. What would you do to get the witness to talk and disclose relevant information?

$* * *$ Thank you very much for your time and contribution $* * *$ 


\section{Appendix 2}

Chapter 3

\section{Survey for Criminal Investigators - Dutch Translation}

\section{Verhoren met niet-meewerkende getuigen}

1. Wat is uw leeftijd:

2. Wat is uw geslacht?

3. Wat is het hoogste onderwijsniveau dat $u$ heeft behaald?

4. In welk land werk u bij de politie?

5. Op welke afdeling werkt $\mathrm{u}$ ?

6. Wat is uw functie?

7. Hoe lang werkt $u$ al bij de politie?

8. Neemt u verhoren af (meerdere antwoorden mogelijk):

$\square$ Nee, ik neem geen verhoren af

$\square$ Ja, met verdachten

$\square$ Ja, met slachtoffers

$\square \mathrm{Ja}$, met getuigen

$\square$ Ja, met kwetsbare verdachten:

Bij 'nee', ga verder naar vraag 10.

9. Hoeveel getuigen verhoort u gemiddeld per week?

10. Heeft $\mathrm{u}$ een opleiding gevolgd in hoe $\mathrm{v}$ een getuigenverhoor moet uitvoeren?

$\square \mathrm{Ja}$

$\square$ Nee

Bij ja, geef alstublieft aan welke opleiding(en) $\mathrm{u}$ heeft voltooid in het verhoren van getuigen:

11. Heeft $\mathrm{u}$ een speciale opleiding gevolgd voor het verhoren van niet-meewerkende getuigen?

$\square \mathrm{Ja}$

$\square$ Nee

Bij 'ja', geef alstublieft aan welke opleidingen $u$ heeft voltooid voor het verhoren van nietmeewerkende getuigen: 
12. Worden niet-meewerkende getuigen verhoord door verhoorders met speciale opleiding op uw afdeling?
$\square$ Nooit
$\square$ Zelden
$\square$ De helft van de tijd
$\square$ Vaak
$\square$ Altijd

13. Hoe vaak worden getuigenverhoren op audio of op video opgenomen op uw afdeling?
$\square$ Nooit
$\square$ Zelden
$\square$ De helft van de tijd
$\square$ Vaak
$\square$ Altijd

Bij "nooit", ga verder naar vraag 16.

14. Kunt $u$ aangeven wanneer de getuigenverhoren auditief worden opgenomen?

15. Kunt $\mathrm{u}$ aangeven wanneer de getuigenverhoren audiovisueel worden opgenomen?

16. Hoe vaak komt $u$ zelf een niet-meewerkende getuige tegen?
$\square$ Nooit
$\square$ Zelden
$\square$ De helft van de tijd
$\square$ Vaak
$\square$ Altijd

17. Wat zijn vaak de redenen waarom getuigen niet meewerken? (meerdere antwoorden mogelijk):

\begin{tabular}{|c|c|c|c|c|c|}
\hline & Nooit & Zelden & $\begin{array}{l}\text { De helft } \\
\text { van de tijd }\end{array}$ & Vaak & Altijd \\
\hline \multicolumn{6}{|l|}{ Ze zijn familie van de verdachte } \\
\hline \multicolumn{6}{|l|}{ Ze kennen de verdachte } \\
\hline \multicolumn{6}{|l|}{ Ze willen zichzelf niet belasten } \\
\hline \multicolumn{6}{|l|}{ Ze hebben een crimineel verleden } \\
\hline \multicolumn{6}{|l|}{$\begin{array}{l}\text { Ze zijn bang voor wraak door de } \\
\text { verdachte/dader }\end{array}$} \\
\hline \multicolumn{6}{|l|}{ Ze vertrouwen de politie niet } \\
\hline \multicolumn{6}{|l|}{$\begin{array}{l}\text { Ze zijn zelf slachtoffer geweest in } \\
\text { het verleden }\end{array}$} \\
\hline \multicolumn{6}{|l|}{$\begin{array}{l}\text { Ze willen niet belemmerd worden, } \\
\text { door hun tijd te besteden aan } \\
\text { juridische procedures }\end{array}$} \\
\hline \multicolumn{6}{|l|}{ Culturele verschillen } \\
\hline \multicolumn{6}{|l|}{$\begin{array}{l}\text { Ze hebben een mentale stoornis of } \\
\text { een handicap }\end{array}$} \\
\hline $\begin{array}{l}\text { Ze hebben een beroepsgeheim (bv., } \\
\text { huisarts, maatschappelijk werker) }\end{array}$ & & & & & \\
\hline
\end{tabular}


18. Hoe vaak komt u tegen dat een niet-meewerkende getuigen de volgende contrastrategieën gebruikt tijdens een verhoor:

\begin{tabular}{|l|l|l|l|l|l|}
\hline & Nooit & Zelden & $\begin{array}{c}\text { De helft } \\
\text { van de tijd }\end{array}$ & Vaak & Altijd \\
\hline Weigeren te spreken & & & & \\
\hline Zo min mogelijk zeggen & & & & \\
\hline $\begin{array}{l}\text { Het geven van niet te weinig, maar } \\
\text { ook niet te veel informatie }\end{array}$ & & & & \\
\hline $\begin{array}{l}\text { Irrelevante informatie geven } \\
\text { Onjuiste informatie geven (bv., } \\
\text { vertellen van leugens) }\end{array}$ & & & & \\
\hline Incomplete informatie geven & & & & \\
\hline Tegenstrijdige informatie geven & & & & \\
\hline
\end{tabular}

19. Geef alsjeblieft aan in hoeverre $u$ het eens bent met de volgende uitspraken:

$1=$ zeer mee oneens, $2=$ mee oneens, $3=$ neutraal, $4=$ mee eens, $5=$ zeer mee eens

\begin{tabular}{|c|c|c|c|c|c|}
\hline & 1 & 2 & 3 & 4 & 5 \\
\hline & ZMO & $\mathrm{MO}$ & $\mathrm{N}$ & ME & ZME \\
\hline \multicolumn{6}{|l|}{$\begin{array}{l}\text { Burgers kunnen niet weigeren om met de politie te praten als } \\
\text { ze getuige zijn van een misdrijf }\end{array}$} \\
\hline \multicolumn{6}{|l|}{$\begin{array}{l}\text { Een gebrek aan meewerken door een getuige voorkomt dat de } \\
\text { politie informatie krijgt dat zou helpen met het onderzoek }\end{array}$} \\
\hline \multicolumn{6}{|l|}{$\begin{array}{l}\text { Als een getuige continu weigert om mee te werken, voelt het } \\
\text { alsof je met een verdachte praat }\end{array}$} \\
\hline \multicolumn{6}{|l|}{ Een niet-meewerkende getuige verbergt iets } \\
\hline \multicolumn{6}{|l|}{$\begin{array}{l}\text { Het is mijn taak als een verhoorder om de getuige te overtuigen } \\
\text { hun verklaring te geven }\end{array}$} \\
\hline \multicolumn{6}{|l|}{$\begin{array}{l}\text { Het is mijn taak als een verhoorder om te zorgen dat een } \\
\text { getuige stress-vrij is voor het begin van een verhoor }\end{array}$} \\
\hline \multicolumn{6}{|l|}{$\begin{array}{l}\text { Je moet tijd besteden aan het opbouwen van een band met de } \\
\text { niet-meewerkende getuige om vertrouwen te krijgen en hen } \\
\text { mee te laten werken }\end{array}$} \\
\hline \multicolumn{6}{|l|}{$\begin{array}{l}\text { Om weerstand te voorkomen, vraag je eerst aan de getuige de } \\
\text { reden waarom hij niet meewerkt }\end{array}$} \\
\hline \multicolumn{6}{|l|}{$\begin{array}{l}\text { Het geven van informatie over de procedure aan het begin van } \\
\text { het verhoor verhoogt de kans dat getuigen meewerken }\end{array}$} \\
\hline $\begin{array}{l}\text { Open-vragen stellen is niet effectief als iemand niet vrijwillig } \\
\text { informatie wil geven in het verhoor }\end{array}$ & & & & & \\
\hline
\end{tabular}




\begin{tabular}{l}
$\begin{array}{l}\text { Het is een goede tactiek om niet-meewerkende getuigen te } \\
\text { confronteren met wat je al weet over het misdrijf en enkel } \\
\text { bevestiging te zoeken }\end{array}$ \\
$\begin{array}{l}\text { Getuigen zouden je vragen niet moeten mijden. Je moet } \\
\text { pushen en de vraag opnieuw stellen om het antwoord te krijgen }\end{array}$ \\
$\begin{array}{l}\text { Het is slim om een suggestieve vraag te gebruiken als lokaas } \\
\text { om een niet-meewerkende getuige te laten praten }\end{array}$ \\
$\begin{array}{l}\text { Een moreel beroep doen op het slachtoffer overtuigt getuigen } \\
\text { om mee te werken }\end{array}$ \\
$\begin{array}{l}\text { Je kunt een getuige overtuigen te praten, door de getuige te } \\
\text { wijzen op het belang van zijn verklaring als zijnde het enige } \\
\text { bewijs }\end{array}$ \\
$\begin{array}{l}\text { Om niet-meewerkende getuigen een verklaring te laten geven } \\
\text { kun je hun anonimiteit aanbieden (bv., niet hun werkelijke } \\
\text { adres noteren) }\end{array}$ \\
$\begin{array}{l}\text { Met niet-meewerkende getuigen werkt het beter om het } \\
\text { verhoor buiten het politiebureau te houden }\end{array}$ \\
\hline $\begin{array}{l}\text { Verhoorders zouden getuigen die een familielid zijn van de } \\
\text { verdachte eraan moeten herinneren dat hun verklaring } \\
\text { vrijwillig is }\end{array}$
\end{tabular}

20. Stel je voor dat je een belangrijke getuige verhoort in een lopend onderzoek. Jij moet het eerste verhoor met hem/haar doen. De getuige wil kritische informatie niet delen en is nietmeewerkend gedurende het hele verhoor. Wat zou je doen om de getuige te laten praten en hem relevante informatie te laten delen?

*** Hartelijke dank voor uw tijd en bijdrage *** 


\section{Appendix 3}

Chapter 3

\section{Survey for Criminal Investigators - Swedish Translation}

\section{Förhör med samarbetsovilliga vittnen}

Tack för att du visar intresse för vår forskning. Innan du delar i studien vill vi be dig att läsa igenom följande information:

\section{Syftet med studien}

Vår målsättning är att få ökad kunskap om förhör med samarbetsovilliga vittnen samt en ökad förståelse för enskilda utredares uppfattningar om samarbetsovilliga vittnen och olika motiv till samarbete. Med samarbetsovilliga vittnen menas vittnen som av olika skäl (t.ex. att de blivit hotade eller att de har en fientlig inställning mot polisen) är ovilliga att bidra med information som kan vara av värde för utredningen (t.ex. att de inte ger någon information eller att de undanhåller viss information).

\section{Vad ska du göra?}

Om du väljer att delta i studien kommer du att bli ombedd att svara på ett antal frågor om förhör med samarbetsovilliga vittnen. $\mathrm{Vi}$ är intresserade av din uppfattning och erfarenhet och det finns därför inga svar som är rätt eller fel.

\section{Vem kan delta?}

För att delta i studien krävs att du i egenskap av anställd av polismyndigheten genomfört ett eller flera förhör med vittnen.

\section{Samtycke}

Ditt deltagande är helt frivilligt och det tar ungefär 20 minuter att genomföra studien. Du har rätt att när som helst avbryta ditt deltagande. Skulle du välja att avbryta ditt deltagande behöver du inte ange någon förklaring till detta.

\section{Sekretess}

Dina svar kommer att behandlas anonymt och konfidentiellt. Vi är mycket måna om att skydda din integritet och kommer därför inte be dig lämna några personuppgifter. Den enda information som samlas in om dig är den geografiska plats där du befinner dig. Resultaten från denna studie kommer att rapporteras på gruppnivå vilket gör att de svar du lämnar inte kommer att kunna kopplas till dig som person.

\section{Vem driver och finansierar denna forskning?}

Forskningen utförs av forskare från Maastricht University (Nederländerna), University of Portsmouth (Storbritannien) och Göteborgs universitet (Sverige), och det finansieras av Erasmus Mundus Joint Doctorate Program: The House of Legal Psychology. 


\section{Etiskt godkännande}

Studien följer vetenskapsrådets forskningsetiska principer inom humanistisk-samhällsvetenskaplig forskning och har fått ett etiskt godkännande av den etiska granskningskommittén vid Maastricht University (ERCIC_031_20_03_2017).

Om du har några frågor eller vill diskutera forskningen är du varmt välkommen att kontakta mig, Alejandra De La Fuente Vilar via e-post: a.delafuentevilar@maastrichtuniversity.nl

Klicka nedan för att fortsätta

$\square$ Jag har tagit del av information om studien "Förhör med samarbetsovilliga vittnen" 


\section{Samtycke}

Jag har fått information om syftet med studien "Förhör med samarbetsovilliga vittnen". Jag har läst den skriftliga informationen och har haft möjlighet att ställa frågor om studien. Jag har kunnat fundera över mitt deltagande i studien, och vet att det är helt frivilligt. Jag vet också att jag när som helst har rätt att avbryta mitt deltagande i studien utan att behöva ge någon anledning till detta. Jag är medveten om att resultaten av denna studie kan komma att publiceras i en vetenskaplig rapport och/eller presenteras vid akademiska konferenser. Jag ger mitt samtycke till att mina anonyma svar, som inte kan kopplas till mig som person, får användas för vidare vetenskaplig forskning.

Klicka nedan för att fortsätta till studien

$\square$ Jag har tagit del av informationen ovan och samtycker till att mina svar får användas $i$ forskningsstudien "Förhör med samarbetsovilliga vittnen" 


\section{Förhör med samarbetsovilliga vittnen}

1. Hur gammal är du?

2. Vilket kön har du?

3. Ange din högsta utbildningsnivå:

4. I vilket land arbetar du som anställd inom polismyndighten?

5. Vid vilken polisenhet/avdelning jobbar du?

6. Ange din roll (t.ex yttre tjänst, utredare):

7. Hur länge har du varit anställd av polismyndigheten?

8. Håller du förhör? (du kan markera ett eller flera svar)

$\square$ Nej, jag håller inte förhör

$\square \mathrm{Ja}$, med misstänkta $\square \mathrm{Ja}$, med målsägande

$\square$ Ja, med vittnen

$\square$ Ja, med sårbara individer, nämligen

Om Nej, hoppa över till fråga 10.

9. Hur många förhör med vittnen håller du i genomsnitt per vecka?

10. Enligt din uppfattning, hur ofta spelas förhör med vittnen in (ljud och/eller bild) på din polisstation?

$\square$ Aldrig $\quad \square$ lbland $\quad \square$ Cirka hälften $\quad \square$ För det mesta $\quad \square$ Alltid Om "Aldrig", hoppa över till frågan 13.

11. I vilka fall spelas av förhör med vittnen in på ljudfil:

12. I vilka fall spelas förhör med vittnen in på ljud och bildfil:

13. Har du gått någon utbildning/träning kring förhör med vittnen?
$\square \mathrm{Ja}$
$\square \mathrm{Nej}$

Om ja, vänligen ange vad denna utbildning/träning bestod av:

14. Har du fått någon särskild utbildning/träning kring förhör med samarbetsovilliga vittnen?

$\square \mathrm{Ja}$

$\square \mathrm{Nej}$

Om ja, vänligen ange vad denna utbildning/träning bestod av: 
15. Hur ofta förhörs samarbetsovilliga vittnen av utredare med särskild träning på din polisstation?
$\square$ Aldrig
$\square$ Ibland
$\square$ Cirka hälften
$\square$ För det mesta
$\square$ Alltid

16. Hur ofta upplever du att vittnen är samarbetsovilliga?

$\square$ Aldrig $\quad \square$ lbland $\quad \square$ Cirka hälften $\quad \square$ För det mesta $\quad \square$ Alltid

17. Enligt din uppfattning, varför tror du att vittnen är samarbetsovilliga? (Flera möjliga svar)

\begin{tabular}{|l|l|l|l|l|l|}
\hline & Aldrig & Ibland & $\begin{array}{c}\text { I cirka hälften } \\
\text { av alla fall }\end{array}$ & $\begin{array}{c}\text { För det } \\
\text { mesta }\end{array}$ & Alltid \\
\hline $\begin{array}{l}\text { Den misstänkte är en } \\
\text { familjemedlem }\end{array}$ & & & & \\
\hline De känner den misstänkte & & & \\
\hline $\begin{array}{l}\text { De vill undvika att ge information } \\
\text { om egen kriminalitet }\end{array}$ & & & & \\
\hline De har själva ett kriminellt förflutet & & & & \\
\hline $\begin{array}{l}\text { De är rädda för vedergällning från } \\
\text { den misstänkte }\end{array}$ & & & & \\
\hline De misstror polisen & & & & \\
\hline De har tidigare utsatts för brott & & & & \\
\hline $\begin{array}{l}\text { De vill inte spendera sin tid genom } \\
\text { att delta i rättsliga förfaranden }\end{array}$ & & & & \\
\hline De är från en annan kultur & & & & \\
\hline $\begin{array}{l}\text { De har lider/har lidit av psykisk } \\
\text { sjukdom eller funktionsnedsättning }\end{array}$ & & & & \\
\hline $\begin{array}{l}\text { De har tystnadsplikt (t.ex. läkare, } \\
\text { socialarbetare) }\end{array}$ & & & & \\
\hline
\end{tabular}

18. Hur ofta upplever du att samarbetsovilliga vittnen gör följande under ett förhör?:

\begin{tabular}{|l|l|l|l|l|l|}
\hline & Aldrig & Ibland & $\begin{array}{c}\text { I cirka hälften } \\
\text { av tiden }\end{array}$ & $\begin{array}{c}\text { För det } \\
\text { mesta }\end{array}$ & Alltid \\
\hline Vägrar att prata & & & & \\
\hline $\begin{array}{l}\text { Säger så lite som möjligt } \\
\text { Ger varken för lite eller för mycket } \\
\text { information }\end{array}$ & & & & \\
\hline $\begin{array}{l}\text { Ger irrelevant information } \\
\text { Ger felaktig information (t.ex. } \\
\text { påhitt, lögner) }\end{array}$ & & & & \\
\hline Ger ofullständig information & & & & \\
\hline Ger inkonsekvent information & & & & \\
\hline
\end{tabular}


19. Ange i vilken utsträckning du håller med om följande påståenden:

1 = håller inte alls med, 2 = håller inte med, 3 = varken eller, 4 = håller med, $5=$ håller med i mycket hög utsträckning

\begin{tabular}{|c|c|c|c|c|c|}
\hline \multirow{2}{*}{$\begin{array}{l}\text { Människor kan inte vägra att prata med polisen } \\
\text { om de bevittnat ett brott }\end{array}$} & 1 & 2 & 3 & 4 & 5 \\
\hline & & & & & \\
\hline \multicolumn{6}{|l|}{$\begin{array}{l}\text { Bristande samarbete hindrar polisen från att få } \\
\text { fram information som hjälper utredningen }\end{array}$} \\
\hline \multicolumn{6}{|l|}{$\begin{array}{l}\text { Om ett vittne vägrar att samarbeta, känns det } \\
\text { som att prata med en misstänkt }\end{array}$} \\
\hline \multicolumn{6}{|l|}{ Ett samarbetsovilligt vittne döljer något } \\
\hline \multicolumn{6}{|l|}{$\begin{array}{l}\text { Det är polisens jobb att övertyga vittnet om att } \\
\text { ge ett uttalande }\end{array}$} \\
\hline \multicolumn{6}{|l|}{$\begin{array}{l}\text { Det är polisens ansvar som utredare att se till att } \\
\text { vittnen är avslappnade när förhöret startar }\end{array}$} \\
\hline \multicolumn{6}{|l|}{$\begin{array}{l}\text { För att nå förtroende och samarbete, måste man } \\
\text { avsätta tid för att få god kontakt med } \\
\text { samarbetsovilliga vittnen }\end{array}$} \\
\hline \multicolumn{6}{|l|}{$\begin{array}{l}\text { För att övervinna vittnens motstånd är det } \\
\text { viktigt att börja med att fråga varför de inte vill } \\
\text { samarbeta }\end{array}$} \\
\hline \multicolumn{6}{|l|}{$\begin{array}{l}\text { Att inleda förhöret genom att ge information } \\
\text { om hur det kommer gå till kan öka vittnens } \\
\text { samarbetsvilja }\end{array}$} \\
\hline \multicolumn{6}{|l|}{$\begin{array}{l}\text { Öppna frågor är inte särskilt effektiva att } \\
\text { använda när någon ej samarbetar }\end{array}$} \\
\hline \multicolumn{6}{|l|}{$\begin{array}{l}\text { Det kan vara en bra idé att konfrontera } \\
\text { samarbetsovilliga vittnen med sådant polisen } \\
\text { redan vet för att få bekräftelse på detta }\end{array}$} \\
\hline \multicolumn{6}{|l|}{$\begin{array}{l}\text { Vittnen borde besvara polisens frågor. Som } \\
\text { utredare måste man ibland pressa på och fråga } \\
\text { igen för att få svar }\end{array}$} \\
\hline \multicolumn{6}{|l|}{$\begin{array}{l}\text { Det kan vara smart att använda en ledande fråga } \\
\text { som bete för att få ett samarbetsovilligt vittne } \\
\text { för att börja prata }\end{array}$} \\
\hline \multicolumn{6}{|l|}{$\begin{array}{l}\text { För att få vittnen att samarbeta kan det vara bra } \\
\text { att vädja till vittnets medkänsla om offret }\end{array}$} \\
\hline $\begin{array}{l}\text { När vittnens utsagor är det enda beviset kan } \\
\text { man övertyga vittnen om att prata genom att } \\
\text { vädja till deras ansvarskänslor }\end{array}$ & & & & & \\
\hline
\end{tabular}




\begin{tabular}{|l|l|l|l|l|}
\hline $\begin{array}{l}\text { För att få samarbetsovilliga vittnen att prata kan } \\
\text { man erbjuda anonymitet (t.ex. inte skriva deras } \\
\text { riktiga adresser) }\end{array}$ & & & & \\
\hline $\begin{array}{l}\text { Med samarbetsovilliga vittnen fungerar det } \\
\text { bättre att genomföra förhöret utanför } \\
\text { polisstationen }\end{array}$ & & & & \\
\hline $\begin{array}{l}\text { För vittnen som har en relation till den } \\
\text { misstänkte bör man påminna att deltagandet är } \\
\text { frivilligt }\end{array}$ & & & & \\
\hline $\begin{array}{l}\text { Det är bra att uppmana samarbetsovilliga } \\
\text { vittnen att inte ljuga, och upplysa dem om } \\
\text { konsekvenserna av ett sådant handlande }\end{array}$ & & & & \\
\hline $\begin{array}{l}\text { Samarbetsovilliga vittnen måste påminnas om } \\
\text { de rättsliga följderna av att hålla in information } \\
\text { om ett brott }\end{array}$ & & & & \\
\hline
\end{tabular}

20. Föreställ dig att du ska förhöra ett nyckelvittne i en pågående utredning. Du är just på väg att genomföra det första förhöret. Vittnet är dock inte villigt att dela med sig av kritisk information och är samarbetsovillig under hela intervjun. Vad skulle du göra för att få vittnet att prata och avslöja relevant information?

*** Tack så mycket för din tid och ditt bidrag *** 


\section{Appendix 4 \\ Chapter 4 \\ Mock-Investigation - Case File}

\section{CASE SUMMARY}

Last Saturday just before 6:00 am, the police received 999 calls reporting gun shots on 99 Victoria Road North. Upon arrival to the crime scene, police found a victim fatally wounded. Paramedics reported the victim dead upon arrival to the crime scene. The incident has been categorised as a suspected murder. The street and neighbouring areas were searched thoroughly, and no suspects were found.

\section{ABOUT THE VICTIM}

The victim has been identified as Alex D. The victim was affiliated to an organised criminal gang. He was a convicted felon that served time for charges of assault, conspiracy to distribute heroin and illegal possession of firearms.

\section{DISCOVERY SUMMARY}

It was revealed that the crime stemmed, in part, from a conflict between two factions of the gang who distribute cocaine and heroin. It is said that the victim Alex D. led one of the factions.

There is no CCTV coverage of the street of the incident. However, CCTV footage shows an identified man walking on Winston Churchill Avenue towards Victoria Road North at 05:53 am. Car registration plates caught from the neighbouring streets have been monitored, but there are no leads. 


\section{MAP OF THE AREA}

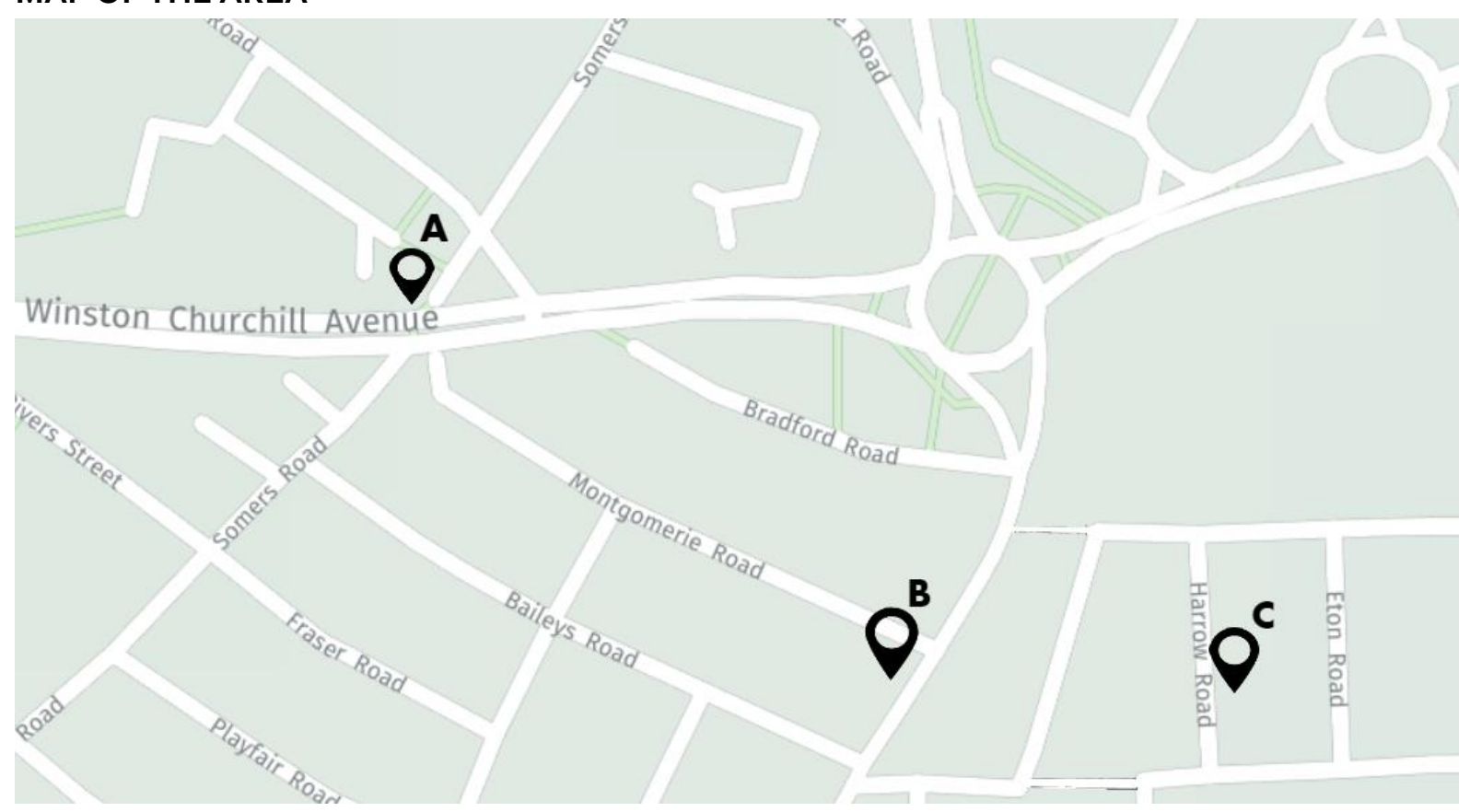

Point A - CCTV footage shows witness Jan T. walking on Winston Churchill Avenue towards Victoria Road North at 05:53 am.

Point B - 99 Victoria Road North. Crime scene.

Point C - House of the witness Jan T.

Distance between point A \& B $=275 \mathrm{~m}$ or $900 \mathrm{ft}$. (5-minute walk).

\section{CONFIDENTIAL}

For Authorized Personnel Only 


\section{Appendix 5}

Chapter 4

\section{Mock-Investigation - Witness Interview Reports}

\section{EYEWITNESS TESTIMONIES}

WITNESS Kay D. [2017PO01-M32/01], wife of the victim, reported to have been woken up by the gun shots. She remembers jumping from her bed to look at the window. She saw her husband already shot down, so she called 999. She reported that she did not see any people or vehicles when she looked outside. However, she heard a squeaky wheel's noise immediately after the last gun shot.

POLICE WITNESS [2017POo1-M32/02], first responder to the scene, who took the witness statement from Kay, reported that many people in the area did not want to talk at all to any of the authorities or local news reporters.

WITNESS Jan T. [2017PO01-M32/03] was identified from CCTV footage turning right from Winston Churchill Avenue into Victoria Road North on Saturday at 05:53. On Saturday at 14:00 pm., Jan was visited in his home by a police officer. Jan has no criminal record, he is not related to the victim and does not have known ties to the criminal gang.

\section{Control Condition}

POLICE WITNESS Officer Luke Jones [2017PO01-M32/04], recorded no comments. The witness Jan was invited to the police station for a witness interview.

\section{Cooperation Condition}

POLICE WITNESS Officer Luke Jones [2017PO01-H32/04], reported that Jan had already voluntarily reported himself to the police to provide his testimony. Jan agreed to answer questions and was happy to fulfil his civil duty to cooperate with the police investigation. Jan mentioned his willingness to share important information. Jan was invited to the police station for a witness interview.

\section{No Cooperation Condition}

POLICE WITNESS Officer Luke Jones [2017POo1-H32/04], reported that Jan seemed nervous and surprised to be identified near the crime scene at the time of the crime. Jan could not provide a different alibi. Jan refused to answer questions in his home. Jan seems to be hiding important information and not to be willing to cooperate with the police investigation. Jan was invited to the police station for a witness interview. 


\section{Appendix 6}

\section{Chapter 4}

\section{Lists of Interviewing Techniques}

Instruction: Indicate which interviewing techniques you think would be the most effective for you in this case, and choose (by highlighting them) those that you can employ when you are conducting your interview:

1. Warn the witness that it is illegal to lie to the police.

2. Make the witness feel valued for his knowledge about the event.

3. Offer support if the witness seems distressed by the situation.

4. Point out inconsistencies and contradictions.

5. Encourage the witness to tell you in their own words and in detail what they witnessed.

6. Repeat the same question until the witness gives you an answer.

7. Convince the witness that cooperating is in his best interest, else he can be summoned by the judge.

8. If the witness is unwilling to talk to you, ask why. Find out his reasons to be uncooperative.

9. Be friendly and try to establish rapport with the witness.

10. Emphasise the seriousness of the offense and the consequences for protecting those involved in the crime.

11. Appeal to the moral character of the witness and remind him that he is needed to get justice (for the victim and his family).

12. Make sure the witness understands that he is not obliged to talk to the police.

13. Get the witness talking about another topic to start the conversation.

14. Trust your instinct and keep pushing for information when the witness avoids a question or gives short answers.

15. Use closed and short questions about specific details.

16. Offer to make the statement anonymous if they are afraid of the suspect(s).

17. Confront the witness when he claims 'I don't remember' or 'I don't know'.

18. Do not interrupt the witness.

19. Before starting the interview, clearly explain the interview situation and everything that is going to happen.

20. Tell the witness you suspect he is hiding something. 


\section{Lists of Interviewing Techniques and Questions}

Instruction: Indicate which questions you think would be the most effective for you in this case, and choose (by highlighting them) those that you can employ when you are conducting your interview:

1. You must know, in which vehicle did the suspect(s) flee the crime scene?

2. You mentioned " $x$ ", what did you mean by that?

3. Are you involved in gang activities?

4. You cannot deny you saw something, what happened and why are you not telling me?

5. Just admit you accidentally saw something. Are you protecting yourself or someone involved in this crime?

6. You mentioned " $x$ ", can you tell me more about it?

7. Why were you seen on Victoria North Road at the time of the crime?

8. Please report everything even if it seems irrelevant to you, it may be important.

9. Describe everything you saw when you were walking home on Saturday early morning

10. Try hard to remember, do you remember anything else?

11. You were seen near the crime scene minutes before the shooting, what do you know about it?

12. Did you see how the shooting took place?

13. Why don't you know anything else about the shooting if you were there?

14. Where were you and what were you doing on Saturday at 6:00?

15. It's not your fault if you saw something. Just tell me what happened.

16. You were near the crime scene on Saturday. Did you see who committed this crime?

17. Could you please tell me everything that you remember from Saturday early morning?

18. Could you please report what happened in as much as detail as possible?

19. Did you see anyone in the area where the shooting took place?

20. Please tell me what happened after/before " $x$ "? 


\section{Appendix 7}

Chapter 5

\section{Supplementary Materials: Method Section}

\section{Instructions for Experimental Conditions}

Participants received the following cooperativeness instructions according to their experimental condition:

\section{Control}

"You must pretend that you are an independent eyewitness of the event. This means you do not know the suspect or the victim. You have been asked to come in to the police station for an interview".

\section{Cooperation}

"You must pretend that you are the key eyewitness of the event. You have been asked to come in to the police station for an interview. All information might be important to the police".

\section{No Cooperation and No Cooperation plus Cooperation (Interview 1)}

"You must pretend that you were present at the crime scene. You have been asked to come in to the police station for an interview. We know that you were also working in the house that was burglarized. The police believes that you planned and committed this crime together with your colleague. You are innocent; however, you cannot deny that you were there. I must warn you that your testimony may incriminate you in this crime because you cannot deny you were present in the house at the time of the burglary".

\section{No Cooperation plus Cooperation (Interview 2)}

"New evidence shows that you were not involved in the crime at all. Now, you must pretend that you are an independent eyewitness of the event. This means you do not know the suspect or the victim. You have been asked to come in to the police station for a second interview. The police know that you were not working in the house when it was burglarized. They no longer believe that you know the burglar. You are innocent".

In addition, participants in all conditions received a hand out with a written repetition of the verbal instruction for each condition, and the following warning to incentivise adherence to the experimental paradigm: "In order to win your research participation point/voucher you must [...]": a) "Cooperate with the police" - for participants in the Cooperation and No cooperation plus Cooperation - Interview 2; b) "Not cooperate with the police as you can be incriminated and arrested"- for participants in the No cooperation and No Cooperation plus Cooperation - Interview $1_{i}$ C) "Be convincing in your testimony" - for participants in all conditions; and d) "Never forget the situation you are in" - for participants in all conditions. 


\section{Appendix 8}

Chapter 5

\section{Supplementary Materials: Results Section}

\section{Hypotheses Testing}

\section{Does Cooperativeness Affect Communication Strategies to Disclose Information?}

To test hypothesis 4, ANOVAs were carried out for each communication strategy, and followed up with Bonferroni-corrected post hoc comparisons. When the assumption of homogeneity of variance was violated, corrected Welch F-ratios were computed and Games-Howell post hoc comparisons calculated. In this section, we report the non-significant results that were not included in the main section of Results (See Table 3 for complete descriptive and inferential statistics).

We found that instructed cooperativeness did not overall affect participants' willingness to provide inaccurate information, Welch $F(3,132)=2.67, p=.054, \omega^{2}=.039$. Nonetheless, post hoc comparisons revealed that participants in the Cooperation condition indicated including less inaccurate information in their statements compared to those in the No Cooperation condition, $t(132)=-2.68, p=.046, d=.65,95 \% \mathrm{Cl}[-0.04,-1.34]$. In addition, instructed cooperativeness did not affect participants' willingness to provide complete information, $F(3,132)=2.65, p=.051, \omega^{2}=.035$. Similarly, there was a non-significant effect for provision of incomplete information, $F(3,132)=1.61$, $p=.190, \omega^{2}=.013$. Lastly, instructed cooperativeness did not affect participants' willingness to provide statements refusing to engage, Welch $F(3,132)=2.00, p=.121, \omega^{2}=.037$. In general, participants reported rarely stating they did not want to engage. Those who used that communication strategy were not affected by the cooperativeness instruction. Overall, this set of analyses indicates that participants were not inclined to provide more or less inaccurate, complete, incomplete information or refuse engagement in the interviews according to the cooperativeness instructions. Nonetheless, they used some communication strategies differently to strategically control information disclosure according to cooperativeness instructions. In particular, when instructed to not cooperate, participants were more frequently inclined to disclose less accurate information and more inclined to disclose a combination of accurate and inaccurate information in their statements (see main Results section). 


\section{Exploratory Analyses}

Does Repeated Interviewing Affect Information Disclosure in Interview 2?

We conducted a post-hoc repeated measures analysis of variance (ANOVA) with cooperativeness instructions as the between subject factor and information disclosure in two interviews as the within subject factor. The interaction effect was non-significant, $F(3,132)=1.88, p$ $=.137, \omega^{2}=0.002$. There were significant independent main effects for both factors. The main effect for the repeated interviews indicated a significant difference of information disclosure across the interviews, $F(1,132)=9.88, p=.002, \omega^{2}=0.019$. The main effect for the cooperativeness instructions indicated a significant difference of information disclosure between the conditions, $F(3,132)=11.92$, $p<.001, \omega^{2}=0.194$. Overall, cooperativeness instructions affected information disclosure, which significantly increased during the second interview across all conditions.

\section{Does Increased Cooperativeness Affect Later Accuracy in Interview 2?}

An exploratory ANOVA indicated that there was a non-significant effect of cooperativeness instructions on the overall accuracy of the information disclosed in the second interview, Welch $F(3$, 132) $=1.95, p=.129, \omega^{2}=.01$. 

